\title{
Effects of insecticides on aquatic ecosystems in Bangladesh
}




\section{Thesis committee}

\section{Promotor}

Prof. Dr Paul J. van den Brink

Personal chair at the Aquatic Ecology and Water Quality Management Group

Wageningen University \& Research

\section{Co-promotors}

Dr Roel H. Bosma

Project manager, Aquaculture and Fisheries Group

Wageningen University \& Research

Dr Edwin T.H.M. Peeters

Associate professor, Aquatic Ecology and Water Quality Management Group

Wageningen University \& Research

Dr Harunur Rashid

Associate professor, Fisheries Management Department

Bangladesh Agricultural University

\section{Other members}

Prof. Dr Albertinka J. Murk, Wageningen University \& Research

Prof. Dr Karel A.C. de Schamphelaere, Ghent University, Belgium

Prof. Dr Martina G. Vijver, Leiden University, The Netherlands

Dr Udo Hommen, Fraunhofer Institute for Molecular Biology and Applied Ecology, Schmallenberg, Germany

This research was conducted under the auspices of the Graduate School for Socio-Economic and Natural Sciences of the Environment (SENSE) 


\section{Effects of insecticides on aquatic ecosystems in Bangladesh}

\section{Kizar Ahmed Sumon}

Thesis

submitted in fulfilment of the requirements for the degree of doctor at Wageningen University by the authority of the Rector Magnificus

Prof. Dr A.P.J. Mol, in the presence of the

Thesis Committee appointed by the Academic Board to be defended in public on Monday 27 August 2018 at 4 p.m. in the Aula. 


\section{Kizar Ahmed Sumon}

Effects of insecticides on aquatic ecosystems in Bangladesh, 151 Pages.

PhD thesis, Wageningen University, Wageningen, the Netherlands (2018)

With references, with summary in English

DOI: https://doi.org/10.18174/455257

ISBN: 978-94-6343-473-7 


\section{Propositions}

1. Low education level and poverty have a direct correlation with irrational use of pesticides and the associated ecological risks in (sub-) tropical Bangladesh.

(this thesis)

2. More mechanistic knowledge is needed to explain the difference in sensitivity between tropical and temperate aquatic arthropods to the insecticide imidacloprid.

(this thesis)

3. In Bangladesh, the use of chemicals in agriculture is not a cure for sustainable economic growth.

4. The (eco)toxicological knowledge used in developed countries can be helpful for environmental risk assessment in developing countries.

5. Multidisciplinary knowledge leads to stronger science, but needs more time to reach consensus.

6. With enormous practice you can reach far, but a good supervisor is indispensable to achieve perfection.

7. In order to produce a good $\mathrm{PhD}$, having some mental stress is better than no stress.

Propositions belonging to the thesis entitled:

"Effects of insecticides on aquatic ecosystems in Bangladesh"

Kizar Ahmed Sumon

Wageningen, 27 August 2018 
To my beloved wife Sharmin Akter Boby 


\section{Contents}

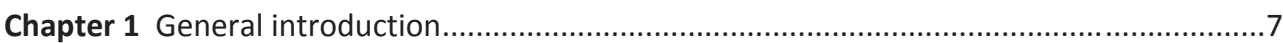

Chapter 2 Risk assessment of pesticides used in rice-prawn concurrent systems in Bangladesh....

Chapter 3 Environmental monitoring and risk assessment of organophosphate pesticides in aquatic ecosystems of north-west Bangladesh.

Chapter 4 Effects of imidacloprid on the ecology of sub-tropical freshwater microcosms.......59

Chapter 5 Acute toxicity of chlorpyrifos to embryo and larvae of Banded Gourami

Trichogaster fasciata.......

Chapter 6 Effects of long-term chlorpyrifos exposure on mortality and reproductive tissues of

Banded Gourami (Trichogaster fasciata) . .93

Chapter 7 General discussion and concluding remarks. .115

References. .126

Summary .144

Acknowledgements

About the author 150

Publications .151 
Chapter 1

General Introduction 


\section{Agro-ecosystems in Bangladesh}

Bangladesh has a merely agrarian economy. About $80 \%$ of the country's population resides in rural areas and most of the people are directly or indirectly engaged in agricultural activities (Bhattacharjee et al., 2012). Agriculture is the single largest sector contributing to the national economy (Gumma et al., 2014) and mainly consists of crop, fisheries, livestock and forestry. Bangladesh has fertile soils and a suitable climate with respect to temperature, rainfall and humidity for crop production. The total cropped area of Bangladesh is close to 15 million hectares (BBS, 2016). A considerable volume of cereal crops like rice, wheat, maize and other important crops e.g. vegetables, jute, pulses, oilseeds, fruits, sugarcane, tea, spices, cotton and tobacco are grown. The contribution of the agriculture sector to the national gross domestic product (GDP) is $15 \%$, whereas the crop sector solely contributes approximately $8 \%$ (BBS, 2016). The sector plays a crucial role in employment generation, poverty reduction, human resource development and food security needs (Alam, 2005).

Bangladesh is blessed with different wetland ecosystems: inland water bodies, brackish waters and marine environments. The inland open water systems include rivers, streams, lakes, marshes, haors and beels. A hoar is a temporary marshy wetland ecosystem which is physically a saucer or bowl shaped depression that looks like an inland sea during monsoon while a beel is a deeper depression where water remains permanent throughout the year. Together, all these inland aquatic systems comprise an area of about 3.9 million hectares. The inland closed water bodies encompass ponds, ditches and baors (oxbow lakes, formed by dead arms of rivers which are situated in the moribund delta of the Ganges in the western part of the country), and cover about 0.8 million hectares. The brackish water environment includes estuarine systems with extensive mangrove swamps, and coastal shrimp and prawn farms (FRSS, 2017). The prawns are often cultured in combination with rice, and these farming systems occupy more than 0.2 million hectare in the southwest coastal area of Bangladesh and contribute to the main livelihood for poor people in the region (FRSS, 2017). Rice-prawn farming is practiced in modified rice fields, locally known as 'gher' (Ito, 2004). The Bengali term 'gher', meaning 'perimeter', refers to an enclosure made for prawn culture by modifying rice fields through building higher dikes around the field and excavating a canal several feet deep inside the periphery to retain water during the dry season (Ahmed and Garnett, 2010). Bangladesh's marine water resources cover approximately $698 \mathrm{~km}^{2}$ in the Bay of Bengal (FRSS, 2017). 
Bangladesh has become one of the world's leading (freshwater) fish producing country with a total fish production of about 3.8 million metric tons per year (FRSS, 2017). Approximately $27 \%$ of the fish production comes from inland open water (capture fisheries), 57\% from inland closed water (culture fisheries) and 16\% from brackish water and marine fisheries. The fisheries sector contributes approximately $3.7 \%$ to the national GDP and provides $60 \%$ of the population' animal protein intake. More than $11 \%$ of the total population of the country is directly or indirectly employed in this sector for their livelihoods (FRSS, 2017). Wetlands are also utilized for cattle bathing and sometimes for grazing in winter season. When farmers cultivate rice and other crops, they use water for irrigation.

\section{Intensification of agriculture and pesticide use}

Despite of having hundreds of agro-ecosystems, the population of Bangladesh (approximately 157 million people on $147,570 \mathrm{~km}^{2}$ with a relatively high growth rate $1.05 \%$; BDP 2016) is suffering from food deficit. The food needs of this rapidly growing population and the present food production practices result in land scarcity and intensification of agriculture through the cultivation of more than one crop per year in the same location. Several agro-climatic conditions like sudden and flash flood ( $80 \%$ of the total area of the country is susceptible to flooding), drought (north and north-western region of the country), cyclones (usually south and southeastern part of the country) and salinity intrusion (coastal belt along with Bay of Bengal) are posing further difficulties in meeting the growing demands for food (Sikder and Xiaoying, 2014). However, there is no or little possibility to expand the farming area, so the challenge is to feed the growing population by improving the productivity of the currently farmed land (MurshedE-Jahan and Pemsl, 2011).

Now-a-days farmers are growing high-yielding cultivars of different crops to meet the increasing demand of food. However, one important phenomenon of these high-yielding varieties is that most of them are highly susceptible to pests and diseases (Ali et al., 2018), which may cause about $40 \%$ crop loss (Uddin et al., 2013). As a consequence, pesticides have been used extensively to protect crops from those pests, herewith improving the yield quality as well as quantity (Ansara-Ross et al., 2012; Peluso et al., 2014; Rahman, 2013). Pesticides were introduced in Bangladesh in 1951 but their use was negligible until the end of the 1960s (Ara et al. 2014). A sharp increase is their use has occured from 7,350 metric tons active ingredient of pesticides in 1992 to 45,172 metric tons in 2010 (Rahman, 2013). One of the reasons of 
increasing pesticide use is that Bangladesh government has adopted a policy initiative to stimulate the control of pests by means of chemical measures to increase the overall yield and to prevent pre- and post-harvest crop losses (Rahman, 2013).

Approximately 84 pesticide active ingredients belonging to 242 trade names of numerous chemical groups such as organochlorine compounds, organophosphates, carbamates, pyrethroids, neonicotinoids, heterocyclic pesticides, nitro compounds and amides are registered in Bangladesh and are used in agriculture and household applications (Ara et al., 2014). However, organochlorine pesticides have been banned in Bangladesh in 1993 (Matin et al., 1998) due to their high human and environmental toxicity, chronic persistence, ability to bioaccumulate and biomagnify in the food chain (Sun et al., 2006; Teklu et al., 2016). Among other groups of pesticides, the use of organophosphorus pesticides has become increasingly popular in Bangladesh. Approximately, 35\% of the crop-producing area is treated with them for a variety of crop protection purposes (Chowdhury et al., 2012a).

\section{Potential effects of pesticides on the aquatic environment}

Pesticides applied on agricultural land may reach the aquatic environment through several ways, including spray drift, surface runoff, ground water leaching, and careless disposal of empty containers and equipment washing water (Sankararamakrishnan et al., 2005 ; Hossain et al., 2015; Sumon et al., 2016). The aquatic contamination by pesticides used in agriculture may constitute potential (eco)toxicological risks to non-target aquatic organisms of different trophic levels in a food chain i.e. primary producers (Daam et al., 2008a; Malev et al., 2012; Liu et al., 2013; Kumar et al., 2014), invertebrates (Maltby et al., 2005; Palma et al., 2009; Rubach et al., 2011; Roessink et al., 2013; Van den Brink et al., 2016), and fish (Tillitt et al., 2010; Marimuthu et al., 2013; Manjunatha and Philip, 2016; Ali et al., 2018; Sumon et al., 2017), when exceeding the threshold levels.

As fish is considered an important food source for human beings in Bangladesh (about $60 \%$ of the animal protein comes from fisheries; FRSS, 2017), the prediction and quantification of the toxic effects of insecticides on fish are important for policy making. Some direct (eco)toxicological effects of pesticides on fish, like mortality, alterations of normal behavioural patterns, of physiology and of normal reproductive behaviour have been studied earlier (Dutta and Maxwell, 2003; Clotfelter et al., 2004; Scott and Sloman, 2004). Furthermore, Oruç (2010) observed the effects of the insecticide chlorpyrifos on the mortality of juvenile and adult nile 
tilapia (Oreochromis niloticus). Insecticides may cause severe histopathological alterations in various tissues (e.g. liver, kidney, gill and gonad) of fish. For example, Dutta and Maxwell (2003) have reported several histopathological alterations in bluegill sunfish ovary including cytoplasmic and karyoplasmic clumping, cytoplasmic retraction, atretic oocytes, adhesion, necrosis and thinning of follicular lining exposed to diazinon. Male bluegill sunfish, exposed to diazion, have been reported to have irregular shape and breakage of seminiferous tubules, empty and larger lumen, damaged sertoli cells and degeneration of interstitial cell of Leydig etc. (Dutta and Meijer, 2003). Some of the insecticides (e.g. monocrotophos) might be responsible for phenotypic feminization or sterility resulting in reproductive infertility in fish (e.g. zebrafish) (Zhang et al., 2013). Abnormal behavioural patterns like lethargic activities, irregular and erratic swimming, hyper excitation or restlessness of Labeo rohita occurred due to exposure to imidacloprid (Desai and Parikh, 2014). Insecticides may also cause serious malformations to the developmental stages of fish (Marimuthu et al., 2013). Furthermore, sometimes physiological alterations may be evoked through creating a hypoxic condition of the water body leading to low oxygen supply and resulting in excess mucous secretion on gills thereby reducing the respiratory activity and finally causing the death of the fish (Kind et al., 2002; Desai and Parikh, 2014). Direct toxicological effects of pesticides (i.e. insecticides (Maltby et al, 2005); herbicides (Van den Brink et al., 2006); and fungicides (Maltby et al., 2009)) on invertebrates and primary producers have also been reported in earlier studies.

Pesticides might have indirect effects on fish through decreasing fish's food sources (algae and plankton), changing food habits and deteriorating the quality of aquatic habitat (Fleeger et al., 2003; Van Wijngaarden et al., 2005; Azizullah et al., 2011; Cochard et al., 2014). Some pesticides e.g. herbicides may reduce the abundance of primary producers thus ultimately decrease the primary and secondary consumers (Brock et al., 2000; Van den Brink et al., 2006; Gregorio et al., 2012; Halstead et al., 2014). The primary consumers such as zooplankton (Daphnia magna) are severely affected by chlorpyrifos (Palma et al., 2008, 2009; Demetrio et al., 2014). In addition, insecticides like imidacloprid may adversely affect arthropods (e.g. insects like the mayfly Cloeon dipterum) (Roessink et al., 2013; Van den Brink et al., 2016).

\section{Effects of pesticides on (sub-) tropical aquatic ecosystems}

Ecotoxicological research into the fate and effects of pesticides on aquatic ecosystems has mainly focused on temperate countries (i.e., Europe, USA), while little information is available 
for tropical ecosystems (Daam and Van den Brink, 2010). A few studies, however, have been conducted to understand the fate and effects of pesticides for the (sub-) tropical freshwater environments over the last decades. These study included single species toxcitity tests (Maltby et al., 2005; Kwok et al., 2007; Freitas and Rocha, 2012; Mansano et al., 2016; Daam and Rico, 2016; Amid et al., 2017), multiple species toxicity tests (Rico et al., 2010, 2011; Echeverría-Sáenz et al., 2016; Méndez et al., 2016; Stadlinger et al., 2016; Svensson et al., 2017) and model ecosytem studies (i.e. microcosms) (Laabs et al., 2007; Daam et al., 2008a, 2008b, 2009a, 2009b, 2010; Daam and Van den Brink, 2010, 2011; Leboulanger et al., 2011).

\section{Regulatory risk assessment of pesticides}

Environmental risk assessment of chemicals like pesticides is a process entailing three different phases: exposure assessment, effect assessment, and risk characterization phase (Van Leeuwen and Vermeire, 2007). Exposure assessment frequently uses chemical application data and empirical environmental data in combination with established fate models or analytical measurements of the compounds to which environmental compartments such as water or sediments are or may be exposed. Effect assessment aims at the estimation of the relationship between the dose or concentration of exposure and the incidence of a particular ecological effect in response to this exposure (e.g. through the establishment of a dose-response relationship). Finally, risk characterization combines the output of the previously mentioned studies in order to provide an estimation of the risks, frequently expressed as risk quotients (Brock et al., 2006; Van Leeuwen and Vermeire, 2007).

Environmental risk assessment of pesticides should be performed using the best available methods. In order to achieve the goal, tiered approaches can be used in such risk assessment processes. The overall idea of tiered approach is to start with a simple and conservative approach (lower-tier). The higher-tier approach may only be performed when the lower-tier risk assessment indicates a possible risk (Van Leeuwen and Vermeire, 2007). The higher-tier risk assessment often requires more advanced studies to provide the realistic inputs, with greater complexity and a higher data requirement, while lower-tier requires less effort (Solomon et al., 2008). The use of tier-based risk assessment approaches in developing countries like Bangladesh is currently lacking, while they have been used in Europe and USA for many years. It is, therefore, important to take into account the different options available for such an risk assessment of pesticides in developing countries like Bangladesh. 


\section{Overall aims of this study}

In Bangladesh, the use of different types and amounts of pesticides are increasing at an alarming rate due to agricultural intensification. As mentioned before, there are various likely direct and indirect effects of pesticides on the aquatic environment. Pesticides may be responsible for changing community composition and ecosystem properties (Halstead et al., 2014). These cumulative effects may account for a great loss of different species in the aquatic ecosystems of a sub-tropical country like Bangladesh. During the past years, a large number of studies focusing on the toxicity of different pesticides to the aquatic environment have been conducted mostly in temperate countries. To date, information on the toxicity of pesticides on the aquatic organisms in sub-tropical Bangladesh is largely lacking. To address this knowledge gap, the present research aimed at assessing the potential environmental risks of the current wide-ranging use of insecticides on aquatic environment in Bangladesh.

The specific research objectives of this thesis are:

1. To assess the current status of pesticide use in crop production in Bangladesh and their associated potential risks to aquatic organisms.

2. To perform a chemical monitoring program to quantify the residues in the aquatic environment and to calculate the potential risks posed by insecticides to the aquatic ecosystems.

3. To derive the safe environmental concentration for a insecticide for certain structural and functional endpoints of sub-tropical freshwater ecosystems.

4. To investigate the potential toxic effects of insecticides on the developmental stages and the reproductive tissues of fish

\section{Thesis outline}

Chapter 2 provides information on the current use of pesticides in rice-prawn concurrent systems in south-west Bangladesh and human health issues posed by the application of pesticides. In this chapter, also model-based potential risks of pesticides for the aquatic ecosystems that support the culture of freshwater prawns (Macrobrachium rosenbergii) are assessed. The TOXSWA model calculates pesticide exposure (peak and time-weighted average concentrations) in surface waters of rice-prawn systems for different spray drift scenarios and a simple first-tier risk assessment based on threshold concentrations derived from single 
species toxicity tests used to assess the ecological risk in the form of risk quotients. The PERPEST model refines the ecological risks when the first-tier risk assessment indicates a potential risk.

Chapter 3 describes the outcomes of chemical monitoring in surface water and sediment samples collected from two different water bodies in north-west Bangladesh. The residues of ten most commonly used organophosphate pesticides are quantified in surface water and sediment samples in that region. The risk assessment of the pesticide concentrations in surface water and sediment based on risk quotient approach (RQ) for three different trophic levels is also presented and discussed. Like the modelling study, the higher-tier PERPEST model is used to confirm the risk of pesticides when the first-tier risk assessment indicates a possible risk.

Chapter 4 aims at assessing the fate and effects of the insecticide imidacloprid on structural (phytoplankton, zooplankton, macroinvertebrates and periphyton) and functional (organic matter decomposition) endpoints of freshwater, sub-tropical ecosystems in Bangladesh. The no observed effect concentrations (NOECs) values of imidacloprid for all individual taxa and a few communities are assessed. The sensitivity of different species of micro- and macroinvertebrates to imidacloprid in sub-tropics is compared with those from the temperate counterparts. Furthermore, single species toxicity test using two most responding species from the microcosm study (i.e. Cloeon sp. and Diaptomus sp.) are conducted to confirm their sensitivity observed in the microcosm study.

Chapters 5 and 6 describe laboratory experiments focussing on toxicity effects of chlorpyrifos on the development and reproduction of Banded Gourami (Trichogaster fasciata). Chapter 5 pays attention to the effects of chlorpyrifos on the incubation period of embryo, hatching success, mortality of embryos and two-day old larvae of Banded Gourami. Malformations of embryos and larvae for different time interval when exposed to different chlorpyrifos concentrations are also studied. Chapter 6 investigates the long-term toxicity of chlorpyrifos on the mortality and reproductive tissues of both male and female Banded Gourami (Trichogaster fasciata). The NOEC values of chlorpyrifos for all endpoints including the male and female mortality, GSI, histopathologcal alterations of ovary and testis are presented for different time intervals.

In chapter 2, the lower-tier TOXSWA model was used to calculate the exposure concentrations of pesticides in surface water in rice-prawn systems. In chapters 2 and 3, the higher-tier 
PERPEST model was used to refine the risks of pesticides which were previously derived from the RQ-based risk assessment approach.

Chapter 7 presents a general discussion on the core findings and tries to asnwer the research questions. An overall picture of risks posed by pesticides in sub-tropical Bangladesh is presented and disscussed as well as which tools can be used in future risk assessment practices in Bangladesh. 
16 


\section{Chapter 2}

\section{Risk assessment of pesticides used in rice-prawn concurrent systems in Bangladesh}

Kizar Ahmed Sumon, Andreu Rico, Mechteld M.S. Ter Horst, Paul J. Van den Brink, Mohammad Mahfujul Haque, Harunur Rashid

This chapter has been published in Science of the Total Environment (2016), 568: 498-506. 


\begin{abstract}
The objectives of the current study were to determine the occupational health hazards posed by the application of pesticides in rice-prawn concurrent systems of south-west Bangladesh and to assess their potential risks for the aquatic ecosystems that support the culture of freshwater prawns (Macrobrachium rosenbergii). Information on pesticide use in rice-prawn farming was collected through structured interviews with 38 farm owners held between January and May of 2012. The risks of the pesticide use to human health were assessed through structured interviews. The TOXSWA model was used to calculate pesticide exposure (peak and timeweighted average concentrations) in surface waters of rice-prawn systems for different spray drift scenarios and a simple first tier risk assessment based on threshold concentrations derived from single species toxicity tests were used to assess the ecological risk in the form of risk quotients. The PERPEST model was used to refine the ecological risks when the first tier assessment indicated a possible risk. Eleven synthetic insecticides and one fungicide (sulphur) were recorded as part of this investigation. The most commonly reported pesticide was sulphur (used by $29 \%$ of the interviewed farmers), followed by thiamethoxam, chlorantraniliprole, and phenthoate (21\%). A large portion of the interviewed farmers described negative health symptoms after pesticide applications, including vomiting (51\%), headache (18\%) and eye irritation (12\%). The results of the first tier risk assessment indicated that chlorpyrifos, cypermethrin, alpha-cypermethrin, and malathion may pose a high to moderate acute and chronic risks for invertebrates and fish in all evaluated spray drift scenarios. The higher-tier assessment using the PERPEST model confirmed the high risk of cypermethrin, alphacypermethrin, and chlorpyrifos for insects and macro- and micro-crustaceans thus indicating that these pesticides may have severe adverse consequences for the prawn production yields.
\end{abstract}




\section{Introduction}

The cultivation of the freshwater prawn or giant river prawn (Macrobrachium rosenbergii), in combination with rice (Oryza sativa) occupies more than 0.2 million hectare in the southwest coastal area of Bangladesh (DoF, 2013) and constitutes the main livelihood for poor people in the region (Ahmed et al., 2013). Rice-prawn farming is practiced in modified rice fields locally known as 'gher' (Chapman and Abedin, 2002 ; Ito, 2004 ). The Bengali term 'gher', meaning 'perimeter', is an enclosure made for fish and prawn cultivation by modifying rice fields through building higher dikes around the field and excavating a canal several feet deep inside the periphery to retain water during the dry season (Ahmed and Garnett, 2010; Figure 1). Riceprawn farming is considered as an effective method of integrated agriculture-aquaculture (Ahmed et al., 2008) which maximizes land and water utilization, while providing excellent opportunities for nutrient re-utilization within the system (Kunda et al., 2008). In rice-prawn concurrent systems, the rice crop attracts a series of insect species that constitute the natural food source for the cultured fish and prawns, while the nutrient-rich waste released from the cultivated aquatic animals can be effectively used as fertilizer for rice farming (Huy Giap et al., 2005).

Rice-prawn farming offers a source of staple food (rice) and animal protein (fish) for the people of Bangladesh, while prawns are used as a cash crop to sustain the economy of the rural population (Ahmed and Garnett, 2010). The expansion of rice-prawn farming in Bangladesh has been noticeable over the last two decades, and prawn production has drawn a noteworthy attention due to its export potential to international markets (Ahmed et al., 2008; Mirhaj et al., 2013) such as USA, Europe, and Japan (Ahamed et al., 2014; Ahmed and Garnett, 2010). Between 2011 and 2012, Bangladesh exported 7,060 tons of freshwater prawn, with a market value of 108 million US\$ (DoF, 2013).

Rice production in Bangladesh has steadily increased, but it is still not sufficient to cover the needs of the ever growing population (Shahid, 2011). The rapid population expansion and food security issues have resulted in a decrease of available arable land and a concomitant intensification of agricultural practices. Nowadays, farmers tend to grow high-yield varieties of rice (e.g. boro rice), which are highly susceptible to infestations with pests and diseases that may produce crop losses of up to 40\% (Bagchi et al., 2009; Uddin et al., 2013). As a consequence, pesticides are being used to protect rice crops from pests, herewith improving rice crop yields 
and the quality of the product (Ansara-Ross et al., 2012; Rahman, 2013). As in many developing countries, the government has promoted the use of pesticides to increase agricultural yields in Bangladesh (Dasgupta et al., 2005). Pesticide consumption in Bangladesh has dramatically increased from 7,350 metric tons in 1992 to 45,172 metric tons in 2010 (Hasan et al., 2014).

The application of pesticides in rice production may lead to the contamination of the surrounding aquatic environments by several ways including spray drift, runoff, and leaching (Van den Brink, 2013; Van Wijngaarden et al., 2005; Capri and Karpouzas, 2008). Pesticides applied in rice-prawn concurrent systems may constitute a potential toxicological risk for the aquatic organisms that are cultured in the gher as well as for the maintenance of the aquatic communities that support the aquatic ecosystem of the gher, and herewith can make the whole system less profitable as it may eradicate organisms that are a food source for the cultured prawns (Huy Giap et al., 2005). Furthermore, pesticides applied by farmers with poor education on safe pesticide use practices could result in human health hazards, including risks of acute intoxication and/or other diseases e.g. skin diseases, eye diseases, gastro-intestinal diseases, urinary and reproductive diseases (Miah et al., 2014).

Several studies have investigated pesticide use patterns in different agricultural crops of Bangladesh (e.g. Dasgupta et al., 2005; Meisner, 2004); however, only one study has investigated pesticide use in rice-prawn concurrent systems (Hasan et al., 2014). The study by Hasan et al. (2014), however, did not investigate the potential aquatic risks of pesticides applied in these systems, and neither reported the impacts of pesticide use on farmers' health. The objectives of the current study were to determine the farmers' knowledge, perception and occupational health hazards related to the pesticides applied in concurrent rice-prawn farms of south-west Bangladesh and to assess their potential risks for the aquatic ecosystems that support the culture of the freshwater prawns Macrobrachium rosenbergii. For this, modelling approaches were developed to calculate pesticide risks in the gher of these systems which included an exposure assessment based on physical characteristics of the farms, pesticide use practices, and physico-chemical data and an effect assessment based on ecotoxicological data for the recorded pesticides.

\section{Materials and methods}

2.1. Pesticide data collection

2.1.1. Farm interviews 
Information on pesticide use, agricultural management practices and occupational health hazards related to pesticide use in rice-prawn farming was collected through structured interviews performed in the Khulna region (south-west Bangladesh). Such interviews were performed to 38 farm owners in 6 villages (namely Kaligati, Gutudia, Rudhagora, Dhopakhola, Moddapara, and Kola) between January and May 2012. The pesticide use information included: active ingredient, applied dose, mode of application, number of applications per crop, application interval, and approximate date of application. Information on human health issues, i.e. risk and health of applicators, short/long term impacts of pesticides on farmers' health, most common negative health symptoms experienced by farmers, was collected (see Supporting Information).

\subsubsection{Pesticide physico-chemical properties}

Physico-chemical properties of the reported pesticides were collected from online databases (e.g. Lewis et al., 2016; http://www.chemspider.com) and peer-reviewed literature sources. Information was collected for the parameters listed in Table 1. The half-life of pesticides in sediment $($ DT50 sed), was set to 1000 days for all reported pesticides (for rationale see FOCUS, 2006).

Table 1. Physico-chemical properties of the reported pesticides.

\begin{tabular}{|c|c|c|c|c|c|c|c|}
\hline Pesticide name & $\begin{array}{c}\mathrm{M}^{\mathrm{a}} \\
(\mathrm{g} / \mathrm{mol})\end{array}$ & $\begin{array}{c}\text { SOL }\left(T_{\text {ref }}\right)^{b} \\
(\mathrm{mg} / \mathrm{L})\end{array}$ & $\mathrm{Kow}^{\mathrm{c}}$ & $\begin{array}{l}\text { VP }\left(T_{\text {ref }}\right)^{d} \\
\quad(P a)\end{array}$ & $\begin{array}{c}\text { DT50 }_{\text {water }} \\
\text { hydrolysis } \\
\text { hyd) }\end{array}$ & $\mathrm{Koc}^{f}$ & $1 / n^{g}$ \\
\hline Alpha-cypermethrin & 416.30 & 0.004 & 316000 & $3.40 \cdot 10^{-7}$ & 101 & 57889 & 0.90 \\
\hline Carbofuran & 221.26 & 322 & 631 & $8.00 \cdot 10^{-5}$ & 37 & 70.8 & 0.89 \\
\hline Cartap & 273.80 & 200000 & 0.112 & $1.00 \cdot 10^{-13}$ & 1.9 & 41.7 & 0.90 \\
\hline Chlorantraniliprole & 483.15 & 0.88 & 724 & $6.30 \cdot 10^{-12}$ & 1000 (stable) & 362 & 0.95 \\
\hline Chlorpyrifos & 350.89 & 1.05 & 50100 & $1.43 \cdot 10^{-3}$ & 25.5 & 8151 & 0.90 \\
\hline Cypermethrin & 416.30 & 0.009 & 200000 & $2.30 \cdot 10^{-7}$ & 179 & 156250 & 0.90 \\
\hline Imidacloprid & 255.66 & 610 & 3.72 & $4.00 \cdot 10^{-10}$ & 1000 (stable) & 6719 & 0.80 \\
\hline Isoprocarb & 193.24 & 270 & 209 & $2.80 \cdot 10^{-3}$ & 1.2 & 107.5 & 0.90 \\
\hline Malathion & 330.36 & 148 & 562 & $3.10 \cdot 10^{-3}$ & 6.2 & 1800 & 0.94 \\
\hline Phenthoate & 320.39 & 11 & 4900 & $5.30 \cdot 10^{-3}$ & 12 & 1000 & 0.90 \\
\hline Sulphur & 32.06 & 0.063 & 1.70 & $9.80 \cdot 10^{-5}$ & 1000 (stable) & 1950 & 0.90 \\
\hline Thiamethoxam & 291.71 & 4100 & 0.741 & $6.60 \cdot 10^{-09}$ & 1000 (stable) & 56.2 & 0.90 \\
\hline \multicolumn{8}{|c|}{ 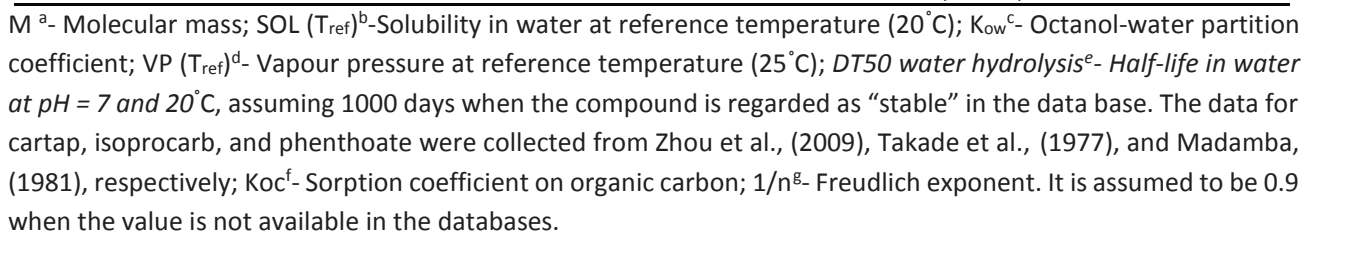 } \\
\hline
\end{tabular}




\subsubsection{Pesticide toxicity data}

Acute and chronic toxicity data for fish, invertebrates, and algae were collected from the FOOTPRINT Pesticide Properties Database (Lewis et al., 2016), the ECOTOX Database (http://cfpub.epa.gov/ecotox/quick_query.htm), and other peer-reviewed literature sources (Table 2). Fish toxicity data were also considered relevant because in some instances fish is being cultured together with prawns in the gher systems (Rahman et al., 2011). Acute toxicity data for fish consisted of 96-h LC50 and for invertebrates consisted of 48-h EC50 values was collected. The organisms for which acute toxicity data was available were the fish species Oncorhynchus mykiss, Lepomis macrochirus, Cyprinidae, Cyprinodon variegatus, Salmo gairdneri and Cyprinus carpio; the invertebrate species Daphnia magna and Daphnia carinata; and the algae species Raphidocelis subcapitata, Pseudokirchneriella subcapitata, Scenedemus subspicatus, Selanastrum subspicatus, and Chlamydomonas reinhardtii. Regarding the chronic toxicity data, the No Observed Effect Concentrations (NOEC) for an exposure period of 28, 21, and 3-4 days, were collected for fish, invertebrates, and algae, respectively. The species used for the chronic toxicity evaluation were the fish species Pimephales promelas, O. mykiss and Salmo trutta; the invertebrate species D. magna; and the algae species S. subspicatus.

Table 2. Acute and chronic toxicity data for the recorded pesticides for fish, invertebrates and algae.

\begin{tabular}{|c|c|c|c|c|c|}
\hline \multirow[b]{2}{*}{ Pesticide name } & \multicolumn{2}{|c|}{ Acute toxicity } & \multicolumn{3}{|c|}{ Chronic toxicity } \\
\hline & $\begin{array}{l}\text { LC50 } \\
\text { Fish } \\
(\mu g / L)\end{array}$ & $\begin{array}{c}\text { EC50 } \\
\text { Invertebrates } \\
(\mu \mathrm{g} / \mathrm{L})\end{array}$ & $\begin{array}{l}\text { NOEC } \\
\text { Fish } \\
(\mu \mathrm{g} / \mathrm{L})\end{array}$ & $\begin{array}{c}\text { NOEC } \\
\text { Invertebrates } \\
(\mu \mathrm{g} / \mathrm{L})\end{array}$ & $\begin{array}{c}\text { NOEC Algae } \\
(\mu \mathrm{g} / \mathrm{L})\end{array}$ \\
\hline Alpha-cypermethrin & 2.8 & 0.3 & 0.03 & 0.03 & NA \\
\hline Carbofuran & 180 & 9.4 & 2.2 & 8 & 3200 \\
\hline Cartap & 1600 & 10 & 20 & 2 & NA \\
\hline Chlorantraniliprole & 12000 & 11.6 & 110 & 4.47 & NA \\
\hline Chlorpyrifos & 1.3 & 0.1 & 0.14 & 4.6 & 43 \\
\hline Cypermethrin & 2.8 & 0.3 & 0.03 & 0.04 & 1300 \\
\hline Imidacloprid & 211000 & $1.02^{\mathrm{a}}$ & 9020 & $0.033^{a}$ & 10000 \\
\hline Isoprocarb & 22000 & 24 & 3200 & NA & NA \\
\hline Malathion & 18 & 0.7 & 91 & 0.06 & NA \\
\hline Phenthoate & 2500 & 1.7 & NA & NA & NA \\
\hline Sulphur & 63 & 63 & NA & NA & NA \\
\hline Thiamethoxam & 125000 & $44.8^{b}$ & 20000 & 100000 & NA \\
\hline
\end{tabular}

${ }^{a}$ For the acute and chronic toxicity evaluation of imidacloprid on invertebrates, the 96-hour EC50 and 28-day EC10 of Cloeon dipterum (belonging to the Ephemeroptera order) were used, since this species has been demonstrated to be significantly more sensitive than Daphnia magna (Roessink et al., 2013).

${ }^{b}$ For the acute toxicity evaluation of thiamethoxam, the 96-hour EC50 for Hemiptera was taken from Morrissey et al. (2015).

NA: Data not available 


\subsection{Pesticide exposure calculations}

\subsubsection{The Gher scenario}

A scenario was created that represents the characteristics of the rice-prawn production systems in which pesticides are applied (Figure 1; Table 3). Farmers typically cultivate boro rice during the dry season, starting on the $3^{\text {rd }}-4^{\text {th }}$ week of December and harvesting it by the $2^{\text {nd }}-3^{\text {rd }}$ week of May. During the dry season, the paddy field and the adjacent gher are separated by a low dike. Farmers start stocking the prawns in the post-larval stage at the end of the rice season or just after it. Prawns are mainly grown during the wet season (June to December), when the dike is removed and the prawns are allowed to freely move around the entire flooded paddy field. Farmers usually harvest their prawn in December, however many of the prawns that have not reached the marketable size are kept in the gher for rearing until they reach a sufficient size or until the next year, thus keeping a continuously growing population.
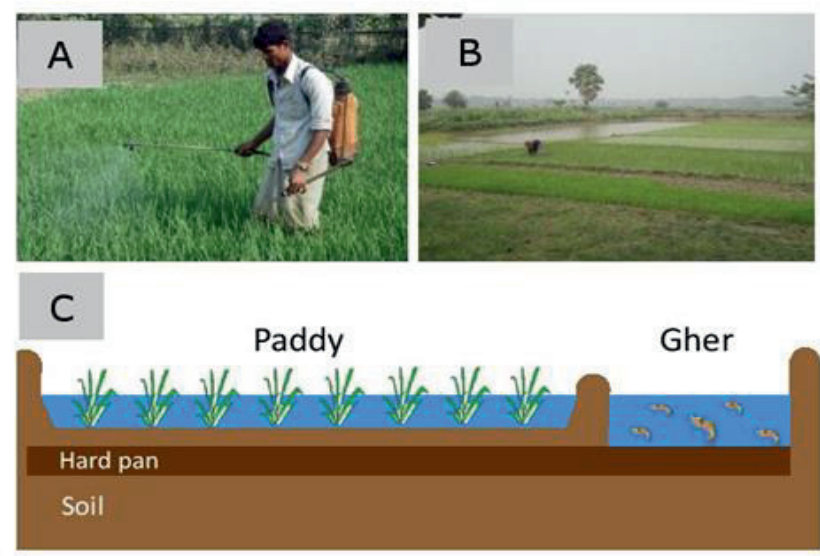

Figure 1. Pesticide application (A), typical rice-prawn concurrent production system from the Khulna region in Bangladesh (B), and schematic overview of the rice-prawn concurrent system (C).

During the farm interviews, information was collected describing the physical characteristics of the rice-prawn farms. The collected information was used to build a physical scenario for the pesticide exposure simulations and included: area of the paddy rice field, water depth in the paddy rice field, dike height, canal area, canal length, canal width and water depth, number of irrigation events per rice growing season and water height irrigation (Table 3). 
Table 3. Physical characteristics of the rice-prawn concurrent systems in Khulna region. Based on the information collected during the farm interviews $(n=38)$.

\begin{tabular}{lc}
\hline Parameter & Mean \pm SD \\
\hline Rice paddy area (ha) & $0.6 \pm 0.2$ \\
Rice paddy water depth $(\mathrm{cm})$ & $12 \pm 4.6$ \\
Dam height $(\mathrm{cm})$ & $22 \pm 7$ \\
Canal area $(\mathrm{ha})$ & $0.06 \pm 0.14$ \\
Canal length $(\mathrm{m})$ & $51 \pm 54$ \\
Canal width $(\mathrm{m})$ & $12 \pm 25$ \\
Canal water depth $(\mathrm{m})$ & $1.55 \pm 0.40$ \\
Rice irrigation $(\mathrm{n}$ per cycle) & $12 \pm 14$ \\
Water height irrigation $(\mathrm{cm})$ & $12 \pm 5$ \\
\hline
\end{tabular}

\subsubsection{Pesticide exposure modelling}

We initially assumed that pesticides applied on rice production could enter the gher via spraydrift deposition or via runoff produced by precipitation events leading to water overflowing the small dikes that separate the rice-production area from the gher. However, it is questionable whether the later should be considered as a relevant pesticide exposure process due to the low amount of precipitation typically recorded during the rice growing season. To investigate the relevance of the pesticide exposure caused via water runoff events during the rice-growing season we parameterised the PEARL model (Leistra et al., 2001) which was modified for applications in (flooded) paddy rice according to Ter Horst et al. (2014). Although other models simulating pesticide fate in paddy rice exist (MED-Rice, 2003; Karpouzas et al., 2006; Inao et al., 2008; Inao and Kitamura, 1999; Watanabe et al., 2006; Young, 2012) the PEARL model was selected because it is a field scale model that simulates the runoff and pesticide concentrations in the runoff. Furthermore, the model is freely available and allows calibration without an extensive dataset being available (Ter Horst et al., 2014). PEARL simulations were performed for the period 2004-2012 and included an evaluation of the hydrology of the whole rice-prawn production system during the entire year. Due to a lack of measured data (e.g. time series of percolation, groundwater tables, water depth on the field) we calibrated PEARL manually only considering the rice-growing period and using a set of requirements established using literature data (see SI). The main calibration parameters were the saturated conductivity of the plough pan and two bottom boundary flux parameters used to describe the downward flux at the bottom of the soil column as function of the groundwater level. For these calibrated simulations, we calculated the number of runoff events in the rice growing season and found a range of 0.3 to 0.7 events per year (see $\mathrm{SI}$ ). We considered this number to be too low to indicate 
runoff overflow as a major driver for pesticide exposure in the gher, and decided to only take into account spray-drift deposition for the pesticide exposure calculations.

Pesticide exposure concentrations due to spray-drift deposition were calculated using the TOXSWA v3.3.2 model (Adriaanse, 1997; Beltman et al., 2006). TOXSWA is a pseudo-twodimensional numerical model describing pesticide behavior in the water layer and its underlying sediment at the edge-of-field scale (Adriaanse, 1997; Adriaanse et al., 2013). A TOXSWA scenario was created based on the information provided in Section 2.2.1 and Table 4. The TOXSWA scenario comprised only the rice-growing season from January $1^{\text {st }}$ to May $10^{\text {th }}$, as being considered the most vulnerable period for pesticide risks to aquatic organisms. We simulated the gher as a stagnant rectangular water body (51 m long and $12 \mathrm{~m}$ wide) with a (constant) water depth of $1.55 \mathrm{~m}$ (Table 3). We assumed the concentration of suspended solids to be 15 $\mathrm{g} / \mathrm{m}^{3}$ with an organic matter content of $9 \%$ (FOCUS, 2001). Data on sediment properties were based on the EU-FOCUS sediment properties and segmentation characteristics (FOCUS, 2001). Spray drift was conservatively assumed to be perpendicular to the long side of the gher $(51 \mathrm{~m})$. During the farm interviews farmers reported to keep a distance of $0.80 \pm 0.95 \mathrm{~m}$ (mean \pm SD) to the edge of the field when spraying. Given the variability of the spray distance reported by the farmers, we estimated different spray-drift deposition scenarios into the gher based on different distances between the spray area and the gher dike: $0.3 \mathrm{~m}, 0.5 \mathrm{~m}, 1 \mathrm{~m}, 5 \mathrm{~m}$, and $10 \mathrm{~m}$. The percentage of pesticide spray-drift deposition into the gher for each scenario were calculated using the method described by Franke et al. (2010), assuming a crop height of $5 \mathrm{~cm}$ and warm and humid climate conditions. The calculated percentages of the applied dose that were considered to be deposited into the gher surface by spray drift were: 5.52\%, 3.85\%, 2.98\%, $0.66 \%$, and $0.23 \%$ for each scenario, respectively. Finally, the pesticide exposure in surface water of the gher system for the different spray drift scenarios was conservatively calculated by FOCUS using the maximum active ingredient dose $(\mathrm{kg} / \mathrm{ha})$ and the maximum number of applications with average application intervals used by farmers, as reported in Table 4 . The model simulations were performed using meteorological data (i.e., temperature, precipitation) for the year 2005, as it was considered a representative year for the time series for which information was available (2004-2012). The peak Predicted Environmental Concentrations (PECs; global maximum water concentration including suspended solids) and the maximum Time Weighted Average Exposure Concentrations (TWAECs) over the simulation period were obtained from the pesticide exposure profiles calculated by TOXSWA. 


\subsection{Aquatic risk assessment}

The first tier aquatic risk assessment was performed using a Risk Quotient (RQ) approach. We could not estimate the risk for carbofuran and sulphur among the evaluated pesticides reported by farmers since carbofuran was applied using broadcast method and sulphur is an inorganic chemical, whereas we simulated the TOXSWA for spray drift exposures and the dissipation processes modelled by TOXSWA were designed for organic chemicals. Acute RQs for fish and invertebrates were calculated by dividing the peak PECs by acute Predicted No Effect Concentrations (PNECs), while chronic RQs for algae, invertebrates, and fish were calculated by dividing the calculated 3-day, 21-day and 28-day TWAECs, respectively, by their respective chronic PNECs. Acute PNECs for invertebrates and fish were calculated by dividing the acute EC50 or LC50 values by an assessment factor of 100. The chronic PNECs for algae, invertebrates, and fish were calculated by dividing No Observed Effect Concentration (NOEC) values by an assessment factor of 10 . RQs were classified as no risk $(R Q<1)$, moderate risk, $(1<R Q<10)$ and high risk $(R Q>10)$.

Since the first tier RQ-based risk assessment is based on worst-case assumption, we used the higher-tier PERPEST v4.0.0.0 (Predicting the Ecological Risks of PESTicides) model to refine the risks of the PEC values of pesticides with a RQs $>1$. For the PERPEST model, we considered average case scenario while using average number of pesticide application and worst case scenario while using maximum number of pesticide application reported by farmers. The PERPEST model predicts the toxic effects of a particular concentration of a pesticide on grouped endpoints (Van den Brink et al., 2002; Ansara-Ross et al., 2008). The PERPEST model is based on a case-based reasoning $(C B R)$ approach. For developing the model, empirical data were extracted from published literature describing the results from mesocosm and microcosm experiments for freshwater model ecosystem studies with pesticides (Van den Brink et al., 2002) and were collated within a database. The PERPEST model results in a prediction showing the probability of the evaluated pesticide concentration leading to no, slight or clear classes of effects on the 8 grouped endpoints: algae and macrophytes, community metabolism, fish, insects, macrocrustacenas, micro-crustaceans, other invertebrates, and rotifers. The PERPEST model refines the outcome of the risk as determined by the RQ approach. For a more detailed description on the equations and calculations used for PERPEST model, the reader is referred to Van den Brink et al. (2002). 


\section{Results and discussion}

\subsection{Pesticides and their application patterns}

Twelve different pesticide active ingredients were recorded from the farm interviews. All substances recorded were synthetic insecticides, except for one fungicide (sulphur) (Table 4). Most pesticides were sold as a powder form (50\%), followed by liquid (46\%), and granule (4\%) formulations. The most commonly reported pesticide was sulphur ( $29 \%$ farmers used it), followed by thiamethoxam, chlorantraniliprole, and phenthoate (21\%; Table 4). Farmers applied pesticides in their rice field between January and March using spray (96\%) and broadcast (4\%) application methods. The full list of recorded active ingredients, together with their dose, number of application, average application interval, and approximate date of first application are provided in Table 4.

\section{2 . Farmers' perceptions on pesticide risks and occupational health hazards}

The $87 \%$ of the interviewed farmers reported to use pesticides during the rice-growing season. The compounds reported and application practices resemble those reported by a similar study performed in the same region (Hasan et al., 2014) and those reported by vegetable farmers in other areas of Bangladesh (Dasgupta et al., 2007). Most of the interviewed farmers had been working in their farm for long periods (on average 12 years), however only $21 \%$ of them reported having received any sort of training from government institutions (e.g. agriculture extension officers and fisheries officers) on pesticide use practices. The majority of the interviewed farmers reported to understand the pesticide application recommendations stated on the pesticide labels, except of two cases due to illiteracy.

Overall, farmers were sceptical about the impacts of pesticide use on the productivity of their prawn and fish. Some of them, however, $(25 \%)$ reported to have observed prawn mortalities after pesticide application at least once and suggested this to be related to the introduction of new 'more toxic' pesticides. The majority of the farmers (7 $0 \%$ ) reported to have increased pesticide dosages per land area during the last 5 years because of pest resistance and because of their attempts to increase productivity. 
Table 4. Pesticides used in rice-prawn concurrent systems of the Khulna region (Bangladesh) together with their dosages and interval between applications.

\begin{tabular}{|c|c|c|c|c|c|c|c|}
\hline Pesticide name & Type & Group & $\begin{array}{c}\text { Use by } \\
\text { farmers } \\
(\%)\end{array}$ & $\begin{array}{c}\text { Active } \\
\text { ingredient } \\
\text { dose }(\mathrm{kg} / \mathrm{ha}) \\
\text { (min-max) }\end{array}$ & $\begin{array}{l}\text { Number of } \\
\text { applications } \\
\text { (times) }\end{array}$ & $\begin{array}{l}\text { Average } \\
\text { application } \\
\text { interval } \\
\text { (days) }\end{array}$ & $\begin{array}{l}\text { Date of first } \\
\text { application }\end{array}$ \\
\hline Alpha-cypermethrin & I & Pyrethroid & 5 & 0.1 & 2 & 15 & 4 February \\
\hline Carbofuran & I & Carbamate & 5 & $0.008-0.009$ & 1 & 0 & 10 January \\
\hline Cartap & I & Unclassified & 8 & 0.5 & $2-4$ & 15 & 10 February \\
\hline Chlorantraniliprole & I & Anthranilic diamide & 21 & $0.014-0.015$ & $2-4$ & 18 & 8 March \\
\hline Chlorpyrifos & I & Organophosphate & 2.5 & 0.2 & 1 & 0 & 18 January \\
\hline Cypermethrin & I & Pyrethroid & 8 & $0.05-0.1$ & $2-4$ & 11 & 10 January \\
\hline Imidacloprid & I & Neonicotinoid & 2.5 & 0.2 & 2 & 20 & 4 March \\
\hline Isoprocarb & 1 & Carbamate & 10 & 1.005 & $2-3$ & 12 & 24 March \\
\hline Malathion & I & Organophosphate & 8 & 0.57 & $2-3$ & 15 & 24 January \\
\hline Phenthoate & I & Organophosphate & 21 & 0.5 & $2-8$ & 13 & 24 February \\
\hline Sulphur & $\mathrm{F}$ & Inorganic & 29 & 1.98 & $2-4$ & 10 & 24 February \\
\hline Thiamethoxam & 1 & Neonicotinoid & 21 & $0.014-0.015$ & $2-4$ & 18 & 10 March \\
\hline
\end{tabular}

$\mathrm{I}=$ Insecticide, $\mathrm{F}=$ Fungicide

The vast majority of the interviewed farmers (94\%) assumed pesticide use to have short or longterm impacts on their health. The majority of the farmers (81\%) indicated some health symptoms after pesticide application and reported to be very confident that these symptoms had been occurred due to pesticide intoxication. In this study, the most common negative symptoms experienced by farmers' after pesticide application were vomiting, which was reported by the $51 \%$ of the interviewed farmers, followed by headache $(18 \%)$, and eye irritation ( $12 \%)$. This could be explained by the fact that $82 \%$ of the interviewed farmers only used cloths to cover their body and face during pesticide application whereas other equipment such as gloves, appropriate masks or glasses was rarely used. The results of this study are in line with those recently reported by other investigations on human health risks of pesticides. For example, Miah et al. (2014) reported eye irritation, headache and nausea in vegetable farmers in Bangladesh and witnessed that $72 \%$ of their farmers used only cloths as a protection during pesticide application. They also reported some short-term diseases such as skin diseases, eye diseases, gastro-intestinal diseases, and urinary and reproduction impairment, probably related to pesticide use. Another study including 821 farmers among 11 districts in Bangladesh showed some negative symptoms after pesticide application such as headache (27\%), dizziness (8\%), eye irritation (26\%), skin disease (13\%), vomiting (9\%) and other multiple diseases (Dasgupta et al., 2005). Dasgupta et al. (2007) also found some intoxication symptoms by Bangladeshi farmers that used pesticides. The most commonly reported were: headache, dizziness, eye irritation and dermal diseases, gastrointestinal problems and vomiting, and reported that $87 \%$ did not use any protective measures either during or after pesticide application. 
Sixty percent of the farmers' reported to be aware of human health and environmental risks associated with pesticide application, however, the other forty percent were not informed. More than half of the recorded farmers (55\%) were not informed about banned pesticides, the other part of them were informed by other farmers and local agricultural officers. The majority of the farmers (94\%) reported not to know alternatives to pesticide use to control rice pests, and the knowledge on integrated pest management (IPM) practices or alternative bio-pesticides was reported by only one farmer.

Our study demonstrated that the use of cloths to protect their mouth and nose during pesticide application is not sufficient. The resulting negative symptoms could be reduced by not only using cloths but also averting behaviour like e.g. wearing masks, hand gloves, eye glasses, and gumboot during handling of pesticides and washing hands or taking a shower after pesticide handling. The promotion of safe use of pesticides and suitable averting behaviour depends on some crucial factors like farmers' education level, extension contact, participation in training programme, etc. (Kabir and Rainis, 2012). Due to the limited access to these factors, farmers are lagging behind to promote suitable averting behaviour during pesticide application. In this context, both the public and the private sector can play a major role to eradicate the problems. For instance, the government should launch education programs for farmers. The Department of Agricultural Extension (DAE), the largest agro-based public organization, is mainly responsible for providing extension services through Sub-Assistant Agricultural Officer (SAAO), a person who live in the farming village and visits local farms individually and in group meetings. The SAAO can play a substantial role to change farmer application practices. However, the number of extension agents is inadequate in comparison to the total amount of farmers. So, the government should increase the extension agent-farmer ratio making the extension services more accessible to the farmers. There is also an urgent need to ensure basic training among the farmers to gather knowledge and to build awareness on safe use and handling of pesticides so that they can properly interpret the recommendations on the pesticide label and they can promote the suitable averting behaviour (Dasgupta et al., 2007; Kabir and Rainis, 2012). Furthermore, our study also suggests applying risk assessment models for pesticide applicators that emphasize the reduction of risks through the promotion of suitable protective measures (Feola et al., 2012; Remoundou et al., 2015). 

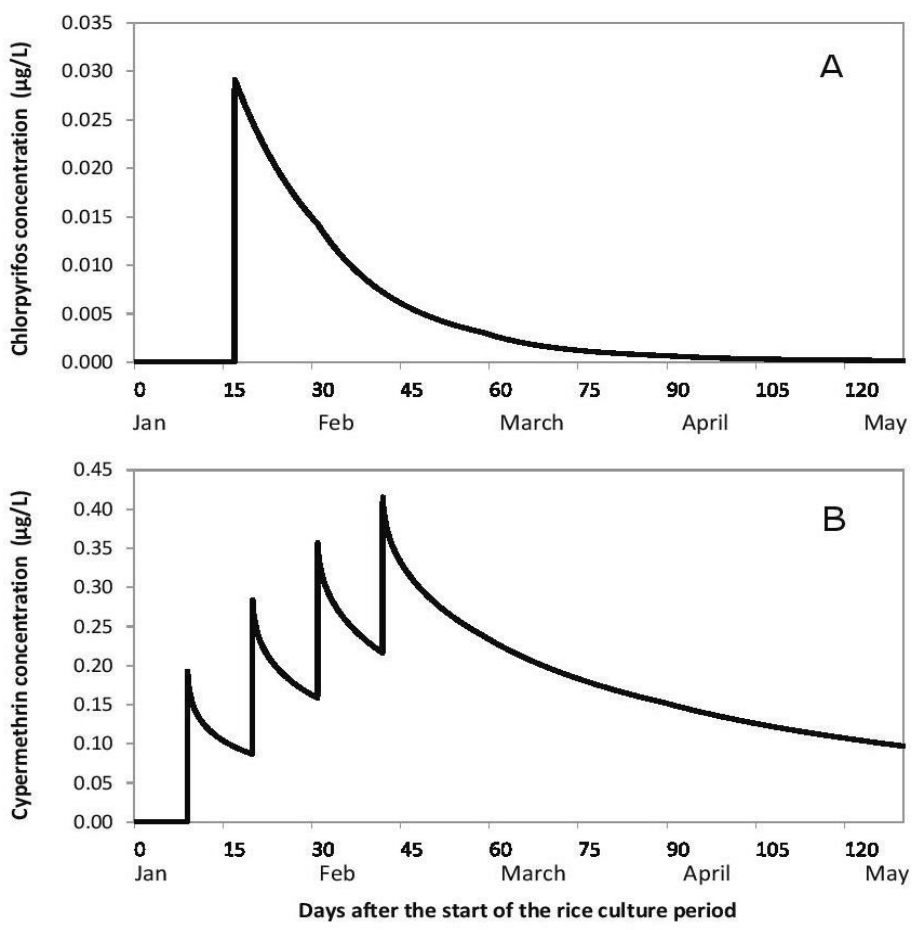

Figure 2. Water concentration dynamics of chlorpyrifos (A) and cypermethrin (B) in the gher system calculated with the TOXSWA model for the $0.5 \mathrm{~m}$ application distance scenario (i.e., spray-drift deposition in the gher of $3.85 \%$ of the applied dose.

\subsection{Pesticide exposure and first tier risk assessment}

Figure 2 shows an example of the calculated pesticide exposure profiles calculated with the TOXSWA model for chlorpyrifos and cypermethrin in the gher system, whereas the calculated peak PECs and the TWAECs for the list of evaluated pesticides are provided in Table S11. Chlorpyrifos showed the highest acute RQs for fish in all evaluated spray drift scenarios, followed by cypermethrin, alpha-cypermethrin, and malathion (Table S12), however, the rest of the evaluated compounds did not show potential risks (acute RQs $<1$ ). The highest chronic RQs for fish were calculated for cypermethrin, followed by alpha-cypermethrin, and chlorpyrifos while rest of them showed no risk (RQs<1) (Table S13). The majority of the recorded pesticides showed high acute RQs for invertebrates for all spray drift scenarios with the exception of carbofuran, thiamethoxam, and chlorantraniliprole. Among the pesticides evaluated, the highest acute RQs for invertebrates were also calculated for chlorpyrifos, followed by malathion, cypermethrin, 
alpha-cypermethrin, and phenthoate for all scenarios (Table S14). The highest chronic RQs for invertebrates were calculated for imidacloprid, followed by malathion, cypermethrin, alphacypermethrin for all spray drift scenarios (Table S15). We also calculated chronic RQs for algae for chlorpyrifos, cypermethrin, and imidacloprid (Table S16) but for the other pesticides this was not possible due to a lack of toxicity data. Among the calculated chronic RQs for these compounds, none of them showed risk $(R Q s<1)$ thus indicating the algae are not at risk as a result of exposure to the recorded pesticides in the gher system.

The highest acute and chronic RQs including the three taxonomic groups for all spray drift scenarios are provided in Figure 3. The most sensitive species based on the lowest acute PNECs and the highest acute RQs and the lowest chronic PNECs and the highest chronic RQs among three taxonomic groups are presented in Table S17 and Table S18, respectively. Regarding the evaluation including the three taxonomic groups, four pesticides (e.g. chlorpyrifos, cypermethrin, apha-cypermethrin, and malathion) showed a moderate to high acute risk to fish when the spray distances were between 0.3 and $5 \mathrm{~m}$, from the edge of the rice field during pesticide application. Chlorpyrifos, however, even showed a moderate risk when the spray distance was $10 \mathrm{~m}$ (Table S12). Cypermethrin, alpha-cypermethrin, and chlorpyrifos showed a moderate to high chronic risk to fish with spray distances between $0.3 \mathrm{~m}$ and $10 \mathrm{~m}$ (Table S13). Most of the pesticides showed high acute risk for invertebrates even up to $5 \mathrm{~m}$ of spray distance and moderate risk up to $10 \mathrm{~m}$ of spray distance with the exception of chlorpyrifos and malathion. They showed high risk even with a spray distance up to $10 \mathrm{~m}$ (Table S14). For some pesticides, a moderate to high chronic risk was indicated for invertebrates, even with spray distances up to $10 \mathrm{~m}$ (Table S15). Overall, for the vast majority of the evaluated pesticides moderate to high risks are indicated for invertebrates and fish even when a spray distance of $10 \mathrm{~m}$ from the edge of the rice field is used. Since in our study farmers reported to keep a spray distance of only $0.80 \pm$ $0.95 \mathrm{~m}$ (mean $\pm \mathrm{SD}$ ) between the rice crop and canal during pesticides application, it is very likely that the pesticides will affect the aquatic ecosystems in the gher system. 


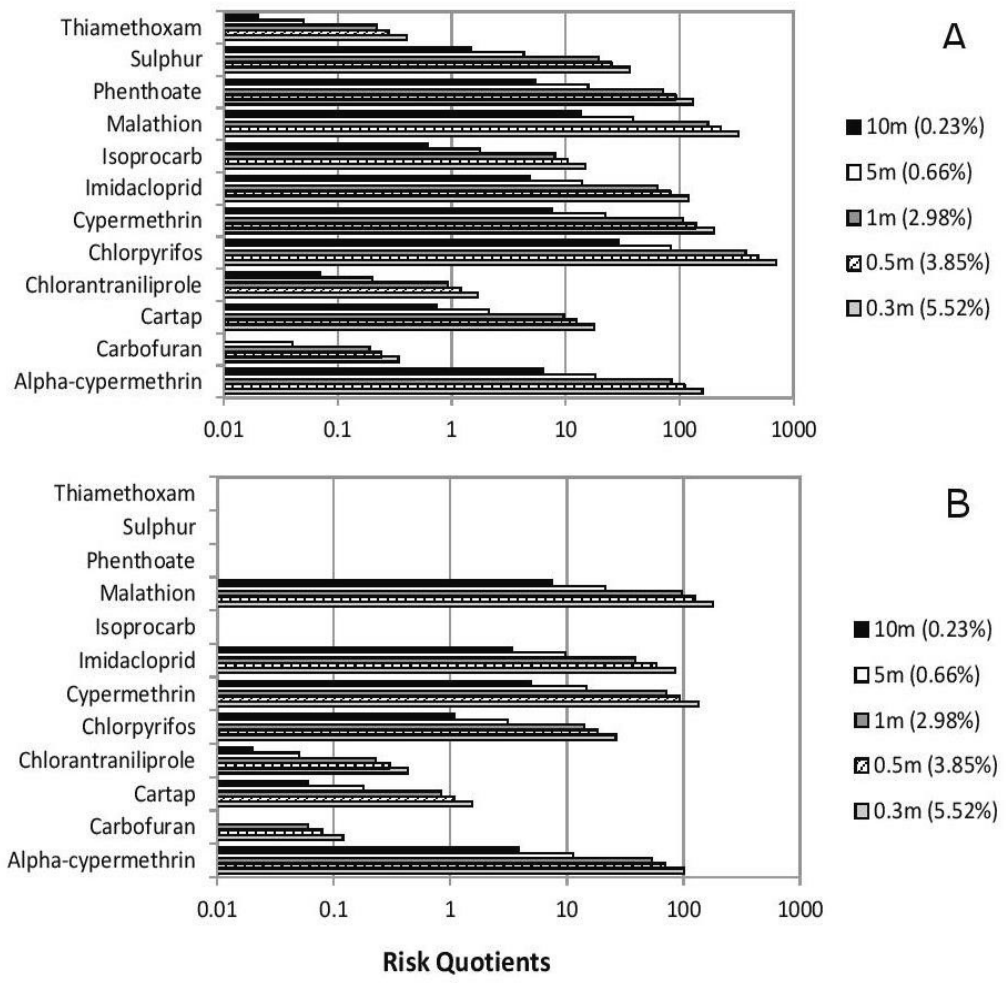

Figure 3. Calculated highest acute $(A)$ and chronic (B) risk quotients among the three evaluated taxonomic groups for the different spray drift scenarios evaluated in this study. The spray drift scenarios are represented as the distance from the pesticide application point to the gher and the calculated spray drift percentage.

\subsection{PERPEST model results}

The probability of effect classes (no effect, slight effect and clear effect) on 8 grouped ecological endpoints of the selected pesticides in respect to different spray drift distances are shown in Table S19-S23. The model results showed high probability of clear effects on aquatic insects, macro- and micro-crustaceans for cypermethrin, followed by alpha-cypermethrin, and chlorpyrifos for different spray drift distances. A high probability of clear effect is taken into account when one of the chemical poses the probability of higher than $50 \%$. Cypermethrin (for both average and worst case scenario) and alpha-cypermethrin showed a high probability of clear effects on insects, macro- and micro-crustaceans even with spray distances up to 10 $\mathrm{m}$ whereas chlorpyrifos showed a clear effect on these endpoints with spray distances up to $0.5 \mathrm{~m}$. Phenthoate showed a high probability of clear effect on insect and micro-crustacean 
with spray distances up to $0.5 \mathrm{~m}$ for both the average and the worst case scenario, while imidacloprid showed a high probability of clear effects on micro-crustaceans with spray distances up to $1 \mathrm{~m}$. Other pesticides (e.g. cartap, chlorantraniliprole, isoprocarb, and malathion) showed a lower probability of clear effects occurring on these ecological endpoints. Community metabolism, fish, algae and macrophytes, other macro-invertebrates, and rotifers were found to be impacted to a lesser extent by any of the selected pesticides. So, the result of the PERPEST model refined the risks of the top three pesticides (cypermethrin, alpha-cypermethrin, and chlorpyrifos) on the gher system which were previously derived following the RQ approach.

To date, it has been challenging to perform site specific aquatic risk assessments of pesticides in the (sub-) tropics due to the absence of sensitivity data for local species (Rico et al., 2011). The present study, however, provides the first modelling exercise in Bangladesh to assess the potential risks of pesticides for the aquatic ecosystems that support the culture of the freshwater prawns. One of the limitations of our study is that we could not estimate the risks of the pesticides for the prawns because of a lack of toxicity data for most pesticides for $M$. rosenbergii. So, this study recommends that $M$. rosenbergii should be used as a test animal to refine the risk assessment. For example, tests with caged prawn larvae and fish placed at the edge of the rice area could be used to evaluate possible direct effects during and after pesticide applications, and to better quantify aquaculture productivity losses. Besides direct toxic effects, pesticides may impair the ecology of the gher system and indirectly affect the sustainability of the aquaculture production system. Pesticides may be responsible for changing the whole community structure and ecosystem properties of an ecosystem like the gher (Halstead et al., 2014) as a result of alterations in the food web and propagated effects (De Laender et al., 2015; Hela et al., 2005). The direct effects of insecticides typically reduce organisms' abundance by increased mortality or reduced fecundity or alter normal behavioural patterns, of physiology (e.g. sensorial, hormonal, neurological and metabolic systems), and of normal reproductive behaviour (Van Wijngaarden et al., 2005; Scott and Sloman, 2004). Indirect toxicant effects (Fleeger et al., 2003), may lead to ecological imbalance of a system by decreased abundance via reduced availability of preferred food sources e.g. algae and plankton (Cochard et al., 2014) and micro-crustaceans (Daam et al., 2008; Van den Brink et al., 2002); via changing food habits, and deteriorating aquatic habitat (Cochard et al., 
2014). Prawns are merely dependent on natural food sources (e.g. phytoplankton, zooplankton, benthos, and detritus) in a gher system (Ahmed et al., 2008) and those are sensitive to indirect toxicant effects. Pesticides may accumulate in sediments as well as in the body of the cultured prawns, possibly resulting in long-term risks for consumers (Hernández et al., 2013) and for the international export of the produce to countries (Ahmed and Garnett, 2010). So, unsustainable pesticide use practices may result in international bans from prawnimporting countries, such as USA, Europe, and Japan, and influence the long-term net economic return from these systems.

The risk assessment of pesticide in aquatic ecosystem like gher from adjacent paddy field largely depends on simulation models to estimate the predicted environmental concentrations (PECs). Available mathematical models are not always flexible to represent the different scenarios and the required input data is not always available or can be produced. So, in order to establish a realistic assessment and management procedure for more sustainable rice production practices, it is important to develop and validate mathematical models adapted to the rice-prawn systems in Bangladesh and in other regions of south-east Asia (Inao et al., 2008).

\section{Conclusions}

In rice-prawn concurrent systems, farmers' aim to keep a dual benefit i.e. a higher rice yield through pesticide use without inducing prawn mortalities or yield reductions. To make the rice-prawn system more sustainable, mitigation measures or alternatives should be sought for the pesticides used in rice crop protection. The present study suggests that the mitigation of risk arising from spray drift may be achieved by the implementation of spray drift buffer or the avoidance of spray drift (Maltby and Hills, 2008; Hilz and Vermeer, 2013). This study also suggests that the adoption of Integrated Pest Management (IPM) practices may provide an alternative, which is a popular method of sustainable and eco-friendly crop production in many countries (Azad et al., 2009). To date, the rate of IPM adoption in Bangladesh is minimal (only $0.27 \%$ of the estimated 37 million farmers), though it was first introduced back in the 1981 through the alliance of Food and Agriculture Organization (FAO) (Kabir and Rainis, 2013). The Department of Agricultural Extension (DAE) of Bangladesh has developed some dissemination techniques on IPM practices e.g. Extension Agent Visit, Farmers Field School (FFS), IPM club, and Field Days; but still shows little impact at the wide national scale. The 
government should invest more funds and improve the dissemination campaigns to the rural population e.g. by the use of different print and electronic media like TV, radio, newspapers and magazines. Furthermore, although hundreds of NGOs are nowadays working in Bangladesh, very few are devoted to the implementation of IPMs. More NGOs should be involved with GOs to disseminate the IPM through raising awareness among the farmers. One of the main reasons behind this may be the poor socio-economic characteristics of the farmers and the low literacy rate. Most of the farmers are reluctant to adopt new technologies since the majority have no risk bearing capacity. So, this study suggests that both DAE and NGOs should motivate the farmers in a way that IPM practice is not only seen as an ecologically sound and socially acceptable technique, but also it is presented as a more profitable farming practice than the conventional one (i.e., farming with intensive use of pesticides).

\section{Acknowledgements}

This study has been funded by the EU-FP7 Sustaining Ethical Aquaculture Trade (SEAT) project (contract number 222889) and the Netherlands Universities Foundation for International Cooperation (NUFFIC) project "'Integrated Management of Crop-fish-water resources to enhance agricultural production systems towards sustainable food security in Bangladesh NICHE-BGD-1 56 ". The authors are indebted to Md. Saifullah Bin Aziz, Md. Amirul Islam, Ranjan Das and A.M. Shahabuddin for their contribution during data collection. We would also like to express our gratitude to the interviewed farmers for their kind cooperation.

\section{Supporting information}

The supporting information can be downloaded from: https://doi.org/10.1016/j.scitotenv.2016.06.014. 
36 


\section{Chapter 3}

Environmental monitoring and risk assessment of organophosphate pesticides in aquatic ecosystems of north-west Bangladesh

Kizar Ahmed Sumon, Harunur Rashid, Edwin T.H.M. Peeters, Roel H. Bosma, Paul J. Van den Brink 


\section{Abstract}

The use of organophosphate pesticides (OPPs) to protect a variety of crops has increased in Bangladesh. OPPs may contaminate surrounding aquatic environments through several routes including spray drift, surface runoff and groundwater leaching. Since it is unknown how much OPP end ups in aquatic environment in Bangladesh, the objectives of the present study were to quantify the residues of ten most commonly used OPPs in water and sediment of water bodies of north-west Bangladesh and to assess their ecological risks for aquatic organisms. The risks of the pesticides in surface water and sediment were assessed using a first-tier risk quotient (RQ) approach. The higher-tier PERPEST model was used to refine the ecological risks of pesticides when RQ indicated a potential risk. Results showed the most frequently detected pesticides that appeared in high concentrations were chlorpyrifos, diazinon and quinalphos in surface water and sediment. The highest concentration of OPPs measured in water was 9.1 $\mu \mathrm{g}$ chlorpyrifos/L (median of $1.95 \mu \mathrm{g} / \mathrm{L}$ ), while this was $51 \mu \mathrm{g}$ diazinon/kg dw (median of 11 $\mu \mathrm{g} / \mathrm{kg} \mathrm{dw}$ ) for sediment. Furthermore, results showed high acute and/or chronic RQs (RQ > 1) in surface water and sediment for chlorpyrifos, diazinon, quinalphos, malathion and fenitrothion. The higher-tier PERPEST model confirmed risks of chlorpyrifos, diazinon, quinalphos and fenitrothion for aquatic insects, micro- and macro-crustaceans which were previously derived by RQ-based risk assessment for aquatic organisms. Furthermore, the results of the PERPEST model also indicated possible indirect effects of these pesticides on algae and macrophytes, community metabolism, rotifers and other macro-invertebrates. 


\section{Introduction}

Agriculture is the single largest sector contributing to the national economy of Bangladesh. About $80 \%$ of the country's population resides in rural areas and most of them are somehow, directly or indirectly, employed in agricultural activities (Bhattacharjee et al., 2012). A further intensification of agriculture in Bangladesh, however, is needed due to its' ever increasing population (about 157 million people on 147,570 $\mathrm{km}^{2}$ with $1.05 \%$ growth rate; BDP, 2016), as well as land scarcity and food security needs (Dasgupta et al., 2007). Severe agro-climatic conditions (e.g. flash floods, seasonal water scarcity, and salinity intrusion in the coastal belt) pose further challenges to agricultural crop production. To meet the growing demand of food under these harsh conditions, farmers are cultivating high-yielding cultivars of crops to get higher yields (Hasanuzzaman et al., 2017), but most of these cultivars are highly vulnerable to pests and diseases (Ali et al., 2018). Hence, like many other developing countries, pesticides are used extensively in Bangladesh to protect the crops (Shahjahan et al., 2017). The government of Bangladesh also fosters the pesticide use to amplify the agricultural frontiers and to increase output per acre of land (Rahman, 2013). In Bangladesh, the Plant Protection Wing of the Ministry of Agriculture (MoA) controls the pesticide registration process. The Pesticide Technical Advisory Committee grants registration to a brand of pesticide after thorough examination of all reports (Rahman, 2013).

The use of pesticides started in Bangladesh around 1951 and remained negligible until 1960s (Ara et al., 2014), but increased dramatically from 7,350 metric tons in 1992 to 45,172 metric tons in 2010 (Rahman et al., 2013). At present, about 84 pesticide active ingredients belonging to 242 trade names of numerous chemical groups such as organochlorine compounds, organophosphates (including all evaluated ones), carbamates, pyrethroids, neonicotinoids, heterocyclic pesticides, nitro compounds and amides have been registered in Bangladesh and are routinely used in agriculture and household applications (Chowdhury et al., 2012a; Ara et al., 2014). Since organochlorine pesticides have been banned in Bangladesh in 1993 (Matin et al., 1998) due to their high toxicity, persistence, and ability to bioaccumulate and biomagnify in the food chain (Sankararamakrishnan et al., 2005; Sun et al., 2006; Teklu et al., 2016), the agricultural sectors have shifted towards organophosphorous pesticides (OPPs) (Chowdhury et al., 2012b). In Bangladesh, an estimated 35\% of the crop-producing area is sprayed with OPPs for a variety of crop protection purposes (Chowdhury et al., 2012a). 
OPPs may reach the surrounding aquatic environment through several routes including spray drift, direct runoff, ground water leaching, careless disposal of empty containers and equipment washing (Sankararamakrishnan et al., 2005 ; Hossain et al., 2015; Sumon et al., 2016, 2017). Due to their bioaccumulation ability, OPPs have been detected in different environmental compartments e.g. surface and ground water (Leong et al., 2007; Rahmanikhah et al., 2010; Bhattacharjee et al., 2012; Chowdhury et al., 2012a; Hossain et al., 2015; Hasanuzzaman et al., 2017), sediment (Xue et al., 2005; Abdel-Halim et al., 2006; Nasrabadi et al., 2011; Kanzari et al., 2012; Masiá et al., 2015), and aquatic organisms (Abdel-Halim et al., 2006; Aktar et al., 2009; Malhat and Nasr, 2011; Yang et al., 2012; Masiá et al., 2015; Otieno et al., 2015) in different parts of the world with concentrations ranging from $0.003 \mathrm{ng}$ chlorpyrifos/L (Rahmanikhah et al., 2010) to $0.8 \mathrm{mg}$ chlorpyrifos/L (Akan et al., 2014) in aqueous matrices and $40 \mathrm{ng}$ diazinon/kg (Masiá et al., 2015) to $4.3 \mathrm{mg}$ diazinon/kg (Akan et al., 2014) in solid matrices. OPPs have raised great concern in the scientific community due to their possible ecological risks to the aquatic ecosystems (Masiá et al., 2015; Wee and Aris, 2017), in particular to arthropod invertebrates (Maltby et al., 2005).

The residues of OPPs in the surface water of different water bodies in Bangladesh including rivers, paddy fields and seasonal ponds, have hardly been monitored (Bhattacharjee et al., 2012; Chowdhury et al., 2012a, 2012b; Uddin et al., 2013; Ara et al., 2014; Hossain et al., 2015; Hasanuzzaman et al., 2017). The few available studies, however, did not quantify the residues of OPPs in sediments from aquatic systems and neither assessed pesticides risks for any of the environmental matrices. Hence, the objectives of the present study were to quantify the residues of ten most commonly used OPPs in water and sediments collected from two different water systems in north-west Bangladesh and to assess the ecological risks to aquatic organisms posed by these residues. This study also aimed to identify further research priorities concerning the risks of pesticides for aquatic ecosystems in Bangladesh.

\section{Materials and methods}

\subsection{The study area}

Two types of beels, namely Baitkamari and Pirijpur were selected as study sites. A beel is a deep depression along a river where water remains permanent throughout the year. These beels are located in Islampur upazila area of Jamalpur district in north-west Bangladesh, which lies around $25^{\circ} 04^{\prime} 59.88^{\prime \prime} \mathrm{N}$ and $89^{\circ} 47^{\prime} 30.12^{\prime \prime} \mathrm{E}$ (Fig. 1). These beels were chosen because local 
farmers routinely use a variety of pesticides to protect the crops in their vicinity throughout the year. Rice is the dominant crop in the surrounding of the Baitkamari beel and occasionally water chestnut is grown, whereas around the Pirijpur beel the focus is on vegetable production including eggplant, potato, tomato, cauliflower, cabbage, cucumber, pumpkin, and rice and jute. As it is surrounded by much more intensive agriculture, the Pirijpur beel is hypothesised to be more impacted by the pesticide contamination than the Baitkamari beel. The total area of the Baitkamari and Pirijpur beels in the wet season (June-October) is approximately 55 ha and 3 ha with an average water depth of approximately $5 \mathrm{~m}$ and $1 \mathrm{~m}$, respectively. In wet season, the water level of both beels becomes high due to rain and flood water received from nearby Brahmaputra River. In dry season (November-March), however, the area of Baitkamari and Pirijpur beel is reduced to approximately 10 ha and 0.1 ha with an average water depth of about $1.8 \mathrm{~m}$ and $0.5 \mathrm{~m}$, respectively. Information on crop cultivation and pesticide use in vicinity of both Baitkamari and Pirijpur beels was collected from agricultural officers of Islampur upazila. Since farmers use organophosphate pesticides extensively to protect the crops in the vicinity of both Baitkamari and Pirijpur beels, we selected this groups of pesticides in our study.

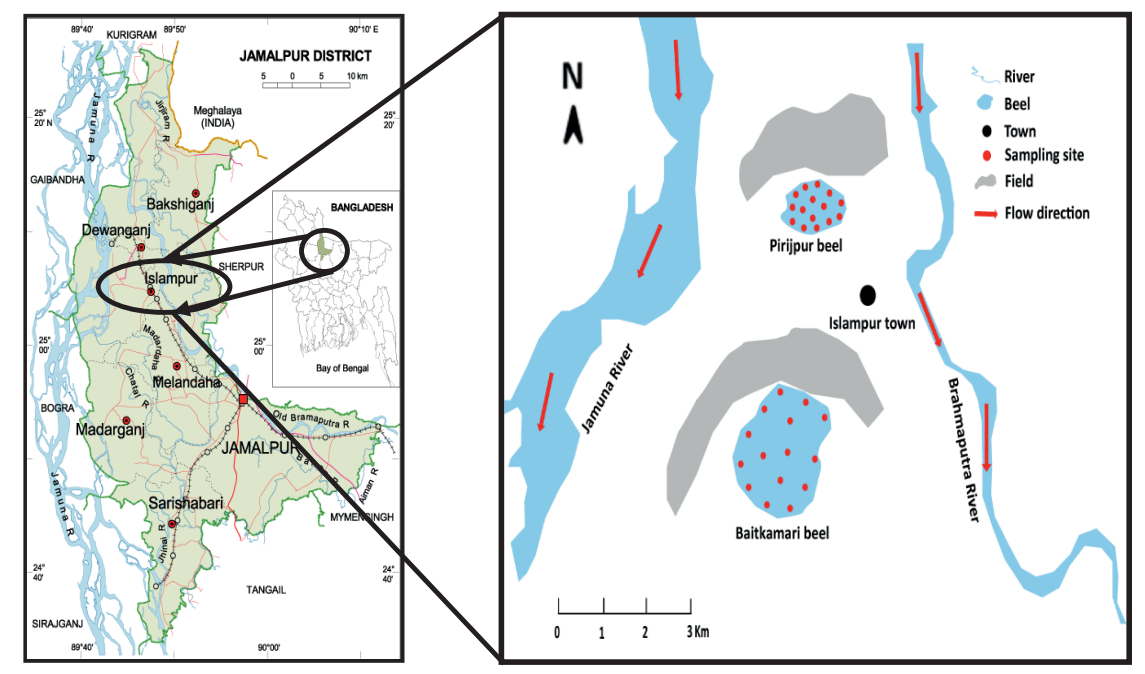

Figure 1. Map of the sampling sites. 


\subsection{Collection and preservation of samples}

Both surface water and sediment samples were collected from 15 sampling sites of both the Baitkamari as the Pirijpur beel (Fig. 1). Sampling took place in August 2016 (wet season) and in January 2017 (dry season). Surface water samples (approximately $10 \mathrm{~cm}$ below water surface) were collected using the hand grab method in $1 \mathrm{~L}$ amber glass bottles, filled up to the seal, leaving no space for air bubbles and stored at $4{ }^{\circ} \mathrm{C}$ in dark until analysis (Forrest, 2000). The physico-chemical variables of water including temperature, dissolved oxygen, $\mathrm{pH}$ and electrical conductivity were measured in situ using a portable multimeter (Hach, HQ 40d). Turbidity was measured in situ using a Secchi disk. Total alkalinity, ammonia, nitrite, nitrate and phosphate concentrations were measured in the Wet laboratory of the Bangladesh Agricultural University in Mymensingh, according to the methods described in American Public Health Association (APHA, 2005). An Ekman grab (length and width: $15 \mathrm{~cm}$ and height: 16.5 $\mathrm{cm}$ ) was used for sampling the upper sediment (upper 5-10 cm). They were homogenized, sieved (mesh size: $1 \mathrm{~mm}$ ) and stored in $500 \mathrm{~mL}$ plastic bottles at $4{ }^{\circ} \mathrm{C}$ in dark until analysis. Organic matter, sediment texture and $\mathrm{pH}$ were measured in Soil Science Department of Bangladesh Agricultural University in Mymensingh. $\mathrm{pH}$ was determined using a glass electrode $\mathrm{pH}$ meter. Organic matter was measured according to the method described by Walkley and Black (1934) and sediment texture was determined by the hydrometer method (Bouyoucos, 1962).

\subsection{Analysis of samples}

All chemicals and reagents used to analyse the pesticide residues in water and sediment samples were Sigma-Aldrich analytical grade. Standard of ten OPPs (acephate, chlorpyrifos, diazinon, dimethoate, ethion, fenitrothion, fenthion, malathion, methyl-parathion and quinalphos) were purchased from Sigma-Aldrich, FAO-UN, Italy (purity: 99.9\%). The QuEChERS (Quick, Easy, Cheap, Effective, Rugged and Safe) method with a slight modification was applied to extract and clean-up the water and sediment samples (Anastassiades et al., 2003). Briefly, $10 \mathrm{~g}$ of each sample (both water and sediment) was transferred to a $50 \mathrm{~mL}$ centrifuge tube. Then $10 \mathrm{~mL}$ acetonitrile was added to the tube and shaken vigorously for 1 minute. Subsequently $7.5 \mathrm{~g}$ anhydrous $\mathrm{MgSO}_{4}$ and $1 \mathrm{~g} \mathrm{NaCl}$ were added and the tube was shaken vigorously again and centrifuged at $5000 \mathrm{rpm}$ for 5 minutes. Approximately, a $2 \mathrm{~mL}$ aliquot of the extract was transferred to an Eppendorf containing $100 \mathrm{mg}$ primary secondary amine 
(PSA) sorbent, $150 \mathrm{mg}$ anhydrous $\mathrm{MgSO}_{4}$ and $30 \mathrm{mg}$ graphitized carbon black (GCB). They were shaken vigorously for 2 minutes and centrifuged at $10000 \mathrm{rpm}$ for 5 minutes. The final extracts were used to analyse the OPPs residue by GC-MS (GCMS-QP2010 ${ }^{\circ}$, Shimadzu, Japan). Rxi ${ }^{\circledR}-5 \mathrm{~ms}$ column (fused silica) low polarity phase: Crossbond ${ }^{\circledR} 5 \%$ diphenyl/95\% dimethyl polysiloxane (30 $\mathrm{m} \times 250 \mu \mathrm{m} \times 0.25 \mu \mathrm{m}$ ) was used to separate and analyse the extracted samples, with 1 $\mu \mathrm{L}$ volume being injected automatically. The split less mode was applied for injection and the injector inlet temperature was $250^{\circ} \mathrm{C}$. The column temperature was programmed as follows: from $90^{\circ} \mathrm{C}$ to $180^{\circ} \mathrm{C}$ for $1 \mathrm{~min}$ at $25^{\circ} \mathrm{C} / \mathrm{min}$, from 180 to $270{ }^{\circ} \mathrm{C}$ for $1 \mathrm{~min}$ at $3^{\circ} \mathrm{C} / \mathrm{min}$ and from 270 to $310^{\circ} \mathrm{C}$ for $3 \mathrm{~min}$ at $20^{\circ} \mathrm{C} / \mathrm{min}$. Helium was used as carrier gas at a constant flow rate of $1 \mathrm{~mL} / \mathrm{min}$, while nitrogen was used as make up gas. The total run time was $40 \mathrm{~min}$. The recoveries, limit of detection (LOD) and limit of quantification (LOQ) for all pesticides were listed in Table S1.

\subsection{Risk assessment}

The aquatic risk assessment of OPPs in surface water and sediment was performed using the deterministic risk quotient (RQ) method. Acute and chronic RQs were estimated by dividing the measured environmental concentrations (MECs) by the acute and the chronic predicted no effect concentrations (PNECs), respectively (Van Leeuwen, 2003). RQs were classified as no risk $(R Q<1)$ and potential risk $(R Q>1)$. Before calculating the $R Q$ s in sediment, the concentrations of pesticides in sediment were converted to concentrations in pore water due to the lack of sediment toxicity data (Zhang et al., 2015). We used the following equation:

$C_{p w}=1000 * C_{s} /\left(K_{o c} * f_{o c}\right)$

where $C_{p w}$ means pesticide concentrations in pore water, $C_{s}$ means measured pesticide concentrations in sediment, $\mathrm{K}_{\mathrm{oc}}$ means the sorption coefficient on organic carbon (see physicochemical properties in Table S2) and $f_{\text {oc }}$ means the fraction of organic carbon in sediment (see supporting information in Table S3).

When the MEC was below the LOD, acute and chronic RQs were estimated by dividing half of the LOD of that particular pesticide by the acute and the chronic PNECs, respectively (Van den Brink and Kater, 2006). Acute PNECs for Daphnia and standard test fish species were derived by dividing the acute LC50 or EC50 values by an assessment factor of 100 . Chronic PNECs for standard test algae, Daphnia and standard test fish species were calculated by dividing the no 
observed effect concentrations (NOECs) values by an assessment factor of 10 (Table S4) (Teklu et al., 2016). Eco-toxicological data for fish, Daphnia and algae were collected from FOOTPRINT Pesticide Properties Database (Table S5) (Lewis et al., 2016), except the chronic NOEC value of chlorpyrifos for Daphnia. As the FOOTPRINT Database showed much higher chronic NOEC of chlorpyrifos for Daphnia than the acute EC50, we collected this information from Palma et al. (2009) (Table S5).

The higher-tier model PERPEST v4.0.0.0 (Predicting the Ecological Risks of PESTicides; Van den Brink et al. (2002); www.perpest.wur.nl) was used to refine the risks of the MEC values in surface water and sediment (pore water) with $R Q$ values $>1$. This model used higher-tier data (e.g. microcosms and mesocosms) and included indirect effects of pesticides. The PERPEST model resulted in a prediction showing the probability of the evaluated pesticide concentration leading to no, slight or clear effects on eight grouped endpoints: algae and macrophytes, community metabolism, fish, insects, macro-crustaceans, micro-crustaceans, other macro-invertebrates and rotifers. The model is based on a case-based reasoning approach. For developing the model, empirical data resulting from freshwater model ecosystem studies (i.e. microcosm and mesocosm) performed with pesticides were extracted and classified within a database (Van den Brink et al., 2002; Ansara-Ross et al., 2008; Van Wijngaarden et al., 2005).

\subsection{Statistical analyses}

Multivariate analyses were performed to evaluate the differences in pesticide concentrations in water and sediment, their RQs, and the physico-chemical variables between beels and seasons. First, all concentrations, RQs and physico-chemical variables (except $\mathrm{pH}$ ) were Ln $(A X+1)$ transformed to approximate a normal distribution of the data. The value of the $A$ parameter was chosen in such a way that $A X$ yields 2 with $X$ being the lowest number above 0 for each concentration, $\mathrm{RQ}$ or physico-chemical variable. So the factor A was determined for each endpoint separately. For each of the 5 datasets (sediment and water concentrations and RQs and physico-chemical parameters) two permutation tests under the RDA option were performed: one testing the significance of the differences between the beels, using beel as an explanatory variable and season as covariable, and one testing the significance of the differences between the seasons, using season as an explanatory variable and beel as covariable. If either variable was significant an RDA was performed using the interaction 
between both variables as explanatory variables in order to show the correlations between the endpoints and the beels and seasons.

To assess the correlation between physico-chemical variables and pesticide concentrations in the water and sediment and their associated RQs, an RDA was performed on each of the four data sets (water and sediment concentrations and RQs) using physico-chemical parameters as explanatory variables. This yields the significance of the correlation of each physico-chemical parameters with each of the four data sets.

Spatial and seasonal differences were further assessed for all endpoints by univariate independent t-test using SPSS 23.0. The non-parametric Mann-Whitney $U$ test was used when the data did not follow a normal distribution.

\section{Results and discussion}

\subsection{Physico-chemical variables of water and sediment}

The results of the RDA showed significant differences between seasons ( $\begin{aligned} & P \leq 0 \\ & 0.0\end{aligned}$ $(\mathrm{P} \leq 0.001$ ) for the physicochemical variables of water and sediment (Fig. 2 ). Temperature was significantly higher in wet season than dry season in both beels $(P<0.001)$. For DO and nitrate, no significant difference was observed between seasons, but was between the beels $(P<$ 0.001). EC, ammonia, phosphate and silt values were not significantly different between beels and seasons. The differences were significant between seasons and beels for $\mathrm{pH}$, turbidity, total alkalinity, nitrite, sediment $\mathrm{pH}, \mathrm{OM}$ and sediment textures (sand and clay) $(\mathrm{P}<0.05)$.

The differences in physico-chemical variables of water and sediment between beels and seasons might be due to other sources of pollution than OPPs. The highest DO was measured in Baitkamari beel $(10 \mathrm{mg} / \mathrm{L})$ in wet season while lowest DO was measured in Pirijpur beel (5.2 $\mu \mathrm{g} / \mathrm{L}$ ) in same season. The significant difference of DO between beels could be explained by the occurrence of jute retting near the sampling location in Pirijpur beel during wet season. A huge amount of biomass undergoes decomposition, and herewith consuming $\mathrm{DO}$, during the jute retting process (Banik et al., 1993). The observed significant increase of temperature in Pirijpur beel during wet season (Hasan and Rahman, 2013) might have had a great influence on the decomposition of jute biomass, thus leading to increased turbidity and decreased DO. The significant reduction of DO due to jute retting was observed by earlier studies in water bodies in Bangladesh (Haque et al., 2002) and in India (Mondal and Kaviraj, 2008). 


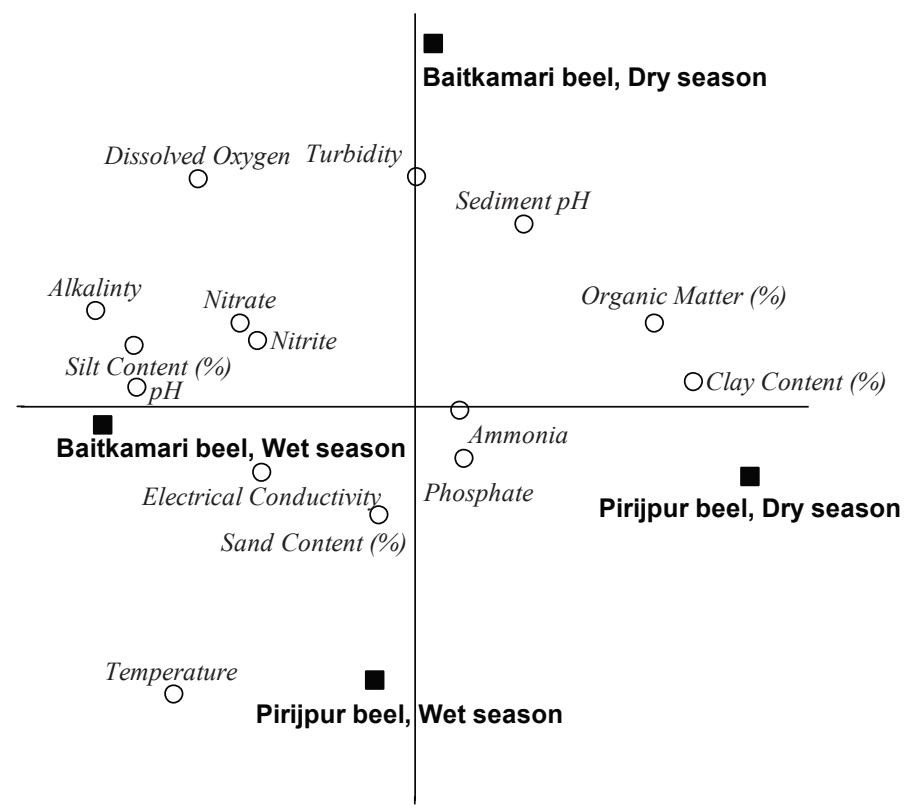

Figure 2. RDA biplot showing the difference in physico-chemical parameters between the beels and seasons. The interaction between beels and seasons explained $44 \%$ of the total variance, of which $62 \%$ is displayed on the horizontal axis and another $28 \%$ on the vertical axis.

None of the physico-chemical variables had a significant correlation with pesticide concentrations in water or sediment, nor with the water and sediment RQs. Only ammonia had a significant $(P=0.045)$ correlation with pesticide concentrations in sediment, but this significance disappears when a $p$ value correction is used to account for the number of statistical tests performed (false discovery rate, $\mathrm{P}=0.675$ ). 


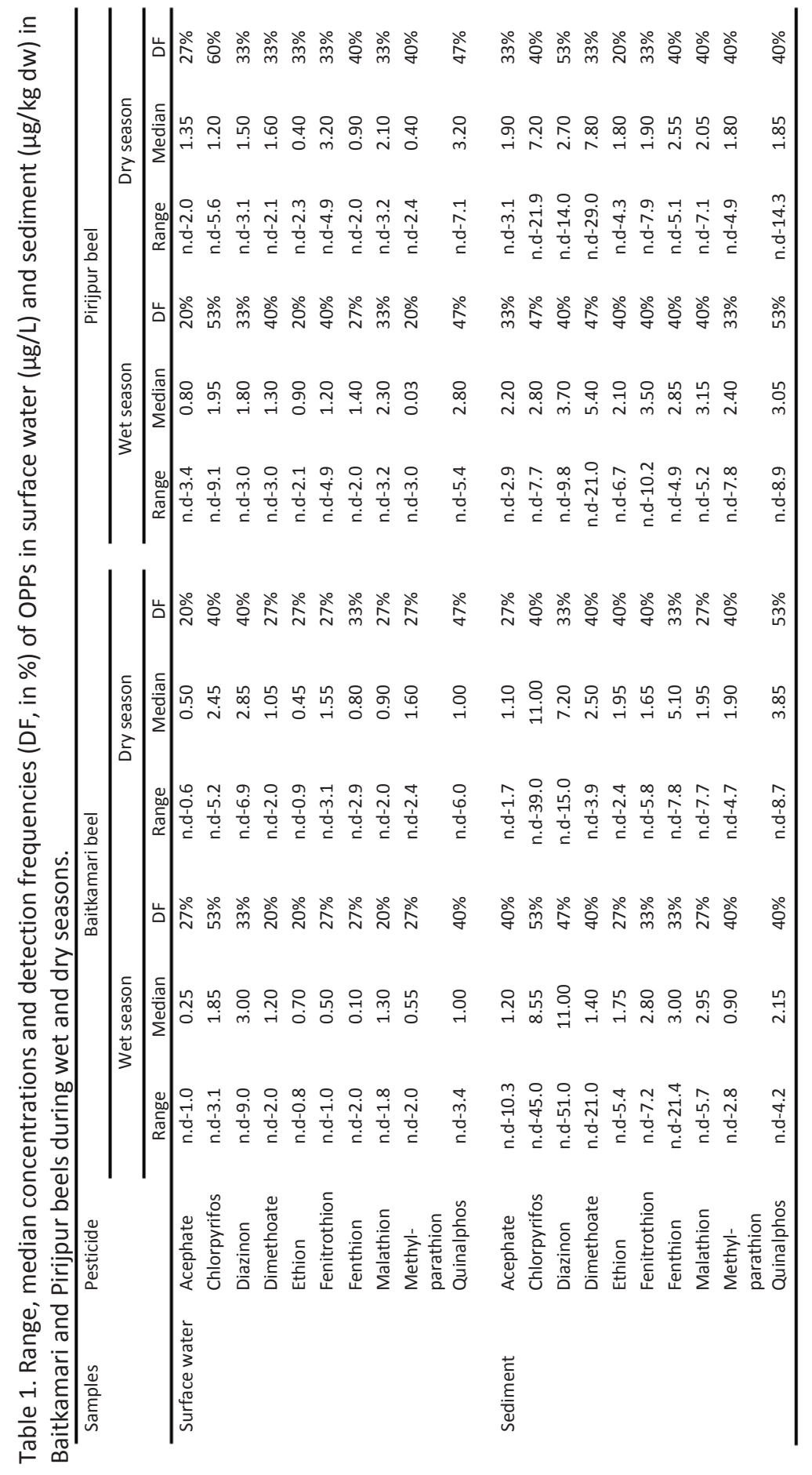




\subsection{Occurrence of OPPs in surface water}

In both beels, all of the OPPs exceeded their LOQ in surface water at least at one of the sampling sites in both seasons. The total pesticide concentration in water in Baitkamari beel ranged from n.d-0.19 $\mu \mathrm{M}$ in the wet season and n.d-0.26 $\mu \mathrm{M}$ in the dry season, while in Pirijpur beel concentrations ranged from n.d-0.34 $\mu \mathrm{M}$ in wet season and $\mathrm{n} . \mathrm{d}-0.35 \mu \mathrm{M}$ in dry season. Thus, the total OPPs concentrations in water were higher in Pirijpur beel than in Baitkamari beel during both seasons as could be expected given the level of agricultural intensification and the lower dilution factor because Pirijpur beel has a smaller depth and width compared with that of Baitkamari beel. However, RDA showed no significant differences between seasons and beels for the OPPs concentrations in water $(p>0.05)$.

In the Baitkamari beel, the most frequently detected pesticide in wet season was chlorpyrifos (53\%), followed by quinalphos (40\%) and diazinon (33\%), while in dry season those were quinalphos (47\%), chlorpyrifos (40\%) and diazinon (40\%) (Table 1). In the Pirijpur beel, the two most frequently detected pesticides were also chlorpyrifos (53\% in wet season and $60 \%$ in dry season) and quinalphos ( $47 \%$ for both seasons). Among the ten OPPs, acephate and ethion (20-27\%) were the less frequently detected pesticides in surface water in both beels during both seasons (Table 1). The highest concentration in surface water of $9.1 \mu \mathrm{g} / \mathrm{L}$ was measured for chlorpyrifos in the Pirijpur beel at S10 during wet season (Table 1). The results of this study are in line with an earlier study by Hossain et al. (2015) in the sense that they found a similar maximum chlorpyrifos concentration $(9.31 \mu \mathrm{g} / \mathrm{L})$ in lake water in Bangladesh. Most earlier studies from different sub-(tropical) countries, however, reported lower concentrations of chlorpyrifos than our study (Leong et al., 2007; Rahmanikhah et al., 2011; Chowdhury et al., 2012a; Lari et al., 2014; Dahshan et al., 2016; Wee and Aris, 2017). Abdel-Halim et al. (2006), however, reported the highest chlorpyrifos concentration as $303.8 \mu \mathrm{g} / \mathrm{L}$ in water samples collected from New Damietta drainage canal in Egypt, which is about 33 folds higher than our study. In our study, the highest diazinon concentration in water was $9 \mu \mathrm{g} / \mathrm{L}$ in the Baitkamari beel at S8 during the wet season (Table 1). Almost similar results were reported in a previous study by Hossain et al. (2015) in Bangladesh as they report a highest diazinon concentration of $7.86 \mu \mathrm{g} / \mathrm{L}$ in lake water. The highest concentrations of diazinon $(9 \mu \mathrm{g} / \mathrm{L})$ measured in this study was higher than the concentration range $(0.0001-1.2 \mu \mathrm{g} / \mathrm{L})$ reported for other sub(tropical) countries (Leong et al., 2007; Carvalho et al., 2008; Nasrabadi et al., 2011; 
Rahmanikhah et al., 2011; Chowdhury et al., 2012b; Wee and Aris, 2017) and a Mediterranean country (Masiá et al., 2015).

The observed variation in pesticide water concentrations in different studies could be explained by differences in cropping pattern, intensity of pesticide usage, distance of agricultural fields from sampling location, climate, etc. in different countries. Differences in pesticide concentrations might also be expected due to differences in efficiency of analytical verification methods used between different studies (Wee and Aris, 2017). The results, however, indicate that most of the concentration of the detected pesticides (e.g. chlorpyrifos, diazinon) were higher in our study than those found in other countries which might be due to the extensive and irrational usage of pesticide in north-west Bangladesh. For instance, earlier study by Sumon et al. (2016) reported that $70 \%$ of the studied farmers overdosed the recommended dose of pesticides (e.g. $0.6 \mathrm{~kg}$ malathion/ha; number of applications 3 times with an average application intervals of 15 days) in rice-prawn systems in south-west Bangladesh, which might have resulted in the high concentrations. Another earlier study by Dasgupta et al. (2007) found approximately $47 \%$ of the farmers overdosed, with an average overuse of $3.4 \mathrm{~kg}$ of different pesticides/ha per growing season (e.g. chlorpyrifos has been used 10 times per crops) in rice and vegetables in different parts of Bangladesh. Hence, the present study suggests future monitoring studies in the vicinity of Baitkamari and Pirijpur beels including other groups of pesticides e.g. pyrethroids (cypermethrin and alphacypermethrin) than organophosphates which were also heavily used in that region. This study also recommends to reduce the environmental risks of pesticides by firstly adhering to the recommended doses and through the adoption of integrated pest management (IPM) practices in Bangladesh.

\subsection{Occurrence of OPPs in sediment}

All OPPs were detected above the LOQ in sediment samples at least at one of the sampling sites in both Baitkamari and Pirijpur beels during both seasons. The total OPPs concentration in sediment samples in Baitkamari beel ranged from n.d-1.35 $\mu \mathrm{M}$ in wet season and n.d-0.85 $\mu \mathrm{M}$ in dry season, whereas in Pirijpur beel ranged from n.d-0.86 $\mu \mathrm{M}$ in wet season and n.d$0.93 \mu \mathrm{M}$ in dry season. The results of the RDA, however, showed no significant differences between seasons and beels for the OPPs concentrations in sediment $(p>0.05)$. 
In Baitkamari beel, the most frequently detected pesticide was chlorpyrifos (53\%), followed by diazinon (47\%), dimethoate, methyl-paration, and quinalphos $(40 \%)$ in wet season, while quinalphos (53\%) was the most detected pesticide in dry season, followed by chlorpyrifos (40\%). The three most frequently detected pesticides in the Pirijpur beel during the wet season were quinalphos (53\%), chlorpyrifos (47\%) and dimethoate $(47 \%)$, while diazinon (53\%) was the most frequently detected pesticide in dry season (Table 1). In the present study, the highest OPP sediment concentration of $51 \mu \mathrm{g} / \mathrm{kg} d w$ was measured for diazinon in the Baitkamari beel during the wet season (Table 1). Earlier studies in sub- (tropical) waterbodies reported lower concentrations $(0.56-3.79 \mu \mathrm{g} / \mathrm{kg})$ of diazinon compared to those found in our study (Musa et al., 2011; Wu et al., 2015), which may be a result of the extensive pesticide usage in our study sites. However, somewhat higher diazinon concentration in sediment have been reported for Spain, $72 \mu \mathrm{g} / \mathrm{kg}$ in the Ebro River Basin (Navarro-Ortega et al., 2010) and $175 \mu \mathrm{g} / \mathrm{kg}$ in the Guadalquivir River (Masiá et al., 2013). In our study, the highest chlorpyrifos concentration in sediment compartment of $45 \mu \mathrm{g} / \mathrm{kg} \mathrm{dw}$ was measured in the Baitkamari beel during the wet season at S6 (Table 1). Two studies from Spain found approximately three times higher chlorpyrifos concentrations than our study in the Turia River and the Llobregat River (130-141 Mg/kg), (Ccanccapa et al., 2016a; Masiá et al., 2015). However, a few earlier studies reported lower concentrations $(0.02-16 \mu \mathrm{g} / \mathrm{kg})$ of chlorpyrifos in sediment in different parts of the world than we reported in our study (Xue et al., 2005; Kanzari et al., 2012; Masiá et al., 2013; Montuori et al., 2015). Like surface water concentrations, the differences of pesticide concentrations in sediment in different studies could also be explained by the differences in cropping pattern, pesticide usage, climate, registration status of OPPs, analytical verification, etc. The results, however, indicate that most of the pesticides detected (e.g. diazinon and chlorpyrifos) in our study was higher than those found in other countries, which might be result of the extensive and irrational usage of pesticide in the vicinity of Baitkamari and Pirijpur beels in north-west Bangladesh.

In our study, the total OPPs concentrations including most of the individual compounds in both Baitkamari and Pirijpur beels during both wet and dry seasons were higher in sediments than those in surface water. Moreover, there was a positive correlation between the most of the water and sediment concentrations in both Baitkamari and Pirijpur beels. For example, the highest measured diazion and chlorpyrifos concentrations were $51 \mu \mathrm{g} / \mathrm{kg} \mathrm{dw}$ and $45 \mu \mathrm{g} / \mathrm{kg}$ 
$\mathrm{dw}$, respectively in sediments while those were $9 \mu \mathrm{g} / \mathrm{L}$ and $9.1 \mu \mathrm{g} / \mathrm{L}$, respectively in surface waters. This could be explained by the hydrophobic nature and high adsorption tendency to the organic matter content in sediment of these pesticides (Gebremariam et al., 2011).

\subsection{Risk assessment}

Variable acute and chronic RQs for each trophic level (fish, invertebrates and algae) were calculated for the OPP concentrations in the surface water and the sediment compartment for the two beels in both seasons (Table 2). However, RDA did not show any significant differences of RQs between beels and seasons in surface water and sediment $(p>0.05)$. Among the evaluated compounds, the highest acute (700) and chronic (650) RQs for fish in surface water was calculated for chlorpyrifos ( $R Q>1$ for $52 \%$ of the samples), followed by quinalphos and malathion, however, the other pesticides did not show potential risks (RQs < 1) (Table 2). The majority of the OPPs showed potential acute and chronic risks for Daphnia in surface water except acephate, dimethoate and ethion. Four pesticides including chlorpyrifos, malathion, quinalphos and fenitrothion showed higher acute and/or chronic potential risks for Daphnia than other pesticides as they showed RQs $>1$ for $100 \%$ of the evaluated samples. The highest RQs for Daphnia were also calculated for chlorpyrifos (9100), followed by quinalphos (1076), fenitrothion (563) and malathion (533). Among the 10 evaluated OPPs, none of them showed potential risk (RQs $<1$ ) for algae in surface water (Table 2). Like surface water, the highest acute (426) and chronic (395) RQs for fish were also calculated for chlorpyrifos in sediment, followed by quinalphos, malathion, diazion and fenthion, however, rest of the five OPPs (acephate, dimethoate, ethion, fenitrothion and methyl-parathion) did not show potential risks for any of the evaluated samples (RQs $<1)$. Eight out of ten OPPs showed acute and chronic potential risks for Daphina in sediment except acephate and ethion. Five pesticides including diazinon, chlorpyrifos, quinalphos, malathion and fenitrothion showed acute and/or chronic RQs $>1$ for Daphnia in sediment for $100 \%$ of the samples (Table 2). The highest RQs for Daphnia was calculated for diazinon (10167) in sediment, followed by chlorpyrifos (5533), quinalphos (892), fenitrothion (640) and malathion (520). Like surface water, none of the pesticides showed potential risks (RQs $<1)$ for algae in sediment among 10 OPPs (Table 2). 
Table 2. The percentage (\%) of acute and chronic RQs $>1$ (highest RQs) of OPPs in surface water and sediment for different aquatic organisms.

\begin{tabular}{|c|c|c|c|c|c|c|c|c|c|c|}
\hline \multirow[t]{2}{*}{ Pesticide } & \multicolumn{5}{|c|}{ Surface water } & \multicolumn{5}{|c|}{ Sediment } \\
\hline & $\begin{array}{l}\text { Acute } \\
R Q_{\text {fish }}\end{array}$ & $\begin{array}{c}\text { Acute } \\
\mathrm{RQ}_{\text {Daphnia }}\end{array}$ & $\begin{array}{l}\text { Chronic } \\
\mathrm{RQ}_{\text {fish }}\end{array}$ & $\begin{array}{l}\text { Chronic } \\
\mathrm{RQ}_{\text {Daphnia }}\end{array}$ & $\begin{array}{l}\text { Chronic } \\
\mathrm{RQ}_{\text {algae }}\end{array}$ & $\begin{array}{l}\text { Acute } \\
R Q_{\text {fish }}\end{array}$ & $\begin{array}{c}\text { Acute } \\
\mathrm{RQ}_{\text {Daphnia }}\end{array}$ & $\begin{array}{c}\text { Chronic } \\
\mathrm{RQ}_{\text {fish }}\end{array}$ & $\begin{array}{l}\text { Chronic } \\
\mathrm{RQ}_{\text {Daphnia }}\end{array}$ & $\begin{array}{l}\text { Chronic } \\
\mathrm{RQ}_{\text {algae }}\end{array}$ \\
\hline Acephate & 0 & 0 & 0 & 0 & 0 & 0 & 0 & 0 & 0 & 0 \\
\hline Chlorpyrifos & $\begin{array}{c}52 \\
(700)\end{array}$ & $\begin{array}{l}\text { a100 } \\
(9100)\end{array}$ & $\begin{array}{c}52 \\
(650)\end{array}$ & $\begin{array}{l}{ }^{b} 100 \\
(3033)\end{array}$ & 0 & $\begin{array}{c}67 \\
(425.7)\end{array}$ & $\begin{array}{c}100 \\
(5533)\end{array}$ & $\begin{array}{c}58 \\
(395.3)\end{array}$ & $\begin{array}{c}100 \\
(1844)\end{array}$ & 0 \\
\hline Diazinon & 0 & $\begin{array}{c}35 \\
(900)\end{array}$ & 0 & $\begin{array}{c}33 \\
(160.7)\end{array}$ & 0 & $\begin{array}{c}3 \\
(3.3)\end{array}$ & $\begin{array}{c}100 \\
(10167)\end{array}$ & $\begin{array}{c}2 \\
(1.5)\end{array}$ & $\begin{array}{c}100 \\
(1816)\end{array}$ & 0 \\
\hline Dimethoate & 0 & 0 & 0 & 0 & 0 & 0 & $\begin{array}{c}12 \\
(4.4)\end{array}$ & $\begin{array}{c}7 \\
(2.2)\end{array}$ & $\begin{array}{c}30 \\
(22.2)\end{array}$ & 0 \\
\hline Ethion & 0 & 0 & 0 & 0 & 0 & 0 & 0 & 0 & 0 & 0 \\
\hline Fenitrothion & 0 & $\begin{array}{c}30 \\
(57)\end{array}$ & 0 & $\begin{array}{c}{ }^{c} 100 \\
(563.2)\end{array}$ & 0 & 0 & $\begin{array}{c}38 \\
(64.7)\end{array}$ & 0 & $\begin{array}{c}100 \\
(639.6)\end{array}$ & 0 \\
\hline Fenthion & 0 & $\begin{array}{c}30 \\
(50)\end{array}$ & 0 & 0 & 0 & $\begin{array}{c}2 \\
(2.5)\end{array}$ & $\begin{array}{c}35 \\
(342)\end{array}$ & 0 & 0 & 0 \\
\hline Malathion & $\begin{array}{c}28 \\
(17.8)\end{array}$ & $\begin{array}{l}\mathrm{d} 100 \\
(400)\end{array}$ & 0 & $\begin{array}{c}\text { e100 } \\
(533.3)\end{array}$ & 0 & $\begin{array}{c}30 \\
(17.3)\end{array}$ & $\begin{array}{c}100 \\
(390)\end{array}$ & 0 & $\begin{array}{c}100 \\
(520)\end{array}$ & 0 \\
\hline $\begin{array}{l}\text { Methyl } \\
\text { parathion }\end{array}$ & 0 & $\begin{array}{c}25 \\
(41)\end{array}$ & 0 & 0 & 0 & 0 & $\begin{array}{c}92 \\
(457)\end{array}$ & 0 & 0 & 0 \\
\hline Quinalphos & $\begin{array}{c}45 \\
(142) \\
\end{array}$ & $\begin{array}{c}100 \\
(1076)\end{array}$ & 0 & 0 & 0 & $\begin{array}{c}48 \\
(117.7)\end{array}$ & $\begin{array}{c}100 \\
(891.5) \\
\end{array}$ & 0 & 0 & 0 \\
\hline
\end{tabular}

${ }^{a}$ For acute RQs of chlorpyrifos on Daphnia in surface water, $46 \%$ of the samples showed RQs $>1$ when this pesticide was not even detected and rest of the $54 \%$ of the samples showed RQs $>1$ when they were calculated with respective measured concentrations.

${ }^{b}$ For chronic RQs of chlorpyrifos on Daphnia in surface water, 48\% of the samples showed RQs $>1$ when this pesticide was not even detected and rest of the $52 \%$ of the samples showed RQs $>1$ when they were calculated with respective measured concentrations.

${ }^{\mathrm{C}}$ For chronic RQs of fenitrothion on Daphnia in surface water, 68\% of the samples showed RQs > 1 when this pesticide was not even detected and rest of the $32 \%$ of the samples showed RQs $>1$ when they were calculated with respective measured concentrations.

${ }^{d}$ For acute RQs of malathion on Daphnia in surface water, $70 \%$ of the samples showed RQs $>1$ when this pesticide was not even detected and rest of the $30 \%$ of the samples showed RQs $>1$ when they were calculated with respective measured concentrations.

eFor chronic RQs of malathion on Daphnia in surface water, $72 \%$ of the samples showed RQs $>1$ when this pesticide was not even detected and rest of the $28 \%$ of the samples showed RQs $>1$ when they were calculated with respective measured concentrations. 
To assess the risks of pesticides for sediment-dwelling organisms, the measured sediment concentrations in our study were compared to the sediment toxicity data derived in earlier studies. For this, all sediment concentrations were normalized to sediment organic carbon (OC) content (For rationale, see Diepens et al. (2017)). The results indicated that the highest concentrations of two pesticides (diazinon and chlorpyrifos) in this study were lower than the calculated threshold values for Chironomus sp. in previous studies. For example, Ding et al. (2011) calculated the $10-\mathrm{d}$ LC50 value of diazinon $(54,300 \mu \mathrm{g} / \mathrm{kg} \mathrm{OC})$ for Chironomus dilutus, which is approximately eight times higher than measured $(6375 \mu \mathrm{g} / \mathrm{kg} \mathrm{OC})$ in our study. However, earlier studies reported 10-d LC50 of chlorpyrifos for Chironomus tentans of 9956 $\mu \mathrm{g} / \mathrm{kg}$ OC (Ankley et al., 1994) and for Chironomus dilutus of 10,800 $\mu \mathrm{g} / \mathrm{kg}$ OC (Harwood et al., 2009), which is almost two times higher than our study (4500 $\mathrm{\mu g} / \mathrm{kg} \mathrm{OC}$ ).

In our study, several pesticides showed very high RQs (RQ $>1)$ in water and sediment, demonstrating a high potential risks to cause adverse effects for aquatic organisms. However, the potential risks of three pesticides (chlorpyrifos, malathion and fenitrothion) is present in surface water for Daphnia even without detection (Table 2). This, because the LOD of chlorpyrifos, malathion and fenitrothion in surface water was higher than the acute and/or chronic PNECs for Daphnia. Hence, the present study suggests that the analytical verification for several pesticides should be improved in future studies. In the present study, the invertebrate Daphnia was found to be at higher risk than other organisms (i.e. fish and algae). The reason behind the high acute and chronic RQs for Daphnia might be due to a combination of high MEC values for several sampling sites and relatively low PNEC values of these pesticides (Maltby et al., 2005). The results of this study are in accordance with one of the previous studies in tropical Thailand in the sense that they also calculated high RQs of different pesticides based on the sensitivity of Daphnia (Satapornvanit et al., 2004). Most of the earlier studies, however, calculated much lower RQ values of different pesticides for aquatic organisms than we reported in our study. For instance, one study from Spain by Ccanccapa et al. (2016a) calculated the highest RQ value of chlorpyrifos for Daphnia of 9 for the Turia River. Ccanccapa et al. (2016b) also reported the maximum RQ value of this pesticide of 3.6 for Daphnia in Ebro River, which is several hundred folds lower than we calculated for chlorpyrifos in our study. Almost similar, lower RQ values of chlorpyrifos than our study have been reported for surface water in different parts of the world (Thomatou et al., 2013; Stamatis et 
al., 2013; Montuori et al., 2016; Wee and Aris, 2017). The reason of the high differences in RQs could be due to the use of different PNECs in different studies. The higher RQs values of different pesticides calculated in our study compared to earlier studies for aquatic organisms (i.e. Daphnia and fish) indicate the higher concentrations of pesticides measured in both Baitkamari and Pirijpur beel. The extensive and irrational use of pesticides (e.g. chlorpyrifos, diazinon and quinalphos) might be the main reason behind the high concentrations measured in the vicinity of Baitkamari and Pirijpur beels of north-west Bangladesh (Dasgupta et al., 2007).

Table 3 . The high probability ( $\geq 50 \%$ ) of clear effects of different pesticides in water and sediment (pore water) for several endpoints.

\begin{tabular}{|c|c|c|c|c|c|c|c|c|}
\hline \multirow[t]{2}{*}{ Pesticides } & \multicolumn{2}{|c|}{ Fish } & \multicolumn{2}{|c|}{ Insects } & \multicolumn{2}{|c|}{ Macro-crustaceans } & \multicolumn{2}{|c|}{ Micro-crustaceans } \\
\hline & Water & Sediment & Water & Sediment & Water & Sediment & Water & Sediment \\
\hline Chlorpyrifos & 50 & $\mathrm{NI}$ & 96 & 92 & 94 & 90 & 93 & 88 \\
\hline Diazinon & $\mathrm{NI}$ & $\mathrm{NI}$ & 81 & 100 & 73 & 95 & 77 & 98 \\
\hline Dimethoate & NC & $\mathrm{NI}$ & NC & 66 & NC & 54 & NC & 57 \\
\hline Fenitrothion & $\mathrm{NI}$ & $\mathrm{NI}$ & 78 & 80 & 71 & 73 & 69 & 69 \\
\hline Fenthion & $\mathrm{NI}$ & 52 & 84 & 98 & 79 & 93 & 76 & 94 \\
\hline $\begin{array}{l}\text { Methyl- } \\
\text { parathion }\end{array}$ & $\mathrm{NI}$ & $\mathrm{NI}$ & 73 & 92 & 59 & 87 & 64 & 88 \\
\hline Quinalphos & $\mathrm{NI}$ & $\mathrm{NI}$ & 88 & 87 & 85 & 82 & 83 & 82 \\
\hline
\end{tabular}

$\mathrm{NC}=$ Not calculated by the PERPEST model since they did not show potential risk $(\mathrm{RQ}<1)$ by RQ method; $\mathrm{NI}=$ Not included while any pesticides showed $<50 \%$ probability of clear effects for any of the endpoints both in surface and pore water by PERPEST model.

The PERPEST model showed high probabilities of clear effects for aquatic insects, macro- and micro-crustaceans for both surface water and sediment for nine out of ten OPPs (except malathion in both cases). A high probability of clear effect is considered when OPPs pose a probability of higher than $50 \%$ (Sumon et al., 2016). The highest probability of clear effects in surface water were calculated for chlorpyrifos, followed by quinalphos, fenthion, diazinon and fenitrothion, and in sediment for diazinon, followed by fenthion, chlorpyrifos, methylparathion, quinalphos and fenitrothion (Table 3). The high probability of clear effect for fish was calculated only for chlorpyrifos in surface water while this was calculated for fenthion in sediment. So, the results of the PERPEST model refined the potential clear risks of four pesticides i.e. chlorpyrifos, diazinon, quinalphos and fenitrothion in surface water and 
sediment, which were already derived from the RQ-based risk assessment approach (Table 3). The probability of clear effects for algae and macrophytes, community metabolism, rotifers and other macro-invertebrates in both surface water and sediment, however, was also calculated for these pesticides, thus indicating the indirect effects on these endpoints. The observed indirect effects could be explained by the fact that the presence of these OPPs could lead to the eutrophication in Baitkamari and Pirijpur beels of north-west Bangladesh (Hela et al., 2005).

\section{Conclusions}

This study indicated that chlorpyrifos, diazinon, quinalphos and fenitrothion showed high risks in aquatic ecosystems in the vicinity of Baitkamari and Pirijpur beel of north-west Bangladesh. One of the main reasons of high risks in aquatic ecosystems posed by these OPPs could be their irrational use (i.e. overdose), however, we suggest further studies on the exact usage of pesticides by the farmers in that region. The study recommends to reduce the use of pesticides to the recommended doses, but preferably to lower dosages by promoting integrated pest management (IPM) practices in Bangladesh. We also suggest future studies (e.g. modelling study) to determine the route of pesticide exposure to the aquatic systems so that pesticide contamination may be reduced through the proper implementation of mitigation measures.

\section{Acknowledgements}

The study is financially supported by NUFFIC-NICHE-BGD 156 project. We are thankful to National Food Safety Laboratory (NFSL), Mohakhali, Dhaka-1212, Bangladesh for chemical analysis. The authors would like to express the gratitude to Md. Rakibul Islam, Chayan Chandra Sarker, Md. Helal Uddin and Al Emran for their kind help in sample collection. The authors would also like to thank Changgui Pan for his kind help in making the map. 


\section{Supporting Information}

Table S1. LOD, LOQ and recoveries (mean \pm SD; $n=3$ ) of OPPs in surface water (spiked concentrations of $100 \mu \mathrm{g} / \mathrm{L}$ ) and sediment (spiked concentrations of $100 \mu \mathrm{g} / \mathrm{kg}$ ).

\begin{tabular}{lcccccc}
\hline Pesticide name & \multicolumn{5}{c}{ Surface water } & \multicolumn{2}{c}{ Sediment } \\
\cline { 2 - 7 } & $\begin{array}{c}\text { LOD } \\
(\mu \mathrm{g} / \mathrm{L})\end{array}$ & $\begin{array}{c}\mathrm{LOQ} \\
(\mu \mathrm{g} / \mathrm{L})\end{array}$ & Recoveries $(\%)$ & $\begin{array}{c}\mathrm{LOD} \\
(\mu \mathrm{g} / \mathrm{kg})\end{array}$ & $\begin{array}{c}\mathrm{LOQ} \\
(\mu \mathrm{g} / \mathrm{kg})\end{array}$ & Recoveries $(\%)$ \\
\hline Acephate & 0.001 & $<0.001$ & $96.8 \pm 5.75$ & 0.16 & 0.53 & $73.1 \pm 4.80$ \\
Chlorpyrifos & 0.02 & 0.07 & $87.5 \pm 4.88$ & 0.25 & 0.82 & $79.1 \pm 4.50$ \\
Diazinon & 0.01 & 0.03 & $87.8 \pm 7.81$ & 0.50 & 1.65 & $73.0 \pm 4.58$ \\
Dimethoate & 0.03 & 0.09 & $94.4 \pm 6.25$ & 0.23 & 0.76 & $77.3 \pm 4.16$ \\
Ethion & 0.09 & 0.29 & $85.1 \pm 8.02$ & 0.30 & 0.99 & $68.7 \pm 4.51$ \\
Fenitrothion & 0.02 & 0.06 & $83.3 \pm 4.04$ & 0.25 & 0.82 & $82.3 \pm 4.04$ \\
Fenthion & 0.01 & 0.03 & $90.2 \pm 3.91$ & 0.08 & 0.26 & $71.3 \pm 3.79$ \\
Malathion & 0.08 & 0.26 & $98.6 \pm 3.08$ & 0.29 & 0.96 & $83.8 \pm 5.84$ \\
Methyl parathion & 0.01 & 0.03 & $93.5 \pm 4.10$ & 0.06 & 0.19 & $73.7 \pm 5.50$ \\
Quinalphos & 0.07 & 0.23 & $98.0 \pm 5.29$ & 0.12 & 0.39 & $77.0 \pm 4.58$ \\
\hline
\end{tabular}

Table S2. Physico-chemical properties of 10 OPPs (Source: Lewis et al., 2016).

\begin{tabular}{|c|c|c|c|c|c|c|c|c|}
\hline $\begin{array}{l}\text { Pesticide } \\
\text { name }\end{array}$ & acAS No. & $\begin{array}{c}\text { Molecular } \\
\text { mass }(\mathrm{g} / \mathrm{mol})\end{array}$ & $\begin{array}{l}\text { bWater } \\
\text { solubility } \\
\text { (mg/L) }\end{array}$ & ${ }^{c} K_{o w}$ & $\begin{array}{l}\text { dVapour } \\
\text { pressure } \\
(\mathrm{mPa})\end{array}$ & $\mathrm{e}_{\mathrm{oc}}$ & $\begin{array}{l}\text { fDT50 } \\
\text { water } \\
\text { hydrolysis } \\
\text { (d) }\end{array}$ & $\begin{array}{c}\text { gHenry } \\
\text { coefficient } \\
\left(\mathrm{Pa} \mathrm{m}^{3} \mathrm{moL}^{-1}\right)\end{array}$ \\
\hline Acephate & $30560-19-1$ & 183.17 & 790000 & 0.14 & 0.226 & 302 & 50 & $5.15 \times 10^{-08}$ \\
\hline Chlorpyrifos & $2921-88-2$ & 350.89 & 1.05 & 50100 & 1.43 & 8151 & 25.5 & $4.78 \times 10^{-01}$ \\
\hline Diazinon & $333-41-5$ & 304.35 & 60 & 4900 & 11.97 & 609 & 138 & $6.09 \times 10^{-02}$ \\
\hline Dimethoate & $60-51-5$ & 229.26 & 39800 & 50.6 & 0.247 & $287^{*}$ & 68 & $1.42 \times 10^{-06}$ \\
\hline Ethion & $563-12-2$ & 384.48 & 2 & 117000 & 0.2 & 10000 & 146 & $3.85 \times 10^{-02}$ \\
\hline Fenitrothion & $122-14-5$ & 277.23 & 19 & 2090 & 0.676 & 2000 & 183 & $9.86 \times 10^{-03}$ \\
\hline Fenthion & $55-38-9$ & 278.33 & 4.2 & 6920 & 0.37 & 1500 & 1000 & $2.40 \times 10^{-02}$ \\
\hline Malathion & $121-75-5$ & 330.36 & 148 & 562 & 3.1 & 1800 & 6.2 & $1.00 \times 10^{-03}$ \\
\hline $\begin{array}{l}\text { Methyl } \\
\text { parathion }\end{array}$ & 298-00-0 & 263.21 & 55 & 1000 & 0.2 & 240 & 21 & $8.57 \times 10^{-03}$ \\
\hline Quinalphos & $13593-03-8$ & 298.3 & 17.8 & 2750 & 0.346 & 1465 & 39 & $4.70 \times 10^{-03}$ \\
\hline
\end{tabular}

${ }^{a}$ CAS No.- Chemical Abstracts Service Number of pesticides; ${ }^{b}$ Water solubility at reference temperature $\left(20^{\circ} \mathrm{C}\right)$; ${ }^{\mathrm{C}} \mathrm{K}_{\mathrm{ow}}$ - Octanol-water partition coefficient; ${ }^{\mathrm{d}} \mathrm{Vapour}$ pressure at $25^{\circ} \mathrm{C}$; ${ }^{\mathrm{e}} \mathrm{K}_{\mathrm{oc}}$ - Sorption coefficient on organic carbon ("Koc is collected from Sharma et al. 2013 because it is not available in database) ; ${ }^{\mathrm{f}} \mathrm{DT50}$ water hydrolysis- Halflife in water at $\mathrm{pH}=7$ and $20^{\circ} \mathrm{C}$; ${ }^{8} \mathrm{Henry}$ coefficient at $25^{\circ} \mathrm{C}$. 
Table S3. Foc (OM\%/1.724; see FOCUS, 2014 for rational) values of sediment in Baitkamari and Pirijpur beel during wet and dry season.

\begin{tabular}{ccccc}
\hline Site & \multicolumn{2}{c}{ Baitkamari beel } & \multicolumn{2}{c}{ Pirijpur beel } \\
\cline { 2 - 5 } & Wet & Dry & Wet & Dry \\
\hline 1 & 1.13 & 1.81 & 1.28 & 1.48 \\
2 & 0.72 & 1.60 & 0.92 & 1.25 \\
3 & 0.97 & 1.15 & 1.25 & 1.86 \\
4 & 1.00 & 1.58 & 1.38 & 2.10 \\
5 & 1.22 & 1.47 & 1.46 & 1.71 \\
6 & 1.00 & 1.03 & 1.44 & 1.57 \\
7 & 1.00 & 1.68 & 1.17 & 1.45 \\
8 & 1.02 & 1.83 & 0.93 & 1.84 \\
9 & 1.15 & 1.39 & 0.92 & 1.22 \\
10 & 1.11 & 1.90 & 1.35 & 1.08 \\
11 & 1.17 & 1.12 & 1.40 & 1.42 \\
12 & 0.82 & 1.08 & 1.25 & 1.80 \\
13 & 1.25 & 1.26 & 1.46 & 1.51 \\
14 & 1.22 & 1.62 & 0.97 & 1.89 \\
15 & 1.23 & 1.42 & 1.22 & 1.84 \\
\hline
\end{tabular}

Table S4. Acute and chronic PNECs of OPPs for fish, Daphnia and algae.

\begin{tabular}{lccccc}
\hline Pesticide name & \multicolumn{4}{l}{ Acute PNECs $(\mu \mathrm{g} / \mathrm{L})$} & \multicolumn{3}{c}{ Chronic PNECs $(\mu \mathrm{g} / \mathrm{L})$} & \\
\cline { 2 - 6 } & Fish & Daphnia & Fish & Daphnia & Algae \\
\hline Acephate & 1100 & 672 & 470 & 4300 & 98000 \\
Chlorpyrifos & 0.013 & 0.001 & 0.014 & 0.003 & 4.3 \\
Diazinon & 31 & 0.01 & 70 & 0.056 & 1000 \\
Dimethoate & 302 & 20 & 40 & 4 & 3200 \\
Ethion & 5 & $\mathrm{NA}$ & $\mathrm{NA}$ & $\mathrm{NA}$ & $\mathrm{NA}$ \\
Fenitrothion & 13 & 0.086 & 8.8 & 0.0087 & 130 \\
Fenthion & 8 & 0.058 & $\mathrm{NA}$ & $\mathrm{NA}$ & 179 \\
Malathion & 0.18 & 0.008 & 9.1 & 0.006 & 1300 \\
Methyl parathion & 27 & 0.073 & $\mathrm{NA}$ & $\mathrm{NA}$ & 300 \\
Quinalphos & 0.05 & 0.0066 & $\mathrm{NA}$ & $\mathrm{NA}$ & $\mathrm{NA}$ \\
\hline
\end{tabular}

NA = Not available 
Table S5. Acute and chronic toxicity data of OPPs for fish, Daphnia and algae (Source: Lewis et al., 2016).

\begin{tabular}{lccccc}
\hline Pesticide name & \multicolumn{2}{c}{ Acute toxicity $(\mu \mathrm{g} / \mathrm{L})$} & \multicolumn{3}{c}{ Chronic toxicity $(\mu \mathrm{g} / \mathrm{L})$} \\
\cline { 2 - 6 } & $\begin{array}{c}\text { Fish }(96-\mathrm{h} \\
\text { LC50) }\end{array}$ & $\begin{array}{c}\text { Daphnia } \\
(48-\mathrm{h}\end{array}$ & $\begin{array}{c}\text { Fish }(21-\mathrm{d} \\
\text { NOEC) }\end{array}$ & $\begin{array}{c}\text { Daphnia }(21-\mathrm{d} \\
\text { NOEC) }\end{array}$ & $\begin{array}{c}\text { Algae } \\
(72-\mathrm{h} \text { EC50/96-h } \\
\text { NOEC) }\end{array}$ \\
\cline { 2 - 6 } Acephate & 110000 & 67200 & 4700 & 43000 & 980000 \\
Chlorpyrifos & 1.3 & 0.1 & 0.14 & $0.03^{\mathrm{a}}$ & 43 \\
Diazinon & 3100 & 1 & 700 & 0.56 & $>10000$ \\
Dimethoate & 30200 & 2000 & 400 & 40 & 32000 \\
Ethion & 500 & NA & NA & NA & NA \\
Fenitrothion & 1300 & 8.6 & 88 & 0.087 & 1300 \\
Fenthion & 800 & 5.8 & NA & NA & 1790 \\
Malathion & 18 & 0.8 & 91 & 0.06 & 13000 \\
Methyl parathion & 2700 & 7.3 & NA & NA & 3000 \\
Quinalphos & 5 & 0.66 & NA & NA & NA \\
\hline
\end{tabular}

NA = Not available; ${ }^{a}$ The chronic 21-d NOEC of chlorpyrifos for Daphnia was collected from Palma et al. (2009). 


\section{Chapter 4}

\section{Effects of imidacloprid on the ecology of sub-tropical freshwater microcosms}

Kizar Ahmed Sumon, Afifat Khanam Ritika, Edwin T.H.M. Peeters, Harunur Rashid, Roel H. Bosma, Md. Shahidur Rahman, Mst. Kaniz Fatema, Paul J. Van den Brink

This chapter has been published in Environmental Pollution (2018), 236: 432-441. 


\section{Abstract}

The neonicotinoid insecticide imidacloprid is used in Bangladesh for a variety of crop protection purposes. Imidacloprid may contaminate aquatic ecosystems via spray drift, surface runoff and ground water leaching. The present study aimed at assessing the fate and effects of imidacloprid on structural (phytoplankton, zooplankton, macroinvertebrates and periphyton) and functional (organic matter decomposition) endpoints of freshwater, subtropical ecosystems in Bangladesh. Imidacloprid was applied weekly to 16 freshwater microcosms (PVC tanks containing $400 \mathrm{~L}$ de-chlorinated tap water) at nominal concentrations of $0,30,300,3000 \mathrm{ng} / \mathrm{L}$ over a period of 4 weeks. Results indicated that imidacloprid concentrations from the microcosm water column declined rapidly. Univariate and multivariate analysis showed significant effects of imidacloprid on the zooplankton and macroinvertebrate community, some individual phytoplankton taxa, and water quality variables (i.e. DO, alkalinity, ammonia and nitrate), with Cloeon sp., Diaptomus sp. and Keratella sp. being the most affected species, i.e. showing lower abundance values in all treatments compared to the control. The observed high sensitivity of Cloeon sp. and Diaptomus sp. was confirmed by the results of single species tests. No significant effects were observed on the species composition of the phytoplankton, periphyton biomass and organic matter decomposition for any of the sampling days. Our study indicates that (sub-)tropical aquatic ecosystems can be much more sensitive to imidacloprid compared to temperate ones. 


\section{Introduction}

The shift from traditional to modern and intensive agricultural practices in developing countries like Bangladesh, has led to an increasing use of pesticides over the last decades (Rahman, 2013). Pesticide use in Bangladesh raised from 7,350 metric tons in 1992 to 45,172 metric tons in 2010 (Ali et al., 2018). This was partly due to governments' policy to stimulate chemical control measures against insect pests to increase crop production as well as to prevent pre- and post-harvest crop losses (Shahjahan et al., 2017; Sumon et al., 2016).

Imidacloprid ((E)-1-(6-chloro-3-pyridylmethyl)- $N$-nitroimidazolidin-2-ylideneamine; CAS No. 138261-41-3) is a neonicotinoid synthetic insecticide and veterinary substance. It was first introduced in the USA in the 1990s to control insect pests and is now registered in about 120 countries for use in more than 140 crops including rice, maize, cotton, potatoes, tomatoes, sugar beets and various greenhouse-grown plants (Jeschke and Nauen, 2008; Morrissey et al., 2015; Lewis et al., 2016).

Imidacloprid may affect non-target aquatic organisms via exposure due to spray drift (Hilz and Vermeer, $\left.\begin{array}{llllll}2 & 0 & 1 & 2\end{array}\right)$ and runoff due to its' high solubility in water (Armbrust and Peeler, $\left.\begin{array}{llllllll}2 & 0 & 0 & 2\end{array}\right)$. After entering into water bodies, the dissipation time 50\% (DT50) of imidacloprid merely depends on photolysis, however, variation in DT50 water was observed between different water bodies. For example, the European Food Safety Authority (EFSA) reported DT50 water values ranging from 30 to 150 days for three water-sediment studies performed at $22^{\circ} \mathrm{C}$ in laboratory in the dark (EFSA, 2008), indicating a likely long-term exposure of imidacloprid to aquatic ecosystem when light conditions are poor. However, imidacloprid was found to dissipate very rapidly in different studies under UV light due to photolysis (e.g. Lavine et al., 2010). Colombo et al. (2013) recorded a DT50 of 1.2 day from the water column monitored for 28 days in fieldbased microcosms in Germany, whereas a DT50 of 8.2 day was reported in a pond microcosm in Germany (Posthuma-Doodeman, 2008). A DT50 of 1 day was recorded by Thuyet et al. (2011) for a rice paddy system in autumn in Japan. However, imidacloprid has been detected worldwide in surface waters at concentrations ranging from 0.001 to $320 \mu \mathrm{g} / \mathrm{L}$, the highest of which was found in Netherlands (Morrissey et al., 2015). Imidacloprid has been found in aquatic ecosystems at $3.29 \mathrm{\mu g} / \mathrm{L}$ in the California's agricultural regions in the USA (Starner and Goh, 2012) and up to $11.9 \mu \mathrm{g} / \mathrm{L}$ in Canadian agricultural areas (CCME, 2007). The field 
monitoring data on imidacloprid is only available for temperate countries, but the systemic study from sub- (tropical) countries is lacking.

During the past years, a large number of studies focusing on the toxicity of imidacloprid to the aquatic environment have been published, partly also due to the debate on the negative relationship between the use of neonicotinoids and non-target beneficial invertebrates, in particular arthropods (EASAC, 2015; Van Dijk et al., 2013; Vijver and Van den Brink, 2014). Both single species laboratory tests (Alexander et al., 2007; Stoughton et al., 2008; Roessink et al., 2013; Cavallaro et al., 2017; Van den Brink et al., 2016) and model ecosystem studies (Hayasaka et al., 2012a; Mohr et al., 2012; Colombo et al., 2013) using imidacloprid, were all conducted in temperate regions. To date no study seem to have been undertaken to investigate the sensitivity of imidacloprid on the aquatic organisms in the sub-tropics and tropics. Van den Brink et al. (2016) found that a reproducing, summer generations of several arthropods were more sensitive to imidacloprid than their non-reproducing, winter generation. Earlier studies demonstrated that higher temperature also might increase the sensitivity of arthropods (Camp and Buchwalter, 2016; Van den Brink et al., 2016). Hence, a difference in sensitivity between tropical and temperate communities to imidacloprid can be hypothesised. To address this knowledge gap, the present study aimed at assessing fate and effects of imidacloprid on the structural (phytoplankton, zooplankton, macroinvertebrates, and periphyton) and functional (organic matter decomposition) endpoints of freshwater ecosystems located in the sub-tropical country Bangladesh.

\section{Materials and methods}

Most of the materials and methods used for the microcosm experiment have been described by Rico et al. (2014).

\subsection{Design of the microcosm study and acute toxicity tests}

The present study was conducted in sixteen freshwater microcosms at the Faculty of Fisheries, Bangladesh Agricultural University (Mymensingh, Bangladesh; $24.7434^{\circ} \mathrm{N}, 90.3984^{\circ} \mathrm{E}$ ). The open experimental area was roofed with transparent plastic slates (Fig. S1). Each microcosm comprised of a PVC tank (diameter: $172 \mathrm{~cm}$; total height: $78 \mathrm{~cm}$ ) which was coated with nontoxic epoxy paint. Each microcosm was initially filled with $4.5 \mathrm{~cm}$ of sediment (collected from nearby ponds of Bangladesh Agricultural University campus) and $400 \mathrm{~L}$ of tap water (a layer of 
$56 \mathrm{~cm}$ ). Microcosm water was allowed to dissipate the possible chlorine residues for one week. Each system was gently aerated to provide some water movement. The systems were stocked with algae and invertebrates collected from same ponds where sediment was collected. These ponds were selected because they were uncontaminated sources (as agricultural activities were not practised near the Bangladesh Agricultural University campus) and were quite biodiverse in terms of algae and invertebrates. Macroinvertebrates were stocked by distributing an equal numbers of each of the taxa into each microcosm, while equal amounts of concentrated plankton in terms of volume were added into each microcosm. The algae and invertebrate communities were allowed to develop themselves over a pretreatment period of 6 weeks. During the pre-treatment period, every two weeks about $20 \%$ of the water volume was exchanged between the microcosms to promote the uniformity in the structure of the communities between the microcosms. As recommended by Daam and Van den Brink (2011), urea (containing $1.4 \mathrm{mg} / \mathrm{L}$ nitrogen) and trisodium phosphate $(0.18 \mathrm{mg} / \mathrm{L}$ phosphorus) were administered every two weeks to the systems during the experimental period.

For the acute toxicity tests, Cloeon sp. and Diaptomus sp. were collected from the nearby ponds of Bangladesh Agricultural University campus (see some photos of Cloeon sp. and Diaptomus sp. in Fig. S2 and S3, respectively). Cloeon sp. was transferred in an aerated plastic bucket with a mixture of pond and de-chlorinated test water first and then only in test water to acclimate to the laboratory conditions for at least 3 days at ambient temperature. During the acclimation period, they were fed ad libitum with Enhydra fluctuans, Eichhornia crassipes and biofilms. Diaptomus sp. was stocked in an aerated glass beaker with de-chlorinated test water in the laboratory condition at ambient temperature and fed with algae. After an acclimation period of 3 days, 10 individuals of Cloeon sp. were transferred into each of the 21 glass beakers containing $500 \mathrm{~mL}$ de-chlorinated tap water (water holding capacity: $750 \mathrm{~mL}$ ) and 20 individuals of Diaptomus sp. were transferred into 21 glass beakers containing $50 \mathrm{~mL}$ de-chlorinated tap water (water holding capacity: $100 \mathrm{~mL}$ ), which were put in the laboratory at ambient temperature and receiving no direct sunlight. An aeration system was introduced in all beakers to provide sufficient oxygen throughout the experimental period of $96 \mathrm{~h}$. Feeding was stopped $24 \mathrm{~h}$ before and throughout the exposure period. Both species were exposed to seven different concentrations $(0,3,10,30,100,300,3000 \mathrm{ng} / \mathrm{L})$ of imidacloprid including 
control with triplicate treatment for $96 \mathrm{~h}$ separately. Imidacloprid (as Premier with $20 \%$ active ingredient, $6 \%$ adjuvants and 74\% water and produced by the world of Hayleys) was purchased from a local pesticide seller (Mymensingh, Bangladesh). The stock solutions were prepared by dissolving the required weighed amount of imidacloprid in distilled water so a concentration of $200 \mathrm{~g} / \mathrm{L}$ imidacloprid was achieved. Water quality variables (i.e. dissolved oxygen, temperature, $\mathrm{pH}$ and $\mathrm{EC}$ ) were measured in the lowest and highest treatment, and in the control at $0 \mathrm{~h}$ and $96 \mathrm{~h}$ of exposure. Mortality and immobility were checked at every $24 \mathrm{~h}$ of exposure for Cloeon sp. and after $96 \mathrm{~h}$ of exposure for Diaptomus sp. Individuals were considered immobile when there was no observed movement within $20 \mathrm{~s}$ for Cloeon sp. and $15 \mathrm{~s}$ for Diaptomus sp., and dead when there was no observed movement within 3-5 s for both after a tactile stimulation using a Pasteur's capillary pipette (OECD, 2004 ). Dead individuals were removed immediately from the experimental units. Immobile individuals were kept in the systems because there was a possibility for recovery, and these specimens were used to calculate effect concentration levels based on immobilization. The test was valid when the mortality of the control did not exceed $10 \%$ at the end (96 h) of the test (OECD, 2004).

\subsection{Application and analysis of imidacloprid}

Like acute toxicity tests, imidacloprid (as Premier) with $20 \%$ active ingredient was used in microcosm experiment. Imidacloprid was applied to each microcosms weekly at either nominal concentrations of $0,30,300$ or $3000 \mathrm{ng} / \mathrm{L}$ over a period of 4 weeks, using four replicates for each treatment. The doses were chosen based on the acute and chronic toxicity of imidaclooprid to the most sensitive organisms, mayflies. The lowest concentration ( $30 \mathrm{ng} / \mathrm{L}$ ) was based on the 28-d EC10 value of imidacloprid for Cloeon dipterum (33 ng/L; Roessink et al., 2013) in the Netherlands. The highest concentration of $3000 \mathrm{ng} / \mathrm{L}$ of imidacloprid in both the microcosm experiment and the acute toxicity tests reflected the acute toxicity (96h-EC50) for the same species (1770 ng/L; Roessink et al., 2013). The four microcosms serving as controls received only aerated tap water. The control and treatments were randomly assigned to the experimental microcosms prior to the first imidacloprid application. Stock solutions of $1 \mathrm{~L}$ were prepared for each of the 4 applications by dissolving the weighed amount of imidacloprid with distilled water in a volumetric flask so a concentration of $200 \mathrm{~g} / \mathrm{L}$ imidacloprid was achieved and the solution was sonicated for $30 \mathrm{~min}$ at $45^{\circ} \mathrm{C}$. 
The imidacloprid concentrations were analytically verified in microcosm water samples collected from one of the four replicates of all treatments just after application and before the next application. Water samples were collected at $1 \mathrm{~h}$, and 1, 2, 6.9, 7.1, 13.9, 14.1, 20.9, 21.1 and 28 days. For the acute toxicity tests, water samples were collected to measure imidacloprid concentrations from one of the replicates of the control, the lowest and the highest treatment at $0 \mathrm{~h}$ and $96 \mathrm{~h}$. Approximately $3 \mathrm{ml}$ water samples were collected using a pipette and kept in a glass vial containing $1 \mathrm{ml}$ of acetonitrile for both experiments. The samples were shaken thoroughly by hand and subsequently preserved in a freezer $\left(-20{ }^{\circ} \mathrm{C}\right)$ until analysis. Imidacloprid concentrations from the water samples were analysed by liquid chromatography-tandem mass spectrometry (LC-MS) as described in Roessink et al. (2013). In this study, matrix-matched method was used to correct matrix effects in the instrumental quantification for imdacloprid. The limit of detection (LOD) and the limit of quantification (LOQ) in the microcosm study were $9 \mathrm{ng} / \mathrm{L}$ and $29 \mathrm{ng} / \mathrm{L}$, respectively, and in the acute toxicity tests $6 \mathrm{ng} / \mathrm{L}$ and $19 \mathrm{ng} / \mathrm{L}$, respectively.

\subsection{Invertebrates and algae}

The macroinvertebrate community was sampled using two pebble baskets (height: around 30 $\mathrm{cm}$; diameter: around $20 \mathrm{~cm}$ ) that served as artificial substrates in each microcosm. Each of the two artificial substrates was placed on the sediment's surface and were left for colonization for two weeks. Macroinvertebrates were sampled 7 days before the first imidacloprid application and on days 2, 9, 16 and 23 after the first imidacloprid application. The two artificial substrates present in the same microcosm were sampled alternately. For sampling, one of the substrates was carefully retrieved from the sediment and immediately enfolded by a nylon net. The substrate was carefully shaken in the net to extract the invertebrates from the substrate. In order to sample the pelagic macroinvertebrates, the net was moved through the water column close to one quarter of the microcosm wall. A core sediment sampler (inner diameter: around $8 \mathrm{~cm}$ ) was used to collect the invertebrates inhabiting the sediment (Chironomid larvae and Tubifex tubifex) on day 28 after the first imidacloprid application. All sampled invertebrates were transferred to a white tray, subsequently identified and counted alive, and finally placed back into their original microcosms. 
Plankton was sampled on days 7 and 1 before the first imidacloprid application, and on days 2, 9, 16, 23 and 28 after the first imidacloprid application. Two $5 \mathrm{~L}$ depth-integrated water samples were collected using a Perspex tube in a plastic bucket and filtered over a net with a mesh size of either $20 \mu \mathrm{m}$ for phytoplankton or $55 \mu \mathrm{m}$ for zooplankton, yielding two samples of $100 \mathrm{~mL}$. The samples were preserved in plastic bottles with $10 \%$ buffered formalin solution and stored at $4{ }^{\circ} \mathrm{C}$. The individuals present in a sub-sample $(1 \mathrm{~mL})$ of the concentrated phytoplankton and zooplankton samples were identified to the lowest practical level with an inverted microscope (Olympus CX 41) and recalculated to numbers of individuals per litre of microcosm water.

The possible effects of imidacloprid on the chlorophyll-a content of the periphyton biomass was evaluated by introducing three series of 3 microscopic glass slides $(7.5 \mathrm{~cm} \times 2.5 \mathrm{~cm})$ at 30 $\mathrm{cm}$ water depth in each microcosm 7 days before the first imidacloprid application. A glass slide series was retrieved on days 2, 16 and 28 after the first imidacloprid application and attached periphyton was collected by scraping and then the scraped periphyton was transferred to a glass vial containing $0.25 \mathrm{~L}$ tap water. The chlorophyll-a in the resulting periphyton - water mixture was measured according to APHA (2005) and the amount of chlorophyll-a per square centimetre of glass slide was determined.

\subsection{Water quality variables and organic matter decomposition}

Temperature $(\mathrm{T})$, dissolved oxygen (DO), $\mathrm{pH}$, electrical conductivity $(\mathrm{EC})$ were monitored at 8 am on 7 days and 1 day before the first imidacloprid application, and on days $0,9,16,23$ and 28 after the first imidacloprid application, using a multimeter (Hach, HQ 40d). On these days, also total alkalinity levels and ammonia, nitrite, nitrate and total phosphorus concentrations were measured in water samples collected from each microcosm. For this, a depth-integrated water sample of approximately $1 \mathrm{~L}$ was collected in each microcosm using a Perspex tube and stored at $4{ }^{\circ} \mathrm{C}$ in a plastic bottle in the dark. Alkalinity and nutrient concentrations were determined within 7 days according to APHA (2005).

Litter bags were used to study the effects of the insecticide on organic matter decomposition. The litter bags included $2 \mathrm{~g}$ of banana (Musa) leaves and three of them were introduced into each microcosm 1 day before the first imidacloprid application. The banana leaves were leached in tap water ( 2 days) and subsequently dried $\left(40{ }^{\circ} \mathrm{C}\right.$ for $48 \mathrm{~h}$ ) before addition to the litter bags. The litter bags were placed approximate $30 \mathrm{~cm}$ below the water surface. On days 
2, 16 and 28 after the first imidacloprid application, one of the three litter bags was sampled and the retrieved material was dried $\left(40^{\circ} \mathrm{C}\right.$ for $\left.48 \mathrm{~h}\right)$ and weighted. The percentage of organic matter decomposition was calculated by calculating the loss of the initial dry weight over 2 , 16 and 28 days.

\subsection{Data analyses}

No-observed-effect-concentrations (NOECs) were determined for the variables including water quality, all taxa of phytoplankton, zooplankton, macroinvertebrates, periphyton community, and organic matter decomposition data using the Williams test (Williams, 1972; $\mathrm{p}<0.05$ ) as available in the Community Analysis computer program, version 4.3.05 (Hommen et al., 1994). Prior to the analysis, the abundance data sets were $\ln (A x+1)$ transformed. For the determination of $A$ and the rationale behind the transformation is referred to Van den Brink et al. (2000).

The phytoplankton, zooplankton and macroinvertebrate data sets were analysed by the principal response curve (PRC) method using the CANOCO Software package, version 5 (Van den Brink and Ter Braak, 1999 ; Ter Braak and Šmilauer, 20102 ). The PRC method is a specific type of redundancy analysis (RDA) that is able to extract the variation in community composition due to the stressor from the total variation by including the treatment regime and its interaction with time as explanatory variables, and the sampling date as co-variables. The overall significance of the effect of imidacloprid treatment on the variation in community composition ( $p \leq 0.05$ ) was tested by performing 999 Monte Carlo permutations (Van den Brink and Ter Braak, 1999). Each treatment was tested against the control for each sampling date using Monte Carlo permutation tests under the RDA option in order to evaluate the significance of the imidacloprid induced community effects in time.

The LC10, LC50 and LC90 and EC10, EC50 and EC90 values of imidacloprid resulting from the toxicity tests performed with Cloeon sp. and Diaptomus sp. were determined using log-logistic regression as programmed in the software GenStat $11^{\text {th }}$ (VSN International Ltd., Oxford, UK) according to Rubach et al. (2011). 


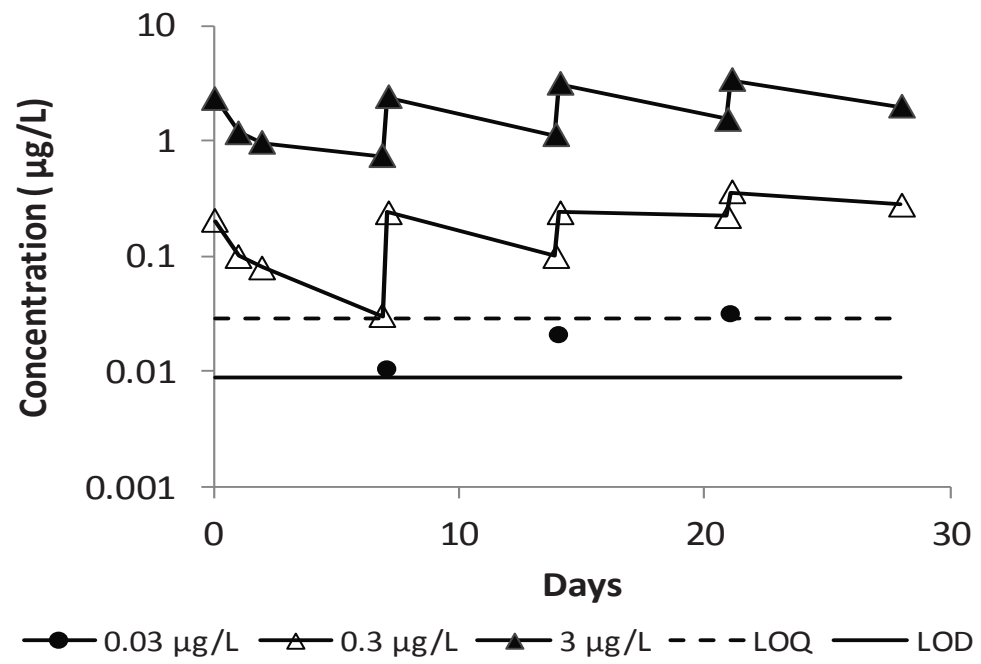

Figure 1. Dynamics of measured imidacloprid concentrations in microcosm water during the experimental period.

\section{Results and discussion}

\subsection{Fate of imidacloprid}

One hour after each of the four applications, on average, 93\% of the applied concentration was found in the highest treatment and on average, $87 \%$ was found in the second highest treatment (Fig. 1; Table S1). After 7 days, between $45 \%$ and $53 \%$ of the applied concentration was present in microcosm water in the highest and second highest treatment, respectively. In the acute toxicity tests $79 \%$ of the intended concentration was found in the highest treatment just after imidacloprid application, whereas after 96 hours of exposure $47 \%$ of the applied concentration was left (Table S2). In our study, the lower dissipation of imidacloprid in the microcosm experiment compared to the acute toxicity tests might be due to UV light absorption by natural organic matter and suspended particulate matter in microcosms which decreases the photodegradation of imidacloprid (Lu et al., 2015). The dissipation was, however, found to be faster in the present sub-tropical study compared to earlier model ecosystem studies (i.e. microcosm and mesocosm studies) and acute studies conducted in temperate regions. For example, Pestana et al. (2009) found $88 \%$ of the intended concentrations of imidacloprid after $24 \mathrm{~h}$ of exposure in the highest concentration in recirculatory flow-through stream mesocosms at $20^{\circ} \mathrm{C}$ in Canada. Van den Brink et al. (2016) 
measured $94 \%$ and $91 \%$ of the intended imidacloprid concentration just after application and after 96 hours of exposure, respectively in an acute study performed under very low light intensities at $18{ }^{\circ} \mathrm{C}$ in Netherlands. The rapid dissipation of imidacloprid in both microcosm and acute studies suggests that the dissipation is higher in the tropics than in temperate region due to higher temperature $\left(28.2 \pm 2{ }^{\circ} \mathrm{C}\right.$ for microcosm experiment and $27.4 \pm 0.6^{\circ} \mathrm{C}$ for acute toxicity tests) and photodegradation during the experimental period (Laabs et al., 2007; Chai et al., 2009; Sánchez-Bayo and Hyne, 2011). In the present study, however, we found a buildup of imidacloprid concentrations in later applications in all treatment levels as compared to the first application in microcosm study. For instance, $25 \%$ of the intended dose was found after 7 days of first application in the highest treatment while, $65 \%$ was present 7 days after the fourth application in the same treatment (Fig. 1; Table S1).

\subsection{Invertebrates}

The zooplankton community was dominated by Rotifera ( 6 taxa), followed by Cladocera (4 taxa) and Copepoda (3 taxa) during the experimental period and all of them showed a relatively constant abundance in time (Fig. S4). The PRC showed significant negative effects of

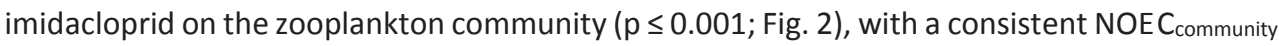
value of $300 \mathrm{ng} / \mathrm{L}$ (Table 1 and S3). Species weight in the PRC indicated that Diaptomus sp. was the taxon most responding to the treatments, followed by nauplius, two Rotifera taxa and three Cladocera taxa (Fig. 2). Univariate analysis indicated that four taxa showed a consistent negative response to the imidacloprid treatment, i.e. with NOECs calculated for at least two consecutive sampling dates (Table 1 and S3). Among the 13 taxa identified, Diaptomus sp. was the most negatively affected from day 2 after the first imidacloprid application onwards in almost all treatment levels with a consistent NOEC of $300 \mathrm{ng} / \mathrm{L}$, followed by Keratella sp., Sida sp. and Brachionus sp. (Table 1 and S3; Fig. 2, 3 and S4). Our single species toxicity test confirmed the sensitivity of Diaptomus sp. when exposed to imidacloprid since an 96-h EC50 of $38.6 \mathrm{ng} / \mathrm{L}$ was calculated for this genus (Table 2 and S4 and S5). Unfortunately, temperate toxicity values for Diaptomus sp. and the three other affected taxa could not be found in the literature and therefore comparison with published data is impossible. One study by Song et al. (1997), however, demonstrated a $48-\mathrm{h}$ LC50 value of $361,230,000 \mathrm{ng} / \mathrm{L}$ for one of the copepods nauplius exposed to imidacloprid, which is several thousand folds higher than we reported for Diaptomus sp. In this study, the Cladoceran Sida sp. were consistently affected 
on day $9(\mathrm{NOEC}=<30 \mathrm{ng} / \mathrm{L})$ and 16 (NOEC $=300 \mathrm{ng} / \mathrm{L})$ after the first imidacloprid application. The toxicity data for neonicotinoids towards Sida sp. are also not available in the literature for comparison. For Cladocera, the species Daphnia magna was tested most often.

Table 1. The No Observed Effect Concentrations (NOECs) for phytoplankton, zooplankton, macroinvertebrates and water quality endpoints expressed in terms of nominal single-dose of imidacloprid concentrations ( $\mathrm{ng} / \mathrm{L}$ ) measured on each sampling day (Williams test; $\mathrm{p} \leq 0.05$ ). Only individual taxa or parameters that showed treatment-related effect on at least two successive sampling days are included. See Table S3, S6, S7 and S8 for the results for all species and parameters.

\begin{tabular}{|c|c|c|c|c|c|c|c|}
\hline \multirow[t]{2}{*}{ Endpoint } & \multicolumn{7}{|c|}{ Sampling days } \\
\hline & -7 & -1 & $0-2$ & 9 & 16 & 23 & 28 \\
\hline \multicolumn{8}{|l|}{ Zooplankton } \\
\hline Community & $>$ & $>$ & $>$ & 300 & $>$ & 300 & 30 \\
\hline Diaptomus sp. & $>$ & $>$ & $300(-)$ & $300(-)$ & $<30(-)$ & $300(-)$ & $<30(-)$ \\
\hline Brachionus sp. & $>$ & $>$ & $>$ & $>$ & $>$ & $300(-)$ & $30(-)$ \\
\hline Keratella sp. & $>$ & $>$ & $<30(-)$ & $<30(-)$ & $>$ & $<30(-)$ & $>$ \\
\hline Sida sp. & $>$ & $>$ & $>$ & $<30(-)$ & $300(-)$ & $>$ & $>$ \\
\hline \multicolumn{8}{|l|}{ Macroinvertebrates } \\
\hline Community & $>$ & NM & 300 & 300 & 300 & $>$ & NM \\
\hline Cloeon sp. & $>$ & NM & $<30(-)$ & $<30(-)$ & $300(-)$ & $30(-)$ & NM \\
\hline Notonecta sp. & $>$ & NM & $30(-)$ & $300(-)$ & $300(-)$ & $>$ & NM \\
\hline Chironomid larvae & NM & NM & NM & NM & NM & NM & $300(-)$ \\
\hline Tubifex tubifex & NM & NM & NM & NM & NM & NM & $300(-)$ \\
\hline \multicolumn{8}{|l|}{ Phytoplankton } \\
\hline Community & $>$ & $>$ & $>$ & $>$ & $>$ & $>$ & $>$ \\
\hline Scenedesmus sp. & $>$ & $>$ & $>$ & $>$ & $300(-)$ & $300(-)$ & $>$ \\
\hline Tetraedon sp. & $>$ & $>$ & $>$ & $>$ & $<30(-)$ & $30(-)$ & $>$ \\
\hline \multicolumn{8}{|l|}{ Water quality } \\
\hline Dissolved oxygen & $>$ & $>$ & $>$ & $<30(-)$ & $30(-)$ & $<30(-)$ & $30(-)$ \\
\hline Alkalinity & $>$ & $>$ & $>$ & $<30(-)$ & $300(-)$ & $>$ & $<30(-)$ \\
\hline Ammonia & $>$ & $>$ & $>$ & $>$ & $>$ & $300(+)$ & $300(+)$ \\
\hline Nitrate & $300(-)$ & $>$ & $30(-)$ & $300(-)$ & $300(-)$ & $300(-)$ & $>$ \\
\hline
\end{tabular}

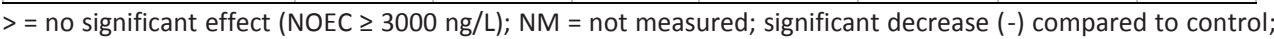
significant increase (+) compared to control 


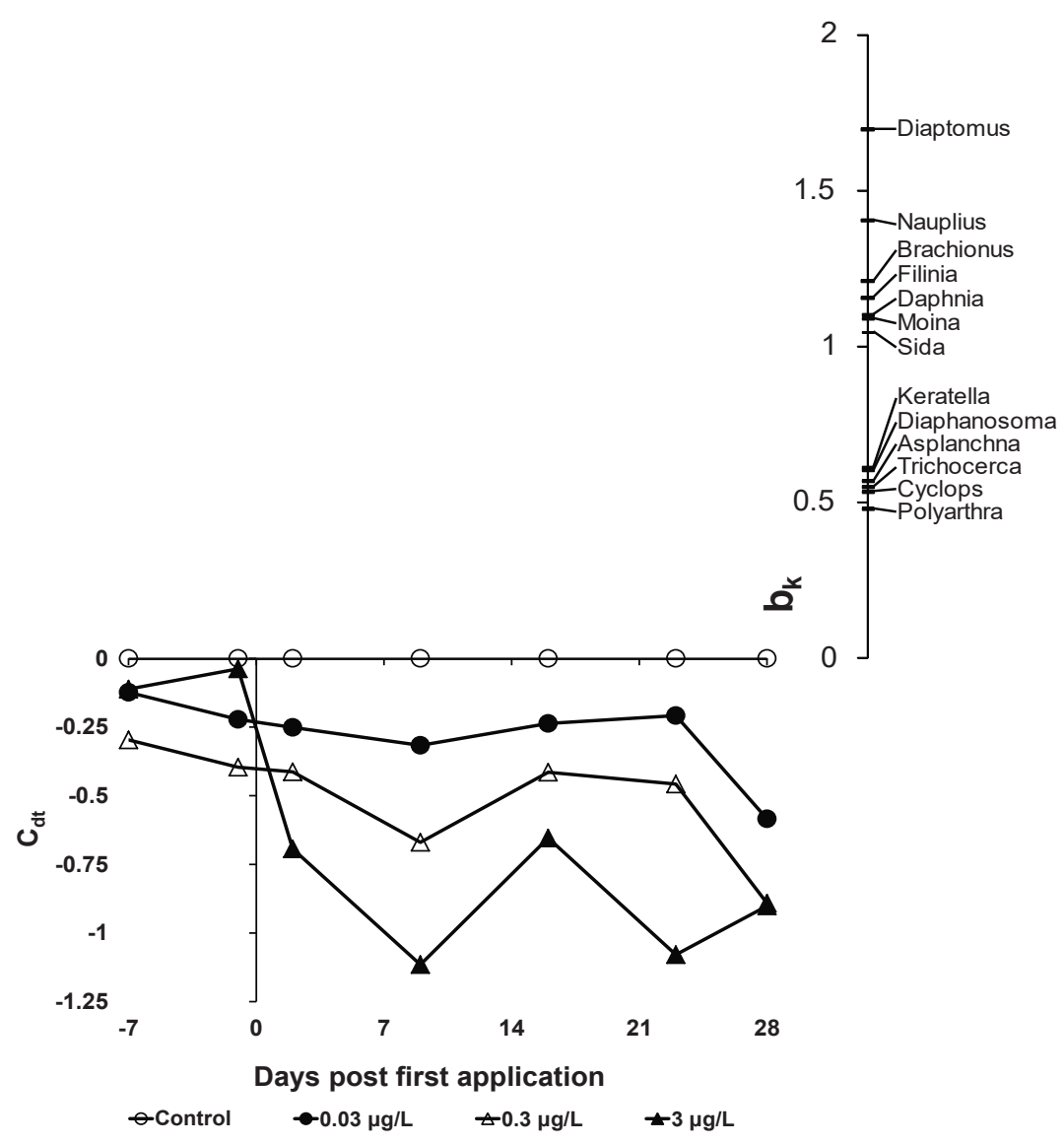

Figure 2. PRC resulting from the analysis of the zooplankton data set, indicating the effects of imidacloprid on the zooplankton community. Of all variance, $7 \%$ could be attributed to sampling date; this is displayed on the horizontal axis. $20 \%$ percent of all variance could be attributed to treatment. Of this variance, $49 \%$ is displayed on the vertical axis. The lines represent the course of the treatment levels in time. The species weight $\left(b_{k}\right)$ can be interpreted as the affinity of the taxon with the PRC. The Monte Carlo permutation test indicated that a significant part of the variance explained by treatment is displayed in the diagram ( $\left.p \leq \begin{array}{llll}0 & 0 & 0 & 1\end{array}\right)$. The second PRC was not significant. 


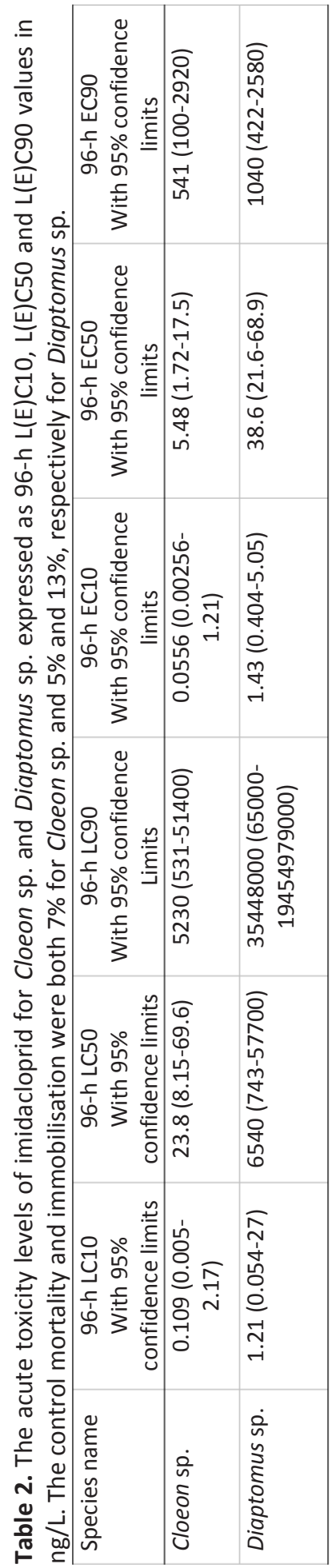


Earlier temperate studies, however, demonstrated a lower acute sensitivity of $D$. magna to imidacloprid than we reported for Sida sp. (i.e. several thousands of nanograms per litre) (Sánchez-Bayo and Goka, 2006; Tišler et al., 2009 ; Ashauer et al., 20 yłałakạ lltłal., 2012b; Daam et al., 2013). A chronic temperate study by leromina et al. (2014) also found lower sensitivity of D. magna to imidacloprid since an 9-d EC10 and 15-d EC10 (survival endpoint) of $54,160,000 \mathrm{ng} / \mathrm{L}$ and $29,630,000 \mathrm{ng} / \mathrm{L}$, respectively was calculated. The higher sensitivity of Cladoceran to imidacloprid in this study compared to o earlier acute and chronic studies could partly be explained by the higher temperature in sub-tropics (Sarma et al., 2005). For example, leromina et al. (2014) conducted their study at $20{ }^{\circ} \mathrm{C}$ while we recorded an average temperature of $28.2{ }^{\circ} \mathrm{C}$ during our microcosm experiment. The differences of sensitivity to imidacloprid might also be due to the different species tested in our study as compared to earlier studies (Hayasaka et al., 2012b). However, earlier studies on the toxicity of neonicotinoid insecticides towards microcrustaceans focused on acute effects (96 h or shorter) and only one on chronic effects on a standard test species (i.e., Daphnia sp.). Hence, we recommend future acute and chronic studies with more (sub-)tropical crustaceans to get a clearer picture of neonicotinoids toxicity towards tropical freshwater ecosystems, as we cannot fully explain why in our experiment Diaptomus sp. is so sensitive as compared to temperate crustaceans.
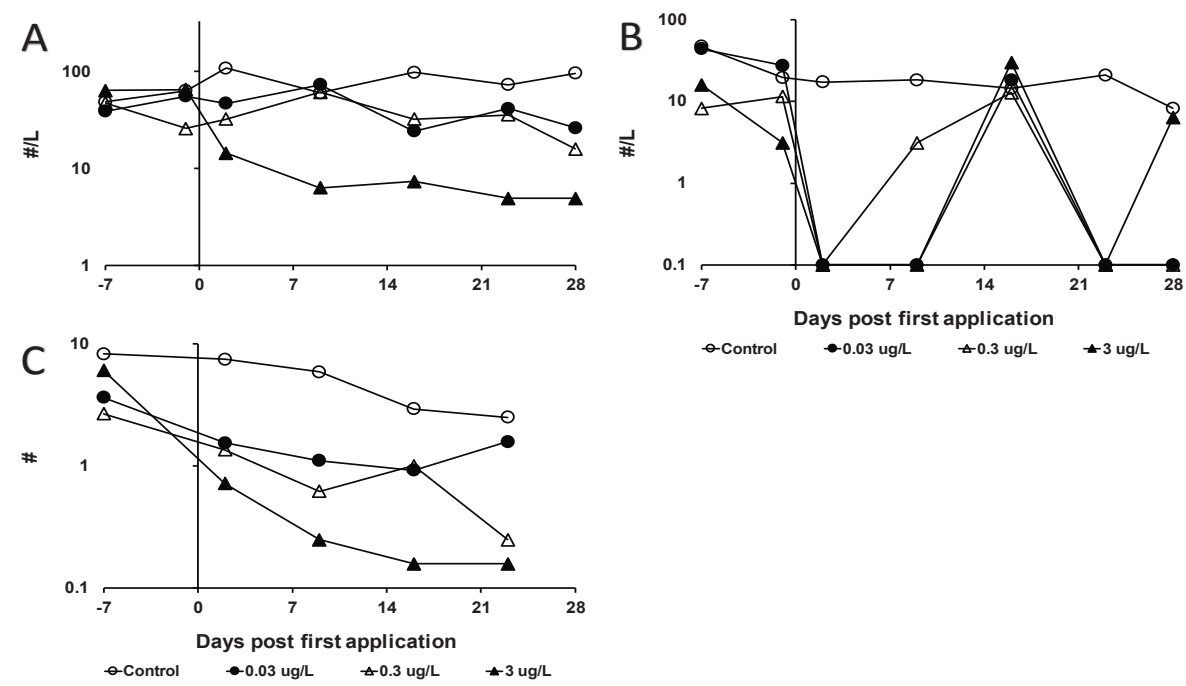

Figure 3. The population dynamics of the zooplankton taxa Diaptomus sp. (A) and Keratella $\mathrm{sp}$. (B) and the macroinvertebrate taxon Cloeon sp. (C) under the four imidacloprid concentrations. 


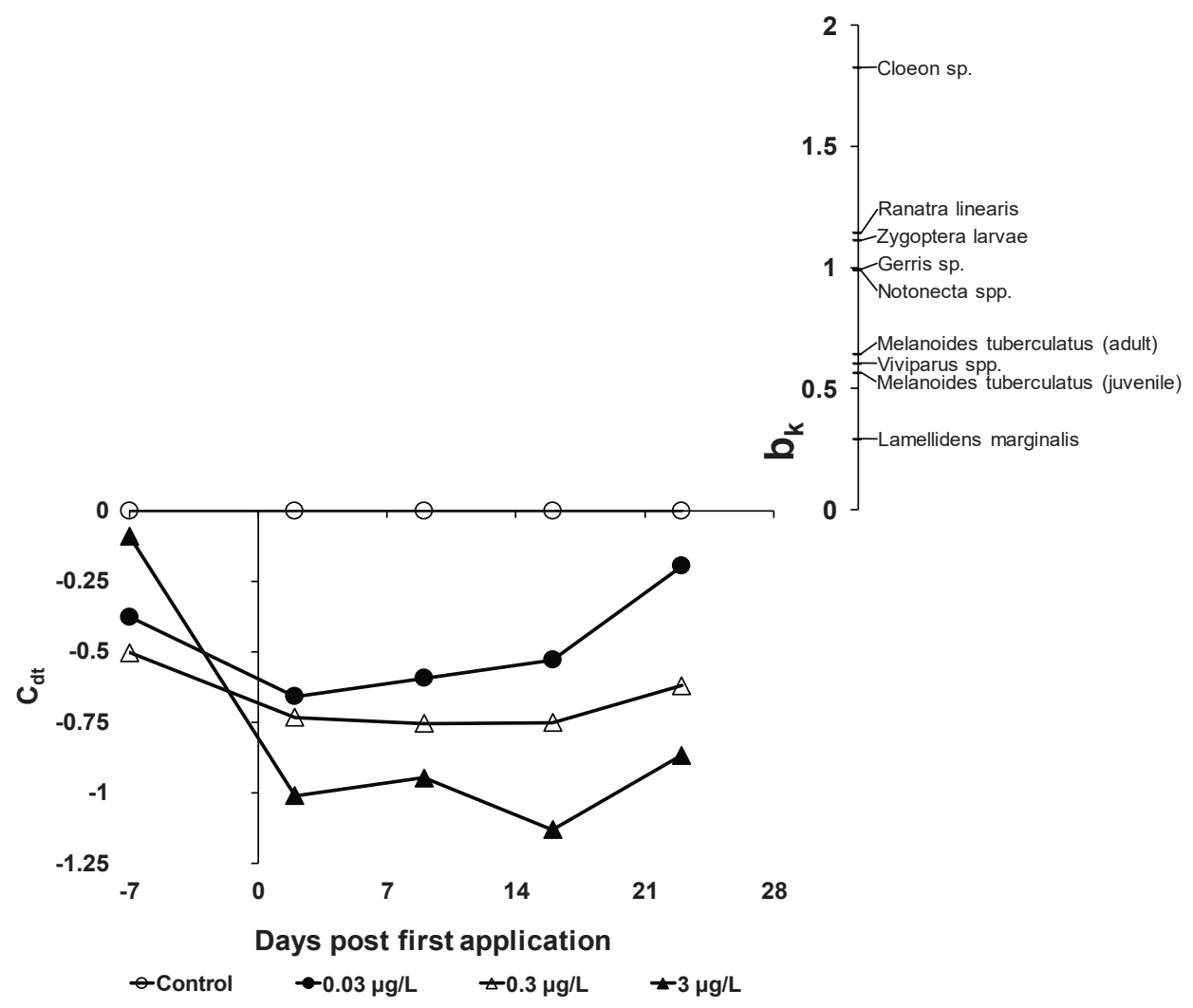

Figure 4. PRC resulting from the analysis of the macroinvertebrate data set, indicating the effects of imidacloprid on the macroinvertebrate community. Of all variance, $22 \%$ could be attributed to sampling date; this is displayed on the horizontal axis. $14 \%$ percent of all variance could be attributed to treatment. Of this variance, $74 \%$ is displayed on the vertical axis. The lines represent the course of the treatment levels in time. The species weight $\left(b_{k}\right)$ can be interpreted as the affinity of the taxon with the PRC. The Monte Carlo permutation test indicated that a significant part of the variance explained by treatment is displayed in the diagram $(p=0.002)$. The second PRC was not significant.

In the present study, 10 macroinvertebrate taxa were identified belonging to three different taxonomic groups: Insecta (6 taxa), Mollusca (3 taxa) and Annelida (1 taxon). The results of the PRC showed significant effects of imidacloprid on the macroinvertebrate community $(p=$ 0.002; Fig. 4), with a consistent NOEC community value of $300 \mathrm{ng} / \mathrm{L}$ (Table 1 and S6). The species weights in the PRC indicated that Cloeon sp. was the taxon most strongly responding to the treatments i.e. showing lower abundance values in all treatments compared to the control (Fig. 3 and 4). The univariate analysis showed consistent significant negative effects of 
imidacloprid on two insect species, as well as on Tubifex tubifex and Chironomid larvae, which were only sampled once (Table 1 and S6). Among 10 identified taxa, Cloeon sp. was the most affected taxon (NOEC $<30 \mathrm{ng} / \mathrm{L}$ on day 2 and 9), followed by Notonecta sp., who also showed a consistent response to the treatments (Table 1, S6 and Fig. S5). The single species toxicity test confirmed the high sensitivity of Cloeon sp. towards imidacloprid since an 96-h EC50 and LC50 of 5.48 and $23.8 \mathrm{ng} / \mathrm{L}$, respectively, was calculated for this genus (Table 2 and S4 and S5). The results of our study are in accordance with the previous study by Roessink et al. (2013) in the sense that Cloeon sp. was the most sensitive taxa among the studied invertebrates in both studies. In our study, however, effects were found at much lower concentrations since they reported the $96-\mathrm{h}$ and 28-d EC50 values of $1000 \mathrm{ng} / \mathrm{L}$ and $130 \mathrm{ng} / \mathrm{L}$, respectively for Cloeon dipterum, which are about two orders of magnitude higher than the 96-h EC50 reported in our study. Alexander et al. (2007) reported a $96-\mathrm{h}$ LC50 value of $650 \mathrm{ng} / \mathrm{L}$ for one of the mayfly species Epeorus longimanus, which is again about 27 folds higher than the value we reported for Cloeon sp. The higher sensitivity of Cloen sp. to imidacoprid in our study can partly be explained by differences in temperature as Van den Brink et al. (2016) showed an increase in the sensitivity of Cloeon dipterum due to increased temperature. They reported that the 96-h EC50 and LC50 values of imidacloprid for Cloeon dipterum were 1.7 and 4.2 folds lower, respectively at $18{ }^{\circ} \mathrm{C}$ compared to $10^{\circ} \mathrm{C}$. The higher temperature in the sub-tropics might modify the toxicity of imidacloprid through the elevation of metabolic rates of Cloeon sp., which leads to increased uptake rates of imidacloprid and thus could partly explain the higher sensitivity (Camp and Buchwalter, 2016). Moreover, the species of Cloeon sp. we used in our study continuously reproduces which could be another reason of their high sensitivity to imidacloprid. An earlier study by Van den Brink et al. (2016) found that the reproducing, summer generations of Cloeon dipterum $(28-\mathrm{d}$ EC50 $=130 \mathrm{ng} / \mathrm{L})$ were approximately five times more sensitive to imidacloprid than their non-reproducing, winter generations $(28-\mathrm{d}$ EC50 = $680 \mathrm{ng} / \mathrm{L})$. The sensitivity differences between summer and winter generations of aquatic insects towards toxicants might depend on the differences in their physiologies and life histories, with concomitant implications for sensitivity to toxicants (Kwok et al., 2007). For example, based on metabolic principle, it has been hypothesized that tropical aquatic insects might be more sensitive to toxicants than their temperate counterparts (Castillo et al., 1997). The higher sensitivity of Cloeon sp. in our study can also be explained by the differences in use of different formulations or technical grade of imidacloprid in earlier studies, as the 
formulated product can enhance the bioavailability and toxicity to target organisms (Malev et al., 2012). For instance, Stoughton et al. (2008) reported the $96-\mathrm{h}$ LC50 value $(654,30 \mathrm{ng} / \mathrm{L})$ of technical-grade imidacloprid for Hyalella azteca, which is approximately four times higher than the $96-\mathrm{h}$ value $(174,40 \mathrm{ng} / \mathrm{L})$ of commercial formulation Admire $(240 \mathrm{~g} / \mathrm{L})$ for the same species; thus indicating Admire is more toxic than the technical-grade imidacloprid. All these differences between temperate and tropical circumstances and species, can, however, not fully explain why the tropical Cloeon sp. is so much more sensitive to imidacloprid compared to its temperate counterpart.

The second most sensitive taxon after Cloeon sp. tested in our study was Notonecta sp., which was negatively affected from day 2 after the first imidacloprid application onwards for three consecutive sampling dates with a consistent NOEC value of $300 \mathrm{ng} / \mathrm{L}$ (Table 1). The present study showed, however, higher sensitivity of Notonecta sp. to imidacloprid than that was reported by Roessink et al. (2013) because they calculated an 96-h EC10 of 3000 ng/L, which is about ten times higher than we reported the NOEC value for this genus. Kobashi et al. (2017) demonstrated no treatment-related significant effects of imidacloprid (at 157,000 ng/L) on Notonecta triguttata in their rice mesocosm study in Japan. The higher sensitivity of Notonecta sp. to imidacloprid in this study compared to earlier temperate studies could be explained by the higher temperature in sub-tropics (Camp and Buchwalter, 2016).

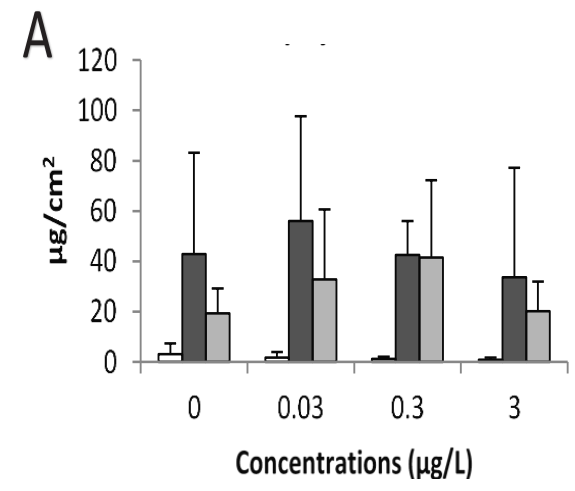

口Day 2 口Day 16 Day 28

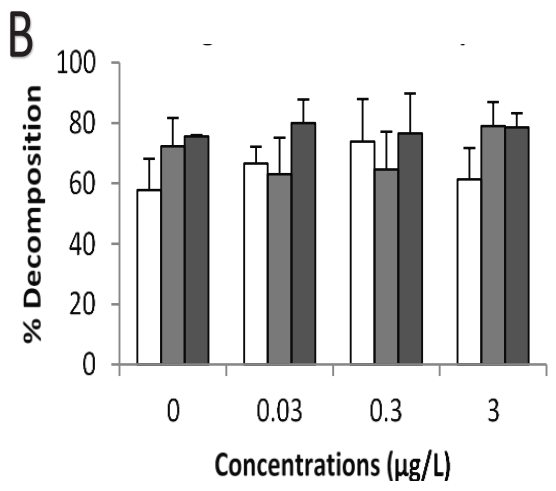

口Day 2 Day 16 Day 28

Figure 5. Chlorophyll-a in periphyton (A) and organic matter decomposition of banana (Musa) leaves (B) on day 2,16 , and 28 after first imidacloprid application (mean \pm standard deviation) (NOEC $\geq 3 \mu \mathrm{g} / \mathrm{L}$ ). 


\subsection{Primary producers}

A total of 32 different phytoplankton taxa were identified in the present study belonging to five major taxonomic groups: Chlorophyceae (12 taxa), Bacillariophyceae (10 taxa), Cyanophyceae (7 taxa), Euglenophyceae (2 taxa) and Desmidiaceae (1 taxon). The most abundant taxa in decreasing order were Ankistrodesmus sp., followed by Microcystis sp., Fragillaria sp., Oscillatoria sp., Ulothrix sp., and Tetraedon sp. during the experimental period. The PRC did not reveal significant effects of imidacloprid on the phytoplankton community ( $p$ $=0.718)$. However, univariate analysis showed significant effects of imidacloprid on certain phytoplankton taxa (15 out of 32) (Table S7; Fig. S6). Among 15 significant taxa, however, only two taxa (Scenedesmus sp. and Tetraodon sp.) were negatively affected for two consecutive sampling days (Table 1). Scenedesmus sp. had lower abundance values on day 16 and 23 in the highest treatment level (NOEC of $300 \mathrm{ng} / \mathrm{L}$ for both sampling days) (Table 1 and S7; Fig. S6A) and Tetraedon sp. had lower abundance values on day 16 in all treatment levels (NOEC $<30 \mathrm{ng} / \mathrm{L}$ ) and on day 23 in the second highest and highest treatment level (NOEC of $30 \mathrm{ng} / \mathrm{L}$ ) (Table 1 and S7; Fig. S6B).

The chlorophyll-a density in periphyton biomass increased in all treated microcosms including the controls on day 16 after the first imidacloprid application but decreased slightly on day 28 (Fig. 5A). However, the results of the univariate analysis did not show any significant effects of imidacloprid on periphyton biomass for any of the sampling days (NOECs $\geq 3 \quad 0 \quad 0 \mathrm{G} / \mathrm{L}$ ).

The results of this study indicates that the majority of the primary producers were tolerant to imidacloprid. This could be explained by the fact that the primary producers are not sensitive to neonicotinic imidacloprid based on their known insecticidal type of action (Daam et al., 2013; Anderson et al., 2015). Furthermore, we noticed a bloom of floating algae and macrophytes (Lemna minor) in all microcosms including control in the present study which we, unfortunately, did not quantify. On average, $75 \%$ surface area of microcosms was covered with primary producers in the highest concentrations of imidacloprid, while on average, $40 \%$ area was covered in control microcosms (visual observation). Toxicity data for neonicotinoids towards primary producers, such as algae and macrophytes is limited, however, the available

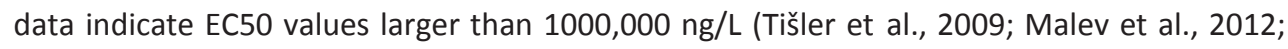
Bayer CropScience, 2013; Daam et al., 2013). 

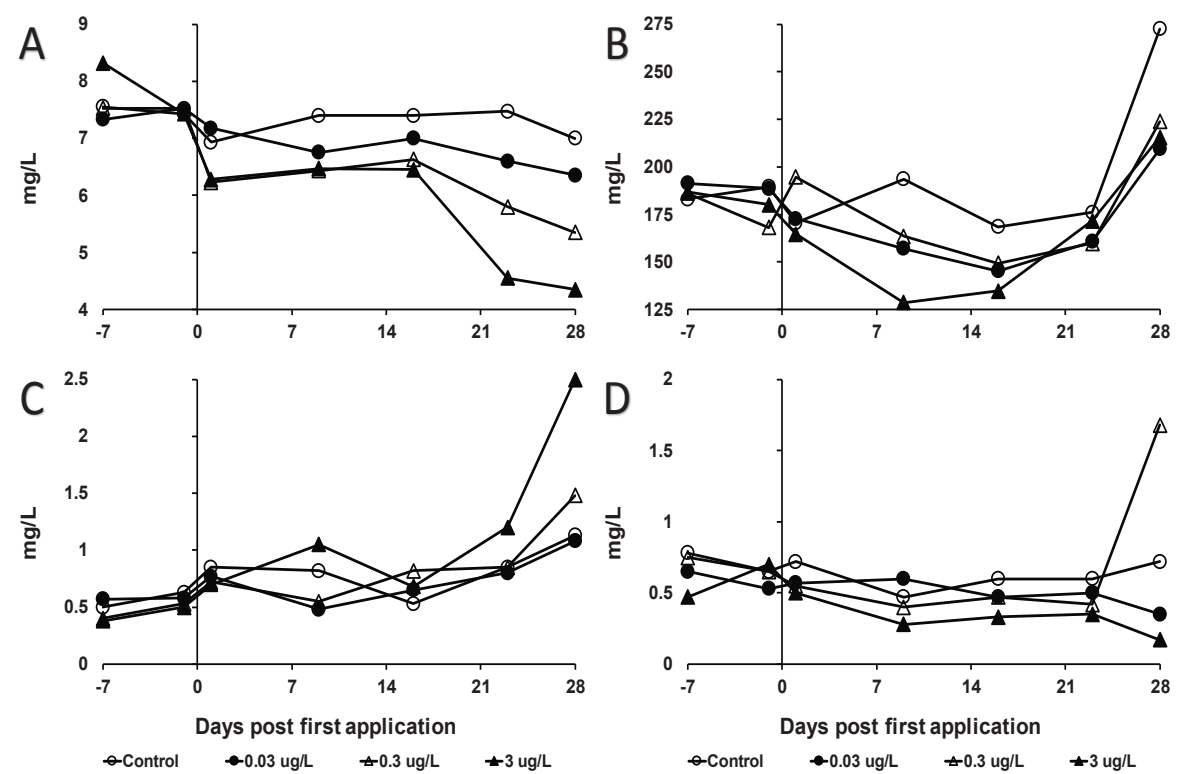

Figure 6. The dynamics of the water quality parameters DO (A), alkalinity (B), ammonia (C) and nitrate $(D)$ measured during the experimental period.

\subsection{Water quality variables}

The daily average water temperature in microcosms gradually increased during the experimental period from $27.9^{\circ} \mathrm{C}, 1 \mathrm{~h}$ after first application, to $31.7^{\circ} \mathrm{C}$ on day 28 after the first application (Fig. S7A). However, a decrease to $24.3^{\circ} \mathrm{C}$ was observed on day 16 after the first application. The latter day coincided with cloudy weather while the other days were not cloudy. The average DO between replicates measured in the microcosm water during the experimental period ranged between $4.35 \mathrm{mg} / \mathrm{L}$ and $8.33 \mathrm{mg} / \mathrm{L}$. DO concentrations decreased significantly on day 9 and onwards after the first application with a consistent NOEC value of $30 \mathrm{ng} / \mathrm{L}$. The lowest average DO (4.35 mg/L) was measured on day 28 in the highest treatment level (Table 1; Fig. 6A). The pH, EC, phosphate and nitrite showed no consistent response to the treatment (Table S8; Fig. S7). A significant decrease was observed for alkalinity levels for two consecutive sampling days on day 9 and 16 for almost all treatment levels (Table 1; Fig. 6B). Average ammonia concentrations in the experimental microcosms ranged between 0.4 $\mathrm{mg} / \mathrm{L}$ (pre-treatment period) and $2.5 \mathrm{mg} / \mathrm{L}$ (on day 28 after the first application). Ammonia concentrations increased significantly for the two consecutive sampling days on day 23 and 28 in the highest treatment level with a NOEC of $300 \mathrm{ng} / \mathrm{L}$ (Table 1; Fig. 6C). Nitrate 
concentrations decreased consistently in the highest treatment level at all sampling days except on day 28 with a NOEC of $300 \mathrm{ng} / \mathrm{L}$. The highest nitrate concentration $(1.7 \mathrm{mg} / \mathrm{L})$ was measured on day 28 in the second highest treatment level (300 ng/L) (Table 1; Fig. 6D).

In the present study, the effects found on water quality variables exposed to imidacloprid concentrations were indirect. Dissolved oxygen was consistently affected from day 9 after the first imidacloprid exposure onwards. This reduced dissolved oxygen level in microcosm water could be explained by reduced photosynthesis in the water column due to a bloom of floating algae and macrophytes. In our study, we observed that the majority of macro- and microcrustaceans were negatively affected on day 9 after the first imidacloprid application. Reduced grazing of these invertebrates and nutrient-rich environment in microcosms (e.g. ammonia, phosphate and nitrite were significantly increased for different sampling days) might have led to a bloom of floating algae and macrophytes (own observations) which hindered the light penetration into cosms and thus affected the photosynthesis. The reduced light penetration induced by floating algae and macrophytes might have reduced the photolysis of imidacloprid, thus increasing the exposure of macro- and micro-crustaceans to imidacloprid.

\subsection{Organic matter decomposition}

The decomposition rates of banana (Musa) leaves (mean $\pm \mathrm{SD}$ ) in the control microcosms were $58 \pm 10 \%, 72 \pm 9 \%$ and $76 \pm 0.5 \%$ on day 2,16 and 28 , respectively after the first imidacloprid application (Fig. 5B). In this study, the decomposition of banana leaves increased gradually with an increasing exposure period. The results of the univariate analysis, however, did not show any treatment-related significant effects of imidacloprid on the decomposition of banana leaves for any of the sampling days (NOECs $\geq 3 \quad 0 \quad \mathrm{O} g / L$ ) (Fig. 5B). The results of this study is line with earlier microcosm and mesocosm studies in the sense that they did not find treatment-related significant effects of imidacloprid on the microbial decomposition of different leaves used in their studies (Kreutzweiser et al., 2008; Pestana et al., 2009; Böttger et al., 2013).

\section{Conclusions}

This is the first study assessing the effects of 4 weekly applications of imidacloprid on the freshwater ecosystem under semi-field conditions in sub-tropics. In this study, imidacloprid concentrations between 30 and $3000 \mathrm{ng} / \mathrm{L}$ demonstrated significant effects on water quality 
variables, certain phytoplankton taxa, and on communities of zooplankton and macroinvertebrates. The study revealed toxic effects of imidacloprid on a (sub-)tropical freshwater ecosystem at much lower concentrations than found for temperate systems. Whether these differences in sensitivity holds true for all (sub-)tropical aquatic ecosystems remains to be investigated. This study generates safe environmental values of imidacloprid for individual taxa and community levels of some endpoints through the derivation of NOECs. For certain taxa, the present study found low levels of NOECs ( $<30 \mathrm{ng} / \mathrm{L})$ indicating that the standard of imidacloprid (30 ng/L) used in Europe (Vijver and Van den Brink, 2014) might not protect freshwater communities in Bangladesh. We recommend further long-term studies with (sub-)tropical aquatic species and ecosystems to get more insight into the comparative toxicity of imidacloprid using the data obtained from this study with those previously obtained in temperate regions.

\section{Acknowledgements}

The study was financially supported by the NUFFIC-NICHE-BGD-156 project. We would like to express the gratitude to National Food Safety Laboratory (NFSL), Mohakhali, Dhaka-1212, Bangladesh for analytical verification of imidacloprid. The authors are indebted to Tajmine Naher and Sagiya Sharmin for their kind help in water quality variables analysis and to Rakibul Islam, Most. Farzana Yesmin, Sampa Saha and Sharmin Sultana for macroinvertebrates sampling and counting. We also thank Md. Alal Uddin for his kind cooperation in phytoplankton and zooplankton analyses.

\section{Supporting information}

The supporting information can be downloaded from: https://www.sciencedirect.com/science/article/pii/S0269749117345694. 


\section{Chapter 5}

Acute toxicity of chlorpyrifos to embryo and larvae of Banded Gourami Trichogaster fasciata

Kizar Ahmed Sumon, Sampa Saha, Paul J. Van den Brink, Edwin T.H.M. Peeters, Roel H. Bosma, Harunur Rashid B (2017), 52: 92-98. 


\section{Abstract}

This study elucidated the acute toxicity of chlorpyrifos on the early life stages of Banded Gourami (Trichogaster fasciata). To determine the acute effects of chlorpyrifos on their survival and development, we exposed the embryos and two-day-old larvae to six concentrations $(0,0.01,0.10,1.0,10$ and $100 \mathrm{mg} / \mathrm{L})$ of chlorpyrifos in plastic bowls. Log-logistic regression was used to calculate LC10 and LC50 values. Results showed that embryo mortality significantly increased with increasing chlorpyrifos concentrations. The 24-h LC10 and LC50 values (with 95\% confidence limits) of chlorpyrifos for embryos were $0.89(0.50-1.58)$ and 11.8 (9.12-15.4) mg/L, respectively. Hatching success decreased and mortality of larvae significantly increased with increasing concentrations of chlorpyrifos. The 24-h LC10 and LC50 values (with 95\% confidence limits) of chlorpyrifos for larvae were $0.53(0.27-1.06)$ and 21.7 (15.9-29.4) mg/L, respectively; the 48-h LC10 and LC50 for larvae were 0.04 (0.02-0.09) and $5.47(3.77-7.94) \mathrm{mg} / \mathrm{L}$, respectively. The results of this study suggest that $1 \mathrm{mg} / \mathrm{L}$ of chlorpyrifos in the aquatic environment may adversely affect the development and the reproduction of Banded Gourami. Our study also suggests that Banded Gourami fish can serve as an ideal model species for evaluating developmental toxicity of environmental contaminants. 


\section{Introduction}

In Bangladesh, agricultural intensification is indispensable due to the country's ever-increasing population, leading to land scarcity as well as food security needs. To meet the growing demand for food, farmers grow high-yielding crop varieties all over the country. However, these high-yielding varieties are highly susceptible to various pests and diseases (Bagchi et al., 2009); thus, to protect their crops from pests and to improve their crop yields and quality of their products, farmers use pesticides (Ansara-Ross et al., 2012; Rahman, 2013). The Bangladesh government, like many other developing countries, has promoted the use of pesticides to increase agricultural yields (Dasgupta et al., 2007). The use of pesticides in Bangladesh was negligible until 1960s (Rahman, 2013), but has dramatically increased from 7,350 metric tons in 1992 to 45,172 metric tons in 2010 (Hasan et al., 2014).

At present, farmers use a number of pesticides (Shahjahan et al., 2017). One that is widely used in agriculture and households is chlorpyrifos (0,0-diethyl 0-3,5,6-trichloro-2-pyridyl phosphorothioate and CAS No. 2921-88-2), a synthetic organophosphate insecticide and acaricide (Yen et al., 2011). Farmers use this insecticide to control pests in rice, coconut and vegetable crops, such as beans and potatoes. This insecticide poisons the stomach of the pest (Kienle et al., 2009) and inhibits enzyme activity by binding the enzyme acetyl cholinesterase (AChE) through phosphorylation (Palma et al., 2009; Jin et al., 2015). Its' potential danger to humans, however, has made the US Environmental Protection Agency impose a ban on its sale for residential use (US EPA, 2006), while no such ban exists in Europe as chlorpyrifos is one of the top-selling insecticides (Bernabò et al., 2011). Chlorpyrifos is relatively persistent in nature as compared to other organophosporus insecticides, with a half-life in watersediment systems ranging from 29 to 74 days (Palma et al., 2009).

Through spray drift, runoff and leaching, chlorpyrifos-contaminated soils move down and cause hazardous impact to the aquatic environment (Agbohessi et al., 2013; Van den Brink, 2013). Chlorpyrifos shows a high toxicity to non-target aquatic organisms including vertebrates (Kienle et al., 2009; Bernabò et al., 2011; Xing et al., 2012; Jin et al., 2015) and invertebrates (Daam et al., 2008; Palma et al., 2009; Rubach et al., 2011, 2012). Like other groups of vertebrates, fish embryos and larvae are also considered to be the most sensitive stages in the life cycle and sensitive to low levels of environmental pollutants (Marimuthu et 
al., 2013). A number of studies have been conducted to assess the toxicity of chlorpyrifos to various stages of different fishes (Table 1).

The Banded Gourami or striped gourami (Trichogaster fasciata; family Osphronemidae; order Perciformis) is naturally abundant in Bangladesh, India, Myanmar, Nepal and Pakistan. This fish commonly inhabits freshwater pools, ditches, ponds, marshes and rivers, as well as lakes with vegetation (Mitra et al., 2007). The species has drawn attention for its taste and contribution to nutrition, and for its value as an indigenous ornamental aquarium fish in Bangladesh (Hossen et al., 2014). However, to date no study has been done to investigate the toxicity of chlorpyrifos on the early stage of Banded Gourami. The objective of the present study was to elucidate the acute toxicity of chlorpyrifos on the embryo and the larvae of Banded Gourami fish. The results of the study could serve as a baseline for other researchers in using the Banded Gourami fish as a model species for assessing the developmental toxicity of environmental contaminants.

Table 1. An overview of chlorpyrifos toxicity on various stages of different fish species.

\begin{tabular}{|c|c|c|c|c|c|}
\hline Species & Life stage & Region & Endpoint & $\begin{array}{l}\text { Threshold } \\
\text { effects i.e. } \\
\text { LC50 ( } \mu \mathrm{g} / \mathrm{L})\end{array}$ & Reference \\
\hline $\begin{array}{l}\text { Eastern Rainbow fish } \\
\text { (Melanotaenia splendida } \\
\text { splendida) }\end{array}$ & $\begin{array}{c}\text { Eggs } \\
\text { 16-day-old larvae } \\
\text { Adult }\end{array}$ & Temperate & Mortality (96h) & $\begin{array}{c}23 \\
117 \\
396\end{array}$ & $\begin{array}{l}\text { Humphrey and } \\
\text { Klumpp (2003) }\end{array}$ \\
\hline $\begin{array}{l}\text { Walleye (Stizostedion } \\
\text { vitreum) }\end{array}$ & $\begin{array}{l}\text { Pro-larvae (1-5 day } \\
\text { after hatch) }\end{array}$ & Temperate & Mortality (48h) & 316 & Phillips et al. (2002) \\
\hline Turbot (Psetta maxima) & $\begin{array}{c}\text { Eggs } \\
\text { Larvae }\end{array}$ & Temperate & $\begin{array}{l}\text { Mortality (48h) } \\
\text { Mortality (96h) }\end{array}$ & $\begin{array}{l}116.6 \\
94.65\end{array}$ & $\begin{array}{l}\text { Mhadhbi and Beiras } \\
\qquad(2012)\end{array}$ \\
\hline $\begin{array}{l}\text { Mezquital silverside } \\
\text { (Chirostoma jordani) }\end{array}$ & Semi-adult & Tropical & Mortality (24h) & 0.17 & $\begin{array}{l}\text { Dzul-Caamal et al. } \\
\qquad(2012)\end{array}$ \\
\hline $\begin{array}{l}\text { Spotted snakehead } \\
\text { (Channa punctatus) }\end{array}$ & Adult & Tropical & $\begin{array}{l}\text { Mortality (96h) } \\
\text { Mortality (24h) }\end{array}$ & $\begin{array}{c}811.98 \\
5.38\end{array}$ & $\begin{array}{l}\text { Ali et al. (2008); } \\
\text { Mishra and Devi } \\
\qquad(2014)\end{array}$ \\
\hline $\begin{array}{l}\text { Guppy (Poecilia } \\
\text { reticulata) }\end{array}$ & Adult & Tropical & Mortality (96h) & $\begin{array}{l}7.17 \\
176\end{array}$ & $\begin{array}{l}\text { De Silva et al. (2005); } \\
\text { Sharbidre et al. (2011) }\end{array}$ \\
\hline $\begin{array}{l}\text { Nile tilapia (Oreochromis } \\
\text { niloticus) }\end{array}$ & $\begin{array}{l}\text { Juvenile } \\
\text { Adult }\end{array}$ & Temperate & Mortality (96h) & $\begin{array}{c}98.67 \\
154.01\end{array}$ & Oruc (2010) \\
\hline $\begin{array}{l}\text { Stinging catfish } \\
\text { (Heteropneustes fossilis) }\end{array}$ & Adult & Tropical & Mortality (96h) & 2200 & Srivastav et al. (1997) \\
\hline $\begin{array}{l}\text { Japanese medaka } \\
\text { (Oryzias latipes) }\end{array}$ & $\begin{array}{c}\text { 30-day-old juvenile } \\
\text { Adult }\end{array}$ & $\begin{array}{l}\text { Temperate } \\
\text { Temperate }\end{array}$ & $\begin{array}{l}\text { Mortality (48h) } \\
\text { Mortality (96h) }\end{array}$ & $\begin{array}{l}250 \\
120\end{array}$ & $\begin{array}{l}\text { Rice et al. (1997) } \\
\text { Khalil et al. (2013) }\end{array}$ \\
\hline $\begin{array}{l}\text { Banded gourami } \\
\text { (Trichogaster fasciata) }\end{array}$ & $\begin{array}{c}\text { Eggs } \\
\text { 2-day-old larvae }\end{array}$ & Tropical & $\begin{array}{l}\text { Mortality (24h) } \\
\text { Mortality (24h) } \\
\text { Mortality (48h) }\end{array}$ & $\begin{array}{l}11.8 \\
21.7 \\
5.47\end{array}$ & The present study \\
\hline
\end{tabular}




\section{Materials and methods}

\subsection{Fish and pesticide collection}

Semi-adult fish were collected from Bara beel of Gauripur, Mymensingh District. A beel is a deep depression along a river where water remains permanent throughout the year. These fish were reared till adult stage in cemented rectangular cisterns $(250 \times 195 \times 70 \mathrm{~cm}$; water height: $30 \mathrm{~cm}$ ) at the hatchery of the Faculty of Fisheries, Bangladesh Agricultural University, Bangladesh. They were supplied commercial feed twice a day. After three months of rearing, fish were found ready for spawning. The experiment was approved by the Animal Care and Use Committee of Bangladesh Agricultural University, Mymensingh, Bangladesh.

Chlorpyrifos (in the form of Dursban and 20EC; Dow AgroSciences India Pvt. Ltd., India) was purchased from a local pesticide supplier (Mymensingh, Bangladesh).

2.2. Hormone administration, collection of gametes, artificial fertilization and incubation of eggs

We selected five healthy female (weight: $14 \pm 1.1 \mathrm{~g}$; length: $8.7 \pm 0.6 \mathrm{~cm}$ ) and ten male (weight: $15 \pm 1.1 \mathrm{~g}$; length: $9.2 \pm 0.6 \mathrm{~cm}$ ) broods for spawning by examining the gonads and based on the external morphological features as described by Swarup et al. (1972): the upper lip of the male is more pronounced and the dorsal ventral fins are more pointed at the posterior end than those of the female. Both male and female broods were artificially induced by intramuscular injection of carp pituitary powder suspended in a $0.9 \% \mathrm{NaCl}$ solution. The pituitary powder was administered at a dose of $2 \mathrm{mg} / \mathrm{kg}$ body weight of fish for males and 12 $\mathrm{mg} / \mathrm{kg}$ body weight of fish for females. Hormone-injected fish were then kept in a moderately aerated glass aquarium $(45 \times 30 \times 32 \mathrm{~cm})$ containing dechlorinated tap water (50L). About $24 \mathrm{~h}$ after hormone administration, eggs were stripped into plastic tray and testes were collected from males and cut into small pieces by using a scalpel for milt collection. Milt and eggs were stirred thoroughly into a plastic tray by using a clean and soft poultry feather for fertilization. After 2 min of gentle stirring, the eggs were washed with tap water to remove excess milt. Then the eggs were released into previously prepared experimental units for embryo toxicity evaluation. A certain amount of fertilized eggs were stocked into a glass aquarium to get larvae for larval toxicity evaluation.

\subsection{Experimental design}


Six different concentrations of chlorpyrifos $(0,0.01,0.1,1,10$, and $100 \mu \mathrm{g} / \mathrm{L})$ were used by adding chlorpyrifos stock solution for embryonic and larval bioassay. The stock solution was prepared by dissolving the weighed amount of chlorpyrifos in distilled water containing 200 g/L chlorpyrifos. We used 18 plastic bowls containing $2 \mathrm{~L}$ dechlorinated water for this experiment. The control group was kept in dechlorinated water. Each of the treatment and control group was set up in triplicate. Treatments were randomly allotted in the experimental units. The values of the water quality variables were determined according to APHA (1985). The values (mean $\pm S D$ ) for water quality were as follows: temperature, $27.7 \pm 0.2{ }^{\circ} \mathrm{C}$; dissolved oxygen, $5.7 \pm 1.3 \mathrm{mg} / \mathrm{L} ; \mathrm{pH}, 8.9 \pm 0.14$; total alkalinity, $184 \pm 8.9 \mathrm{mg} / \mathrm{L}$; electrical conductivity, $386 \pm 12.6 \mu \mathrm{S} / \mathrm{cm}$; and total dissolved solids, $179.2 \pm 0.4 \mathrm{mg} / \mathrm{L}$.

For the evaluation of embryonic toxicity, we randomly selected 18 sets of 100 fertilized eggs and exposed these to different concentrations. The incubation period and hatching rate were recorded for both treatment and control groups. Dead embryos were counted at $24 \mathrm{~h}$ of chlorpyrifos exposure. Then these were removed and the rest of the live ones were kept in the experimental units till hatching. To evaluate the larval toxicity, we randomly selected 18 sets of 100 two-day-old larvae and released them into each of the 18 plastic bowls. The mortality of larvae was counted at $24 \mathrm{~h}$ and at $48 \mathrm{~h}$ of chlorpyrifos exposure. Mortality of embryo and larvae is defined here as white opaque and not responding to the agitation with a plastic rod.

Malformations were observed for embryo at every 6-hour interval and for larvae at every 12hour interval from each of the 18 sets under a digital microscope (Olympus CX 41). Images were made by using a camera (Magnus analytics, Model-MIPS) connected between the microscope and a computer.

\subsection{Statistical analyses}

The hatching success and the mortality of embryos and larvae were calculated as the average of the three replicates. The LC10 and LC50 values of the toxicity experiment were calculated by means of log-logistic regression using the software GenStat $11^{\text {th }}$ (VSN International Ltd., Oxford, UK) according to Rubach et al. (2011). To evaluate the toxic effects of different chlorpyrifos concentrations in embryo and larvae and hatching rate, we computed a one-way analysis of variance (ANOVA) by using the Duncan's multiple comparison with SPSS (version 20; SPSS Inc., Chicago, IL) at 5\% significant level. Before any analyses were performed, the 
one-way ANOVA assumptions of normality and homoscedasticity were evaluated using the Shapiro-Wilkes test and Levene's test, respectively.

\section{Results}

The acute toxicity of chlorpyrifos on the embryo of Banded Gourami fish, i.e. the mortality of embryos, significantly increased (one-way ANOVA; $F_{5,12}=106 ; p=0.000$ ) with increasing chlorpyrifos concentrations (Table 2). A prolonged incubation period was observed due to increased concentrations of chlorpyrifos. Table 2 presents the 24-h LC10 and LC50 values (with 95\% confidence interval) of chlorpyrifos for embryos. The hatching rate significantly decreased with increasing chlorpyrifos concentrations (one-way ANOVA; $F_{5,12}=180 ; p=0.000$ ). The number of dead larvae at $24 \mathrm{~h}$ (one-way ANOVA; $F_{5,12}=113 ; p=0.000$ ) and at $48 \mathrm{~h}$ (one-way ANOVA; $F_{5,12}=144 ; p=0.000$ ) of exposure significantly increased with increasing chlorpyrifos concentrations (Table 2). The calculated 24-h and 48-h LC10 and LC50 (with 95\% confidence limit) values of chlorpyrifos for Banded Gourami larvae were presented in Table 2.

Table 2. Toxicity of chlorpyrifos on the embryo and the larvae of banded gourami $(n=100$ embryos and 100 two-day old larvae).

\begin{tabular}{|c|c|c|c|c|c|}
\hline $\begin{array}{l}\text { Concentration } \\
(\mu \mathrm{g} / \mathrm{L})\end{array}$ & $\begin{array}{c}\text { Incubation } \\
\text { period }\end{array}$ & $\begin{array}{c}\text { Number of } \\
\text { dead embryos } \\
\text { at } 24 \mathrm{~h}\end{array}$ & $\begin{array}{c}\text { Hatching } \\
\text { success (\%) }\end{array}$ & $\begin{array}{c}\text { Number of } \\
\text { dead larvae } \\
\text { at } 24 \mathrm{~h}\end{array}$ & $\begin{array}{c}\text { Number of } \\
\text { dead larvae at } \\
48 \mathrm{~h}\end{array}$ \\
\hline 0 & 23 & $5.7 \pm 2.5$ & $91.3 \pm 2.5$ & $3 \pm 3.6$ & $6.7 \pm 3.8$ \\
\hline 0.01 & $23 \mathrm{~h} 30 \mathrm{~min}$ & $14.3 \pm 5.0$ & $81 \pm 4.6$ & $5 \pm 1$ & $10 \pm 1$ \\
\hline 0.1 & $24 \mathrm{~h} 30 \mathrm{~min}$ & $15.7 \pm 7.4$ & $77.7 \pm 6.1$ & $15.3 \pm 6.1$ & $22.3 \pm 4.5$ \\
\hline 1 & $25 \mathrm{~h}$ & $26.3 \pm 4.0$ & $66.3 \pm 2.5$ & $18.3 \pm 4.2$ & $40 \pm 6.6$ \\
\hline 10 & $27 \mathrm{~h}$ & $45.7 \pm 5.5$ & $48.3 \pm 4.6$ & $33.3 \pm 6.5$ & $51 \pm 4.0$ \\
\hline 100 & $30 \mathrm{~h} 30 \mathrm{~min}$ & $91 \pm 6$ & $3.7 \pm 3.1$ & $78 \pm 3.6$ & $83.3 \pm 3.2$ \\
\hline$P$ value & & 0.000 & 0.000 & 0.000 & 0.000 \\
\hline \multicolumn{2}{|c|}{$\begin{array}{l}\text { LC10 value with 95\% } \\
\text { confidence limits }\end{array}$} & $0.89(0.50-1.58)$ & $1.05(0.60-1.84)$ & $0.53(0.27-1.06)$ & $0.04(0.02-0.09)$ \\
\hline \multicolumn{2}{|c|}{$\begin{array}{l}\text { LC50 value with 95\% } \\
\text { confidence limits }\end{array}$} & $11.8(9.12-15.4)$ & $9.56(7.39-12.4)$ & $21.7(15.9-29.4)$ & $5.47(3.77-7.94)$ \\
\hline
\end{tabular}

In embryos, malformations were not found but some eggs were unhatched and eventually died after chlorpyrifos exposure (Fig. 1 A). However, several malformations were evident in Banded Gourami larvae, like abnormal head and eye shape, lordosis, body arcuation, caudal 
fin damage, notochordal abnormality when exposed to 10 and $100 \mu \mathrm{g} / \mathrm{L}$ chlorpyrifos concentrations (Fig. 1 B-F). Morphological deformities were not found when embryos and larvae were exposed to $<10 \mu \mathrm{g} / \mathrm{L}$ chlorpyrifos concentration.
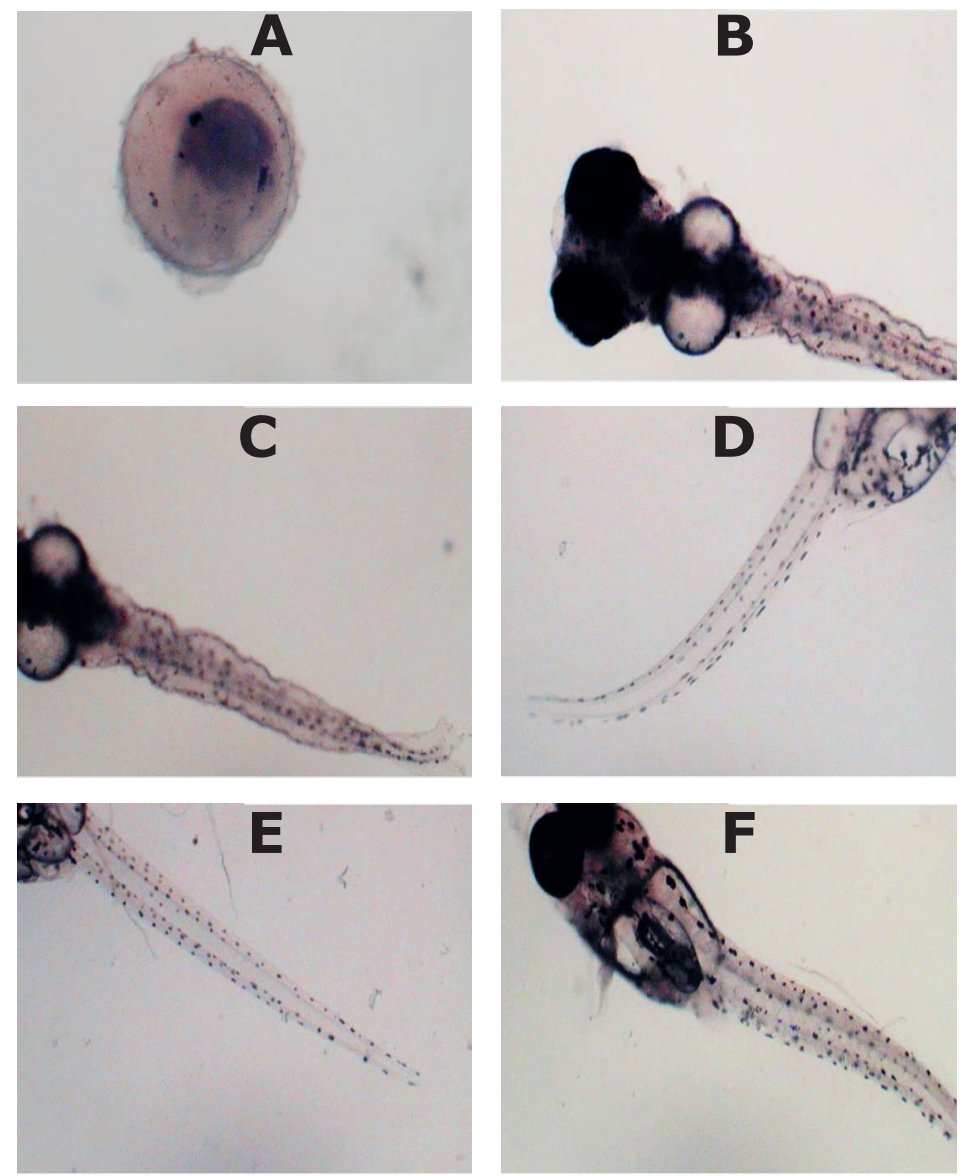

Figure 1. Malformations observed in banded gourami embryos and larvae due to chlorpyrifos toxicity. (A) unhatched embryo (B) Irregular head and eye shape and lordosis after $24 \mathrm{~h}$ of exposure to $100 \mu \mathrm{g} / \mathrm{L}$ concentration of chlorpyrifos (C) Lordosis and caudal fin damage after $24 \mathrm{~h}$ of exposure to $100 \mu \mathrm{g} / \mathrm{L}$ concentration of chlorpyrifos (D) Body arcuation after $36 \mathrm{~h}$ of exposure to $100 \mu \mathrm{g} / \mathrm{L}$ concentration of chlorpyrifos (E) Caudal fin damage after $36 \mathrm{~h}$ of exposure to $10 \mu \mathrm{g} / \mathrm{L}$ concentration of chlorpyrifos (F) Notochordal abnormality after $48 \mathrm{~h}$ of exposure to $100 \mu \mathrm{g} / \mathrm{L}$ concentration of chlorpyrifos. 


\section{Discussion}

The present study showed that the acute exposure to different concentrations of chlorpyrifos affects the hatching success, incubation period and the mortality of embryo and larvae of Banded Gourami. The hatching success significantly decreased with increasing chlorpyrifos concentrations. For instance, eggs exposed to the lowest chlorpyrifos concentration (0.01 $\mu \mathrm{g} / \mathrm{L})$ had $81 \%$ hatching success, while those with the highest concentration (100 $\mu \mathrm{g} / \mathrm{L})$ had only $3.7 \%$ hatching success. Our study is in accordance with the hatching success described by Humphrey and Klumpp (2003) for eastern rainbow fish (Table 1). They found a hatching success of $90 \%$ for eastern rainbow fish exposed to $6.2 \mu \mathrm{g} / \mathrm{L}$; a hatching success of $52 \%$ for the same species when exposed to $100 \mu \mathrm{g} / \mathrm{L}$ chlorpyrifos. Sreedevi et al. (2014) reported an almost similar finding on the reduced hatching success of zebrafish embryos due to chlorpyrifos toxicity. Earlier reports have showed that other organophosphate pesticides, like chlorpyrifos, may also have negative effects on the hatchability of different fishes. Aydin and Koprucu (2005) reported a significant decrease in hatching success of common carp embryos due to different diazinon concentrations. A similar finding was also reported by Mhadhbi and Beiras (2012) for turbot eggs when exposed to diazinon concentrations. Another study by Ansari and Ansari (2011) found a significant decrease of hatching success for zebrafish embryos exposed to dimethoate concentrations. A reduced hatching success was also observed for African catfish embryos when exposed to different buprofezin (Marimuthu et al., 2013) and endosulfan concentrations (Agbohessi et al., 2013) and for zebrafish embryos exposed to alphamethrin concnetrations (Ansari and Ansari, 2012).

Our study demonstrates that chlorpyrifos retards hatching of fish embryos (Table 2). This might be due to hypoxia or disturbances of the hatching enzyme. During the normal hatching process of fish embryos, the chorion is digested by the hatching enzyme, which is a proteolytic enzyme secreted from hatching gland cells of the embryo. The structure and function of the protease might be destroyed by toxicants that block the pore canals of the chorions; thus resulting in shortage of oxygen supply for the development of embryos (Fan and Shi, 2002). The physiological processes involved, as well as the mechanism underlying neural control in hatching of fish embryos are still unclear. Therefore, it is important to know the normal biology of the hatching process and how chlorpyrifos interfere with the development of the hatching gland of Banded Gourami. 
In this study, we also observed that the mortality rate of embryos and larvae significantly increased with increasing chlorpyrifos concentrations (Table 2). The 24-h LC50 of chlorpyrifos for Banded Gourami embryo was $11.8 \mu \mathrm{g} / \mathrm{L}$, which is two times lower than those of the $96-\mathrm{h}$ LC50 for eastern rainbow fish eggs (Humphrey and Klumpp, 2003) and is one-tenth of the 48h LC50 for turbot eggs (Psetta maxima) (Mhadhbi and Beiras, 2012). We showed that Banded Gourami eggs were more sensitive to chlorpyrifos than two-day-old larvae. However, during the early development, fish show variable sensitivity with some compounds displaying higher sensitivity in embryos whereas others are more toxic to larvae (Ansari and Ansari, 2012; Gaikowski et al., 1996; Arufe et al., 2010). In this study, the 24-h and 48-h LC50 of chlorpyrifos for two-day-old larvae were 21.7 and $5.47 \mu \mathrm{g} / \mathrm{L}$, respectively. This indicates that chlorpyrifos is highly toxic to Banded Gourami larvae. Oruc (2010) estimated the 96-h LC50 of chlorpyrifos for juvenile nile tilapia (Oreochromis niliticus) as $98.67 \mu \mathrm{g} / \mathrm{L}$, which was 18 times higher than our finding. Several studies covering both temperate and tropical regions show higher LC50 of chlorpyrifos for other fishes than that for Banded Gourami larvae (Table 1). For instance, the 96-h LC50 of juvenile common carp (Cyprinus carpio) ranged between $149 \mu \mathrm{g} / \mathrm{L}$ (Li et al., 2013) and $582 \mu \mathrm{g} / \mathrm{L}$ (Xing et al., 2015), which is 7 to 26 times higher than that of Banded Gourami larvae we reported. The higher LC50 of chlorpyrifos for adult spotted snakehead (Channa punctatus) than that of the larvae Banded Gourami was also reported by Ali et al. (2008).

In our study, we found several malformations in Banded Gourami larvae due to chlorpyrifos exposure, whereas none on embryos (Fig. 1). All deformities were observed when the larvae were exposed to concentrations higher than $10 \mu \mathrm{g} / \mathrm{L}$ chlorpyrifos. Likewise, Shahjahan et al. (2017) observed malformations in stinging catfish when exposed to sumithion and Marimuthu et al. (2013) in African catfish when exposed to buprofezin. In the present study, the most observed notable malformation of Banded Gourami larvae was notochordal deformity, when larvae were mostly exposed to the highest concentration $100 \mu \mathrm{g} / \mathrm{L}$ chlorpyrifos (Fig. 1). Our study is supported by earlier findings on zebrafish exposed to chlorpyrifos (Sreedevi et al., 2014; Yu et al., 2015), cartap (Zhou et al., 2009), malathion (Fraysse et al., 2006), cypermethrin (Shi et al., 2011) bifenthrin (Jin et al., 2010), fipronil (Stehr et al., 2006) and acetofenate (Xu et al., 2008).

In conclusion, we report a first study on the developmental toxicity of chlorpyrifos by using Banded Gourami as a model. Chlorpyrifos significantly affects the hatching, survival of embryo 
and larvae and induces malformations. The results of the study suggest that $1 \mu \mathrm{g} / \mathrm{L}$ of chlorpyrifos in the aquatic environment may have an adverse effect on the development and the reproduction of Banded Gourami. Our study also suggests that Banded Gourami fish could serve as an ideal model species for evaluating the developmental toxicity of environmental contaminants. This study, however, addresses only the exposure of Banded Gourami fish during their early developmental stages. Therefore, for potential persistence of the toxic effects in the long-term, we recommend future studies to evaluate the same endpoints in juvenile or adult of Banded Gourami to determine whether the effects of chlorpyrifos are transitory or permanent.

\section{Acknowledgements}

This study was funded by Netherlands Universities Foundation for International Cooperation (NUFFIC) project "Integrated Management of Crop-fish-water resources to enhance agricultural production systems towards sustainable food security in Bangladesh - NICHE-BGD156 ". The authors are indebted to Md. Azad for his kind help in induced breedingBaxinded Gourami. 
92 


\section{Chapter 6}

Effects of long-term chlorpyrifos exposure on mortality and reproductive tissues of Banded Gourami (Trichogaster fasciata)

Kizar Ahmed Sumon, Most. Farzana Yesmin, Paul J. Van den Brink, Roel H. Bosma, Edwin T.H.M. Peeters, Harunur Rashid 


\section{Abstract}

The main objective of this study was to assess the long-term toxicity of chlorpyrifos on survival and reproduction of Banded Gourami using mortality, gonado-somatic index (GSI) and histopathological observations as endpoints. Therefore, adult fish were exposed to five different concentrations of chlorpyrifos $(0,15,50,150,500 \mu \mathrm{g} / \mathrm{L})$ in 15 PVC tanks for 15, 30, 45, 60 and 75 days. Results showed that all fish including male and female had died after 15 days of $500 \mu \mathrm{g} / \mathrm{L}$ chlorpyrifos exposure. No consistent significant effect was observed for both male and female GSI. Furthermore, results showed dose- and duration-dependent histopathological alterations for both ovary and testes. The chronic NOEC (60-d) for most histopathological alterations of Banded Gourami ovary and testes was calculated as $50 \mu \mathrm{g} / \mathrm{L}$, while 60-d NOEC for mortality of both male and female fish was $<15 \mu \mathrm{g} / \mathrm{L}$. The results of the study show that the long-term exposure to chlorpyrifos affect the reproductive tissues of Banded Gourami at exposure concentrations also causing mortality. Future studies should evaluate effects at lower concentrations as even the lowest concentration of $15 \mu \mathrm{g} / \mathrm{L}$. 


\section{Introduction}

As many other developing countries, the government of Bangladesh has promoted the use of pesticide to enhance agricultural yields (Dasgupta et al., 2007). Pesticide use in Bangladesh was negligible until 1960s, but has recorded a considerable increase from 7,350 metric tons in 1992 to 45,172 metric tons in 2010 (Ali et al., 2018). The organophosphates have become the most commonly used pesticides in different parts of the world like Bangladesh (Shahjahan et al., 2017), because of the increasing restrictions on the use of organochlorine pesticides in the environment (Benli and Ozkul, 2010).

Chlorpyrifos (CAS No. 2921-88-2; 0,0-diethyl 0-3,5,6-trichloro-2-pyridyl phosphorothioate) is a broad spectrum organophosphate synthetic insecticide and acaricide (Yen et al., 2011; Manjunatha and Philip, 2016). Chlorpyrofis was introduced for agricultural and household applications in the USA in 1965 (Juberg et al., 2013). In agriculture, this insecticide is used to control foliar insects on cotton, soybeans, corn, paddy fields, fruits including coconut, banana, mango, grapes, pineapples, and vegetables including beans, potatoes, tomatoes, cauliflower and cabbage (Rao et al., 2003; Juberg et al., 2013; Lewis et al., 2016; Sumon et al., 2017).

Chlorpyrifos may end up in aquatic habitats including streams, rivers and ponds due to direct overspray, atmospheric transport, agricultural and residential runoff, ground water leaching and improper disposal (Narra et al., 2011; Sumon et al., 2016; 2017). A broad range of concentrations of chlorpyrifos in water have been detected in different (sub-) tropical regions of the world: $0.06 \mu \mathrm{g} / \mathrm{L}$ and $37 \mu \mathrm{g} / \mathrm{L}$ in paddy field waters of Bangladesh (Bhattacharjee et al., 2012; Hasanuzzaman et al., 2018); 0.003-0.006 $\mu \mathrm{g} / \mathrm{L}$ in water in Kaithal and Pant Nagar (Mukherjee and Arora, 2011) and $30 \mu \mathrm{g} / \mathrm{L}$ in river water in India (Mohammed and Penmethsa, 2014); $0.2 \mu \mathrm{g} / \mathrm{L}$ in water of Mae Sa watershed in northern Thailand (Sangchan et al., 2014); $0.007 \mu \mathrm{g} / \mathrm{L}$ in surface water and $0.016 \mu \mathrm{g} / \mathrm{L}$ in ground water in southern coast watershed of Caspian Sea, Iran (Rahmanikhah et al., 2011); between $8.8 \mu \mathrm{g} / \mathrm{L}$ and $26.6 \mu \mathrm{g} / \mathrm{L}$ in water in Lake Naivasha of Kenya (Otieno et al., 2012) and up to $780 \mu \mathrm{g} / \mathrm{L}$ in river water in Nigeria (Akan et al., 2014).

The release of this insecticide into the aquatic environment may have potential toxic effects on non-target aquatic organisms like invertebrates (Maltby et al., 2005; Daam et al., 2008; Palma et al., 2008; 2009; Rubach et al., 2011; 2012), and vertebrates (Maltby et al., 2005; 
Oruç, 2010; Bernabò et al., 2011; Li et al., 2013; Manjunatha and Philip, 2016; Sumon et al., 2017). Among vertebrates, fish is often used as suitable bio-indicator, because of their wide distribution in aquatic environment, long lifespan, free swimming, ability to respond against environmental xenobiotics, and importance as a food source for human beings (Gupta et al., 2009; Narra et al., 2011; Correia et al., 2017).

In different parts of the world studies have assessed the toxicity of chlorpyrifos on several endpoints of different fishes. Chlorpyrifos is reported to affect growth (Huynh and Nugegoda, 2012), survival (Oruç, 2010; Mhadhbi and Beiras, 2012), haematological profiles (Nwani et al., 2013; Narra et al., 2015), hepatic dysfunction (Oruç, 2012), neuro-behavioral dysfunction (Levin et al., 2004), oxidative stress (Oruç, 2012), genotoxic stress (Xing et al., 2015), cytotoxic stress (Palanikumar et al., 2014) and reproduction (De Silva and Samayawardhena, 2005; Hou et al., 2009; Oruç, 2010; Juberg et al., 2013; Lauan and Ocampo, 2013; Manjunatha and Philip, 2016; Brandt et al., 2015) in different fish species, but not yet on Banded Gourami (Trichogaster fasciata) for any of the endpoints as per our literature survey.

The Banded Gourami or Striped Gourami fish belonging to the family Osphronemidae, is one of the perch found in some Asian countries like Bangladesh, India, Myanmar, Nepal and Pakistan (Mitra et al., 2007). The species is important as a nutritional source for humans and as ornamental value used in aquaria (Sumon et al., 2017). In the past, the species was readily available in freshwater pools, ponds, ditches, marshes, rivers, lakes with vegetation, but the natural resources of this fish are declining fast in Bangladesh due to various anthropogenic stressors (Hossen et al., 2014). In our earlier study (Sumon et al., 2017), we investigated the chlorpyrifos toxicity on the early life stages of this fish species. However, the information on the toxicity of chlorpyrifos on mortality and reproduction (key endpoints) of adult Banded Gourami is lacking in earlier studies. To address this knowledge gap, we aimed at assessing the effects of long-term exposure to chlorpyrifos on the mortality and reproductive tissues of adult Banded Gourami using the mortality, gonado-somatic index (GSI) and histopathological observations. We studied the histopathological alterations of Banded Gourami after chronic exposure to chlorpyrifos, because histopathological examination represents a useful and rapid tool to assess the degree of pollution, particularly for sub-lethal and chronic effects in various tissues and organs (Cengiz and Unlu, 2006; Velmurugan et al., 2007; Chourpagar and Kulkarani, 2014; Paruruckumani et al., 2015; Correia et al., 2017). The results of the study 
would elucidate the dose- and duration-dependent mortality and reproductive damages of Banded Gourami fish due to toxic effects of chlorpyrifos.

\section{Materials and methods}

\subsection{Fish and their holding}

Semi-adult fish were collected from the Bara beel of Gauripur, Mymensingh. A beel is a deep depression along a river where water remains permanent throughout the year. Fish were transported in a plastic container and washed with a $0.1 \% \mathrm{KMnO}_{4}$ solution. They were reared in an indoor cemented rectangular cistern $(250 \mathrm{~cm} \times 195 \mathrm{~cm} \times 70 \mathrm{~cm}$; water height: $30 \mathrm{~cm})$ at Faculty of Fisheries, Bangladesh Agricultural University, Bangladesh with continuous aeration over a period of three months. We did the entire experiment under natural light (13-h light/11-h dark photoperiod) and ambient temperature. Fish were fed a commercial feed twice a day at a rate of $2 \% / \mathrm{kg}$ body weight. Banded Gourami fish used in this experiment was approved by the Animal Care and Use Committee of Bangladesh Agricultural University, Mymensingh, Bangladesh.

\subsection{Chemicals}

Chlorpyrifos (Dursban with 20\% active ingredient; manufacturer: Dow AgroSciences India Pvt. Ltd., India) was purchased from a local pesticide supplier (Mymensingh, Bangladesh). All reagents and Haematoxylene-eosin were bought from a local supplier.

\subsection{Experimental design}

After three months rearing of semi-adult fish in cemented cistern, adult fish (length $=6.9 \pm 0.8$ $\mathrm{cm}$; weight $=10.5 \pm 0.8 \mathrm{~g}$ ) were transferred into PVC tanks (top and bottom diameter: $172 \mathrm{~cm}$; total height: $78 \mathrm{~cm}$ ) for a static bioassay. The median lethal concentration (96-h LC50) of chlorpyrifos for the adult Banded Gourami was determined according to the guideline described by the Organization for Economic Cooperation and Development (OECD, 1992). In the present bioassay, seven different chlorpyrifos concentrations $(0,150,250,350,450,550$, and $650 \mu \mathrm{g} / \mathrm{L}$ ) were evaluated in 21 tanks containing $100 \mathrm{~L}$ of dechlorinated tap water with continuous aeration. Each treatment and the control were triplicated and each replicate contained seven fish. Fish were acclimatized for 7 days before chlorpyrifos exposure. Feeding was stopped before $24 \mathrm{~h}$ and throughout the exposure period of $96 \mathrm{~h}$. Mortality of fish was recorded at $24,48,72$, and $96 \mathrm{~h}$ of chlorpyrifos exposure. Dead individuals were removed 
immediately from the experimental units. The water quality (mean $\pm S D$ ) variables in the static bioassay were: temperature $(26.5 \pm 1 \stackrel{\circ}{\circ})$, dissolved oxygen $(7.8 \pm 0.5 \mathrm{mg} / \mathrm{L}), \mathrm{pH}(7.9 \pm 0.3)$ and total alkalinity $(180.3 \pm 7.8 \mathrm{mg} / \mathrm{L})$.

To assess long-term chlorpyrifos exposure, adult healthy Banded Gourami females ( $n=150$; length $=7.97 \pm 0.72 \mathrm{~cm}$; weight $=9.76 \pm 2.30 \mathrm{~g})$ and males $(\mathrm{n}=150$; length=8.63 $\pm 0.72 \mathrm{~cm}$; weight $=11.91 \pm 2.59 \mathrm{~g}$ ) were selected. Twenty fish ( 10 males and 10 females) were stocked into each of the 15 prepared PVC tanks, containing $300 \mathrm{~L}$ of de-chlorinated tap water. These tanks were coated with a non-toxic epoxy paint. An aeration system was installed to mix the water and provide sufficient oxygen during the experimental period of 75 days. Fish were acclimatized to the laboratory conditions for a period of 21 days prior to exposure (OECD, 1996). Fish were exposed to five different concentrations of chlorpyrifos (0, 15, 50, 150 and $500 \mu \mathrm{g} / \mathrm{L}$; the $96-\mathrm{h} \mathrm{LC50}$ in this study was $833 \mu \mathrm{g} / \mathrm{L}$ ) for $15,30,45,60$ and 75 days. The control and treatments were set up in three replicates. The stock solutions were prepared by dissolving the weighed amount of chlorpyrifos in distilled water to obtain $200 \mathrm{~g} / \mathrm{L}$ chlorpyrifos. Natural light and ambient temperature was maintained throughout the acclimation and exposure period. Excess food and excretions were siphoned out every day using a plastic pipette. Water (about 80\%) in the experimental units was changed every three days and fresh chlorpyrifos concentrations were used. In our study, we did not measure the exposure concentrations, however, considering the half-life of chlorpyrifos in water phase $($ DT50 water $=$ 5 days; Lewis et al., 2016), it could be expected that 3-day intervals of water renewal would expose the fishes to relevant concentrations of chlorpyrifos throughout the experimental period. The water quality variables were determined every alternate day according to APHA (APHA, 1985). The values (mean \pm SD) of water quality in the experimental units were as follows: temperature: $27.7 \pm 1.3 \stackrel{\circ}{\circ} \mathrm{C}$; dissolved oxygen: $6.5 \pm 0.8 \mathrm{mg} / \mathrm{L} ; \mathrm{pH}: 8.7 \pm 0.2$; total alkalinity as $\mathrm{CaCO}_{3}: 184.6 \pm 10.2 \mathrm{mg} / \mathrm{L}$; electrical conductivity: $368.5 \pm 2.8 \mu \mathrm{S} / \mathrm{cm}$, and total dissolved solids: $171 \pm 4.5 \mathrm{mg} / \mathrm{L}$.

\subsection{Mortality assessment, gonad collection and GSI estimation}

The number of dead fish was scored every day during the experimental period of 75 days and dead individuals were removed immediately from the experimental units. Fish were considered dead if there was no visible movement (e.g. gill movement) and if touching of the caudal peduncle produced no reaction (OECD, 1992). Two fish (one male and one female) 
were retrieved from each replicate at each sampling date and were anesthetized with 100 $\mathrm{mg} / \mathrm{L}$ of MS222 to prevent any suffering during gonad collection. Prior to gonad collection, the length and body weight of both male and female fish were recorded. Fish were killed by decapitation and gonads were dissected out and weighed. The gonads were rinsed with physiological solution ( $0.9 \%$ sodium chloride) and later transferred to $10 \%$ buffered formalin solution at ambient temperature for appropriate fixation. The value of gonado-somatic index (GSI) was estimated by the following formula: GSI = [(gonad weight/body weight) $\times 100$ ] (Barber and Blake, 2006).

\subsection{Histopathology of gonads}

For histological observation, the fixated gonad tissues were washed with running tap water for $24 \mathrm{~h}$, processed, dehydrated in graded alcohol, cleared in benzene, and embedded in paraffin. The paraffin blocks were sectioned with microtome at a thickness of $5 \mu \mathrm{m}$ and were stained with hematoxylin and counterstained with eosin. Finally, the histopathological alterations were photographed using digital photomicroscope (Olympus CX 41).

\subsection{Statistical analyses}

The mortality and GSI values of female and male Banded Gourami and the histopathological alterations of ovary and testis (\%) were presented as the mean of the three replicates \pm standard deviation (SD). The LC10, LC50 and LC90 values of chlorpyrifos for Banded Gourami were calculated by means of log-logistic regression using the software GenStat $11^{\text {th }}$ (VSN International Ltd., Oxford, UK) according to Rubach et al. (2011). No Observed Effect Concentrations (NOECS) were calculated at taxon level ( $p \leq 0.05$ ) using the Williams test (ANOVA; Williams, 1972) as incorporated in the Community Analysis software (Hommen et al., 1994). Before univariate analyses were performed, the parameter values were log transformed using the formula: In $(A x+1)$; see Van den Brink et al. (2000) for the rationale of calculating A. The GSI values were, therefore, log transformed using In $(200 x+1)$, while all other parameters were transformed with $\ln (0.2 x+1)$. 


\section{Results}

\subsection{Chlorpyrifos effects on mortality of Banded Gourami}

The calculated 96-h LC10, LC50 and LC90 (with 95\% confidence limits) of chlorpyrifos for the adult Banded Gourami were 258 (158-421), 833 (506-1371), and 2689 (727-9942) $\mu \mathrm{g} / \mathrm{L}$, respectively. During the static bioassay, mortality was not observed in the control groups.

The long-term 60-d LC50 for both males and females was around $50 \mu \mathrm{g} / \mathrm{L}$ with the LC1 0 and LC90 only being lightly lower and higher, respectively (Table 1). A dose- and durationdependent significant increase in both male and female mortality was observed after 15 and 30 days of chlorpyrifos exposure to the highest and the second highest concentrations with a NOEC of $50 \mu \mathrm{g} / \mathrm{L}$. But such significant increase in male and female mortality was observed in the lowest concentration ( $15 \mu \mathrm{g} / \mathrm{L}$ ) after 45 and 60 days of exposure, respectively (with a NOEC of $<15 \mu \mathrm{g} / \mathrm{L}$ ) (Table 1 and S1). All fish, including males and females had died 15 days after the first chlorpyrifos exposure in the highest concentration $(500 \mu \mathrm{g} / \mathrm{L})$ (Table 1). In the present study, $100 \%$ mortality for male fish was observed after 45 days in $150 \mu \mathrm{g} / \mathrm{L}$, and 60 days for female fish in the same treatment. After 75 days of exposure, 100\% mortality was observed for male fish when exposed to the lowest concentration (15 $\mu \mathrm{g} / \mathrm{L})$ (Table 1). 


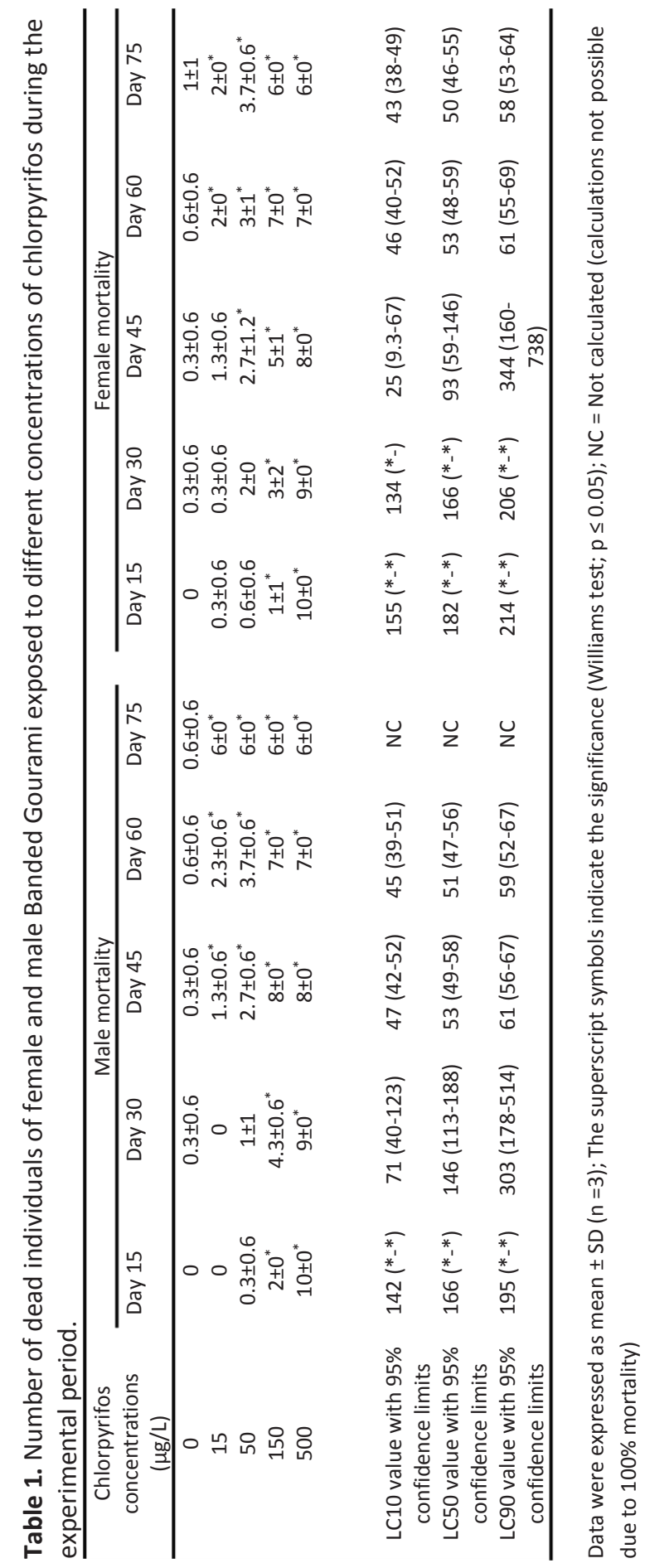




\subsection{Chlorpyrifos effects on female gonad}

A dose- and duration-dependent significant decrease in female GSI was observed after 15 days of chlorpyrifos exposure to the highest concentration with living individuals ( $150 \mu \mathrm{g} / \mathrm{L}$ ) with a NOEC of $50 \mu \mathrm{g} / \mathrm{L}$, but the trend was not consistent for the next sampling days (Table 2 and S1). However, dose- and duration-dependent histopathological alterations in the ovary were evident (Fig. 1). The ovaries extracted from the control fish did not show any histopathological alterations during the experimental period (Fig. 1A). After 15 days of exposure, alterations like cytoplasmic clumping (CC) and cytoplasmic retraction (CR), and atretic follicles (AF) were observed when the fish were exposed to $150 \mu \mathrm{g} / \mathrm{L}$ of chlorpyrifos (Fig. 1B). The most observed notable histopathological alteration in female gonad induced by chlorpyrifos toxicity was the atretic follicles (AF) (Fig. 1B-E and Fig. 1G-H), and this atresia was found to be severe after 75 days of first chlorpyrifos exposure to $50 \mu \mathrm{g} / \mathrm{L}$ (Fig. 1H). Degenerated perinucleolar oocyte (DPNO) was observed after 45 days of chlorpyrifos exposure to 50 and $150 \mu \mathrm{g} / \mathrm{L}$ (Fig. 1D and E). Adhesion ( $A D)$ between numerous oocytes were prominent when exposed to different concentrations of chlorpyrifos (Fig. 1D-F and Fig. 1H). The treated ovary showed degenerations of ovigerous lamellae (DOL) (Fig. 1C-E and $1 \mathrm{G}$ ). Inter follicular spaces (IFS) were evident after 45 days (Fig. 1D) and 75 days (Fig. 1H) of exposure to $50 \mu \mathrm{g} / \mathrm{L}$. A few necrosis (NE) was noticed in treated ovary after 60 days (Fig. 1G) and 75 days (Fig. 1H) of exposure to $50 \mu \mathrm{g} / \mathrm{L}$. A significant increase of histopathological alterations (\%) in ovary were found after 15 and 30 days of $150 \mu \mathrm{g} / \mathrm{L}$ chlorpyrifos exposure (NOEC of $50 \mu \mathrm{g} / \mathrm{L}$ ), but after 45 days of exposure onwards such significant increase in several alterations were observed when exposed to $50 \mu \mathrm{g} / \mathrm{L}$ (NOEC of $15 \mu \mathrm{g} / \mathrm{L}$ ) (Table 3 and S1).

Table 2. GSI data of female and male Banded Gourami fish exposed to different concentrations of chlorpyrifos during the experimental period.

\begin{tabular}{|c|c|c|c|c|c|c|c|c|c|c|}
\hline \multirow{2}{*}{$\begin{array}{c}\text { Chlorpyrifos } \\
\text { concentrations } \\
(\mu \mathrm{g} / \mathrm{L})\end{array}$} & \multicolumn{5}{|c|}{ Days of exposure for female } & \multicolumn{5}{|c|}{ Days of exposure for male } \\
\hline & 15 & 30 & 45 & 60 & 75 & 15 & 30 & 45 & 60 & 75 \\
\hline 0 & $11 \pm 2.6$ & $\begin{array}{c}7.9 \pm 1 \\
3\end{array}$ & $\begin{array}{c}7.6 \pm 2 \\
5\end{array}$ & $\begin{array}{c}5.7 \pm 4 \\
4\end{array}$ & $\begin{array}{c}6.6 \pm 3 \\
7\end{array}$ & $1.0 \pm 0.2$ & $1.1 \pm 0.2$ & $0.07 \pm 0.05$ & $0.13 \pm 0.07$ & $0.1 \pm 0.06$ \\
\hline 15 & $7.4 \pm 4.3$ & $\begin{array}{c}7.5 \pm 0 \\
9\end{array}$ & $\begin{array}{c}5.4 \pm 2 \\
2\end{array}$ & $\begin{array}{c}5.9 \pm 2 \\
5\end{array}$ & $\begin{array}{c}3.4 \pm 3 \\
3\end{array}$ & $0.5 \pm 0.3^{*}$ & $0.6 \pm 0.2^{*}$ & $0.13 \pm 0.1$ & $0.1 \pm 0.08$ & ND \\
\hline 50 & $6.3 \pm 3.4$ & $\begin{array}{c}5.8 \pm 1 \\
4\end{array}$ & $\begin{array}{c}6.7 \pm 0 \\
7\end{array}$ & $\begin{array}{c}3.5 \pm 1 \\
1\end{array}$ & $\begin{array}{c}3.8 \pm 3 \\
4\end{array}$ & $0.4 \pm 0.1^{*}$ & $0.4 \pm 0.1^{*}$ & $0.09 \pm 0.03$ & $0.1 \pm 0.01$ & ND \\
\hline 150 & $4.2 \pm 2.8^{*}$ & $\begin{array}{c}3.7 \pm 3 \\
2\end{array}$ & $\begin{array}{c}5.4 \pm 0 \\
8\end{array}$ & ND & ND & $0.3 \pm 0.1^{*}$ & $\underset{*}{0.1 \pm 0.06}$ & ND & ND & ND \\
\hline 500 & ND & ND & ND & ND & ND & ND & ND & ND & ND & ND \\
\hline
\end{tabular}

Data were expressed as mean \pm SD $(n=3) ; N D=$ No data due to fish mortality; The symbols of superscripts indicate the significance (Williams test; $p \leq 0.05$ ) 
Table 3. Summary of histopathological alterations (\%) of Banded Gourami ovary exposed to different concentrations of chlorpyrifos during the experimental period.

\begin{tabular}{|c|c|c|c|c|c|c|}
\hline \multirow[t]{2}{*}{ Alterations } & \multirow{2}{*}{$\begin{array}{l}\text { Chlorpyrifos } \\
\text { concentrations } \\
(\mu \mathrm{g} / \mathrm{L})\end{array}$} & \multicolumn{5}{|c|}{ Exposure time (days) } \\
\hline & & 15 & 30 & 45 & 60 & 75 \\
\hline Cytoplasmic clumping & 0 & 0 & 0 & 0 & 0 & 0 \\
\hline \multirow[t]{4}{*}{ (CC) } & 15 & 0 & 0 & 0 & 0 & 0 \\
\hline & 50 & 0 & 0 & 0 & 0 & 0 \\
\hline & 150 & $18.3 \pm 16.0^{*}$ & 0 & $11.7 \pm 8.5^{*}$ & ND & ND \\
\hline & 500 & ND & ND & ND & ND & ND \\
\hline \multirow{5}{*}{ (CR) } & 0 & 0 & 0 & 0 & 0 & 0 \\
\hline & 15 & 0 & 0 & 0 & 0 & 0 \\
\hline & 50 & 0 & 0 & 0 & 0 & 0 \\
\hline & 150 & $18.3 \pm 16.0^{*}$ & 0 & $11.7 \pm 8.5^{*}$ & ND & ND \\
\hline & 500 & ND & ND & ND & ND & ND \\
\hline \multirow[t]{5}{*}{ Atretic follicle (AF) } & 0 & 0 & 0 & 0 & 0 & 0 \\
\hline & 15 & 0 & 0 & 0 & 0 & 0 \\
\hline & 50 & 0 & 0 & $35 \pm 4^{*}$ & $43.3 \pm 5.8^{*}$ & $60 \pm 10^{*}$ \\
\hline & 150 & $30 \pm 21.6^{*}$ & $16.7 \pm 23.6$ & $26.7 \pm 16.9^{*}$ & ND & ND \\
\hline & 500 & ND & ND & ND & ND & ND \\
\hline \multirow{5}{*}{$\begin{array}{l}\text { Degenerated } \\
\text { perinucleolar oocyte } \\
\text { (DPNO) }\end{array}$} & 0 & 0 & 0 & 0 & 0 & 0 \\
\hline & 15 & 0 & 0 & 0 & 0 & 0 \\
\hline & 50 & 0 & 0 & $21.7 \pm 2.4^{*}$ & 0 & 0 \\
\hline & 150 & 0 & 0 & $16.7 \pm 4.7^{*}$ & ND & ND \\
\hline & 500 & ND & ND & ND & ND & ND \\
\hline \multirow[t]{5}{*}{ Adhesion (AD) } & 0 & 0 & 0 & 0 & 0 & 0 \\
\hline & 15 & 0 & 0 & 0 & $23.3 \pm 23.6$ & 0 \\
\hline & 50 & 0 & 0 & $15 \pm 4^{*}$ & 0 & $20 \pm 8.2^{*}$ \\
\hline & 150 & 0 & 0 & $23.3 \pm 9.4^{*}$ & ND & ND \\
\hline & 500 & ND & ND & ND & ND & ND \\
\hline \multirow{5}{*}{$\begin{array}{l}\text { Degeneration of } \\
\text { ovigerous lamellae } \\
\text { (DOL) }\end{array}$} & 0 & 0 & 0 & 0 & 0 & 0 \\
\hline & 15 & 0 & 0 & 0 & $23.3 \pm 23.6^{*}$ & 0 \\
\hline & 50 & 0 & 0 & $11.7 \pm 8.5$ & $40 \pm 8.2^{*}$ & 0 \\
\hline & 150 & 0 & $16.7 \pm 23.6$ & $10 \pm 14$ & ND & ND \\
\hline & 500 & ND & ND & ND & ND & ND \\
\hline \multirow{5}{*}{$\begin{array}{l}\text { Interfollicular space } \\
\text { (IFS) }\end{array}$} & 0 & 0 & 0 & 0 & 0 & 0 \\
\hline & 15 & 0 & 0 & 0 & 0 & 0 \\
\hline & 50 & 0 & 0 & $16.7 \pm 6.2$ & 0 & $3.3 \pm 4.7$ \\
\hline & 150 & 0 & 0 & 0 & ND & ND \\
\hline & 500 & 0 & 0 & ND & ND & ND \\
\hline \multirow[t]{5}{*}{ Necrosis (NE) } & 0 & 0 & 0 & 0 & 0 & 0 \\
\hline & 15 & 0 & 0 & 0 & 0 & 0 \\
\hline & 50 & 0 & 0 & 0 & $16.7 \pm 12.5^{*}$ & $16.7 \pm 12.5^{*}$ \\
\hline & 150 & 0 & 0 & 0 & ND & ND \\
\hline & 500 & ND & ND & ND & ND & ND \\
\hline
\end{tabular}

Data were expressed as mean $\pm S D(n=3) ; N D=$ No data due to fish mortality; The symbols of superscripts indicate the significance (Williams test; $p \leq 0.05$ ) 

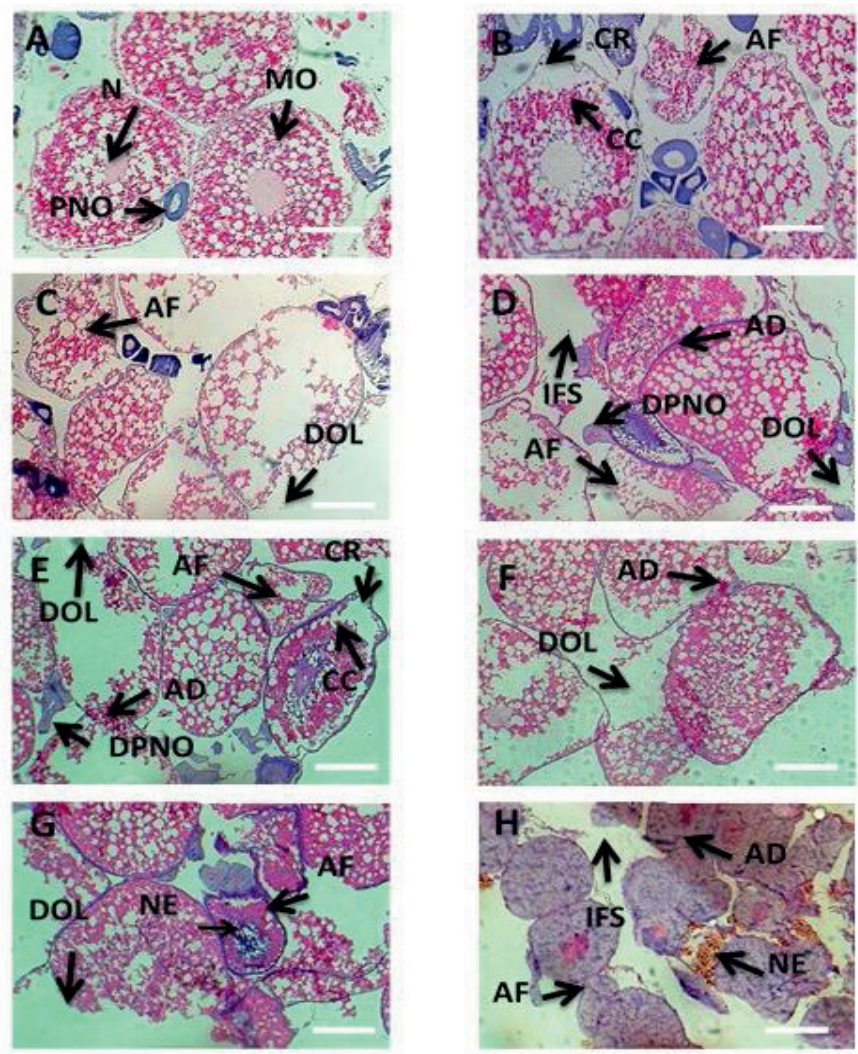

Figure 1. Histopathological alterations observed in banded gourami ovary due to chlorpyrifos toxicity during the experimental period. (A) Mature oocyte (MO), normal structure of nucleus $(\mathrm{N})$, and perineucleolar oocyte (PNO) after 15 days of exposure to $0 \mu \mathrm{g} / \mathrm{L}$ (control ovary); (B) Atretic follicle (AF), cytoplasmic clumping (CC), and cytoplasmic retraction (CR) after 15 days of exposure to $150 \mu \mathrm{g} / \mathrm{L}$; (C) Atretic follicle (AF), and degeneration of ovigerous lamellae (DOL) after 30 days of exposure to $150 \mu \mathrm{g} / \mathrm{L}$; (D) Adhesion (AD), atretic follicle (AF), degenerated perineucleolar oocyte (DPNO), interfollicular space (IFS), and degeneration of ovigerous lamellae (DOL) after 45 days of exposure to $50 \mathrm{\mu g} / \mathrm{L}$; (E) Cytoplasmic clumping (CC), cytoplasmic retraction (CR), adhesion (AD), atretic follicle (AF), degenerated perineucleolar oocyte (DPNO), and degeneration of ovigerous lamellae (DOL) after 45 days of exposure to $150 \mu \mathrm{g} / \mathrm{L}$; (F) Adhesion (AD), and degeneration of granulosa layer (DGL) after 60 days of exposure to $15 \mu \mathrm{g} / \mathrm{L}$; $(\mathrm{G})$ Atretic follicle (AF), necrosis (NE) and degeneration of ovigerous lamellae (DOL) after 60 days of exposure to $50 \mu \mathrm{g} / \mathrm{L}$; (H) Atretic follicle (AF), adhesion (AD), necrosis (NE), and interfollicular space (IFS) after 75 days of exposure to $50 \mu \mathrm{g} / \mathrm{L} ; \mathrm{H}$ and $\mathrm{E}$ stain; $\times 100$; scale bar $=100 \mu \mathrm{m}$. 


\subsection{Chlorpyrifos effects on male gonad}

The male GSI significantly decreased with increasing chlorpyrifos concentrations after 15 and 30 days of exposure with a NOEC of $<15 \mu \mathrm{g} / \mathrm{L}$ (Table 2 and S1). However, no such significant decrease of male GSI was found from day 45 onwards. Several dose- and duration-dependent histopathological alterations of testis were evident due to chlorpyrifos toxicity (Fig. 2). Like ovary, the testes which were extracted from the control fish did not show any histopathological alteration during the experimental period. The control testis contained regular-shaped of seminiferous tubules which were characterised by a round, oval or somewhat rectangular shape, and regular-shaped of sertoli cells and interstitial cell of Leydig (Fig 2A). The treated testis showed several histopathological alterations like irregular shaped seminiferous tubules (ISST), breakage of seminiferous tubules (BST), damaged sertoli cells (DSC), degeneration of interstitial cell of Leydig (DICL), and empty lumen (EL) (Fig. 2B-E and Fig. 2G-H). When exposed to $50 \mu \mathrm{g} / \mathrm{L}$, severe breakage of seminiferous tubules accompanied with empty lumen were observed after 60 days (Fig. $2 \mathrm{H}$ ), as well as some testicular oocytes (TO) in the treated testis after 45 days (Fig. 2E-F). A significant increase of histopathological alterations (\%) in testis were observed after 15 and 30 days of $150 \mu \mathrm{g} / \mathrm{L}$ chlorpyrifos exposure (NOEC of $50 \mu \mathrm{g} / \mathrm{L}$ ), but such significant increase of several alterations were noticed when exposed to $50 \mu \mathrm{g} / \mathrm{L}$ (NOEC of $15 \mu \mathrm{g} / \mathrm{L}$ ) after 45 and 60 days (Table 4 and S1). 
Table 4. Summary of histopathological alterations (\%) of Banded Gourami testes exposed to different concentrations of chlorpyrifos during the experimental period.

\begin{tabular}{|c|c|c|c|c|c|c|}
\hline \multirow[t]{2}{*}{ Alterations } & \multirow{2}{*}{$\begin{array}{l}\text { Chlorpyrifos } \\
\text { concentrations } \\
(\mu \mathrm{g} / \mathrm{L})\end{array}$} & \multicolumn{5}{|c|}{ Exposure time (days) } \\
\hline & & 15 & 30 & 45 & 60 & 75 \\
\hline \multirow{5}{*}{$\begin{array}{l}\text { Irregular shape of } \\
\text { seminiferous tubule } \\
\text { (ISST) }\end{array}$} & 0 & 0 & 0 & 0 & 0 & 0 \\
\hline & 15 & 0 & 0 & $46.7 \pm 4.7$ & $23.3 \pm 17$ & ND \\
\hline & 50 & 0 & 0 & $18.3 \pm 2.4$ & 0 & ND \\
\hline & 150 & 0 & $30 \pm 21.6^{*}$ & ND & ND & ND \\
\hline & 500 & ND & ND & ND & ND & ND \\
\hline \multirow{5}{*}{$\begin{array}{l}\text { Breakage of } \\
\text { seminiferous tubule } \\
\text { (BST) }\end{array}$} & 0 & 0 & 0 & 0 & 0 & 0 \\
\hline & 15 & 0 & 0 & 0 & 0 & ND \\
\hline & 50 & 0 & 0 & 0 & $36.7 \pm 5.8^{*}$ & ND \\
\hline & 150 & $16.7 \pm 12.5^{*}$ & 0 & ND & ND & ND \\
\hline & 500 & ND & ND & ND & ND & ND \\
\hline \multirow{5}{*}{$\begin{array}{l}\text { Degeneration of } \\
\text { interstitial cell of Leydig } \\
\text { (DICL) }\end{array}$} & 0 & 0 & 0 & 0 & 0 & 0 \\
\hline & 15 & 0 & 0 & $28.3 \pm 2.4$ & $23.3 \pm 17^{*}$ & ND \\
\hline & 50 & 0 & 0 & $20 \pm 0$ & $26.7 \pm 5.8^{*}$ & ND \\
\hline & 150 & $26.7 \pm 18.9^{*}$ & $18.3 \pm 13^{*}$ & ND & ND & ND \\
\hline & 500 & ND & ND & ND & ND & ND \\
\hline \multirow{5}{*}{$\begin{array}{l}\text { Damaged sertoli cell } \\
\text { (DSC) }\end{array}$} & 0 & 0 & 0 & 0 & 0 & 0 \\
\hline & 15 & 0 & 0 & $28.3 \pm 2.9$ & $20 \pm 16.3$ & ND \\
\hline & 50 & 0 & 0 & $16.7 \pm 4.7$ & 0 & ND \\
\hline & 150 & $23.3 \pm 17^{*}$ & $18.3 \pm 13^{*}$ & ND & ND & ND \\
\hline & 500 & ND & ND & ND & ND & ND \\
\hline \multirow[t]{5}{*}{ Testicular oocyte (TO) } & 0 & 0 & 0 & 0 & 0 & 0 \\
\hline & 15 & 0 & 0 & 0 & 0 & ND \\
\hline & 50 & 0 & 0 & $25 \pm 5^{*}$ & 0 & ND \\
\hline & 150 & 0 & 0 & ND & ND & ND \\
\hline & 500 & ND & ND & ND & ND & ND \\
\hline \multirow[t]{5}{*}{ Empty lumen (EL) } & 0 & 0 & 0 & 0 & 0 & 0 \\
\hline & 15 & 0 & 0 & 0 & 0 & ND \\
\hline & 50 & 0 & 0 & $20 \pm 0^{*}$ & $36.7 \pm 5.8^{*}$ & ND \\
\hline & 150 & 0 & 0 & ND & ND & ND \\
\hline & 500 & ND & ND & ND & ND & ND \\
\hline
\end{tabular}

Data were expressed as mean \pm SD $(n=3) ; N D=$ No data due to fish mortality; The symbols of superscripts indicate the significance (Williams test; $p \leq 0.05$ ) 

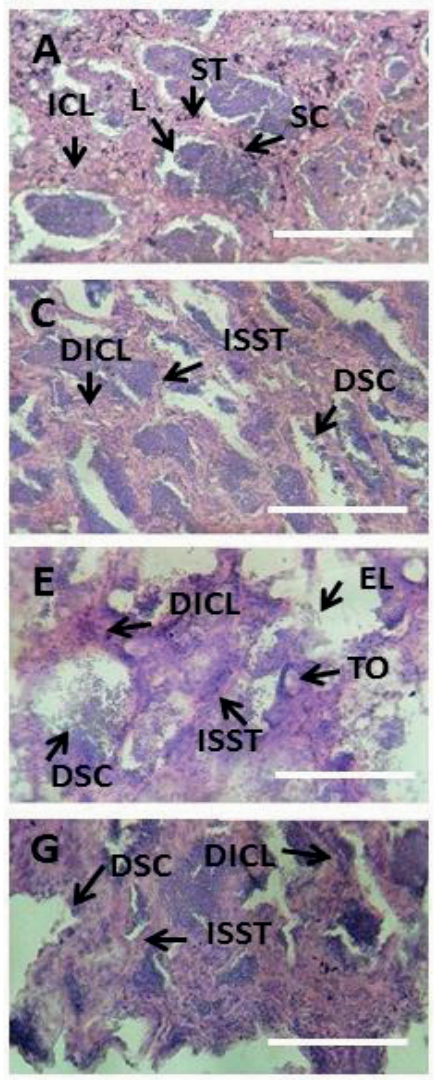
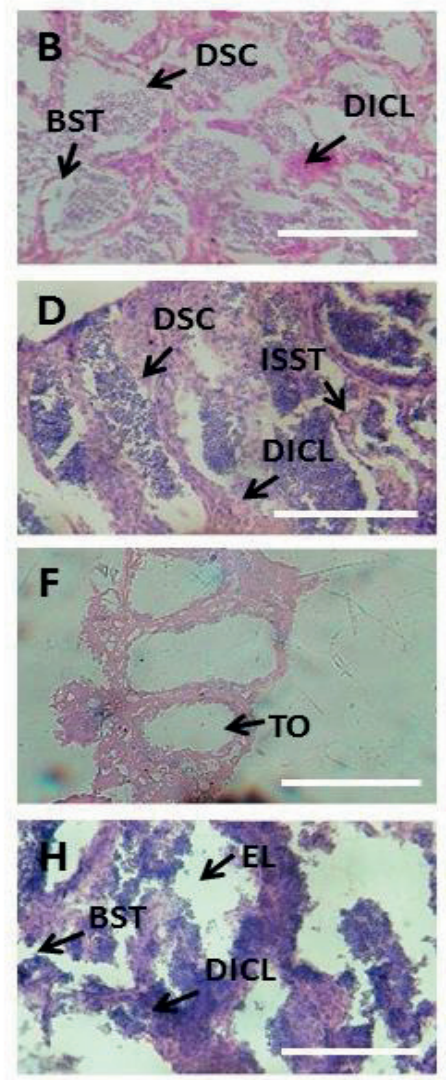

Figure 2. Histopathological alterations observed in banded gourami testis due to chlopyrifos toxicity during the experimental period. (A) normal structure of seminiferous tubule (ST), sertoli cell (SC), lumen (L), and interstitial cell of Leydig (ICL) after 15 days of exposure to 0 $\mu \mathrm{g} / \mathrm{L}$ (control testis); (B) Breakage of seminiferous tubule (BST), damaged sertoli cell (DSC), degeneration of interstitial cell of Leydig (DICL) after 15 days of exposure to $150 \mu \mathrm{g} / \mathrm{L}$; (C) Irregular shape of seminiferous tubule (ISST), damaged sertoli cell (DSC), degeneration of interstitial cell of Leydig (DICL) after 30 days of exposure to $150 \mu \mathrm{g} / \mathrm{L}$; (D) Irregular shape of seminiferous tubule (ISST), damaged sertoli cell (DSC), degeneration of interstitial cell of Leydig (DICL) after 45 days of exposure to $15 \mu \mathrm{g} / \mathrm{L}$; (E) Irregular shape of seminiferous tubule (ISST), damaged sertoli cell (DSC), degeneration of interstitial cell of Leydig (DICL), testicular oocyte (TO), and empty lumen (EL) after 45 days of exposure to $50 \mu \mathrm{g} / \mathrm{L}$; (F) Testicular oocyte (TO) after 45 days of exposure to $50 \mu \mathrm{g} / \mathrm{L}$; (G) Irregular shape of seminiferous tubule (ISST), damaged sertoli cell (DSC), degeneration of interstitial cell of Leydig (DICL) after 60 days of exposure to $15 \mu \mathrm{g} / \mathrm{L} ;(\mathrm{H})$ Breakage of seminiferous tubule (BST), degeneration of interstitial cell of Leydig (DICL), and empty lumen (EL) after 60 days of exposure to $50 \mu \mathrm{g} / \mathrm{L} ; \mathrm{H}$ and $\mathrm{E}$ stain; $\times 400$; scale bar $=50 \mu \mathrm{m}$. 


\section{Discussion}

\subsection{Effects of chlorpyrifos on the mortality of Banded Gourami}

The 96-h LC50 of chlorpyrifos for adult Banded Gourami was $833 \mu \mathrm{g} / \mathrm{L}$ in the static bioassay, while the long-term 60-d LC50 for both male and female was around $50 \mu \mathrm{g} / \mathrm{L}$. Earlier studies demonstrated a varied acute LC50 values of chlorpyrifos for different fish but the data for long-term LC50 of chlorpyrifos for fish is lacking. Mishra and Devi (2014) reported the 96-h LC50 of chlorpyrifos for adult spotted snakehead (Channa punctatus) as $812 \mu \mathrm{g} / \mathrm{L}$, which is almost similar to our study. Oruç (2010) found the 96-h LC50 of chlorpyrifos for adult nile tilapia (Oreochromis niloticus) as $154 \mu \mathrm{g} / \mathrm{L}$, which is about five times lower than we reported for Banded Gourami. Almost similar LC50 values of chlorpyrifos for different fish were estimated by earlier studies (Sharbidre et al., 2011; Mhadhbi and Beiras, 2012; Khalil et al., 2013). Rao et al. (2003) found much more lower short-term LC50 of chlorpyrifos for Oreochromis mossambicus (around $26 \mu \mathrm{g} / \mathrm{L}$ ), while Srivastav et al. (1997) reported for stinging catfish (Heteropneustes fossilis) as $2200 \mu \mathrm{g} / \mathrm{L}$, which is several times higher than we reported for Banded Gourami.

In the present study, the NOEC for both male and female mortality of Banded gourami was calculated as $50 \mu \mathrm{g} / \mathrm{L}$ after 15 and 30 days of first chlorpyrifos exposure. But a lower NOEC of $<15 \mu \mathrm{g} / \mathrm{L}$ was calculated for both male and female mortality after 60 days of exposure, thus indicating the long-term exposure of Banded Gourami to chlorpyrifos showed an elevated mortality even at the lowest concentration (15 $\mathrm{\mu g} / \mathrm{L})$. Earlier studies observed almost similar chronic NOECs for mortality of different fishes. For instance, an average $40-\mathrm{d}$ NOEC of $2.3 \mu \mathrm{g} / \mathrm{L}$ (1.16-116 $\mu \mathrm{g} / \mathrm{L})$ for mortality was calculated for Cyprinus carpio, while an average 30-d and 90-d NOEC of $8.6 \mu \mathrm{g} / \mathrm{L}$ and $2.6 \mu \mathrm{g} / \mathrm{L}$ was calculated for Oreochromis niloticus and Tilapia zilli, respectively (ECOTOX Database (http://cfpub.epa.gov/ecotox/quick_query.htm)).

In our study, we investigated the effects of chlorpyrifos formulation on the short- and longterm mortality of Banded Gourami, however, further studies are needed to investigate the toxicity of chlorpyrifos (technical grade) on the mortality of same species to understand the toxicity differences between technical grade and commercial formulation of chlorpyrifos. Literatures on the differences in toxicity between technical grade and commercial formulation of chlorpyrifos on long-term mortality in fish is lacking. However, only one study by Majumder and Kaviraj (2018) showed that the commercial formulation of chlorpyrifos (96-h LC50 = 42 
$\mu \mathrm{g} / \mathrm{L}$ ) is approximately two folds more toxic to Oreochromis niloticus than the technical grade (96-h LC50 = $90 \mu \mathrm{g} / \mathrm{L}$ ) after an acute exposure. This, because the formulated products might have the added inert ingredients which can enhance the bioavailability and toxicity to target organisms (Cox and Surgan, 2006).

\subsection{Effects of chlorpyrifos on ovary}

The hypothalamic-pituitary-gonadal axis regulates the reproduction of teleost fish and most vertebrates. This axis is dependent on the feedback systems of steroid hormones such as estrogens which are crucial for successful reproduction. Estrogens produced in the ovary may have either a positive or a negative effect on the hypothalamus, pituitary and gonads (Hashimoto et al., 2000). The positive or negative effect is dependent on the hormone concentration needed for normal reproduction and the physiological needs of the fish (Arcand-Hoy and Benson, 1998). The feedback pathways are negatively affected when the hormone concentrations are altered i.e. less production of estrogens due to xenotoxic effects, which may result in impairment of the normal reproductive mechanisms (Maxwell and Dutta, 2005).

The present study found several alterations in the ovarian histopathology of Banded Gourami exposed to different concentrations of chlorpyrifos. The histopathological alterations observed in our study were dose- and duration-dependent because after 15 and 45 days of exposure to $150 \mu \mathrm{g} / \mathrm{L}$, cytoplasmic degenerations like CC and CR were observed, indicating the negative feedback of estrogens to hypothalamic-pituitary-gonadal axis of this fish (Tillitt et al., 2010). Earlier studies demonstrated a strong negative correlation between the damaged ovarian structures and levels of estrogen production in fish exposed to different pesticides (Maxwell and Dutta, 2005; Manjunatha and Philip, 2016). Deka and Mahanta (2012) observed cytoplasmic degenerations in Stinging Catfish (Heteropneustes fossilis) ovary when exposed to $200 \mu \mathrm{g} / \mathrm{L}$ malathion for 10 days. The cytoplasmic alterations were also demonstrated in earlier studies in Bluegill fish (Lepomis macrochirus) ovary exposed to diazinon (Dutta and Maxwell, 2003) and in Puntius ticto ovary exposed to dimethoate (Marutirao, 2013).

In this study, follicular atresia in Banded Gourami ovary was observed after 15 days of chlorpyrifos exposure onwards. The follicular atresia of oocyte stages in chlorpyrifos-exposed ovaries could reflect a disruption in the normal processes of final maturation of oocytes with the subsequent disturbances of ovulation and oviposition which, in turn, may result in 
decreased fertility of Banded Gourami. The atretic follicles were observed by Manjunatha and Philip (2016) in zebrafish (Danio rerio) ovaries after an acute exposure (96 h) to $200 \mu \mathrm{g} / \mathrm{L}$ of chlorpyrifos, Dutta and Maxwell (2003) in bluegill ovary exposed to diazinon, and Narayanaswamy and Mohan (2014) in Glossogobius giuris ovary exposed to malathion. The follicular atresia was also noticed in Puntius ticto ovary after a chronic exposure to dimethoate (Marutirao, 2013), and in Channa punctatus ovary after a sub-chronic exposure to monocrotophos (Maqbool and Ahmed, 2013).

Next to follicular atresia, one of the common histopathological alterations in Banded Gourami ovary when exposed to different concentrations of chlorpyrifos were degenerations of the ovigerous lamellae. Disruption of ovigerous lamellae induced by chlorpyrifos toxicity may cause loss of follicles or empty follicles indicating the loss of genetic material within the follicles. The loss of genetic material in the ovarian follicles of Banded Gourami may hinder the production of estrogens. The results of this study are in line with findings of Dutta and Maxwell (2003) and Maxwell and Dutta (2005) in Bluegill ovary exposed to diazinon, and Marutirao (2013) in Puntius ticto ovary exposed to dimethoate.

Adhesion between oocytes may cause interfollicular space which is evident in our study. In the present study, fusion of oocytes accompanied with interfollicular space was noticed after 45 days of chlorpyrifos exposure to $50 \mu \mathrm{g} / \mathrm{L}$. Oocytes that adhered to one another are prevented from moving on to the next level of maturation. This change in the ovary may inhibit the production of steroids. The results of our study are accordance with earlier studies in Bluegill ovary after $72 \mathrm{~h}$ of diazinon exposure to 60 gg/L (Dutta and Maxwell, 2003; Maxwell and Dutta, 2005).

Necrosis was evident in Banded Gourami ovary after 60 and 75 days of chlorpyrifos exposure to $50 \mu \mathrm{g} / \mathrm{L}$, thus indicating the lack or absence of genetic material after a long-term exposure, which may cause reduced levels of hormone production. Maqbool and Ahmed (2013) observed similar alteration in Channa punctatus ovary after 45 days of $2000 \mu \mathrm{g} / \mathrm{L}$ monocrotophos exposure. Necrosis or loss of genetic materials was also observed in Stinging Catfish ovary after an acute exposure to malathion (Dutta et al., 1994) and in Bluegill ovary exposed to diazinon (Maxwell and Dutta, 2005).

\subsection{Effects of chlorpyrifos on testes}


The testis of fish have different vital structures. Together these structures perform the main function of the testis, which is to make and release mature spermatozoa in order to fertilize eggs. Seminiferous tubules are of primary importance because they hold and release the sperm that is necessary to fertilize eggs. The testis of fish are arranged in lobules that contain germ cells undergoing spermatogenesis (Oropesa et al., 2014; Manjunatha and Philip, 2016).

In this study, the testes of the control Banded Gourami showed more or less regular structure of seminiferous tubules. However, in the treated testes we found certain irregular structures of seminiferous tubules exposed to different concentrations of chlorpyrifos. Severe damage was characterised by the breakage of seminiferous tubules and empty lumen in tubules after 60 days of chlorpyrifos exposure to $50 \mu \mathrm{g} / \mathrm{L}$. The damages of this tubules induced by chlorpyrifos toxicity may disrupt the normal spermatogenesis of Banded Gourami (Oropesa et al., 2014). Manjunatha and Philip (2016) demonstrated seminiferous tubules degeneration of zebrafish testis after an acute exposure to chlorpyrifos. Similar histopathological alteration was reported by Dutta and Meijer (2003) in Bluegill testis exposed to diazinon, Masouleh et al. (2011) in Caspian Kutum testis exposed to diazinon, and Bagchi et al. (1990) in Clarias batrachus testis exposed to quinalphos.

Spermatogenesis is accomplished by the functional activities of reproductive hormones i.e. gonadotrophin releasing hormone, luteinizing hormone, follicle stimulating hormone and testosterone hormone secreted from the hypothalamo-pituitary-testicular axis (Stephen and Yinusa, 2011). Interstitial cells of Leydig are located between the seminiferous tubules maintaining a key role in the spermatogenesis. Their functional activity is regulated by the luteinizing hormone (LH), which binds to LH receptors in the Leydig plasma membrane (Catt and Dufau, 1976). Testosterone secreted by the Leydig cells is essential for normal spermatogenesis and fertility (Farag et al., 2010). Degenerations of interstitial cells of Leydig in Banded Gourami testes due to different concentrations of chlorpyrifos were evident in the present study. Degeneration and destruction processes in Leydig cells of Banded Gourami testis could lead to the failure of spermatogenesis. These results are in concordance with previous studies in Bluegill testis exposed to diazinon (Dutta and Meijer, 2003) and endosulfan (Dutta et al. 2006), in Cichlasoma dimerus testis exposed to endosulfan (Da Cuna et al. 2013), and in zebrafish testis exposed to clotrimazole (Baudiffier et al. 2013). 
Sertoli cells are the somatic cells contained in the seminiferous tubules of the testis. They provide the physical support, nutrients and hormonal signals necessary for successful spermatogenesis (Griswold et al., 1988). For example, testosterone exerts its' effects on spermatogenesis through respective receptors in the sertoli cells (Oropesa et al., 2014). Moreover, these cells constitute the blood-testis barrier (Buzzard and Wreford, 2002). Another function of these cells is the phagocytosis of degenerated germ cells leading to the accumulation of lipid droplets in their cytoplasm (Morales et al., 2004). The present study observed damage of these cells after long-term exposure to different concentrations of chlorpyrifos. The damage of sertoli cells induced by toxicants could lead to the impairment in their normal reproductive functions. The results of this study are in line with earlier studies in Bluegill testis (Dutta et al., 2006) and in Cichlasoma dimerus testis (Da Cuna et al., 2013) when exposed to endosulfan.

In the present study, testicular oocytes indicate an intersex condition, were observed in Banded Gourami fish after 45 days of chlorpyrifos exposure to $50 \mu \mathrm{g} / \mathrm{L}$. The intersex condition of fish indicates a low reproduction capacity and is a threat for fecundity as well as for population viability (Harris et al., 2011). The intersexuality in this study is probably due to the xenoestrogens released from endocrine-disrupting chemicals (EDCs), such as chlorpyrifos, altering normal sexual differentiation and gametogenesis because they interfere with synthesis, storage, release, transport, metabolism, binding action and elimination of endogenous hormones (Mills and Chichester, 2005; Ortiz-Zarragoitia, 2014). Xenoestrogens are structurally similar to 1 7-థstradiol (E2 ), such as 1 7ethinylestradiol (EE2), which exert their estrogenic effects on gonadal differentiation by mimicking the actions of endogenous estrogens and thereby inducing phenotypic feminization (Andersen et al., 2003; Kuhl et al., 2005). The phenotypic feminization in Banded Gourami fish induced by chlorpyrifos toxicity observed in our study is in accordance with earlier studies in fishes exposed to different EDCs (Holbech et al., 2006; Marchand et al., 2010; Tillitt et al., 2010; Tian et al., 2012; Zhang et al., 2013).

\section{Conclusions}

The study is the first assessing the long-term toxicity of chlorpyrifos on the mortality and reproductive tissues of Banded Gourami. The present study revealed no consistent significant impact on GSI, but showed dose- and duration- dependent significant impact on the mortality 
of male and female fish, and histopathological alterations of both ovary and testes after longterm exposure to different concentrations of chlorpyrifos. The chronic NOEC (60-d) for most histopathological alterations of Banded Gourami ovary and testes was calculated as $50 \mu \mathrm{g} / \mathrm{L}$, while 60-d NOEC for mortality of both male and female fishes was $<15 \mu \mathrm{g} / \mathrm{L}$. The results of the study show that the long-term exposure to chlorpyrifos affect the reproductive tissues of Banded Gourami at exposure concentrations also causing mortality. This shows that the effects on reproductive tissues might not be the most critical endpoints for the risk assessment of chlorpyrifos effects on Banded Gourami. Hence, we recommend future studies should evaluate effects at lower concentrations as even the lowest concentration of $15 \mu \mathrm{g} / \mathrm{L}$ resulted in a $100 \%$ mortality of the male fish and $33 \%$ of the female fish after 75 days of exposure, with control mortalities of 11 and $17 \%$, respectively.

\section{Acknowledgements}

This study has been funded by NUFFIC-NICHE-BGD-156 project. The authors are indebted to Sampa Saha, Afifat Khanam Ritika and Md. Mizanur Rahman for their kind help during the sample collection and histopathological work. 


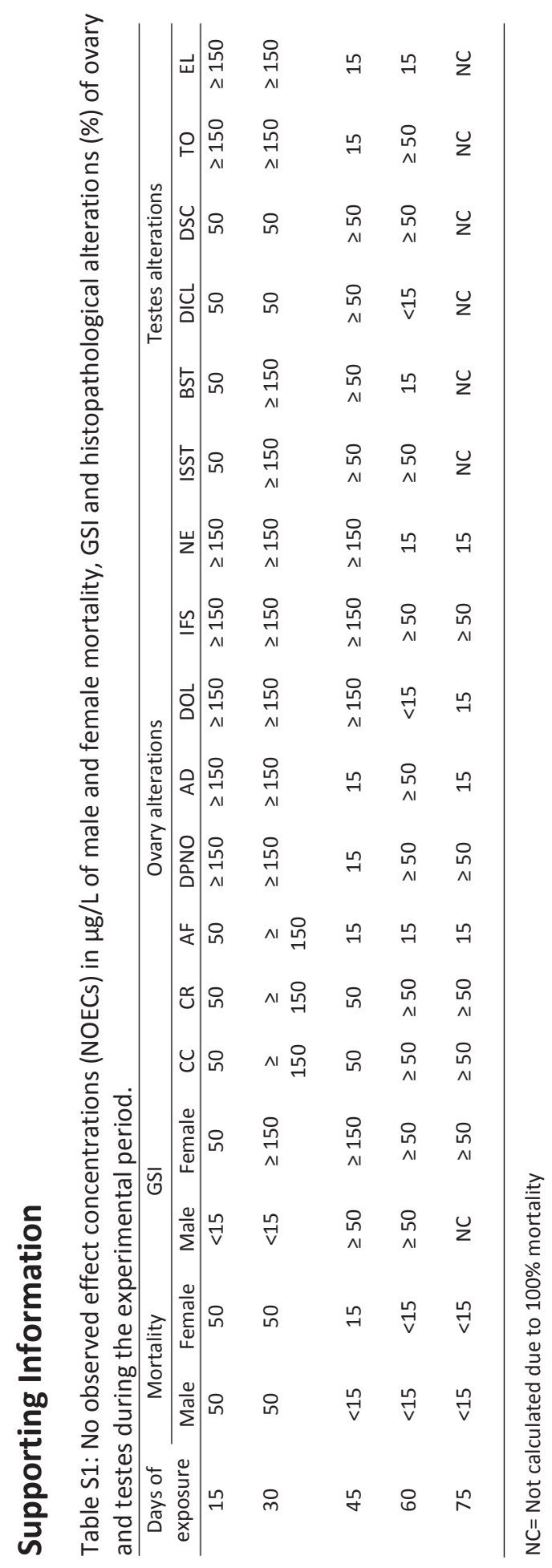


Chapter 7

General discussion and concluding remarks 
The shift from traditional to modern and intensive agricultural practices in Bangladesh has resulted in an increasing use of pesticides to obtain higher agricultural yields, and thereby meeting the growing demand of food for the ever-increasing population (Rahman, 2013). Residues of pesticides applied on agricultural land may enter into the aquatic environment through direct runoff, spray drift and groundwater leaching and this may lead to the contamination of the non-target aquatic organisms like primary producers (Malev et al., 2012; Kumar et al., 2014), invertebrates (Maltby et al., 2005; Van den Brink et al., 2016) and fish (Marimuthu et al., 2013; Manjunatha and Philip, 2016). The inappropriate use of pesticides by the farmers (with poor education on safe pesticide use) may lead to occupational health hazards (Miah et al., 2014). The World Bank (2006) reported that approximately 1-5 million farmers worldwide suffer from pesticide poisoning during application and about 20,000 die annually from exposure, mostly in developing countries.

A systemic study on environmental risk assessment of pesticides is, however, currently lacking in Bangladesh. Moreover, a clear understanding of farmers' perception on the occupational health hazards during handling of pesticides is lacking in developing countries like Bangladesh. Hence, a set of studies including a field survey, a modelling study, a monitoring study, a semifield study (model ecosystem study) and two laboratory studies (Chapters 2-6) were executed to address the research objectives of this thesis (Chapter $\mathbf{1}$ ).

The specific research objectives of this thesis were:

1. To assess the current status of pesticide use in crop production in Bangladesh and their associated potential risks to aquatic organisms.

2. To perform a chemical monitoring program to quantify the residues in the aquatic environment and to calculate the potential risks posed by pesticides to the aquatic ecosystems.

3. To derive the safe environmental concentration for a pesticide for certain structural and functional endpoints of sub-tropical freshwater ecosystems.

4. To investigate the potential toxic effects of pesticides on the developmental stages and the reproductive tissues of fish. 


\section{Human health issues during pesticide application}

Indiscriminate use and improper handling during pesticide application causes serious human health problems in developing countries like Bangladesh. In this thesis, the occupational health hazards of farmers posed by unsafe use of pesticide was reported in the context of riceprawn concurrent systems in south-west Bangladesh (Chapter 2). The most negative symptoms experienced by farmers after pesticide application were vomiting, headache and eye irritation. The majority of the farmers (81\%) were quite sure that these negative health symptoms were the direct results of pesticide intoxication during application (Sumon et al., 2016). The results of these negative symptoms are in line with other studies conducted in other regions in Bangladesh. For example, Dasgupta et al. (2007) reported negative health effects like headache, dizziness, eye irritation, vomiting, dermal diseases and gastrointestinal problems after pesticide application in different parts of Bangladesh. Another study by Miah et al. (2014) found some similar negative health symptoms but also nausea in farmers that grow vegetables in south-east Bangladesh. Almost similar negative health symptoms after pesticide applications have been reported in other south Asian countries like India, Nepal and Pakistan (Chitra et al., 2006; Khan et al., 2010; Shrestha et al., 2010; Atreya et al., 2012; Mohanty et al., 2013).

The negative health symptoms experienced by the farmers could be explained by the lack of or no safety measures taken during pesticide application (Dasgupta et al., 2007; Miah et al., 2014; Atreya et al., 2012; Mohanty et al., 2013). For instance, Sumon et al. (2016) reported about $82 \%$ of the farmers only used cloths to cover their body and face during pesticide application, which is not a sufficient protection measure. The negative symptoms can probably be reduced by not only using cloths but also averting behaviour like wearing masks, hand gloves, eye glasses and gumboot during pesticide application, and washing hands or taking a shower just after pesticide application (Chapter 2). The promotion of suitable averting behaviour often depends on farmers' education level and proper training facilities (Kabir and Rainis, 2012). Due to limited access to these factors, farmers are lagging behind in the use of the suitable averting behaviour during pesticide application by themselves (Sumon et al., 2016). Hence, both public and private sectors might play a vital role in educating the farmers in a way that farmers are aware of the suitable protective measures. For instance, the pesticide companies can introduce the product stewardship programmes making the 
companies themselves co-repsonsible for their products during the use in the field, and the storage. Furthermore, the public sector i.e. the government needs to ensure basic training among the farmers to gather knowledge and to build awareness on safe use and handling of pesticide and subsequently can introduce the license for pesticide spraying only for the trained farmers.

\section{Predicted versus measured environmental concentrations of pesticides}

In this thesis, the TOXSWA v3.3.2 model was used to calculate the predicted environmental concentrations (PECS) of ten pesticides extensively used in rice-prawn concurrent systems in south-west Bangladesh under different spray drift scenarios (Chapter 2). TOXSWA is a pseudotwo-dimensional numerical model describing pesticide behaviour in the water layer and its underlying sediment at the edge-of-field scale (Adriaanse, 1997; Adriaanse et al., 2013).

The measured environmental concentrations (MECs) of some commonly used pesticides were determined in the surface waters and sediments in north-west Bangladesh (Chapter 3). These MEC values of chlorpyrifos and malathion in surface waters collected from beels in north-west Bangladesh (Chapter 3) were compared with the corresponding PEC values determined with TOXSWA for rice-prawn concurrent systems in south-west Bangladesh (Chapter 2). The highest PEC values of chlorpyrifos and malathion were much lower than those of the highest MEC values (Table 1). This could be explained by the fact that crop production and the use of pesticides in north-west Bangladesh (Chapter 3) was much more intensified than those in riceprawn systems in south-west Bangladesh (Chapter 2).

Table 1: Comparison of the highest (median) PECs and MECs of chlorpyrifos and malathion and model-based (south-west Bangladesh) and monitoring-based (north-west Bangladesh) highest (median) RQs of this two pesticides for fish, Daphina and algae (Source: Chapters 2 and 3 ).

\begin{tabular}{|c|c|c|c|c|c|c|c|c|}
\hline \multirow[t]{2}{*}{ Pesticide } & \multirow{2}{*}{$\begin{array}{l}\text { PECs } \\
(\mu \mathrm{g} / \mathrm{L})\end{array}$} & \multicolumn{3}{|c|}{ Model-based RQs } & \multirow{2}{*}{$\begin{array}{l}\text { MECs } \\
(\mu \mathrm{g} / \mathrm{L})\end{array}$} & \multicolumn{3}{|c|}{ Monitoring-based RQs } \\
\hline & & Fish & Daphnia & Algae & & Fish & Daphnia & Algae \\
\hline \multirow[t]{2}{*}{ Chlorpyrifos } & 0.7 & 54.08 & 703 & 0.16 & 9.1 & 700 & 9100 & 1.3 \\
\hline & $(0.38)$ & $(29.2)$ & $(380)$ & $(0.09)$ & (1.9) & (146) & (1900) & $(0.4)$ \\
\hline \multirow[t]{2}{*}{ Malathion } & 2.3 & 12.75 & 327.86 & 0.002 & 3.2 & 17.8 & 400 & 0.002 \\
\hline & (1.3) & (7.2) & (216.7) & $(0.001)$ & (1.3) & $(7.2)$ & (217) & $(0.001)$ \\
\hline
\end{tabular}


The calculation of the predicted environmental concentration (PEC) of pesticides in surface waters through modelling is a way forward for developing countries like Bangladesh. This tool can be used routinely in several south Asian countries and may include more aquatic systems. The determination of MEC values of different pesticides in surface water and sediments is also a way forward in Bangladesh. In this thesis, however, I think that the number of quantified samples (both surface water and sediment) were too low to evaluate the risks of pesticides for aquatic systems. Hence, I recommend further studies including more samples and pesticides (other groups than organophosphate) to better prioritize the research needs for other aquatic ecosystems in Bangladesh. As we did not have the direct comparison of PECs and MECs for the same aquatic systems, we suggest further studies performing the prediction and monitoring for the same aquatic systems using the same scenarios, so that a direct comparison can be made.

\section{Environmental risk assessment of pesticides in Bangladesh}

In this thesis, the lower-tier risk quotient (RQ) method was performed based on predicted environmental concentrations (PECs) from the modelling study (Chapter 2) and measured environmental concentrations (MECs) from the monitoring study (Chapter 3). Different pesticides and trophic levels have been evaluated in this thesis. The higher-tier PERPEST model was used to refine the risk assessment of those pesticides having RQs $>1$ for any of the endpoints.

The RQs of chlorpyrifos and malathion derived from the PEC values for rice-prawn systems in south-west Bangladesh (Chapter 2) were compared with those derived from MEC values in north-west Bangladesh (Chapter 3). The highest RQs of chlorpyrifos and malathion were higher for all aquatic organisms in the monitoring study than those calculated from the modelling study (Table 1). This can be explained by the much higher MEC values of chlorpyrifos and malathion were measured than those calculated PEC values. The RQs for both pesticides were much higher than those calculated in earlier studies, e.g. by Wee and Aris (2017), which calculated the highest $R Q$ of chlorpyrifos being 4.8 in riverine ecosystem in one of the subtropical countries (Malaysia). The higher RQs values of this pesticide calculated in our study for Daphnia than other studies indicate the higher concentrations of this pesticide in Bangladeshi aquatic ecosystems. The higher concentrations of pesticides in Bangladesh might be due to their irrational use (i.e. overuse and/or misuse) of pesticides by farmers (Chapters 
2 and 3; Dasgupta et al., 2007). For instance, according to Dasgupta et al. (2007), over 47\% of the studied farmers were overusing pesticides in different regions in Bangladesh, while Sumon et al. (2016) reported an overuse by $70 \%$ of the interviewed farmers in south-west Bangladesh. Satapornvanit et al. (2004) also obsevred the overdose of pesticides in one of previous studies in tropical Thailand. The reasons behind this irrational use of pesticides include farmers' low and/or lack of education, inadequate product labelling, and lack of proper training facilities (Dasgupta et al., 2007).

The results of both the model-based (Chapter 2) and monitoring-based (Chapter 3) risk assessment indicated that chlorpyrifos had high acute and chronic RQs ( $>1)$, thus posing high risks for aquatic organisms like Daphnia and the standard test fish species. Based on these results, two laboratory experiments were conducted to elucidate the potential toxic effects of chlorpyrifos on the developmental stages and the reproductive tissues of Banded Gourami (Trichogaster fasciata), which is one of the local freshwater fish species in Bangladesh (Chapters 5 and 6).

The results of the Chapter $\mathbf{3}$ of this thesis indicate that the highest MEC value of chlorpyrifos $(9.1 \mu \mathrm{g} / \mathrm{L})$ determined in north-west Bangladesh might have the risk for local fish species (e.g. Banded Gourami), since the results of Chapter 5 show that $1 \mu \mathrm{g} / \mathrm{L}$ chlorpyrifos has adverse effect on the developmental stages of Banded Gourami after an acute exposure. After the long-term exposure to chlorpyrifos, the results suggest that the highest MEC value may not increase the histopathological alterations $(60-\mathrm{d}$ NOEC $=50 \mu \mathrm{g} / \mathrm{L})$, but might affect the mortality (60-d NOEC $=<15 \mu \mathrm{g} / \mathrm{L}$ ) of Banded Gourami (Chapter 6). Further long-term studies, however, are recommended to evaluate the toxic effects of chlorpyrifos on the mortality and reproduction of Banded Gourami at $<15 \mu \mathrm{g} / \mathrm{L}$ (Chapter 6). In Chapters 5 and 6, a first study on the developmental and reproductive toxicity of chlorpyrifos by using Banded Gourami fish as a model is reported, however, analytical verification of exposure concentrations was not possible due to lack of technical facilities. Hence, we recommend to introduce the instrumental facilities to verify the exposure concentrations of chemicals analytically in future laboratory studies in Bangladesh.

\section{Sensitivity differences between tropical and temperate aquatic invertebrates}

The semi-field microcosm experiment derived safe threshold values for the neonicotinoid insecticide imidacloprid for different structural (phytoplankton, zooplankton, 
macroinvertebrates and periphyton) and functional (organic matter decomposition) endpoints of freshwater ecosystems in sub-tropical Bangladesh (Chapter 4). Those microcosms have been used as a valuable tool for the higher-tier risk assessment of pesticides (Daam et al., 2008, 2009; Hayasaka et al., 2012a; Halstead et al., 2014; Hua and Relyea, 2014; Sumon et al., 2018) and veterinary medicines (Rico et al., 2014) over the past decades. There are multiple advantages of using microcosms for toxicity studies, since they allow replications, ecological realism, and are a good tool for validating safety factors used at lower-tier of the risk assessment (Daam and Van den Brink, 2010; Van den Brink, 2013).

The results of Chapter 4 indicated that most zooplankton and macroinvertebrate species were found to be much more sensitive to imidacloprid than their temperate counterparts. Among the zooplankton, Diaptomus sp. was negatively affected from day 2 of the first imidacloprid exposure onwards over a period of 28 days with a consistent NOEC value of $0.3 \mu \mathrm{g} / \mathrm{L}$. The sensitivity of this species to imidacloprid was confirmed by a single species toxicity test, since an $96-\mathrm{h} \mathrm{EC50} \mathrm{of} 0.0386 \mu \mathrm{g} / \mathrm{L}$ was calculated for this genus. Unfortunately, the toxicity data for Diaptomus sp. in temperate countries is lacking, therefore, a comparison is not possible. Among the macroinvertebrates, Cloeon sp. was the most responding species to imidacloprid i.e. showing the lowest abundance values in all treatments from the control (2-d and 9-d NOEC $<0.03 \mu \mathrm{g} / \mathrm{L})$. The sensitivity of this species was also confirmed by a single species toxicity test

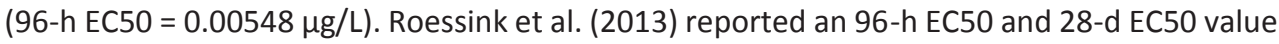
of imidacloprid for Cloeon dipterum of $1.0 \mu \mathrm{g} / \mathrm{L}$ and $0 \mu \mathrm{Mg} / \mathrm{s}$, respectively in the Netherlands, which is about 24-182 folds higher than the 96-h EC50 value calculated in Chapter 4 of this thesis for sub-tropical country. Another study from Canada by Alexander et al. (2007) calculated an 96-h LC5 0 value of $0.65 \mathrm{\mu g} / \mathrm{L}$ for the mayfly speresus longimanus, which is again about 27 folds higher than the value reported for Cloeon sp. in Chapter 4 of this thesis. The higher sensitivity of this species in the microcosm experiment could be partly explained by the higher temperature in (sub-) tropics (Chapter 4; Camp and Buchwalter, 2016; Van den Brink et al., 2016) and may be caused by the lack of having winter generations of this species in our climate zone (Chapter 4; Kwok et al., 2007; Van den Brink et al., 2016). We recommend further studies to perform the risk assessment of imidacloprid (monitoring or model-based) using the threshold values of this insecticide for local organisms (i.e. primary producers, micro- 
and macro invertebrates) of (sub-) tropical Bangladesh derived from the microcosm and single species toxicity tests experiments.

\section{Reducing the use of pesticide in Bangladesh}

The studies presented in this thesis showed the toxic effects of different pesticides on the aquatic environments. To make the agricultural system sustainable, the use of pesticides should either be reduced or mitigation measures should be sought for the pesticide use in a way that pesticides do not exceed the thresholds for the aquatic organisms. For example, taking the spray drift scenarios into account as a route of pesticide exposure in the aquatic ecosystems, the mitigation measure of pesticide risk may be achieved by the implementation of spray drift buffers (Chapter 2; Maltby and Hills, 2008; Hilz and Vermeer, 2013). One of the best options of avoiding pesticide use could be the adoption of Integrated Pest Management (IPM) practices, which is a popular method of sustainable and eco-friendly crop production system in many countries of the world (Azad et al., 2009). According to Prokopy (2003), IPM is "a decision-based process involving coordinated use of multiple tactics for optimizing the control of all classes of pests (insects, pathogens, weeds, vertebrates) in an ecologically and economically sound manner". In Bangladesh, the IPM practices were first introduced in the 1981 for rice systems, when the Food and Agriculture Organization (FAO) played a strong catalytic role with the government officials and donor community (Dasgupta et al., 2007; Kabir and Rainis, 2013). Subsequently, the government, through its Department of Agricultural Extension (DAE), initiated several IPM projects for rice and vegetables with donor funds. The $\mathrm{DAE}$, is the largest agro-based public organization in Bangladesh and the main actor responsible for providing extension services to the rural farmers. The DAE has developed some dissemination techniques on IPM practices e.g. Extension Agent Visit, Farmers Field School (FFS), IPM club and Field Days. Some NGOs are also working to promote the IPM adoption in Bangladesh. The rate of IPM adoption in Bangladesh, however, is minimal (only $0.27 \%$ of the estimated 37 million farmers). The low adoption of IPM indicates that these dissemination techniques have had little impact at the national scale.

One of the main reasons behind the low adoption could be the number of extension agents and NGOs, which are insufficient in comparison to the total farmers to disseminate the techniques. For instance, Sumon et al. (2016) reported in their study that only $6 \%$ of the total farmers knew about the IPM practices as an alternative method of pesticide use. Hence, the 
government should recruit more extension agents and invest more funds to improve the dissemination campaigns to the rural population. Printed and electronic media like TV, radio, newspapers and magazines can also play a substantial role to improve this situation. Furthermore, although hundreds of NGOs are nowadays working in Bangladesh, very few are devoted to the implementation of IPMs. More NGOs should be involved with GOs to disseminate the IPM through raising awareness among the farmers. Another reason of the low adoption of IPM could be the poor socio-economic characteristics of the farmers and the low literacy rate. Most farmers are reluctant to adopt new technologies since the majority of them have no or very low risk bearing capacity. So, this thesis suggests that both DAE and NGOs should motivate the farmers in a way that IPM practice is not only an ecologically sound and socially acceptable technique, but also that it is presented as a more profitable farming practice than the conventional one (i.e., farming with intensive use of pesticides) (Chapter 2; Dasgupta et al., 2007).

\section{Improving the environmental risk assessment scheme underlying the regulation of pesticides in Bangladesh}

Environmental risk assessment of pesticides based on lower-tier RQ method and higher-tier PERPEST model that are presented in Chapters $\mathbf{2}$ and 3. Chapters $\mathbf{4}, \mathbf{5}$ and $\mathbf{6}$ derive threshold values (e.g. LC50, EC50 and NOECs) of the two pesticides (i.e. imidacloprid and chlorpyrifos) for local primary producers, micro- and macro-invertebrates and fish in Bangladesh. These threshold values can be used for future risk assessment processes in (sub-) tropical Bangladesh.

In a developing country like Bangladesh, the improvement the model-based risk assessment of pesticides is important. In order to establish a realistic risk assessment and management procedure for more sustainable rice production practices, however, the mathematical models need to be developed and validated for rice-prawn systems in Bangladesh and in other countries of south Asia to further strengthen the reliability of using the models. Moreover, the introduction of such a model in Bangladesh still needs to convince all stakeholders including government, who are resonsible to support decision making in the policy level to adopt and continue this new tools to estimate the exposure concentrations of pesticides in future.

In this thesis, the monitoring-based risk assessment indicates that the potential risks of several pesticides may be present in surface water for Daphnia even without detection (Chapter 3). 
This, because the limit of detection (LOD) of chlorpyrifos, malathion and fenitrothion in surface water was higher than the acute and/or chronic PNECs for Daphnia, thus indicating the low efficiency of analytical verifications. Hence, we suggest that the analytical verification for several pesticides should be improved in future monitoring-based risk assessment in Bangladesh.

\section{Concluding remarks and future lines of research}

The results of the pesticide use practices reported in this thesis, show that the negative health symptoms experienced by farmers were due to the lack of proper handling of pesticides during application. The government should provide basic training facilities and build awareness to the farmers in a way that farmers can practice the suitable averting behaviour during pesticide application. The model-based risk assessment of this thesis indicates that such assessment approaches can be used as good tools for risk assessment purposes in sub-tropical ecosystems, however, is important to develop and validate mathematical models adapted to the rice-prawn systems in Bangladesh and in other countries of south Asia.

The results of the monitoring study of this thesis demonstrate that some of the measured pesticides (e.g. chlorpyrifos, diazinon, quinalphos, fenitrothion and malathion) pose high risks for surface water organisms like fish and Daphnia in north-west Bangladesh. The risk assessment based on monitoring study is a new approach in sub-tropical Bangladesh. This tool can be used for future environmental risk assessment of different pesticides for other aquatic ecosystems in Bangladesh and other south Asian countries.

The microcosm experiment reveals that the threshold values of imidacloprid for sub-tropical aquatic organisms were much lower than those found for temperate countries. Whether the differences in sensitivity holds true for all sub-tropical aquatic ecosystems and/or more pesticides than imidacloprid alone, remains to be investigated. The results of the microcosm (semi-field) experiment using one of the insecticides (imidacloprid) presented in this thesis, however, are the first microcosm study in sub-tropical Bangladesh while the model ecosystem experiments (i.e. microcosm and mesocosm) were introduced in Europe and North America in the seventies and eighties of the last century. We recommend to conduct more long-term microcosm experiments in Bangladesh including more sub-tropical species to get a clear picture about the toxicity of different pesticides towards sub-tropical freshwater ecosystems. 
The results of the laboratory experiments of this thesis provides threshold values (e.g., LC50, NOEC) of chlorpyrifos for Banded gourami fish. In this thesis, I suggest that Banded Gourami fish could serve as an ideal model species for evaluating the developmental and reproductive toxicity of different environmental contaminants (e.g. pesticides). However, the establishment of the technical facilities (i.e. analytical verification of chemicals) for the standard laboratory experiments in developing countries like Bangladesh is urgently needed. In conclusion, the thesis has made an attempt to provide some tools to assess the risks to aquatic ecosystems of sub-tropical Bangladesh posed by several pesticides. Some pesticides posed serious risks for the aquatic organisms in Bangladesh. Further experimental, monitoring and model validation studies at nationwide, however, are needed to strengthen the present conclusions and characterise the risks of the multitude of other pesticides for Bangladeshi aquatic ecosystems. The results of risk assessment of the pesticides reported on in the thesis can be used as regulatory purposes by the policy makers to protect the surface water organisms. To make the whole agricultural system sustainable, the use of pesticides should be reduced based on recommended doses by agricultural extension officers. Another way of reducing pesticide use could be the adoption of IPM practices. The Bangladeshi government and NGOs should utilize more funds to disseminate the technologies and build awareness among the farmers to reduce/avoid the pesticide use in crop production. 


\section{$\underline{\text { References }}$}

Abdel-Halim, K. Y., Salama, A. K., El-Khateeb, E. N., \& Bakry, N. M. (2006). Organophosphorus pollutants (OPP) in aquatic environment at Damietta Governorate, Egypt: implications for monitoring and biomarker responses. Chemosphere, 63(9), 1491-1498.

Adriaanse, P. I. (1997). Exposure assessment of pesticides in field ditches: the TOXSWA model. Pesticide Science, 49, 210-212.

Adriaanse, P. I., Boesten, J. J., \& Crum, S. J. (2013). Estimating degradation rates in outdoor stagnant water by inverse modelling with TOXSWA: a case study with prosulfocarb. Pest Management Science, 69(6), 755767.

Agbohessi, P. T., Toko, I. I., Houndji, A., Gillardin, V., Mandiki, S. N. M., \& Kestemont, P. (2013). Acute toxicity of agricultural pesticides to embryo-larval and juvenile African catfish Clarias gariepinus. Archives of Environmental Contamination and Toxicology, 64(4), 692-700.

Ahamed, F., Fulanda, B., Siddik, M. A. B., Hossain, M. Y., Rahman, M. M., Mondol, Z. F. A., \& Ohtomi, J. (2014). An overview of freshwater prawn fishery in Bangladesh: present status and future prospect. Journal of Coastal Life Medicine, 2(7), 580-588.

Ahmed, N., \& Garnett, S. T. (2010). Sustainability of freshwater prawn farming in rice fields in southwest Bangladesh. Journal of Sustainable Agriculture, 34(6), 659-679.

Ahmed, N., Demaine, H., \& Muir, J. F. (2008). Freshwater prawn farming in Bangladesh: history, present status and future prospects. Aquaculture Research, 39(8), 806-819.

Ahmed, N., Occhipinti-Ambrogi, A., \& Muir, J. F. (2013). The impact of climate change on prawn postlarvae fishing in coastal Bangladesh: socioeconomic and ecological perspectives. Marine Policy, 39, 224-233.

Akan, J. C., Sodipo, O. A., Mohammed, Z., \& Abdulrahman, F. I. (2014). Determination of organochlorine, organophosphorus and pyrethroid pesticide residues in water and sediment samples by high performance liquid chromatography (HPLC) with UV/visible detector. Journal of Analytical \& Bioanalytical Techniques, 5(6), 1.

Aktar, M. W., Paramasivam, M., Sengupta, D., Purkait, S., Ganguly, M., \& Banerjee, S. (2009). Impact assessment of pesticide residues in fish of Ganga river around Kolkata in West Bengal. Environmental Monitoring and Assessment, 157(1-4), 97-104.

Alam, J. (2005). Enhancing sustainable development of diverse agriculture in Bangladesh. UNESCAP-CAPSA: Centre for Alleviation of Poverty through Secondary Crops, Development in Asia and the Pacific. Working paper 80.

Alexander, A. C., Culp, J. M., Liber, K., \& Cessna, A. J. (2007). Effects of insecticide exposure on feeding inhibition in mayflies and oligochaetes. Environmental Toxicology and Chemistry, 26(8), 1726-1732.

Ali, D., Nagpure, N. S., Kumar, S., Kumar, R., \& Kushwaha, B. (2008). Genotoxicity assessment of acute exposure of chlorpyrifos to freshwater fish Channa punctatus (Bloch) using micronucleus assay and alkaline singlecell gel electrophoresis. Chemosphere, 71(10), 1823-1831.

Ali, M. H., Sumon, K. A., Sultana, M., \& Rashid, H. (2018). Toxicity of cypermethrin on the embryo and larvae of Gangetic mystus, Mystus cavasius. Environmental Science and Pollution Research, 25, 3193-3199.

American Public Health Association (APHA). (1985). Standard Methods for the Examination of Water and Wastewater, $16^{\text {th }}$ ed, Washington, DC, pp 1268.

American Public Health Association (APHA). (2005). Standard Methods for the Examination of Water and Waste Water, 21st edition. American Water Works Association and Federal Water Pollution Control Administration, Washington DC, USA, pp. 1193.

Amid, C., Olstedt, M., Gunnarsson, J. S., Le Lan, H., Minh, H. T. T., Van den Brink, P. J., ... \& Tedengren, M. (2017). Additive effects of the herbicide glyphosate and elevated temperature on the branched coral Acropora formosa in Nha Trang, Vietnam. Environmental Science and Pollution Research, 1-13. 
Anastassiades, M., Lehotay, S. J., Štajnbaher, D., \& Schenck, F. J. (2003). Fast and easy multiresidue method employing acetonitrile extraction/partitioning and "dispersive solid-phase extraction" for the determination of pesticide residues in produce. Journal of AOAC International, 86(2), 412-431.

Andersen, L., Holbech, H., Gessbo, Å., Norrgren, L., \& Petersen, G. I. ( $\left.\begin{array}{llll}2 & 0 & 0 & 3\end{array}\right)$. Effects of exposure to-1 $7 \alpha$ ethinylestradiol during early development on sexual differentiation and induction of vitellogenin in zebrafish (Danio rerio). Comparative Biochemistry and Physiology Part C: Toxicology \& Pharmacology, 134(3), 365-374.

Anderson, J. C., Dubetz, C., \& Palace, V. P. (2015). Neonicotinoids in the Canadian aquatic environment: a literature review on current use products with a focus on fate, exposure, and biological effects. Science of the Total Environment, 505, 409-422.

Ankley, G. T., Call, D. J., Cox, J. S., Kahl, M. D., Hoke, R. A., \& Kosian, P. A. (1994). Organic carbon partitioning as a basis for predicting the toxicity of chlorpyrifos in sediments. Environmental Toxicology and Chemistry, 13(4), 621-626.

Ansara-Ross, T. M., Wepener, V., Van den Brink, P. J., \& Ross, M. J. (2008). Probabilistic risk assessment of the environmental impacts of pesticides in the Crocodile (west) Marico catchment, North-West Province. Water SA, 34, 637-646.

Ansara-Ross, T. M., Wepener, V., Van den Brink, P. J., \& Ross, M. J. (2012). Pesticides in South African fresh waters. African Journal of Aquatic Science, 37(1), 1-16.

Ansari, S. H., \& Ansari, B. A. (2012). Alphamethrin toxicity: effect on the reproductive ability and the activities of phosphatases in the tissues of Zebra fish, Danio rerio. International Journal of Life Science and Pharma Research, 2, 89-100.

Ansari, S.H., \& Ansari, B. A. (2011). Embryo and fingerling toxicity of dimethoate and effect on fecundity, viability, hatchability and survival of zebrafish, Danio rerio (Cyprinidae). World Journal Fish Marine Science, 3(2), 167-173.

Ara, A. G., Haque, W., \& Hasanuzzaman, M. (2014). Detection of Organochlorine and organophosphorus pesticides residues in water samples of Taragong thana in Rangpur district in Bangladesh. Research Journal of Environmental and Earth Sciences, 6(2), 85-89.

Arcand-Hoy, L. D., \& Benson, W. H. (1998). Fish reproduction: an ecologically relevant indicator of endocrine disruption. Environmental Toxicology and Chemistry, 17(1), 49-57.

Armbrust, K. L., \& Peeler, H. B. (2002). Effects of formulation on the run-off of imidacloprid from turf. Pest Management Science, 58(7), 702-706.

Arufe, M. I., Arellano, J. M., Albendín, G., \& Sarasquete, C. (2010). Toxicity of parathion on embryo and yolk-sac larvae of gilthead seabream (Sparus aurata I.): Effects on survival, cholinesterase, and carboxylesterase activity. Environmental Toxicology, 25(6), 601-607.

Ashauer, R., Hintermeister, A., Potthoff, E., \& Escher, B. I. (2011). Acute toxicity of organic chemicals to Gammarus pulex correlates with sensitivity of Daphnia magna across most modes of action. Aquatic Toxicology, 103(1), 38-45.

Atreya, K., Johnsen, F. H., \& Sitaula, B. K. (2012). Health and environmental costs of pesticide use in vegetable farming in Nepal. Environment, Development and Sustainability, 14(4), 477-493.

Aydin, R., \& Köprücü, K. (2005). Acute toxicity of diazinon on the common carp (Cyprinus carpio L.) embryos and larvae. Pesticide Biochemistry and Physiology, 82(3), 220-225. 
Azad, A. K., Jensen, K. R., \& Lin, C. K. (2009). Coastal aquaculture development in Bangladesh: unsustainable and sustainable experiences. Environmental Management, 44(4), 800-809.

Azizullah, A., Richter, P., \& Häder, D. P. (2011). Comparative toxicity of the pesticides carbofuran and malathion to the freshwater flagellate Euglena gracilis. Ecotoxicology, 20(6), 1442-1454.

Bagchi, P., Chatterjee, S., Ray, A., \& Deb, C. (1990). Effect of quinalphos, organophosphorus insecticide, on testicular steroidogenesis in fish, Clarias batrachus. Bulletin of Environmental Contamination and Toxicology, 44(6), 871-875.

Bagchi, S., Azad, A. K., Alomgir, M., Chowdhury, Z., Uddin, M. A., Al-Reza, S. M., \& Rahman, A. (2009). Quantitative analysis of pesticide residues in some pond water samples of Bangladesh. Asian Journal of Water, Environment and Pollution, 6(4), 27-30.

Banik, A., Sen, M., \& Sen, S. P. (1993). Methane emission from jute-retting tanks. Ecological Engineering, 2(1), 73-79.

Barber, B. J., \& Blake, N. J. (2006). Reproductive physiology. Developments in Aquaculture and Fisheries Science, 35, 357-416.

Baudiffier, D., Hinfray, N., Ravaud, C., Creusot, N., Chadili, E., Porcher, J. M., Schulz, R.W. \& Brion, F. (2013). Effect of in vivo chronic exposure to clotrimazole on zebrafish testis function. Environmental Science and Pollution Research, 20(5), 2747-2760.

Bayer CropScience, (2013). Confidor ${ }^{\circledR} 200$ SC Insecticide Safety Data Sheet. Available online: http://www.bayercropscience.com.au/resources/uploads/msds/file7219.pdf? 201412749046, [Accessed on October 6, 2017].

BBS (2016). Bangladesh Bureau of Statistics. Statistical Yearbook of Bangladesh. Dhaka, Bangladesh.

BDP (Bangladesh Demographics $\quad$ Profile). 2016. http://www.indexmundi.com/bangladesh/demographics profile.html.

Beltman, W. H. J., Ter Horst, M. M. S., Adriaanse, P. I., \& De Jong, A. (2006). Manual of FOCUS_TOXSWA version 2.2. 1(No. 586). Alterra, Wageningen.

Benli, A. Ç. K., \& Özkul, A. (2010). Acute toxicity and histopathological effects of sublethal fenitrothion on Nile tilapia, Oreochromis niloticus. Pesticide Biochemistry and Physiology, 97(1), 32-35.

Bernabò, I., Sperone, E., Tripepi, S., \& Brunelli, E. (2011). Toxicity of chlorpyrifos to larval Rana dalmatina: acute and chronic effects on survival, development, growth and gill apparatus. Archives of Environmental Contamination and Toxicology, 61(4), 704-718.

Bhattacharjee, S., Fakhruddin, A. N. M., Chowdhury, M. A. Z., Rahman, M. A., \& Alam, M. K. (2012). Monitoring of selected pesticides residue levels in water samples of paddy fields and removal of cypermethrin and chlorpyrifos residues from water using rice bran. Bulletin of Environmental Contamination and Toxicology, 89(2), 348-353.

Böttger, R., Feibicke, M., Schaller, J., \& Dudel, G. (2013). Effects of low-dosed imidacloprid pulses on the functional role of the caged amphipod Gammarus roeseli in stream mesocosms. Ecotoxicology and Environmental Safety, 93, 93-100.

Bouyoucos, G. J. (1962). Hydrometer Method Improved for Making Particle Size Analyses of Soils 1. Agronomy Journal, 54(5), 464-465.

Brandt, C., Burnett, D. C., Arcinas, L., Palace, V., \& Anderson, W. G. (2015). Effects of chlorpyrifos on in vitro sex steroid production and thyroid follicular development in adult and larval Lake Sturgeon, Acipenser fulvescens. Chemosphere, 132, 179-187.

Brock, T. C. M., Lahr, J., \& Van den Brink, P. J. (2000). Ecological risks of pesticides in freshwater ecosystems; Part 1: herbicides (No. 88, p. 127). Alterra, Wageningen.

Brock, T.C.M., Arts G.H.P., Maltby, L., \& Van den Brink, P.J. (2006). Aquatic risks of pesticides, ecological protection goals and common aims in European Union Legislation. Integrated Environmental Assessment and Management, 2, 20-46.

Buzzard, J. J., \& Wreford, N. G. (2002). Marked extension of proliferation of rat Sertoli cells in culture using recombinant human FSH. Reproduction, 124(5), 633-641. 
Camp, A. A., \& Buchwalter, D. B. ( $\left(\begin{array}{llll}2 & 0 & 1 & 6\end{array}\right)$. Can't take the heat: Temperatenteanced toxicity in the mayfly Isonychia bicolor exposed to the neonicotinoid insecticide imidacloprid. Aquatic Toxicology, 178, 49-57.

Capri, E., \& Karpouzas, D. (Eds.). (2008). Pesticide risk assessment in rice paddies: theory and practice. Elsevier.

Carvalho, F. P., Villeneuve, J. P., Cattini, C., Tolosa, I., Thuan, D. D., \& Nhan, D. D. (2008). Agrochemical and polychlorobyphenyl (PCB) residues in the Mekong River delta, Vietnam. Marine Pollution Bulletin, 56(8), 1476-1485.

Castillo, L. E., de la Cruz, E., \& Ruepert, C. (1997). Ecotoxicology and pesticides in tropical aquatic ecosystems of Central America. Environmental Toxicology and Chemistry, 16(1), 41-51.

Catt, K. J., \& Dufau, M. L. (1976). Isolation and properties of gonadotropin receptors. In: Levey, GS (Eds), Hormone-receptor interactions: Molecular Aspects, Vol 9 of Modern Pharmacology- Toxicology, Marcel Dekker Inc, New York, pp 171-200.

Cavallaro, M. C., Morrissey, C. A., Headley, J. V., Peru, K. M., \& Liber, K. (2017). Comparative chronic toxicity of imidacloprid, clothianidin, and thiamethoxam to Chironomus dilutus and estimation of toxic equivalency factors. Environmental Toxicology and Chemistry, 36(2), 372-382.

Ccanccapa, A., Masiá, A., Andreu, V., \& Picó, Y. (2016a). Spatio-temporal patterns of pesticide residues in the Turia and Júcar Rivers (Spain). Science of the Total Environment, 540, 200-210.

Ccanccapa, A., Masiá, A., Navarro-Ortega, A., Picó, Y., \& Barceló, D. (2016b). Pesticides in the Ebro River basin: occurrence and risk assessment. Environmental Pollution, 211, 414-424.

CCME, 2007. Canadian Water Quality Guidelines: Imidacloprid. Scientific Supporting Document. Canadian Council of Ministers of the Environment, Winnipeg, Canada.

Cengiz, E. I., \& Unlu, E. (2006). Sublethal effects of commercial deltamethrin on the structure of the gill, liver and gut tissues of mosquitofish, Gambusia affinis: a microscopic study. Environmental Toxicology and Pharmacology, 21(3), 246-253.

Chai, L. K., Mohd-Tahir, N., \& Bruun Hansen, H. C. (2009). Dissipation of acephate, chlorpyrifos, cypermethrin and their metabolites in a humid-tropical vegetable production system. Pest Management Science, 65(2), 189-196.

Chapman, G., \& Abedin, J. (2002). A description of the rice-prawn-fish systems of southwest Bangladesh. Rural Aquaculture, 111-116.

ChemSpider Search and Share Chemistry. Available from: http://www.chemspider.com/Search.aspx\# (last accessed on 29 July 2015).

Chitra, G. A., Muraleedharan, V. R., Swaminathan, T., \& Veeraraghavan, D. (2006). Use of pesticides and its impact on health of farmers in South India. International Journal of Occupational and Environmental Health, 12(3), 228-233.

Chourpagar, A. R., \& Kulkarani, G. K. (2014). Effect of mercuric chloride on gill structure of a freshwater female crab, Barytelphusa cunicularis (Westwood). Journal of Global Biosciences, 3(2), 423-427.

Chowdhury, A. Z., Jahan, S. A., Islam, M. N., Moniruzzaman, M., Alam, M. K., Zaman, M. A., Karim, N., \& Gan, S. H. (2012a). Occurrence of organophosphorus and carbamate pesticide residues in surface water samples from the Rangpur district of Bangladesh. Bulletin of Environmental Contamination and Toxicology, 89(1), 202-207.

Chowdhury, M. A. Z., Banik, S., Uddin, B., Moniruzzaman, M., Karim, N., \& Gan, S. H. (2012b). Organophosphorus and carbamate pesticide residues detected in water samples collected from paddy and vegetable fields of the Savar and Dhamrai Upazilas in Bangladesh. International Journal of Environmental Research and Public Health, 9(9), 3318-3329.

Clotfelter, E. D., Bell, A. M., \& Levering, K. R. (2004). The role of animal behaviour in the study of endocrinedisrupting chemicals. Animal Behaviour, 68(4), 665-676.

Cochard, R., Maneepitak, S., \& Kumar, P. (2014). Aquatic faunal abundance and diversity in relation to synthetic and natural pesticide applications in rice fields of Central Thailand. International Journal of Biodiversity Science, Ecosystem Services \& Management, 10(2), 157-173. 
Colombo, V., Mohr, S., Berghahn, R., \& Pettigrove, V. J. (2013). Structural changes in a macrozoobenthos assemblage after imidacloprid pulses in aquatic field-based microcosms. Archives of Environmental Contamination and Toxicology, 65(4), 683-692.

Correia, J. E., Christofoletti, C. A., Marcato, A. C. C., Marinho, J. F. U., \& Fontanetti, C. S. (2017). Histopathological analysis of tilapia gills (Oreochromis niloticus Linnaeus, 1758) exposed to sugarcane vinasse. Ecotoxicology and Environmental Safety, 135, 319-326.

Cox, C., \& Surgan, M. (2006). Unidentified inert ingredients in pesticides: implications for human and environmental health. Environmental health perspectives, 114(12), 1803.

Da Cuña, R. H., Pandolfi, M., Genovese, G., Piazza, Y., Ansaldo, M., \& Nostro, F. L. L. (2013). Endocrine disruptive potential of endosulfan on the reproductive axis of Cichlasoma dimerus (Perciformes, Cichlidae). Aquatic Toxicology, 126, 299-305.

Daam, M. A., \& Van den Brink, P. J. (2010). Implications of differences between temperate and tropical freshwater ecosystems for the ecological risk assessment of pesticides. Ecotoxicology, 19(1), 24-37.

Daam, M. A., \& Van den Brink, P. J. (2011). Conducting model ecosystem studies in tropical climate zones: lessons learned from Thailand and way forward. Environmental Pollution, 159(4), 940-946.

Daam, M. A., Crum, S. J., Van den Brink, P. J., \& Nogueira, A. J. (2008a). Fate and effects of the insecticide chlorpyrifos in outdoor plankton-dominated microcosms in Thailand. Environmental Toxicology and Chemistry, 27(12), 2530-2538.

Daam, M. A., Pereira, A. C. S., Silva, E., Caetano, L., \& Cerejeira, M. J. (2013). Preliminary aquatic risk assessment of imidacloprid after application in an experimental rice plot. Ecotoxicology and Environmental Safety, 97, 78-85.

Daam, M. A., \& Rico, A. (2016). Freshwater shrimps as sensitive test species for the risk assessment of pesticides in the tropics. Environmental Science and Pollution Research, 1-9.

Daam, M. A., Rodrigues, A. M., Van den Brink, P. J., \& Nogueira, A. J. (2009a). Ecological effects of the herbicide linuron in tropical freshwater microcosms. Ecotoxicology and Environmental Safety, 72(2), 410-423.

Daam, M. A., Satapornvanit, K., Van den Brink, P. J., \& Nogueira, A. J. (2009b). Sensitivity of macroinvertebrates to carbendazim under semi-field conditions in Thailand: implications for the use of temperate toxicity data in a tropical risk assessment of fungicides. Chemosphere, 74(9), 1187-1194.

Daam, M. A., Van den Brink, P. J., \& Nogueira, A. J. (2008b). Impact of single and repeated applications of the insecticide chlorpyrifos on tropical freshwater plankton communities. Ecotoxicology, 17(8), 756-771.

Dahshan, H., Megahed, A. M., Abd-Elall, A. M. M., Abd-El-Kader, M. A. G., Nabawy, E., \& Elbana, M. H. (2016). Monitoring of pesticides water pollution-The Egyptian River Nile. Journal of Environmental Health Science and Engineering, 14(1), 15.

Dasgupta, S., Meisner, C., \& Huq, M. (2005). Health effects and pesticide perception as determinants of pesticide use: evidence from Bangladesh, The World Bank.

Dasgupta, S., Meisner, C., \& Huq, M. (2007). A pinch or a pint? Evidence of pesticide overuse in Bangladesh. Journal of Agricultural Economics, 58(1), 91-114.

De Laender, F., Morselli, M., Baveco, H., Van den Brink, P. J., \& Di Guardo, A. (2015). Theoretically exploring direct and indirect chemical effects across ecological and exposure scenarios using mechanistic fate and effects modelling. Environment International, 74, 181-190.

De Silva, P. M. C. S., \& Samayawardhena, L. A. (2005). Effects of chlorpyrifos on reproductive performances of guppy (Poecilia reticulata). Chemosphere, 58(9), 1293-1299.

Deka, S., \& Mahanta, R. (2012). A study on the effect of organophosphorus pesticide malathion on hepato-renal and reproductive organs of Heteropneustes fossilis (Bloch). Science, 1(1).

Demetrio, P. M., Bonetto, C., \& Ronco, A. E. (2014). The effect of cypermethrin, chlorpyrifos, and glyphosate active ingredients and formulations on Daphnia magna (Straus). Bulletin of Environmental Contamination and Toxicology, 93(3), 268-273.

Desai, B., \& Parikh, P. (2014). Behavioural responses to acute exposure of Imidacloprid and Curzate on Labeo rohita (Hamilton, 1822). International Journal of Open Scientific Research, 2(1), 1-12. 
Diepens, N. J., Koelmans, A. A., Baveco, H., van den Brink, P. J., van den Heuvel-Greve, M. J., \& Brock, T. C. (2016). Prospective environmental risk assessment for sediment-bound organic chemicals: a proposal for tiered effect assessment. In Reviews of Environmental Contamination and Toxicology Volume 239 (pp. 1-77). Springer, Cham.

Ding, Y., Weston, D. P., You, J., Rothert, A. K., \& Lydy, M. J. (2011). Toxicity of sediment-associated pesticides to Chironomus dilutus and Hyalella azteca. Archives of Environmental Contamination and Toxicology, 61(1), 83-92.

DoF (Department of Fisheries). Fishery Statistical Yearbook of Bangladesh 2011-12. Fisheries Resources Survey Systems, Ministry of Fisheries and Livestock, Dhaka, Bangladesh;2013.

Dutta, H. M., \& Maxwell, L. B. (2003). Histological examination of sublethal effects of diazinon on ovary of bluegill, Lepomis macrochirus. Environmental pollution, 121(1), 95-102.

Dutta, H. M., \& Meijer, H. J. M. (2003). Sublethal effects of diazinon on the structure of the testis of bluegill, Lepomis macrochirus: a microscopic analysis. Environmental pollution, 125(3), 355-360.

Dutta, H. M., Misquitta, D., \& Khan, S. (2006). The effects of endosulfan on the testes of bluegill fish, Lepomis macrochirus: a histopathological study. Archives of Environmental Contamination and Toxicology, 51(1), 149-156.

Dutta, H. M., Nath, A., Adhikari, S., Roy, P. K., Singh, N. K., \& Munshi, J. D. (1994). Sublethal malathion induced changes in the ovary of an air-breathing fish, Heteropneustes fossilis: a histological study. Hydrobiologia, 294(3), 215-218.

Dzul-Caamal, R., Domínguez-López, M. L., García-Latorre, E., \& Vega-López, A. (2012). Implications of cytochrome 450 isoenzymes, aryl-esterase and oxonase activity in the inhibition of the acetylcholinesterase of Chirostoma jordani treated with phosphorothionate pesticides. Ecotoxicology and Environmental Safety, 84, 199-206.

Echeverría-Sáenz, S., Mena, F., Arias-Andrés, M., Vargas, S., Ruepert, C., Van den Brink, P. J., ... \& Gunnarsson, J. S. (2016). In situ toxicity and ecological risk assessment of agro-pesticide runoff in the Madre de Dios River in Costa Rica. Environmental Science and Pollution Research, 1-13.

ЕСОтОX Database, ЕСОтОХicology Database of the Environmental Protection Agency of the United States Available from: http://cfpubepagov/ecotox/quick queryhtm. Accessed on 28 July 2017.

European Academies Science Advisory Council (EASAC), (2015). Ecosystem services, agriculture and neonicotinoids. EASAC policy report 26, ISBN: 978-3-8047-3437-1.

European Food and Safety Authority (EFSA), (2008). Conclusion regarding the peer review of the pesticide risk assessment of the active substance imidacloprid. EFSA Scientific Report 148, 1-120.

Fan, T., \& Shi, Z. (2002). Advances and prospect in fish hatching enzyme research. Transactions of Oceanology and Limnology, 1, 48-56.

Farag, A. T., Radwan, A. H., Sorour, F., El Okazy, A., El-Agamy, E. S., \& El-Sebae, A. E. K. (2010). Chlorpyrifos induced reproductive toxicity in male mice. Reproductive Toxicology, 29(1), 80-85.

Feola, G., Gallati, J. A., \& Binder, C. R. (2012). Exploring behavioural change through an agent-oriented system dynamics model: the use of personal protective equipment among pesticide applicators in Colombia. System Dynamics Review, 28(1), 69-93.

Fleeger, J. W., Carman, K. R., \& Nisbet, R. M. (2003). Indirect effects of contaminants in aquatic ecosystems. Science of the Total Environment, 317(1), 207-233.

FOCUS (Forum for Co-Ordination of Pesticide Fate Models and Their Use). FOCUS Surface Water Scenarios in the EU Evaluation Process under 91/414/EEC;2001. (Brussels, Belgium. Document Reference SANCO/4802/2001-rev2).

FOCUS (Forum for Co-Ordination of Pesticide Fate Models and Their Use). Guidance document on estimating persistence and degradation kinetics from environmental fate studies on pesticides in EU registration;2006. DG SanCo/10058/version 2.0.

Forrest, J., 2000. Collecting Water Quality Samples for Dissolved Metals in Water. USEPA, Region 6. Water Quality Handbook, $2^{\text {nd }}$ edition. EPA, USA. 
Franke, A. C., Kempenaar, C., Holterman, H. J., \& Van de Zande, J. C. (2010). Spray drift from Knapsack sprayers: a study conducted within the framework of the Sino-Dutch Pesticide Environmental Risk Assessment Project PERAP(No. 658). Plant Research International.

Fraysse, B., Mons, R., \& Garric, J. (2006). Development of a zebrafish 4-day embryo-larval bioassay to assess toxicity of chemicals. Ecotoxicology and Environmental Safety, 63(2), 253-267.

Freitas, E. C., \& Rocha, O. (2012). Acute and chronic effects of atrazine and sodium dodecyl sulfate on the tropical freshwater cladoceran Pseudosida ramosa. Ecotoxicology, 21(5), 1347-1357.

FRSS, 2017. Yearbook of Fisheries Statistics of Bangladesh. Fisheries Resources Survey System (FRSS), Department of Fisheries, Bangladesh. Volume 33: 124 p.

Gaikowski, M. P., Hamilton, S. J., Buhl, K. J., McDonald, S. F., \& Summers, C. H. (1996). Acute toxicity of firefighting chemical formulations to four life stages of fathead minnow. Ecotoxicology and Environmental Safety, 34(3), 252-263.

Gebremariam, S. Y., Beutel, M. W., Flury, M., Harsh, J. B., \& Yonge, D. R. (2011). Nonsingular adsorption/desorption of chlorpyrifos in soils and sediments: experimental results and modeling. Environmental science \& technology, 46(2), 869-875.

Gregorio, V., Büchi, L., Anneville, O., Rimet, F., Bouchez, A., \& Chevre, N. (2012). Risk of herbicide mixtures as a key parameter to explain phytoplankton fluctuation in a great lake: the case of Lake Geneva, Switzerland. Ecotoxicology, 21(8), 2306-2318.

Griswold, M. D., Morales, C. A. R. L. O. S., \& Sylvester, S. R. (1988). Molecular biology of the Sertoli cell. Oxford Reviews of Reproductive Biology, 10, 124-161.

Gumma, M. K., Thenkabail, P. S., Maunahan, A., Islam, S., \& Nelson, A. (2014). Mapping seasonal rice cropland extent and area in the high cropping intensity environment of Bangladesh using MODIS 500m data for the year 2010. ISPRS Journal of Photogrammetry and Remote Sensing, 91, 98-113.

Gupta, A., Rai, D. K., Pandey, R. S., \& Sharma, B. (2009). Analysis of some heavy metals in the riverine water, sediments and fish from river Ganges at Allahabad. Environmental Monitoring and Assessment, 157(1), 449-458.

Halstead, N. T., McMahon, T. A., Johnson, S. A., Raffel, T. R., Romansic, J. M., Crumrine, P. W., \& Rohr, J. R. (2014). Community ecology theory predicts the effects of agrochemical mixtures on aquatic biodiversity and ecosystem properties. Ecology Letters, 17(8), 932-941.

Haque, M. S., Ahmed, Z., Asaduzzaman, M., Quashem, M. A., \& Akhter, F. (2002). Distribution and activity of microbial population for jute retting and their impact on water of jute growing areas of Bangladesh. Pakistan Journal of Biological Sciences, 5(6), 704-706.

Harris, C. A., Hamilton, P. B., Runnalls, T. J., Vinciotti, V., Henshaw, A., Hodgson, D., Coe, T.S., Jobling, S., Tyler, C.R., \& Sumpter, J. P. (2011). The consequences of feminization in breeding groups of wild fish. Environmental Health Perspectives, 119(3), 306.

Harwood, A. D., You, J., \& Lydy, M. J. (2009). Temperature as a toxicity identification evaluation tool for pyrethroid insecticides: toxicokinetic confirmation. Environmental Toxicology and Chemistry, 28(5), 1051-1058.

Hasan, A. S. U., \& Rahman, M. Z. (2013). Change in temperature over Bangladesh associated with degrees of global warming. Asian Journal of Applied Science and Engineering, 2(2), 161-174.

Hasan, M. N., Islam, H. R., Mahmud, Y., Ahmed, K. K. U., \& Siddiquee, S. (2014). Application of pesticides in riceprawn (crustaceans) culture: perception and its impacts. Annual Research \& Review in Biology, 4(8), 1219.

Hasanuzzaman, M., Rahman, M. A., \& Salam, M. A. (2017). Identification and quantification of pesticide residues in water samples of Dhamrai Upazila, Bangladesh. Applied Water Science, 7(6), 2681-2688.

Hasanuzzaman, M., Rahman, M. A., Islam, M. S., Salam, M. A., \& Nabi, M. R. (2018). Pesticide residues analysis in water samples of Nagarpur and Saturia Upazila, Bangladesh. Applied Water Science, 8(1), 8.

Hashimoto, S., Bessho, H., Hara, A., Nakamura, M., Iguchi, T., \& Fujita, K. (2000). Elevated serum vitellogenin levels and gonadal abnormalities in wild male flounder (Pleuronectes yokohamae) from Tokyo Bay, Japan. Marine Environmental Research, 49(1), 37-53. 
Hayasaka, D., Korenaga, T., Suzuki, K., Saito, F., Sánchez-Bayo, F., \& Goka, K. (2012a). Cumulative ecological impacts of two successive annual treatments of imidacloprid and fipronil on aquatic communities of paddy mesocosms. Ecotoxicology and Environmental Safety, 80, 355-362.

Hayasaka, D., Korenaga, T., Suzuki, K., Sánchez-Bayo, F., \& Goka, K. (2012b). Differences in susceptibility of five cladoceran species to two systemic insecticides, imidacloprid and fipronil. Ecotoxicology, 21(2), 421427.

Hela, D. G., Lambropoulou, D. A., Konstantinou, I. K., \& Albanis, T. A. (2005). Environmental monitoring and ecological risk assessment for pesticide contamination and effects in Lake Pamvotis, northwestern Greece. Environmental Toxicology and Chemistry, 24(6), 1548-1556.

Hernández, A. F., Parrón, T., Tsatsakis, A. M., Requena, M., Alarcón, R., \& López-Guarnido, O. (2013). Toxic effects of pesticide mixtures at a molecular level: their relevance to human health. Toxicology, 307, 136-145.

Hilz, E., \& Vermeer, A. W. (2013). Spray drift review: The extent to which a formulation can contribute to spray drift reduction. Crop Protection, 44, 75-83.

Hilz, E., \& Vermeer, A. W. P. (2012). Effect of formulation on spray drift: a case study for commercial imidacloprid products. Aspects of Applied Biology, 114, 445-450.

Holbech, H., Kinnberg, K., Petersen, G. I., Jackson, P., Hylland, K., Norrgren, L., \& Bjerregaard, P. (2006). Detection of endocrine disrupters: evaluation of a Fish Sexual Development Test (FSDT). Comparative Biochemistry and Physiology Part C: Toxicology \& Pharmacology, 144(1), 57-66.

Hommen, U., Veith, D., \& Dülmer, U. (1994). A computer program to evaluate plankton data from freshwater field tests. In Hill, I.R., Heimbach, F., Leeuwangh, P. and Matthiesen, P. (eds) Freshwater Field Tests for Hazard Assessment of Chemicals, pp. 503-513. Boca Raton, FL: Lewis Publishers.

Hossain, M. S., Chowdhury, M. A. Z., Pramanik, M. K., Rahman, M. A., Fakhruddin, A. N. M., \& Alam, M. K. (2015). Determination of selected pesticides in water samples adjacent to agricultural fields and removal of organophosphorus insecticide chlorpyrifos using soil bacterial isolates. Applied Water Science, 5(2), 171-179.

Hossen, M. S., Reza, A. M., Rakhi, S. F., Takahashi, K., \& Hossain, Z. (2014). Effects of polyunsaturated fatty acids (PUFAs) on gonadal maturation and spawning of striped gourami, Colisa fasciatus. International Aquatic Research, 6(2), 65.

Hou, F., Yu, X., Zhao, Y., Wang, D., Liu, X., \& Huang, Y. (2009). Effect of chlorpyrifos on gonad and it's accumulation in the tissue of Carassius auratus. Jiangsu Journal of Agricultural Sciences, 25(1), 188-191.

Hua, J., \& Relyea, R. (2014). Chemical cocktails in aquatic systems: Pesticide effects on the response and recovery of $>20$ animal taxa. Environmental Pollution, 189, 18-26.

Humphrey, C., \& Klumpp, D. W. (2003). Toxicity of chlorpyrifos to the early life history stages of eastern rainbowfish Melanotaenia splendida splendida (Peters 1866) in tropical Australia. Environmental Toxicology, 18(6), 418-427.

Huy Giap, D., Yi, Y., \& Kwei Lin, C. (2005). Effects of different fertilization and feeding regimes on the production of integrated farming of rice and prawn Macrobrachium rosenbergii (De Man). Aquaculture Research, 36(3), 292-299.

Huynh, H. P., \& Nugegoda, D. (2012). Effects of chlorpyrifos exposure on growth and food utilization in Australian catfish, Tandanus tandanus. Bulletin of Environmental Contamination and Toxicology, 88(1), 25-29.

leromina, O., Peijnenburg, W. J., de Snoo, G., Müller, J., Knepper, T. P., \& Vijver, M. G. (2014). Impact of imidacloprid on Daphnia magna under different food quality regimes. Environmental Toxicology and Chemistry, 33(3), 621-631.

Inao, K., \& Kitamura, Y. (1999). Pesticide paddy field model (PADDY) for predicting pesticide concentrations in water and soil in paddy fields. Pest Management Science, 55(1), 38-46.

Inao, K., Watanabe, H., Karpouzas, D. G., \& Capri, E. (2008). Simulation models of pesticide fate and transport in paddy environment for ecological risk assessment and management. Japan Agricultural Research Quarterly: JARQ, 42(1), 13-21.

Ito, S. (2004). Globalization and agrarian change: a case of freshwater prawn farming in Bangladesh. Journal of International Development, 16(7), 1003-1013. 
Jeschke, P., \& Nauen, R. (2008). Neonicotinoids -from zero to hero in insecticide chemistry. Pest Management Science, 64(11), 1084-1098.

Jin, M., Zhang, Y., Ye, J., Huang, C., Zhao, M., \& Liu, W. (2010). Dual enantioselective effect of the insecticide bifenthrin on locomotor behavior and development in embryonic-larval zebrafish. Environmental Toxicology and Chemistry, 29(7), 1561-1567.

Jin, Y., Liu, Z., Peng, T., \& Fu, Z. (2015). The toxicity of chlorpyrifos on the early life stage of zebrafish: a survey on the endpoints at development, locomotor behavior, oxidative stress and immunotoxicity. Fish \& Shellfish Immunology, 43(2), 405-414.

Juberg, D. R., Gehen, S. C., Coady, K. K., LeBaron, M. J., Kramer, V. J., Lu, H., \& Marty, M. S. (2013). Chlorpyrifos: weight of evidence evaluation of potential interaction with the estrogen, androgen, or thyroid pathways. Regulatory Toxicology and Pharmacology, 66(3), 249-263.

Kabir, M. H., \& Rainis, R. ( $\left(\begin{array}{llll}2 & 0 & 1 & 2\end{array}\right)$. Farmers' perception on the adverse effettrsesticides on environment: The Case of Bangladesh. International Journal of Sustainable Agriculture, 4(2), 25-32.

Kabir, M. H., \& Rainis, R. (2013). Integrated pest management farming in Bangladesh: present scenario and future prospect. Journal of Agricultural Technology, 9(3), 515-527.

Kanzari, F., Syakti, A. D., Asia, L., Malleret, L., Mille, G., Jamoussi, B., ... \& Doumenq, P. (2012). Aliphatic hydrocarbons, polycyclic aromatic hydrocarbons, polychlorinated biphenyls, organochlorine, and organophosphorous pesticides in surface sediments from the Arc river and the Berre lagoon, France. Environmental Science and Pollution Research, 19(2), 559-576.

Karpouzas, D. G., Cervelli, S., Watanabe, H., Capri, E., \& Ferrero, A. (2006). Pesticide exposure assessment in rice paddies in Europe: a comparative study of existing mathematical models. Pest Management Science, 62(7), 624-636.

Khalil, F., Kang, I. J., Undap, S., Tasmin, R., Qiu, X., Shimasaki, Y., \& Oshima, Y. (2013). Alterations in social behavior of Japanese medaka (Oryzias latipes) in response to sublethal chlorpyrifos exposure. Chemosphere, 92(1), 125-130.

Khan, D.A., Shabbir, S., Majid, M., Naqvi, T.A., \& Khan, F.A. (2010). Risk assessment of pesticide exposure on health of Pakistani tobacco farmers. Journal of Exposure Science and Environmental Epidemiology, 20(2), 196-204.

Kienle, C., Köhler, H. R., \& Gerhardt, A. (2009). Behavioural and developmental toxicity of chlorpyrifos and nickel chloride to zebrafish (Danio rerio) embryos and larvae. Ecotoxicology and Environmental Safety, 72(6), 1740-1747.

Kind, P. K., Grigg, G. C., \& Booth, D. T. (2002). Physiological responses to prolonged aquatic hypoxia in the Queensland lungfish Neoceratodus forsteri. Respiratory Physiology \& Neurobiology, 132(2), 179-190.

Kobashi, K., Harada, T., Adachi, Y., Mori, M., Ihara, M., \& Hayasaka, D. (2017). Comparative ecotoxicity of imidacloprid and dinotefuran to aquatic insects in rice mesocosms. Ecotoxicology and Environmental Safety, 138, 122-129.

Kreutzweiser, D. P., Good, K. P., Chartrand, D. T., Scarr, T. A., \& Thompson, D. G. (2008). Toxicity of the systemic insecticide, imidacloprid, to forest stream insects and microbial communities. Bulletin of Environmental Contamination and Toxicology, 80(3), 211-214.

Kuhl, A. J., Manning, S., \& Brouwer, M. (2005). Brain aromatase in Japanese medaka (Oryzias latipes): molecular characterization and role in xenoestrogen-induced sex reversal. The Journal of Steroid Biochemistry and Molecular Biology, 96(1), 67-77.

Kumar, K. S., Dahms, H. U., Lee, J. S., Kim, H. C., Lee, W. C., \& Shin, K. H. (2014). Algal photosynthetic responses to toxic metals and herbicides assessed by chlorophyll a fluorescence. Ecotoxicology and Environmental Safety, 104, 51-71.

Kunda, M., Azim, M. E., Wahab, M. A., Dewan, S., Roos, N., \& Thilsted, S. H. (2008). Potential of mixed culture of freshwater prawn (Macrobrachium rosenbergii) and self-recruiting small species mola (Amblypharyngodon mola) in rotational rice-fish/prawn culture systems in Bangladesh. Aquaculture Research, 39(5), 506-517. 
Kwok, K. W., Leung, K. M., Lui, G. S., Chu, V. K., Lam, P. K., Morritt, D., Maltby, L., Brock, T., Van den Brink, P.J., Warne, M.S.J., \& Crane, M. (2007). Comparison of tropical and temperate freshwater animal species' acute sensitivities to chemicals: implications for deriving safe extrapolation factors. Integrated Environmental Assessment and Management, 3(1), 49-67.

Laabs, V., Wehrhan, A., Pinto, A., Dores, E. F. G. C., \& Amelung, W. (2007). Pesticide fate in tropical wetlands of Brazil: an aquatic microcosm study under semi-field conditions. Chemosphere, 67(5), 975-989.

Lari, S. Z., Khan, N. A., Gandhi, K. N., Meshram, T. S., \& Thacker, N. P. (2014). Comparison of pesticide residues in surface water and ground water of agriculture intensive areas. Journal of Environmental Health Science and Engineering, 12(1), 11.

Lauan, M. C. B., \& Ocampo, P. P. (2013). Low-dose effects of carbaryl, chlorpyrifos and imidacloprid insecticides on the gonad and plasma testosterone level of male juvenile and adult Nile tilapia (Oreochromis niloticus Linnaeus). Asia Life Sciences, 22(1), 239-250.

Lavine, B. K., Ding, T., \& Jacobs, D. (2010). LC-PDA-MS studies of the photochemical degradation of imidacloprid. Analytical Letters, 43(10-11), 1812-1821.

Leboulanger, C., Bouvy, M., Carré, C., Cecchi, P., Amalric, L., Bouchez, A., ... \& Sarazin, G. (2011). Comparison of the effects of two herbicides and an insecticide on tropical freshwater plankton in microcosms. Archives of Environmental Contamination and Toxicology, 61(4), 599-613.

Leistra, M., Van der Linden, A. M. A., Boesten, J. J. T. I., Tiktak, A., \& Van den Berg, F. (2001). PEARL model for pesticide behaviour and emissions in soil-plant systems: description of the processes in FOCUS PEARL $v$ 1.1. 1 (No. 13, p. 115). Alterra, Wageningen.

Leong, K. H., Tan, L. B., \& Mustafa, A. M. (2007). Contamination levels of selected organochlorine and organophosphate pesticides in the Selangor River, Malaysia between 2002 and 2003. Chemosphere, 66(6), 1153-1159.

Levin, E. D., Swain, H. A., Donerly, S., \& Linney, E. (2004). Developmental chlorpyrifos effects on hatchling zebrafish swimming behavior. Neurotoxicology and Teratology, 26(6), 719-723.

Lewis, K. A., Tzilivakis, J., Warner, D. J., \& Green, A. (2016). An international database for pesticide risk assessments and management. Human and Ecological Risk Assessment: An International Journal, 22(4), 1050-1064.

Li, X., Liu, L., Zhang, Y., Fang, Q., Li, Y., \& Li, Y. (2013). Toxic effects of chlorpyrifos on lysozyme activities, the contents of complement C3 and IgM, and IgM and complement C3 expressions in common carp (Cyprinus carpio L.). Chemosphere, 93(2), 428-433.

Liu, S. S., Wang, C. L., Zhang, J., Zhu, X. W., \& Li, W. Y. (2013). Combined toxicity of pesticide mixtures on green algae and photobacteria. Ecotoxicology and Environmental Safety, 95, 98-103.

Lu, Z., Challis, J. K., \& Wong, C. S. (2015). Quantum yields for direct photolysis of neonicotinoid insecticides in water: implications for exposure to nontarget aquatic organisms. Environmental Science \& Technology Letters, 2(7), 188-192.

Madamba, C. S. (1981). Chemodynamics of isoprocarb (insecticide) in the rice paddy environment. PhD Thesis at University of Philippines at Los Banos, College, Laguna.

Majumder, R., \& Kaviraj, A. (2018). Acute and sublethal effects of organophosphate insecticide chlorpyrifos on freshwater fish Oreochromis niloticus. Drug and chemical toxicology, 1-9.

Malev, O., Klobučar, R. S., Fabbretti, E., \& Trebše, P. (2012). Comparative toxicity of imidacloprid and its transformation product 6-chloronicotinic acid to non-target aquatic organisms: Microalgae Desmodesmus subspicatus and amphipod Gammarus fossarum. Pesticide Biochemistry and Physiology, 104(3), 178-186.

Malhat, F., \& Nasr, I. (2011). Organophosphorus pesticides residues in fish samples from the River Nile tributaries in Egypt. Bulletin of Environmental Contamination and Toxicology, 87(6), 689-692.

Maltby, L., \& Hills, L. (2008). Spray drift of pesticides and stream macroinvertebrates: experimental evidence of impacts and effectiveness of mitigation measures. Environmental Pollution, 156(3), 1112-1120. 
Maltby, L., Blake, N., Brock, T., \& Van den Brink, P. J. (2005). Insecticide species sensitivity distributions: importance of test species selection and relevance to aquatic ecosystems. Environmental Toxicology and Chemistry, 24(2), 379-388.

Maltby, L., Brock, T. C., \& van den Brink, P. J. (2009). Fungicide risk assessment for aquatic ecosystems: importance of interspecific variation, toxic mode of action, and exposure regime. Environmental Science \& Technology, 43(19), 7556-7563.

Manjunatha, B., \& Philip, G. H. (2016). Reproductive toxicity of chlorpyrifos tested in zebrafish (Danio rerio) Histological and hormonal end points. Toxicology and Industrial Health, 32(10), 1808-1816.

Mansano, A. S., Moreira, R. A., Dornfeld, H. C., Diniz, L. G., Vieira, E. M., Daam, M. A., ... \& Seleghim, M. H. (2016). Acute and chronic toxicity of diuron and carbofuran to the neotropical cladoceran Ceriodaphnia silvestrii. Environmental Science and Pollution Research, 1-12.

Maqbool, A., \& Ahmed, I. (2013). Effects of pesticide monocrotophos (organophosphate), on the gonadal development of female freshwater murrel, Channa punctatus (Bloch). International Journal of Recent Scientific Research, 4, 1454-1458.

Marchand, M. J., Pieterse, G. M., \& Barnhoorn, I. E. J. (2010). Sperm motility and testicular histology as reproductive indicators of fish health of two feral fish species from a currently DDT sprayed area, South Africa. Journal of Applied Ichthyology, 26(5), 707-714.

Marimuthu, K., Muthu, N., Xavier, R., Arockiaraj, J., Rahman, M. A., \& Subramaniam, S. (2013). Toxicity of buprofezin on the survival of embryo and larvae of African catfish, Clarias gariepinus (Bloch). PloS One, 8(10), e75545.

Marutirao, G. R. (2013). Histopathological changes in the ovary of freshwater fish Puntius ticto (Ham) under Dimethoate Toxicity. The Bioscan, 8(3), 989-992.

Masiá, A., Campo, J., Navarro-Ortega, A., Barceló, D., \& Picó, Y. (2015). Pesticide monitoring in the basin of Llobregat River (Catalonia, Spain) and comparison with historical data. Science of the Total Environment, 503, 58-68.

Masiá, A., Campo, J., Vázquez-Roig, P., Blasco, C., \& Picó, Y. (2013). Screening of currently used pesticides in water, sediments and biota of the Guadalquivir River Basin (Spain). Journal of Hazardous Materials, 263, 95-104.

Masouleh, F. F., Amiri, B. M., Mirvaghefi, A. R., \& Nemtollahi, M. A. (2011). In vitro effects of diazinon on male reproductive tissue and sperm motility of Caspian kutum (Rutilus frisii kutum). Research Journal of Environmental Toxicology, 5(2), 108-116.

Matin, M. A., Malek, M. A., Amin, M. R., Rahman, S., Khatoon, J., Rahman, M., Aminuddin, M., \& Mian, A. J. (1998). Organochlorine insecticide residues in surface and underground water from different regions of Bangladesh. Agriculture, Ecosystems \& Environment, 69(1), 11-15.

Maxwell, L. B., \& Dutta, H. M. (2005). Diazinon-induced endocrine disruption in bluegill sunfish, Lepomis macrochirus. Ecotoxicology and Environmental Safety, 60(1), 21-27.

MED-Rice. Guidance document for environmental risk assessments of active substances used on rice in the EU for annex I inclusion. Document prepared by working group on Med-Rice, EU document Reference SANCO/1090/2000-rev.1, Brussels, June 2003, 108pp.

Meisner, C. (2004). Report of pesticide Hotspots in Bangladesh. Development Economics Research Group, Infrastructure and Environmental Department, The World Bank.

Méndez, M., Obando, P., Pinnock-Branford, M., Ruepert, C., Castillo, L. E., Mena, F., \& Alvarado, G. (2016). Acute, chronic and biochemical effects of chlorothalonil on Agalychnis callidryas, Isthmohyla pseudopuma and Smilisca baudinii tadpoles. Environmental Science and Pollution Research, 23(21), 21238-21248.

Mhadhbi, L., \& Beiras, R. (2012). Acute toxicity of seven selected pesticides (alachlor, atrazine, dieldrin, diuron, pirimiphos-methyl, chlorpyrifos, diazinon) to the marine fish (Turbot, Psetta maxima). Water, Air, \& Soil Pollution, 223(9), 5917-5930.

Miah, S. J., Hoque, A., Paul, A., \& Rahman, A. (2014). Unsafe use of pesticide and its impact on health of farmers: a case study in Burichong upazila, Bangladesh. IOSR Journal of Environmental Science, Toxicology and Food Technology, 8, 57-67. 
Mills, L. J., \& Chichester, C. (2005). Review of evidence: are endocrine-disrupting chemicals in the aquatic environment impacting fish populations? Science of the Total Environment, 343(1), 1-34.

Mirhaj, M., Boit, A., Razzak, M. A., \& Wahab, M. A. (2013). Yield performance comparison between cultures of rice cum prawn (Macrobrachium rosenbergii) and rice cum fish (Cyprinus carpio, Oreochromis niloticus) in North-Eastern Bangladesh. Aquaculture, 392, 26-33.

Mishra, A., \& Devi, Y. (2014). Histopathological alterations in the brain (optic tectum) of the fresh water teleost Channa punctatus in response to acute and subchronic exposure to the pesticide Chlorpyrifos. Acta Histochemica, 116(1), 176-181.

Mitra, K., Suresh, V. R., Vinci, G. K., Mazumbar, N. N., \& Biswas, D. K. (2007). Biology and fishery of banded gourami, Colisa fasciata (Bloch and Schneider 1801) in a floodplain wetland of Ganga river basin. Asian Fisheries Science, 20(3/4), 409.

Mohammed, M. P., \& Penmethsa, K. K. (2014). Assessment of pesticide residues in surface waters of Godavari delta, India. J Mater Environ Sci, 5(1), 33-36.

Mohanty, M.K., Behera, B.K., Jena, S.K., Srikanth, S., Mogane, C., Samal, S., \& Behera, A.A. (2013). Knowledge attitude and practice of pesticide use among agricultural workers in Puducherry, South India. Journal of Forensic and Legal Medicine, 20(8), 1028-1031.

Mohr, S., Berghahn, R., Schmiediche, R., Hübner, V., Loth, S., Feibicke, M., Mailahn, W., \& Wogram, J. (2012). Macroinvertebrate community response to repeated short-term pulses of the insecticide imidacloprid. Aquatic Toxicology, 110, 25-36.

Mondal, D. K., \& Kaviraj, A. (2008). Ecotoxicological effects of jute retting on the survival of two freshwater fish and two invertebrates. Ecotoxicology, 17(3), 207-211.

Montuori, P., Aurino, S., Garzonio, F., Sarnacchiaro, P., Polichetti, S., Nardone, A., \& Triassi, M. (2016). Estimates of Tiber River organophosphate pesticide loads to the Tyrrhenian Sea and ecological risk. Science of the Total Environment, 559, 218-231.

Montuori, P., Aurino, S., Nardone, A., Cirillo, T., \& Triassi, M. (2015). Spatial distribution and partitioning of organophosphates pesticide in water and sediment from Sarno River and Estuary, Southern Italy. Environmental Science and Pollution Research, 22(11), 8629-8642.

Morales, E., Horn, R., Pastor, L. M., Santamaria, L., Pallarés, J., Zuasti, A., Ferrer, C., \& Canteras, M. (2004). Involution of seminiferous tubules in aged hamsters: an ultrastructural, immunohistochemical and quantitative morphological study. Histology and Histopathology, 19(2), 445-455.

Morrissey, C. A., Mineau, P., Devries, J. H., Sanchez-Bayo, F., Liess, M., Cavallaro, M. C., \& Liber, K. (2015). Neonicotinoid contamination of global surface waters and associated risk to aquatic invertebrates: a review. Environment International, 74, 291-303.

Mukherjee, I., \& Arora, S. (2011). Impact analysis of IPM programs in basmati rice by estimation of pesticide residues. Bulletin of Environmental Contamination and Toxicology, 86(3), 307-313.

Murshed-E-Jahan, K., \& Pemsl, D. E. (2011). The impact of integrated aquaculture-agriculture on small-scale farm sustainability and farmers' livelihoods: Experience from Bangladesh. Agricultural Systems, 104(5), 392402.

Musa, S., Gichuki, J. W., Raburu, P. O., \& Aura, C. M. (2011). Risk assessment for organochlorines and organophosphates pesticide residues in water and Sediments from lower Nyando/Sondu-Miriu river within Lake Victoria Basin, Kenya. Lakes \& Reservoirs: Research \& Management, 16(4), 273-280.

Narayanaswamy, S. Y., \& Mohan, M. R. (2014). Histopathological studies on hypophysis and ovary of fresh water fish Glossogobius giuris (Hamilton). World Journal of Pharmacy and Pharmaceutical Sciences, 3(8), 841862.

Narra, M. R., Begum, G., Rajender, K., \& Rao, J. V. (2011). Sub-lethal effect of chlorpyrifos on protein metabolism of the food fish Clarias batrachus and monitoring of recovery. Toxicological \& Environmental Chemistry, 93(8), 1650-1658.

Narra, M. R., Rajender, K., Reddy, R. R., Rao, J. V., \& Begum, G. (2015). The role of vitamin C as antioxidant in protection of biochemical and haematological stress induced by chlorpyrifos in freshwater fish Clarias batrachus. Chemosphere, 132, 172-178. 
Nasrabadi, T., Bidhendi, G. N., Karbassi, A., Grathwohl, P., \& Mehrdadi, N. (2011). Impact of major organophosphate pesticides used in agriculture to surface water and sediment quality (Southern Caspian Sea basin, Haraz River). Environmental Earth Sciences, 63(4), 873-883.

Navarro-Ortega, A., Tauler, R., Lacorte, S., \& Barceló, D. (2010). Occurrence and transport of PAHs, pesticides and alkylphenols in sediment samples along the Ebro River Basin. Journal of Hydrology, 383(1-2), 5-17.

Nwani, C. D., Ugwu, D. O., Okeke, O. C., Onyishi, G. C., Ekeh, F. N., Atama, C., \& Eneje, L. O. (2013). Toxicity of the chlorpyrifos-based pesticide Termifos ${ }^{\circledR}$ : effects on behaviour and biochemical and haematological parameters of African catfish Clarias gariepinus. African Journal of Aquatic Science, 38(3), 255-262.

Organisation for Economic Co-operation and Development (OECD), 2004. OECD guideline for testing of chemicals: Daphnia sp. acute immobilisation test, No. 202. Paris, France.

Organization for Economic Cooperation and Development (OECD) (1992) Test No 203: Fish, Acute Toxicity Test, OECD Publishing, Paris, France.

Organization for Economic Cooperation and Development (OECD). 1996. Test No. 305: Bioconcentration: Flowthrough Fish Test, OECD Publishing, Paris, France.

Oropesa, A. L., Jiménez, B., Gil, M. C., Osswald, J., Fallola, C., Pula, H. J., Cuesta, J.M., \& Gómez, L. (2014). Histological alterations in the structure of the testis in tench (Tinca tinca) after exposure to 17 alphaethynylestradiol. Environmental Toxicology, 29(10), 1182-1192.

Ortiz-Zarragoitia, M., Bizarro, C., Rojo-Bartolomé, I., de Cerio, O. D., Cajaraville, M. P., \& Cancio, I. (2014). Mugilid fish are sentinels of exposure to endocrine disrupting compounds in coastal and estuarine environments. Marine Drugs, 12(9), 4756-4782.

Oruc, E. (2012). Oxidative stress responses and recovery patterns in the liver of Oreochromis niloticus exposed to chlorpyrifos-ethyl. Bulletin of Environmental Contamination and Toxicology, 88(5), 678-684.

Oruç, E. Ö. (2010). Oxidative stress, steroid hormone concentrations and acetylcholinesterase activity in Oreochromis niloticus exposed to chlorpyrifos. Pesticide Biochemistry and Physiology, 96(3), 160-166.

Otieno, P. O., Schramm, K. W., Pfister, G., Lalah, J. O., Ojwach, S. O., \& Virani, M. (2012). Spatial distribution and temporal trend in concentration of carbofuran, diazinon and chlorpyrifos ethyl residues in sediment and water in Lake Naivasha, Kenya. Bulletin of Environmental Contamination and Toxicology, 88(4), 526-532.

Otieno, P., Okinda Owuor, P., Lalah, J.O., Pfister, G., Schramm, K.W., 2015. Monitoring the occurrence and distribution of selected organophosphates and carbamate pesticide residues in the ecosystem of Lake Naivasha, Kenya. Toxicol. Environ. Chem. 97, 51-61.

Palanikumar, L., Kumaraguru, A. K., Ramakritinan, C. M., \& Anand, M. (2014). Toxicity, biochemical and clastogenic response of chlorpyrifos and carbendazim in milkfish Chanos chanos. International Journal of Environmental Science and Technology, 11(3), 765-774.

Palma, P., Palma, V. L., Fernandes, R. M., Bohn, A., Soares, A. M. V. M., \& Barbosa, I. R. (2009). Embryo-toxic effects of environmental concentrations of chlorpyrifos on the crustacean Daphnia magna. Ecotoxicology and Environmental Safety, 72(6), 1714-1718.

Palma, P., Palma, V. L., Fernandes, R. M., Soares, A. M. V. M., \& Barbosa, I. R. (2008). Acute toxicity of atrazine, endosulfan sulphate and chlorpyrifos to Vibrio fischeri, Thamnocephalus platyurus and Daphnia magna, relative to their concentrations in surface waters from the Alentejo region of Portugal. Bulletin of Environmental Contamination and Toxicology, 81(5), 485-489.

Paruruckumani, P. S., Maharajan, A., Ganapiriya, V., Narayanaswamy, Y., \& Jeyasekar, R. R. (2015). Surface ultrastructural changes in the gill and liver tissue of asian sea bass Lates calcarifer (Bloch) exposed to copper. Biological Trace Element Research, 168(2), 500-507.

Peluso, F., Dubny, S., Othax, N., \& Castelain, J. G. (2014). Environmental risk of pesticides: applying the DelAzulPestRisk model to freshwaters of an agricultural area of Argentina. Human and Ecological Risk Assessment: An International Journal, 20(5), 1177-1199.

Pestana, J. L. T., Alexander, A. C., Culp, J. M., Baird, D. J., Cessna, A. J., \& Soares, A. M. V. M. (2009). Structural and functional responses of benthic invertebrates to imidacloprid in outdoor stream mesocosms. Environmental Pollution, 157(8), 2328-2334. 
Phillips, T. A., Wu, J., Summerfelt, R. C., \& Atchison, G. J. (2002). Acute toxicity and cholinesterase inhibition in larval and early juvenile walleye exposed to chlorpyrifos. Environmental Toxicology and Chemistry, 21(7), 1469-1474.

Posthuma-Doodeman, C. J. A. M. (2008). Environmental risk limits for imidacloprid. RIVM Letter report, 601716018, 2008.

Prokopy, R.J. (2003). Two decades of bottom-up, ecologically based pest management in a small commercial apple orchard in Massachusetts. Agriculture, Ecosystems \& Environment, 94(3), 299-309.

Rahman, S. (2013). Pesticide consumption and productivity and the potential of IPM in Bangladesh. Science of the Total Environment, 445, 48-56.

Rahman, S., Barmon, B. K., \& Ahmed, N. ( $\left.\begin{array}{llll}2 & 0 & 1 & 1\end{array}\right)$. Diversification economies and efficiencies in a 'tgirmen revolution'combination: a case study of prawn-carp-rice farming in the 'gher'system in Bangladesh. Aquaculture International, 19(4), 665-682.

Rahmanikhah, Z., Sari, A. E., Bahramifar, N., \& Bousjien, Z. S. (2010). Organophosphorous pesticide residues in the surface and ground water in the Southern Coast Watershed of Caspian Sea, Iran. World Applied Sciences Journal, 9(2), 160-162.

Rao, J. V., Rani, C. S., Kavitha, P., Rao, R. N., \& Madhavendra, S. S. (2003). Toxicity of chlorpyrifos to the fish Oreochromis mossambicus. Bulletin of Environmental Contamination and Toxicology, 70(5), 985-992.

Remoundou, K., Brennan, M., Sacchettini, G. A. B. R. I. E. L. E., Panzone, L., Butler-Ellis, M. C., Capri, E. T. T. O. R. E., Charistou, A., Chaideftou, E., Gerritsen-Ebben, M.G., Machera, K., \& Spanoghe, P. (2015). Perceptions of pesticides exposure risks by operators, workers, residents and bystanders in Greece, Italy and the UK. Science of the Total Environment, 505, 1082-1092.

Rice, P. J., Drewes, C. D., Klubertanz, T. M., Bradbury, S. P., \& Coats, J. R. (1997). Acute toxicity and behavioral effects of chlorpyrifos, permethrin, phenol, strychnine, and 2, 4-dinitrophenol to 30-day-old Japanese medaka (Oryzias latipes). Environmental Toxicology and Chemistry, 16(4), 696-704.

Rico, A., Dimitrov, M. R., Van Wijngaarden, R. P., Satapornvanit, K., Smidt, H., \& Van den Brink, P. J. (2014). Effects of the antibiotic enrofloxacin on the ecology of tropical eutrophic freshwater microcosms. Aquatic Toxicology, 147, 92-104.

Rico, A., Geber-Corrêa, R., Campos, P. S., Garcia, M. V., Waichman, A. V., \& van den Brink, P. J. (2010). Effect of parathion-methyl on Amazonian fish and freshwater invertebrates: a comparison of sensitivity with temperate data. Archives of Environmental Contamination and Toxicology, 58(3), 765-771.

Rico, A., Waichman, A. V., Geber-Corrêa, R., \& van den Brink, P. J. (2011). Effects of malathion and carbendazim on Amazonian freshwater organisms: comparison of tropical and temperate species sensitivity distributions. Ecotoxicology, 20(4), 625-634.

Roessink, I., Merga, L. B., Zweers, H. J., \& Van den Brink, P. J. (2013). The neonicotinoid imidacloprid shows high chronic toxicity to mayfly nymphs. Environmental Toxicology and Chemistry, 32(5), 1096-1100.

Rubach, M. N., Baird, D. J., Boerwinkel, M. C., Maund, S. J., Roessink, I., \& Van den Brink, P. J. (2012). Species traits as predictors for intrinsic sensitivity of aquatic invertebrates to the insecticide chlorpyrifos. Ecotoxicology, 21(7), 2088-2101.

Rubach, M. N., Crum, S. J., \& Van den Brink, P. J. (2011). Variability in the dynamics of mortality and immobility responses of freshwater arthropods exposed to chlorpyrifos. Archives of Environmental Contamination and Toxicology, 60(4), 708-721.

Sánchez-Bayo, F., \& Goka, K. (2006). Influence of light in acute toxicity bioassays of imidacloprid and zinc pyrithione to zooplankton crustaceans. Aquatic Toxicology, 78(3), 262-271.

Sanchez-Bayo, F., \& Hyne, R. V. (2011). Comparison of environmental risks of pesticides between tropical and nontropical regions. Integrated Environmental Assessment and Management, 7(4), 577-586.

Sangchan, W., Bannwarth, M., Ingwersen, J., Hugenschmidt, C., Schwadorf, K., Thavornyutikarn, P., Pansombat, K., \& Streck, T. (2014). Monitoring and risk assessment of pesticides in a tropical river of an agricultural watershed in northern Thailand. Environmental Monitoring and Assessment, 186(2), 1083-1099. 
Sankararamakrishnan, N., Sharma, A. K., \& Sanghi, R. (2005). Organochlorine and organophosphorous pesticide residues in ground water and surface waters of Kanpur, Uttar Pradesh, India. Environment International, 31(1), 113-120.

Sarma, S. S. S., Nandini, S., \& Gulati, R. D. (2005). Life history strategies of cladocerans: comparisons of tropical and temperate taxa. Hydrobiologia, 542(1), 315-333.

Satapornvanit, K., Baird, D. J., Little, D. C., Milwain, G. K., Van den Brink, P. J., Beltman, W. H., ... \& Perera, M. W. P. (2004). Risks of pesticide use in aquatic ecosystems adjacent to mixed vegetable and monocrop fruit growing areas in Thailand. Australasian Journal of Ecotoxicology, 10(2), 85-95.

Scott, G. R., \& Sloman, K. A. (2004). The effects of environmental pollutants on complex fish behaviour: integrating behavioural and physiological indicators of toxicity. Aquatic Toxicology, 68(4), 369-392.

Shahid, S. (2011). Impact of climate change on irrigation water demand of dry season Boro rice in northwest Bangladesh. Climatic Change, 105(3), 433-453.

Shahjahan, M., Kabir, M. F., Sumon, K. A., Bhowmik, L. R., \& Rashid, H. (2017). Toxicity of organophosphorus pesticide sumithion on larval stages of stinging catfish Heteropneustes fossilis. Chinese Journal of Oceanology and Limnology, 35(1), 109-114.

Sharbidre, A. A., Metkari, V., \& Patode, P. (2011). Effect of methyl parathion and chlorpyrifos on certain biomarkers in various tissues of guppy fish, Poecilia reticulata. Pesticide Biochemistry and Physiology, 101(2), 132-141.

Shi, X., Gu, A., Ji, G., Li, Y., Di, J., Jin, J., Hu, F., Long, Y., Xia, Y., Lu, C., \& Song, L. (2011). Developmental toxicity of cypermethrin in embryo-larval stages of zebrafish. Chemosphere, 85(6), 1010-1016.

Shrestha, P., Koirala, P., \& Tamrakar, A.S. (2010). Knowledge, practice and use of pesticides among commercial vegetable growers of Dhading district, Nepal. Journal of Agriculture and Environment, 11, 95-100.

Sikder, R., \& Xiaoying, J. (2014). Climate change impact and agriculture of Bangladesh. Journal of Environment and Earth Science, 4(1), 35-40.

Solomon, K.R., Brock, T.C.M., de Zwart, D., Dyer, S.D., Posthuma, L., Richards, S.M., Sanderson, H., Sibley, P.K. and van den Brink, P.J. (Eds) (2008). Extrapolation practice for ecotoxicological effect characterization of chemicals. SETAC Press \& CRC Press, Boca Raton, FI, USA, 380 pp.

Song, M. Y., Stark, J. D., \& Brown, J. J. (1997). Comparative toxicity of four insecticides, including imidacloprid and tebufenozide, to four aquatic arthropods. Environmental Toxicology and Chemistry, 16(12), 24942500.

Sreedevi, B., Suvarchala, G., \& Philip, G. H. (2014). Morphological and physiological abnormalities during development in zebrafish due to chlorpyrifos. Indian Journal of Scientific Research, 5(2), 1-8.

Srivastav, A. K., Srivastava, S. K., \& Srivastava, A. K. (1997). Response of serum calcium and inorganic phosphate of freshwater catfish, Heteropneustes fossilis, to chlorpyrifos. Bulletin of Environmental Contamination and Toxicology, 58(6), 915-921.

Stadlinger, N., Berg, H., Van den Brink, P. J., Tam, N. T., \& Gunnarsson, J. S. (2016). Comparison of predicted aquatic risks of pesticides used under different rice-farming strategies in the Mekong Delta, Vietnam. Environmental Science and Pollution Research, 1-13.

Stamatis, N., Hela, D., Triantafyllidis, V., \& Konstantinou, I. (2013). Spatiotemporal variation and risk assessment of pesticides in water of the lower catchment basin of Acheloos River, Western Greece. The Scientific World Journal, 2013.

Starner, K., \& Goh, K. S. (2012). Detections of the neonicotinoid insecticide imidacloprid in surface waters of three agricultural regions of California, USA, 2010-2011. Bulletin of Environmental Contamination and Toxicology, 88(3), 316-321.

Stehr, C. M., Linbo, T. L., Incardona, J. P., \& Scholz, N. L. (2006). The developmental neurotoxicity of fipronil: notochord degeneration and locomotor defects in zebrafish embryos and larvae. Toxicological Sciences, 92(1), 270-278.

Stephen, A. O., \& Yinusa, R. (2011). Prolonged administration of proguanil induces reproductive toxicity in male rats. The Journal of Toxicological Sciences, 36(5), 587-599. 
Stoughton, S. J., Liber, K., Culp, J., \& Cessna, A. (2008). Acute and chronic toxicity of imidacloprid to the aquatic invertebrates Chironomus tentans and Hyalella azteca under constant-and pulse-exposure conditions. Archives of Environmental Contamination and Toxicology, 54(4), 662-673.

Sumon, K. A., Rico, A., Ter Horst, M. M., Van den Brink, P. J., Haque, M. M., \& Rashid, H. (2016). Risk assessment of pesticides used in rice-prawn concurrent systems in Bangladesh. Science of the Total Environment, 568, 498-506.

Sumon, K. A., Ritika, A. K., Peeters, E. T., Rashid, H., Bosma, R. H., Rahman, M. S., ... \& Van den Brink, P. J. (2018). Effects of imidacloprid on the ecology of sub-tropical freshwater microcosms. Environmental Pollution, 236, 432-441.

Sumon, K. A., Saha, S., van den Brink, P. J., Peeters, E. T., Bosma, R. H., \& Rashid, H. (2017). Acute toxicity of chlorpyrifos to embryo and larvae of banded gourami Trichogaster fasciata. Journal of Environmental Science and Health, Part B, 52(2), 92-98.

Sun, Q., Zhu, L., \& Dong, M. (2006). Risk assessment of organic pesticides pollution in surface water of Hangzhou. Environmental Monitoring and Assessment, 117(1), 377-385.

Svensson, O., Bellamy, A. S., Van den Brink, P. J., Tedengren, M., \& Gunnarsson, J. S. (2017). Assessing the ecological impact of banana farms on water quality using aquatic macroinvertebrate community composition. Environmental Science and Pollution Research, 25, 13373-13381.

Swarup, K., Kumar, A., \& Srivastava, S. (1972). Sexual dimorphism in the Giant Gourami, Colisam fasciata (Anabantidae). In Proceedings of the National Academy of Science (Vol. 42, pp. 93-94).

Takade, D. Y., Seo, M. S., Kao, T. S., \& Fukuto, T. R. (1977). Alteration ofO, O-dimethylS-[ $\alpha$-(carboethoxy) benzyl] phosphorodithioate (phenthoate) in citrus, water, and upon exposure to air and sunlight. Archives of Environmental Contamination and Toxicology, 5(1), 63-86.

Teklu, B. M., Adriaanse, P. I., \& Van den Brink, P. J. (2016). Monitoring and risk assessment of pesticides in irrigation systems in Debra Zeit, Ethiopia. Chemosphere, 161, 280-291.

Ter Braak, C. J. F., \& Šmilauer, P. (2 01 QANOCO reference manual and user's guide: software for ordination (version 5.0). Biometris.

Ter Horst, M. M. S., Wipfler, E. L., Adriaanse, P. I., Boesten, J. J. T. I., Fait, G., Li, W., \& Tao, C. (2014). Chinese scenarios for groundwater leaching and aquatice exposure: development of scenarios for environmental risk assessment procedures of pesticides in China (No. 2559). Alterra Wageningen UR.

The World Bank. Toxic pollution from agriculture: an emerging story. Washington, DC: The World Bank; 2006 [Available at: http://econ.worldbank.org/WBSITE/EXTERNAL/ EXTDEC/0,,contentMDK:21139876 pagePK:64165401 piPK:64165026 theSitePK:469372,00.html].

Thomatou, A. A., Zacharias, I., Hela, D., \& Konstantinou, I. (2013). Determination and risk assessment of pesticide residues in lake Amvrakia (W. Greece) after agricultural land use changes in the lake's drainage basin. International Journal of Environmental Analytical Chemistry, 93(7), 780-799.

Thuyet, D. Q., Watanabe, H., Yamazaki, K., \& Takagi, K. (2011). Photodegradation of imidacloprid and fipronil in rice-paddy water. Bulletin of Environmental Contamination and Toxicology, 86(5), 548-553.

Tian, H., Li, Y., Wang, W., Wu, P., \& Ru, S. (2012). Exposure to monocrotophos pesticide during sexual development causes the feminization/demasculinization of the reproductive traits and a reduction in the reproductive success of male guppies (Poecilia reticulata). Toxicology and Applied Pharmacology, 263(2), 163-170.

Tillitt, D. E., Papoulias, D. M., Whyte, J. J., \& Richter, C. A. (2010). Atrazine reduces reproduction in fathead minnow (Pimephales promelas). Aquatic Toxicology, 99(2), 149-159.

Tišler, T., Jemec, A., Mozetič, B., \& Trebše, P. ( $\left.\begin{array}{llll}2 & 0 & 0 & 9\end{array}\right)$. Hazard identification of imidacloprid to aquatic environment. Chemosphere, 76(7), 907-914.

Uddin, M. A., Saha, M., Chowdhury, M. A. Z., \& Rahman, M. A. (2013). Pesticide residues in some selected pond water samples of Meherpur region of Bangladesh. Journal of the Asiatic Society of Bangladesh, Science, 39(1), 77-82 
US EPA, US Environmental Protection Agency. (2006). Reregistration Eligibility Decision (RED) for Chlorpyrifos, Office of prevention, pesticides and toxic substances, Office of pesticide programs, U.S. Government Printing Office, Washington.

Van den Brink, P. J. (2013). Assessing aquatic population and community-level risks of pesticides. Environmental Toxicology and Chemistry, 32(5), 972-973.

Van den Brink, P. J., \& Kater, B. J. (2006). Chemical and biological evaluation of sediments from the Wadden Sea, The Netherlands. Ecotoxicology, 15(5), 451-460.

Van den Brink, P. J., \& Ter Braak, C. J. (1999). Principal response curves: Analysis of time-dependent multivariate responses of biological community to stress. Environmental Toxicology and Chemistry, 18(2), 138-148.

Van den Brink, P. J., Hattink, J., Bransen, F., Van Donk, E., \& Brock, T. C. (2000). Impact of the fungicide carbendazim in freshwater microcosms. II. Zooplankton, primary producers and final conclusions. Aquatic Toxicology, 48(2), 251-264.

Van den Brink, P. J., Roelsma, J., Van Nes, E. H., Scheffer, M., \& Brock, T. (2002). PERPEST model, a case-based reasoning approach to predict ecological risks of pesticides. Environmental Toxicology and Chemistry, 21(11), 2500-2506.

Van den Brink, P. J., Van Smeden, J. M., Bekele, R. S., Dierick, W., De Gelder, D. M., Noteboom, M., \& Roessink, I. (2016). Acute and chronic toxicity of neonicotinoids to nymphs of a mayfly species and some notes on seasonal differences. Environmental Toxicology and Chemistry, 35(1), 128-133.

Van Dijk, T. C., Van Staalduinen, M. A., \& Van der Sluijs, J. P. (2013). Macro-invertebrate decline in surface water polluted with imidacloprid. PloS One, 8(5), e62374.

Van Leeuwen, C., \& Vermeire, T. (2007). Risk assessment of chemicals: an introduction. Springer. Dordrecht, The Netherlands.

Van Leeuwen, K., 2003. Technical Guidance Document on Risk Assessment Part II. In: Commission E, editor. Office for Official Publications of The European Communities, Luxembourg.

Van Wijngaarden, R. P. A., Brock, T. C. M., \& Van Den Brink, P. J. (2005). Threshold levels for effects of insecticides in freshwater ecosystems: a review. Ecotoxicology, 14(3), 355.

Velmurugan, B., Selvanayagam, M., Cengiz, E. I., \& Unlu, E. (2007). Histopathology of lambda-cyhalothrin on tissues (gill, kidney, liver and intestine) of Cirrhinus mrigala. Environmental Toxicology and Pharmacology, 24(3), 286-291.

Vijver, M. G., \& van den Brink, P. J. (2014). Macro-invertebrate decline in surface water polluted with imidacloprid: a rebuttal and some new analyses. PLoS One, 9(2), e89837.

Walkley, A., \& Black, I. A. (1934). An examination of the Degtjareff method for determining soil organic matter, and a proposed modification of the chromic acid titration method. Soil Science, 37(1), 29-38.

Watanabe, H., Takagi, K., \& Vu, S. H. (2006). Simulation of mefenacet concentrations in paddy fields by an improved PCPF-1 model. Pest Management Science, 62(1), 20-29.

Wee, S. Y., \& Aris, A. Z. (2017). Ecological risk estimation of organophosphorus pesticides in riverine ecosystems. Chemosphere, 188, 575-581.

Williams, D. A. (1972). The comparison of several dose levels with a zero dose control. Biometrics, 28, 519-531.

Wu, Y., Zhang, S., Ren, C., Xie, Y. W., Zhang, X. W., Sojinu, S. O., ... \& Wang, J. Z. (2015). Residues of organophosphorus insecticides in sediment around a highly eutrophic lake, Eastern China. Journal of Soils and Sediments, 15(2), 436-444.

Xing, H., Li, S., Wang, Z., Gao, X., Xu, S., \& Wang, X. (2012). Oxidative stress response and histopathological changes due to atrazine and chlorpyrifos exposure in common carp. Pesticide Biochemistry and Physiology, 103(1), 74-80.

Xing, H., Liu, T., Zhang, Z., Wang, X., \& Xu, S. (2015). Acute and subchronic toxic effects of atrazine and chlorpyrifos on common carp (Cyprinus carpio L.): Immunotoxicity assessments. Fish \& Shellfish Immunology, 45(2), 327-333.

Xing, H., Wang, Z., Wu, H., Zhao, X., Liu, T., Li, S., \& Xu, S. (2015). Assessment of pesticide residues and gene expression in common carp exposed to atrazine and chlorpyrifos: Health risk assessments. Ecotoxicology and Environmental safety, 113, 491-498. 
Xu, C., Zhao, M., Liu, W., Chen, S., \& Gan, J. (2008). Enantioselectivity in zebrafish embryo toxicity of the insecticide acetofenate. Chemical Research in Toxicology, 21(5), 1050-1055.

Xue, N., Xu, X., \& Jin, Z. (2005). Screening 31 endocrine-disrupting pesticides in water and surface sediment samples from Beijing Guanting reservoir. Chemosphere, 61(11), 1594-1606.

Yang, L., Li, H., Zeng, F., Liu, Y., Li, R., Chen, H., ... \& Wu, Y. (2012). Determination of 49 organophosphorus pesticide residues and their metabolites in fish, egg, and milk by dual gas chromatography-dual pulse flame photometric detection with gel permeation chromatography cleanup. Journal of Agricultural and Food Chemistry, 60(8), 1906-1913.

Yen, J., Donerly, S., Levin, E. D., \& Linney, E. A. (2011). Differential acetylcholinesterase inhibition of chlorpyrifos, diazinon and parathion in larval zebrafish. Neurotoxicology and Teratology, 33(6), 735-741.

Young, D. F. (2012). Development and evaluation of a regulatory model for pesticides in flooded applications. Environmental Modeling \& Assessment, 17(5), 515-525.

Yu, K., Li, G., Feng, W., Liu, L., Zhang, J., Wu, W., Lei, Xu., \& Yan, Y. (2015). Chlorpyrifos is estrogenic and alters embryonic hatching, cell proliferation and apoptosis in zebrafish. Chemico-Biological Interactions, 239, 26-33.

Zhang, N. S., Liu, Y. S., Van den Brink, P. J., Price, O. R., \& Ying, G. G. (2015). Ecological risks of home and personal care products in the riverine environment of a rural region in South China without domestic wastewater treatment facilities. Ecotoxicology and Environmental Safety, 122, 417-425.

Zhang, X., Gao, L., Yang, K., Tian, H., Wang, W., \& Ru, S. (2013). Monocrotophos pesticide modulates the expression of sexual differentiation genes and causes phenotypic feminization in zebrafish (Danio rerio). Comparative Biochemistry and Physiology Part C: Toxicology \& Pharmacology, 157(1), 33-40.

Zhou, S., Dong, Q., Li, S., Guo, J., Wang, X., \& Zhu, G. (2009). Developmental toxicity of cartap on zebrafish embryos. Aquatic Toxicology, 95(4), 339-346. 


\section{Summary}

In Bangladesh, the intensification of agriculture is indispensable due to its ever increasing population, the food security needs, and land scarcity. Severe agro-climatic events (e.g. flash floods, seasonal water scarcity and salinity intrusion in coastal land) pose further difficulties to crop production. To meet the growing demand of food under these harsh conditions, farmers are using a variety of pesticides indiscriminately; a sharp increase of their use was observed during the last decades. The government of Bangladesh fosters the pesticide use to amplify the agricultural frontiers and to increase output per acre of land. Residues of pesticide applied on agricultural land may enter into the aquatic environment through drain, runoff and spray drift, thereby contaminating this environment. Hence, this PhD thesis aimed to investigate the human health issues and ecological risks on aquatic ecosystems posed by the large scale use of pesticides in Bangladesh.

In Chapter 1 the current status of pesticide use in intensive agriculture in Bangladesh is described together with their associated potential risks on the aquatic environments posed by pesticides. The available studies on assessing the fate and effects of pesticides for the (sub) tropical aquatic ecosystems are reported. Chapter 1 describes the knowledge gap regarding the environmental risks of pesticides in the context of Bangladesh and discusses the tiredbased approach to take into account for the risk assessment in Bangladesh.

Chapter 2 outlines the information on the current status of pesticide use in rice-prawn concurrent systems of south-west Bangladesh and human health issues posed by the application of pesticides. The ecological risks of 10 pesticides for the aquatic ecosystems that support the culture of freshwater prawns (Macrobrachium rosenbergii) were assessed using exposure and effect models. The TOXSWA model calculated pesticide exposure (peak and time-weighted average concentrations) in surface waters of rice-prawn systems for different spray drift scenarios. The simple first-tier risk assessment for these 10 pesticides were performed using a risk quotient (RQ) method. The results of $R Q$ method indicated that chlorpyrifos, cypermethrin, alpha-cypermethrin and malathion may pose a high to moderate acute and chronic risks for invertebrates and fish for all spray drift scenarios. The higher-tier PERPEST effect model confirmed the high risks of cypermethrin, alpha-cypermethrin and chlorpyrifos for insects and macro- and micro-crustaceans, which were previously derived by the RQ-based risk assessment approach. The PERPEST model also indicated the indirect effects 
of these pesticides on algae and macrophytes, community metabolism, rotifers and other macroinvertebrates. This chapter suggests that the mitigation of risk arising from spray drift may be achieved by the implementation of spray drift buffer or the avoidance of spray drift. We also suggest the adoption of Integrated Pest Management (IPM) practices to make the rice-prawn system in south-west Bangladesh more sustainable.

Chapter 3 presents the results of a chemical monitoring in surface water and sediment samples of north-west Bangladesh. The residues of the 10 most commonly used organophosphate insecticides in surface water and sediment samples were measured in that region. Like Chapter $\mathbf{2}$ of this thesis, the risk assessment of the concentrations of these 10 insecticides for fish, Daphnia and algae was started with a deterministic RQ method based on measured environmental concentrations (MECs) and the threshold concentrations derived from single species toxicity tests. The results showed high acute and/or chronic RQs $(R Q>1)$ in surface water and sediment for chlorpyrifos, diazinon, quinalphos, malathion and fenitrothion. The higher-tier PERPEST effect model also confirmed the risks of chlorpyrifos, diazinon, quinalphos and fenitrothion for aquatic insects, micro- and macro-crustaceans. This model also indicated the indirect effects of these pesticides on algae and macrophytes, community metabolism, rotifers and other macroinvertebrates.

Chapter 4 describes the fate and effects of imidacloprid on several structural and functional endpoints of freshwater ecosystems in Bangladesh as evaluated in freshwater outdoor microcosms. The safe threshold values (i.e. NOECs) of imidacloprid for the individual taxa, community and water quality variables were derived for (sub-)tropical Bangladesh. Single species toxicity tests were also performed using the two most responding species (e.g. Cloeon sp. and Diaptomus sp.) of the microcosm study. The sensitivity of several arthropod species to imidacloprid was much higher in sub-tropical country Bangladesh compared to their temperate counterparts.

Chapter 5 elucidates the acute toxicity of chlorpyrifos on the developmental stages of Banded Gourami (Trichogaster fasciata), which is a local freshwater fish species in Bangladesh. In this chapter, the effects of chlorpyrifos on the incubation period of embryo, hatching success, mortality of embryos and two-day old larvae of Banded Gourami are discussed. The 24-h LC50 of chlorpyrifos for embryo was calculated as $11.8 \mu \mathrm{g} / \mathrm{L}$, while the $24-\mathrm{h}$ and $48-\mathrm{h}$ LC50 of chlorpyrifos for larvae were $21.7 \mu \mathrm{g} / \mathrm{L}$ and $5.5 \mu \mathrm{g} / \mathrm{L}$, respectively. Several malformations of 
larvae including irregular head and eye shape, lordosis, body arcuation, notochordal abnormality and caudal fin damage when exposed to 10 and $100 \mu \mathrm{g} / \mathrm{L}$ chlorpyrifos were also demonstrated.

Chapter 6 investigates the toxicity of chlorpyrifos on the mortality and the reproductive tissues of male and female Banded Gourami (Trichogaster fasciata) over a period of 75 days. The threshold values (NOECs) for male and female mortality, GSI, histopathological alterations of ovary and testis for different time interval were derived in this chapter. The results show that the long-term exposure to chlorpyrifos affect the reproductive tissues of Banded Gourami at exposure concentrations that cause mortality also. Hence, this chapter recommends future studies should evaluate effects at lower concentrations as even the lowest concentration of chlorpyrifos (1 $5 \mathrm{\mu g} / \mathrm{L})$ exerted effects.

In chapter $\mathbf{7}$ the major findings of different studies are discussed and after an overview of the conclusions, this thesis recommends: (1) to promote the suitable averting behaviour by farmers during pesticide application, (2) to conduct future experimental, monitoring and model validation studies nationwide, in order to better characterize the risks posed by pesticides for Bangladeshi aquatic ecosystems, (3) to improve the technical facilities (i.e. analytical verification) for future laboratory studies, (4) to reduce the pesticide use based on the recommended dosage by agricultural extension officers, and (5) to seek alternatives of pesticide use through the adoption of integrated pest management (IPM) practices to avoid the risks posed by pesticides. 


\section{Acknowledgements}

I agree with many of you that the PhD can be a long tedious journey with ups and downs. But you can even handle this situation very nicely if you have a good team around you. Almighty Allah blessed me with a lot of kind and supportive team mates during the whole journey of my PhD.

First of all, I would like to express my wholehearted gratitude to my Promotor Prof. Dr. Paul Van den Brink for your tremendous help during the whole journey of my PhD. Paul, thank you very much for accepting me as a PhD Candidate under your supervision. I have nice memories of the first days at Wageningen when we met at your home for the first time and we had a great lunch then. Your skilful and dynamic supervision really amazed me. You helped me a lot to analyse the data for all of the papers. Your constructive criticism, critical thinking and valuable suggestions to the papers made them possible. I got ample freedom to be creative. You created a space for me to attend an international workshop (MAEGA) and I learned a lot from this. In a nutshell, I enjoyed a lot working with you and now I am going to miss your supervision and guidance.

I am indebted to my daily supervisor Dr. Roel Bosma for your kind cooperation during the PhD. You were involved with my PhD program from the very beginning. I can remember your visit to my home country (Bangladesh) to instruct me on microcosm experiment and the selection of sampling locations for monitoring study. We had a great fun when we visited the rural villages of Islampur Upazila, Jamalpur, Bangladesh. I really thank for your timely and constructive feedback on my papers (in particular the fish papers) and thesis for further improvement. I will never forget the dinner invitation at your home with my NICHE-BGD fellows and it was a nice opportunity to meet your lovely wife.

My warmest gratitude to my daily supervisor Dr. Edwin Peeters for your kind help during this long journey. I really appreciate your visit to Bangladesh to help me in conducting the microcosm experiment and in selecting the sampling sites for monitoring study. I will never forget your effort in collecting macroinvertebrate from nearby ponds of Bangladesh Agricultural University. I recognize your help in identifying the macroinvertebrates in Wageningen when I was struggling with this. Finally, I really thank for your critical and fruitful proofreads, and your suggestions on my papers and thesis were very useful to improve a lot.

I would like to express my profound gratitude to my local supervisor Prof. Dr. Harunur Rashid for your kind help during my PhD. I was motivated to work in Environmental Sciences (Ecotoxicology) when I did my MS under your supervision. From the very beginning of my PhD you always motivated me to choose the current research topic (ecotoxicology) and helped me in preparing the concept note during preliminary selection process of this PhD. I was blessed with your existing lab facilities for the fish 
papers. I can remember your kind help in identifying the histopathological alterations of fish tissues induced by pesticide toxicity.

I am indeed thankful to Andreu Rico for many reasons. You received me very well in Ede with a nice car during my first journey from Bangladesh to Wageningen. I had the great opportunity to use your rice-prawn datasets for the first chapter of my thesis. I recognize your help with deepest gratitude for data analyses, making first draft of this paper and guiding me to write the PhD proposal. I had a skype call with you when I struggled with running the model in Bangladesh. I also want to thank Mechteld for your kind help me in modelling study. It would not have been possible to do model easily without your kind help since it was my first modelling exercise.

I am indebted to the staff of the Aquatic Ecology and Water Quality Management Group of Wageningen University for hosting me as a $\mathrm{PhD}$ and providing me a nice working environment. I can remember comprehensive lunch talks with great lunches although I missed most of them because of being Sandwich PhD (most of the time I spent in Bangladesh for research). Thanks to Jacqueline and Concillia (former PhD), Babak, Fenjiao, Jaber, Jugk, Lemessa, Zhao, Sally, Marie, Ana, Lara, Jasper, Fuad and Goraw for having fun during coffee time. Special thanks to Sanne and Zhang for being my paranymphs. I am grateful to John and Marlies for your kind help in the macroinvertebrate identification and making nice pictures of Cloeon sp.

My deepest gratitude to my dear department (Fisheries Management) of Bangladesh Agricultural University for the enormous help during the long journey of my PhD. First, I would like to thank to nominate me (through the Board of Studies) as a PhD candidate during preliminary selection procedure. The farewell from the department (organized by the then head Harun) inspired a lot to make me confident enough just before starting the $\mathrm{PhD}$. I got the opportunity to use the existing laboratory facilities of this department. The colleagues and MS students (Farzana, Sampa, Ritika, Mizan, Helal, Emran, Rakib, Chayan, Mukti, Tajmine and Sagiya) of this department helped me a lot to conduct all laboratory and microcosm experiments and to collect samples during monitoring study. I am also thankful to Alal for your kind help in phytoplankton and zooplankton analyses.

I would like to thank NUFFIC-NICHE-BGD-156 project along with Interdisciplinary Centre for Food Security (ICF) for funding me to pursue my PhD. I always had nice working environment (through using nice desk and wifi connection) in ICF. Thanks to NUFFIC-NICHE-BGD-156 fellows (Naznin, Lavlu, Mousumi, Zannatun and Sharmin) for having fun in courses and meetings. Special thanks to Haider and Mishu for your spontaneous help in managing ICF vehicles for travelling to the field. I can remember the nice tea of ICF when I was getting tired of working. 
I would like to express my warmest gratitude to the agricultural extension officers of Islampur upazila for hosting us when my supervisory team (Roel, Edwin and Harun) and myself visited the study sites. Special thanks to Matiur, Nazmul and farmers for your continuous help to introduce the sampling locations. It would have been very difficult to manage samplings in these rural areas without your kind help.

I am indeed thankful to my parents, parents-in-law, brother, sister, sister-in-law for your moral support and pray. To both my father and mother, I will never forget your continuous support (moral and financial) throughout my whole life. I couldn't even imagine the PhD without your blessings. I wish your long live and healthy life.

Last but not least, I want to dedicate my PhD work to my sweet and beautiful wife Sharmin. I believe your continuous moral support and love made the $\mathrm{PhD}$ possible. Just after one month of our marriage, I had to leave you for Wageningen to start my PhD. I can remember your dedication then. You were always there to support me when I got heart-breaking rejections of papers and frustrations. During the last year of $\mathrm{PhD}$, you accompanied me with nice food and endless love which I will never forget. 


\section{About the author}

Kizar Ahmed Sumon was born in 1990 in a small village of Jamalpur, Bangladesh. He is the youngest child among the three of his parents. He obtained his B.Sc. in Fisheries in 2011 from Bangladesh Agricultural University. After completing B.Sc., he admitted in the department of Fisheries Management in same University for M.Sc. He got his Masters in 2013 from this department. For his Masters' thesis, he

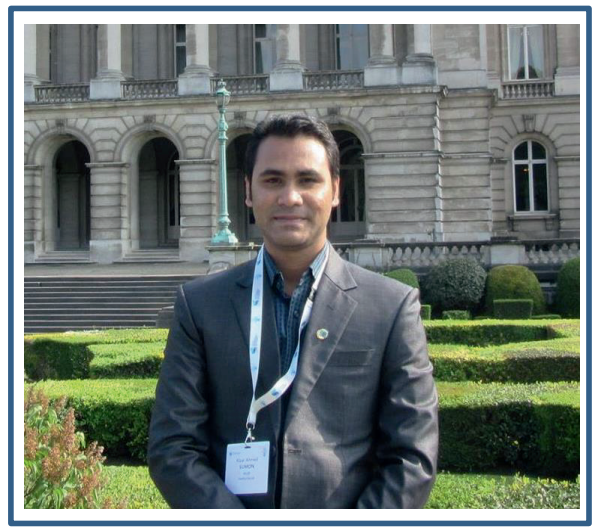
studied the 'Bioaccumulation of heavy metal in aquatic fauna collected from contaminated waters of the River Karnafuli in the South-East coast of Bangladesh'.

He joined the Fisheries Management Department of Bangladesh Agricultural University as a Lecturer in 2013. He has been promoted to Assistant Professor in the same department in 2015. During this time, he taught two B.Sc. courses: Aquatic Pollution and Toxicology and Water Quality Management.

In 2014, he was awarded a scholarship through a project called NUFFIC-NICHE-BGD-156, funded by the Dutch government to pursue his doctoral study at Wageningen University, The Netherlands. He started his PhD in Aquatic Ecology and Water Quality Management Group under the supervision of Prof. Dr. Paul Van den Brink. As a part of his PhD, Kizar followed some courses in Environmental Science, co-supervised three M.Sc. students, participated in national and international seminar, workshop and conferences. In his doctoral thesis, he assessed the occupational health hazards of farmers during pesticide application and ecological risks to aquatic organisms posed by various pesticides in the context of Bangladesh. Currently, Kizar's research interests focus on assessing the environmental fate and effects of agricultural and industrial chemicals on aquatic environment in the (sub-) tropics. 


\section{Publications}

Sumon, K.A., Rashid, H., Peeters, E.T.H.M., Bosma, R.H., Van den Brink, P.J., 2018. Environmental monitoring and risk assessment of organophosphate pesticides in aquatic ecosystems of north-west Bangladesh. Chemosphere, 206, 92-100.

Sumon, K.A., Ritika, A.K., Peeters, E.T.H.M., Rashid, H., Bosma, R.H., Rahman, M.S., Fatema, M.K., Van den Brink, P.J., 2018. Effects of imidacloprid on the ecology of sub-tropical freshwater microcosms. Environmental Pollution, 236, 432-441.

Ali, M.H., Sumon, K.A., Sultana, M., Rashid, H., 2018. Toxicity of cypermethrin on the embryo and larvae of gangetic mystus, Mystus cavasius. Environmental Science and Pollution Research, 25, 3193-3199.

Sumon, K.A., Saha, S., Van den Brink, P.J., Peeters, E.T.H.M., Bosma, R.H., Rashid, H., 2017. Acute toxicity of chlorpyrifos to embryo and larvae of banded gourami Trichogaster fasciata. Journal of Environmental Science and Health, Part B, 52, 92-98.

Shahjahan, M., Kabir, M.F., Sumon, K.A., Bhowmik, L.R., Rashid, H., 2017. Toxicity of organophosphorous pesticide sumithion on larval stages of stinging catfish Heteropneustes fossilis. Chinese Journal of Oceanology and Limnology, 35, 109-114.

Sumon, K.A., Rico, A., Ter Horst, M.M.S., Van den Brink, P.J., Haque, M.M., Rashid, H., 2016. Risk assessment of pesticides used in rice-prawn concurrent systems in Bangladesh. Science of the Total Environment, 568, 498-506.

\section{Submitted}

Sumon, K.A., Yesmin, M.F., Van den Brink, P.J., Bosma, R.H., Peeters, E.T.H.M., Rashid, H., 2018. Effects of long-term chlorpyrifos exposure on mortality and reproductive tissues of Banded Gourami (Trichogaster fasciata). 


\section{SENSE}

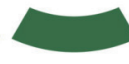

Netherlands Research School for the

Socio-Economic and Natural Sciences of the Environment

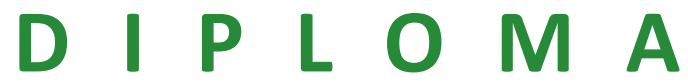

For specialised PhD training

The Netherlands Research School for the

Socio-Economic and Natural Sciences of the Environment

(SENSE) declares that

\section{Kizar Ahmed Sumon}

born on 25 December 1990 in Jamalpur, Bangladesh

has successfully fulfilled all requirements of the

Educational Programme of SENSE.

Wageningen, 27 August 2018

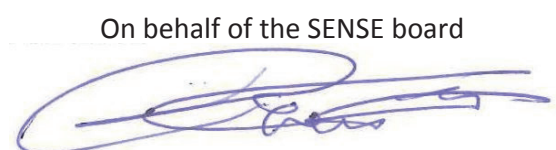

Prof. dr. Huub Rijnaarts the SENSE Director of Education

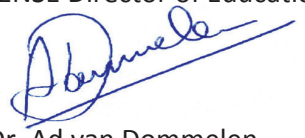

Dr. Ad van Dommelen

The SENSE Research School has been accredited by the Royal Netherlands Academy of Arts and Sciences (KNAW)

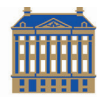

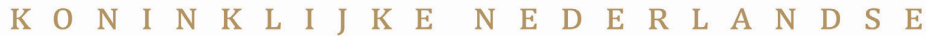

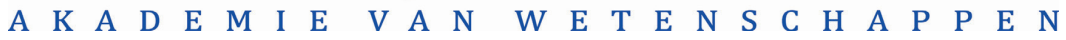




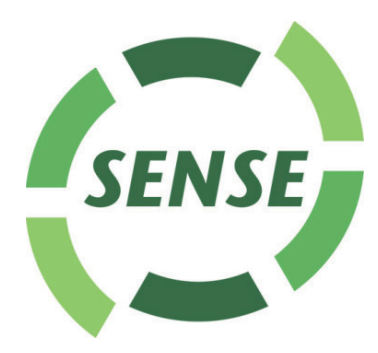

The SENSE Research School declares that Kizar Ahmed Sumon has successfully fulfilled all requirements of the Educational PhD Programme of SENSE with a work load of 40.9, including the following activities:

\section{SENSE PhD Courses}

- Environmental research in context (2014)

- Multivariate Analysis, (2014)

- Research in context activity: 'Initiating and creating Wikipedia page on Banded Gourami (Trichogaster fasciata) and communicating impact of $\mathrm{PhD}$ research in accessible press release' (2018)

\section{Other PhD and Advanced MSc Courses}

- Ecological Risk Assessment: Issues And Applications To Improve Decision Making, Roskilde University, Denmark (2014)

- Techniques for Writing and Presenting a Scientific Paper, Wageningen University (2014)

- Information Literacy including EndNote Introduction, Wageningen University (2014)

- PhD Competence Assessment, Wageningen University (2014)

- PhD Carousel, Wageningen University (2014)

- Food Security in Bangladesh and Interdisciplinary Approaches, Interdisciplinary Centre for Food Security, Bangladesh Agricultural University (2015)

- Application of Statistical Methods for Agricultural Data by SPSS, Interdisciplinary Centre for Food Security, Bangladesh Agricultural University (2015)

\section{External training at a foreign research institute}

- Professional Capacity Building Programme on Design and Implementation of Interdisciplinary Team research, International Centre for development oriented Research in Agriculture (ICRA), Bangladesh Agricultural University (2013)

- Competences for Integrated Agricultural Research (C-IAR), Centre for Development Innovation (CDI), Wageningen, The Netherlands (2014)

\section{Management and Didactic Skills Training}

o Supervising three MSc students (2016)

o Teaching in the BSc. course 'Water Quality Management' (2016)

\section{Oral Presentations}

- Effects of imidacloprid on freshwater outdoor microcosms in Bangladesh. SETAC Europe 27th Annual Meeting, 7-11May 2017, Brussels, Belgium

SENSE Coordinator PhD Education

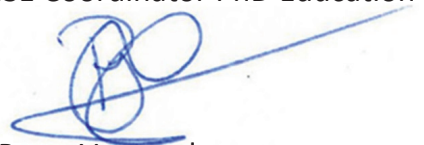

Dr. Peter Vermeulen 
The research described in this thesis was financially supported by the Netherlands Universities Foundation for International Cooperation project "'Integrated Management of Crop-fish-water resources to enhance agricultural production systems towards sustainable food security in Bangladesh (project number: NUFFIC-NICHE-BGD-156)" and EU-FP7 Sustaining Ethical Aquaculture Trade (SEAT) project (contract number 222889).

Financial support from Wageningen University for printing the thesis is gratefully acknowledged.

Cover design and printed by Digiforce-ProefschriftMaken, Wageningen, NL 